\title{
The dynamics of multiple goal management : diary studies at work
}

Citation for published version (APA):

Kirchberg, D. M. (2014). The dynamics of multiple goal management : diary studies at work. [Doctoral Thesis, Maastricht University]. Maastricht University. https://doi.org/10.26481/dis.20141003dk

Document status and date:

Published: 01/01/2014

DOI:

$10.26481 / \mathrm{dis} .20141003 \mathrm{dk}$

Document Version:

Publisher's PDF, also known as Version of record

\section{Please check the document version of this publication:}

- A submitted manuscript is the version of the article upon submission and before peer-review. There can be important differences between the submitted version and the official published version of record.

People interested in the research are advised to contact the author for the final version of the publication, or visit the DOI to the publisher's website.

- The final author version and the galley proof are versions of the publication after peer review.

- The final published version features the final layout of the paper including the volume, issue and page numbers.

Link to publication

\footnotetext{
General rights rights.

- You may freely distribute the URL identifying the publication in the public portal. please follow below link for the End User Agreement:

www.umlib.nl/taverne-license

Take down policy

If you believe that this document breaches copyright please contact us at:

repository@maastrichtuniversity.nl

providing details and we will investigate your claim.
}

Copyright and moral rights for the publications made accessible in the public portal are retained by the authors and/or other copyright owners and it is a condition of accessing publications that users recognise and abide by the legal requirements associated with these

- Users may download and print one copy of any publication from the public portal for the purpose of private study or research.

- You may not further distribute the material or use it for any profit-making activity or commercial gain

If the publication is distributed under the terms of Article $25 \mathrm{fa}$ of the Dutch Copyright Act, indicated by the "Taverne" license above, 


The dynamics of multiple goal management: Diary studies at work 

The dynamics of multiple goal management:

Diary studies at work

\section{DISSERTATION}

to obtain the degree of Doctor

at Maastricht University,

on the authority of the Rector Magnificus, Prof.dr. L.L.G Soete in accordance with the decision of the Board of Deans,

to be defended in public

on Friday October 3rd 2014, 12.00 hours

by

Daniela Maria Kirchberg 
Supervisors:

Prof. dr. Robert A. Roe

Co-supervisor:

Dr. Wendelien van Eerde (University of Amsterdam)

Assessment Committee:

Prof. dr. Martin A. Carree (chair)

Prof. dr. Mariëlle G. Heijltjes

Prof. dr. Sabine Sonnentag (Universität Mannheim)

Prof. dr. Fred R.H. Zijlstra 
Für Papa 


\section{ACKNOWLEDGEMENTS}

When telling people about my research topic most of them are interested to learn more about the subject and ask for practical advice. The subject of multiple goal management evokes so much interest because everyone can immediately relate to it and the challenges it brings along. I was asked questions such as how can I avoid procrastinating, how can I circumvent self-initiated task switching and distractions, or how can I become a better multitasker. Often I had to shrug my shoulders and tell them that I do not have a straight-forward answer.

In my research and also from my own experiences made while writing this dissertation I found out that very often commonly held opinions and theories do not hold in reality. While we think that multitasking is good and increases productiveness, the opposite might be true. While we believe that interruptions are bad for our work, they may also bring positive effects. And we often conveniently assume that we are a certain type of person that e.g. has the tendency to work on multiple things simultaneously or finish goal. A before starting to work on goal B this may not be true.

When starting to work in the business environment I took a closer look at the previously theoretically analyzed concepts from a more practical point of view. Many concepts are of high relevance but it turned out that the work environment is much more complex and hard to be replicated or taken into account for in many of the studies conducted in the field of work motivation.

Throughout the dissertation process I was supported by my promoter Prof. Robert Roe and my co-promoter Dr. Wendelien van Eerde. When I was about to lose faith in the research and wanted to give up Rob motivated me to keep on looking. His experience and ability to look at things from very diverse angles and his enthusiasm to develop new theories and research paradigms helped me to see beyond the obvious and explore new grounds. In 2009 Rob retired. First, I thought - and I am sure not to be the only one- he would be having more free time after his retirement. However, he has been busier ever since. Therefore, I want to thank him very much that despite his full agenda he always found time to talk to me. I enjoyed all our meetings and I fully identify with the German colloquial expression for promoter: Doktorvater. I also want to thank his wife, Marika, for being a good friend and 
supporter throughout the process. In addition, I would like to thank my supervisor Dr. Wendelien van Eerde. The distance between Amsterdam and Maastricht made our meetings scarce. However, every time we met I was inspired and I was very satisfied with the outcomes. Her quick and supportive feedback as well as the belief in the research and me has been vital throughout the process.

In addition, I want to express my gratitude to all participants of my studies. Participating in diary studies that last between one and three weeks can be very tedious and I am thankful that so many people participated in such a committed way.

Moreover, I am thankful to have been surrounded by nice colleagues. The Organization and Strategy department of the Maastricht School of Business and Economics was a very nice place to work at. I want to thank all former colleagues for a great time in the department. I am very thankful for many good discussions and the advice provided during classes and colloquiums. Along the process many friendships have been formed within the university. I especially want to thank: Felix Höppe, Anneloes Raes, Li Jia, Omar Solinger, Maarten Cuijpers, Sjir Uitdewillingen,and Sebastian Pacher. During my stay at Konstanz University I met very nice people that helped me proceed with my dissertation and that became friends. I spent a wonderful and very inspiring time in Konstanz. I especially want to thank Prof. Sabine Sonnentag for making my stay at the department of Work and Organizational Psychology possible and a very valuable experience.

Luckily, I was not free from distractions and interruptions. I am very thankful for the distractions provided by four fabulous office mates: Antonio Della Malva, Johannes Dick, Hans Frankort, and of course Andrea Günster. I truly enjoyed our conversations that were mostly not research related and the fantastic time we shared inside and outside the office up till today.

In October 2013 I was provided with the wonderful opportunity to spend some time at Leipzig University and finish my thesis here. I would like to thank Prof. Dr. Gisela Mohr for her prompt hospitality and providing me a working space throughout my stay.

Three years ago I moved to Cologne and I am very happy that I found true friends at my new place of work. I am very thankful for the friendship and support and the never ending questioning about the progress on my thesis. I want to especially express my gratitude 
towards Manfred Engelking, Ulrich Nießen, Christin Clodius, Robert Szwedo, Marisa Biedermann, Tiina Pokkinen, and my true friend Ines Felix.

I am thankful to have been able to share this important phase of my life with you David. Thank you for listening, reading, discussing, and supporting me while still being busy with your own dissertation.

Without my family I would not be the person I am today. Andreas, Stefanie, Steffi, Uwe, Luise, Lorenz, Cornelius and of course my parents and grandma are a needed and very important support in my life. Es war ein langer Weg bis hierhin und ich möchte Euch für Eure große Unterstützung danken. Ihr habt immer an mich geglaubt, auch in den Momenten, in denen ich größte Selbstzweifel hatte. Es ist unglaublich schön zu wissen, dass ihr immer für mich da seid, besonders dann, wenn ich es am meisten brauche. Worte können nicht beschreiben, was ihr mir bedeutet! 


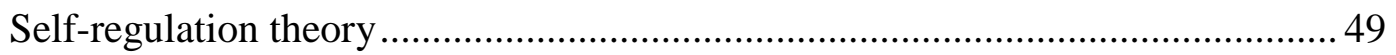

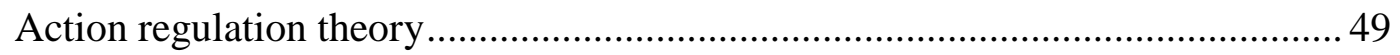

TOWARDS A MODEL OF MULTIPLE GOAL MANAGEMENT ….....................52

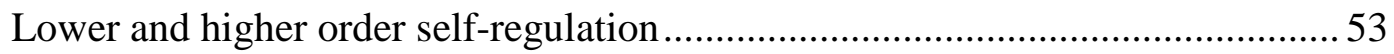

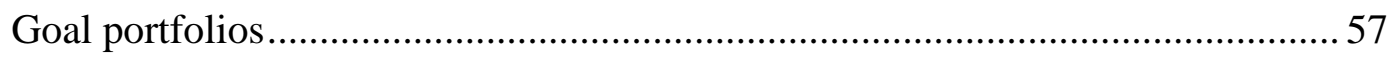

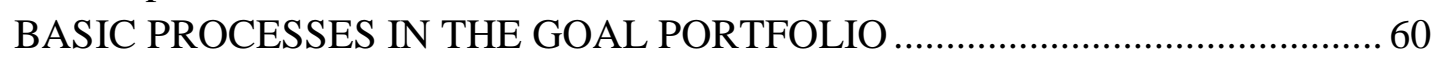

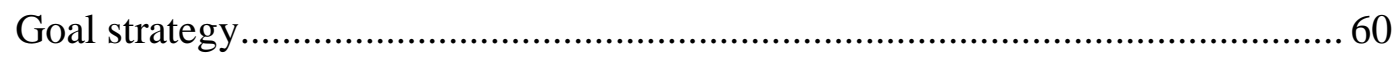

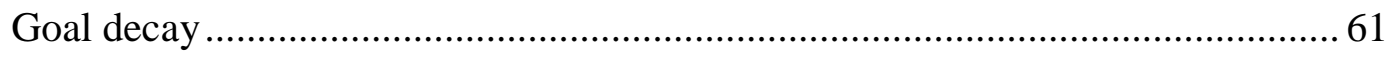

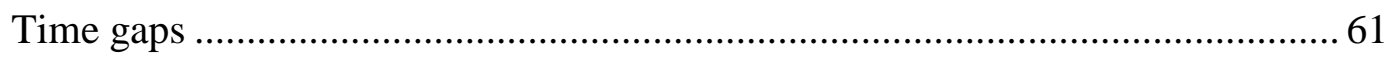

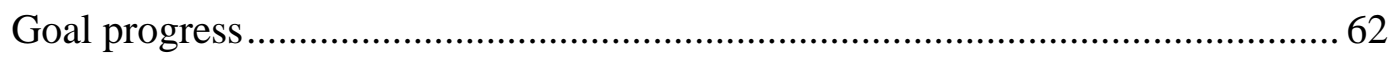

HIGHER ORDER SELF-REGULATION AND MULTIPLE GOAL

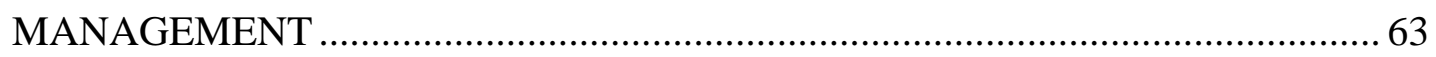

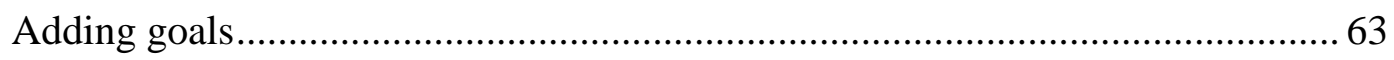

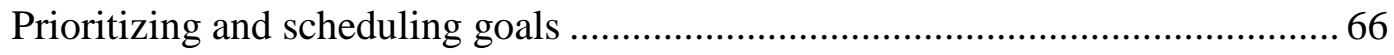



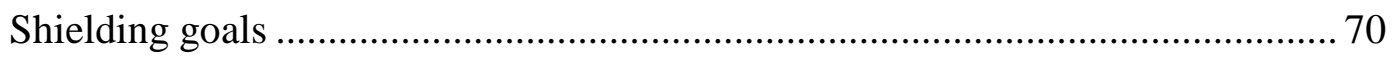

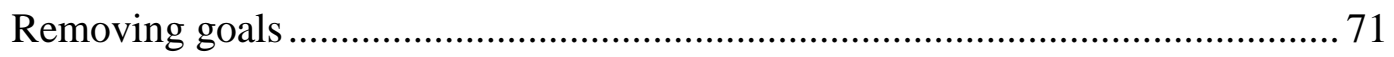

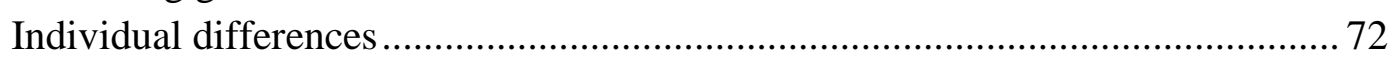

FUTURE RESEARCH \& FUTURE IMPLICATIONS ......................................... 72

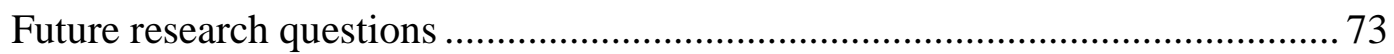

Methodological consideration for future research............................................. 75

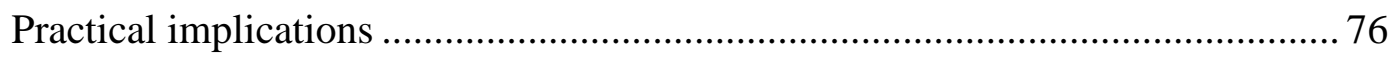

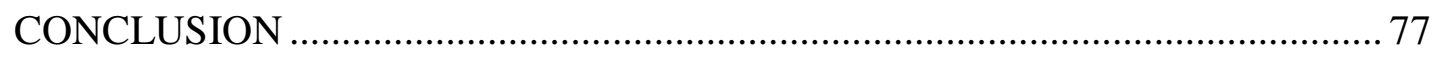

CHAPTER 4

MULTIPLE GOAL PURSUIT, A DESCRIPTIVE AND EXLORATORY

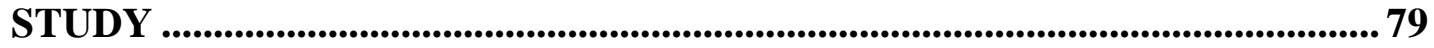

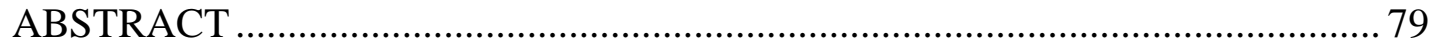





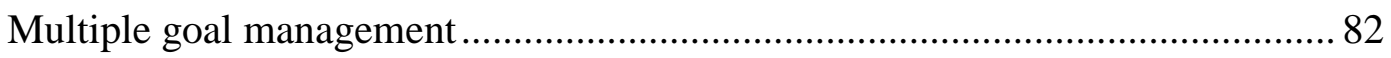





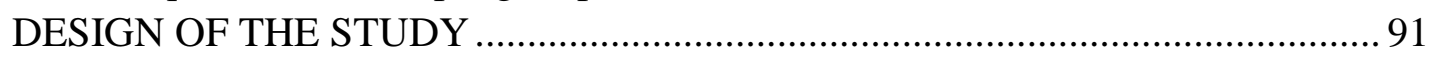

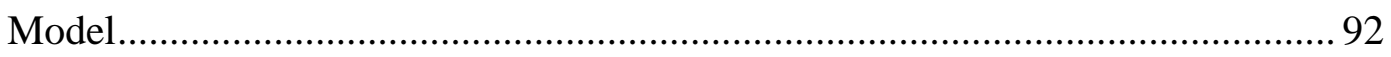

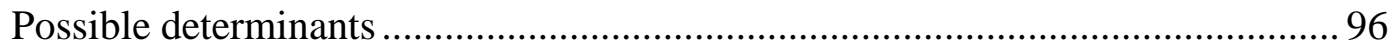



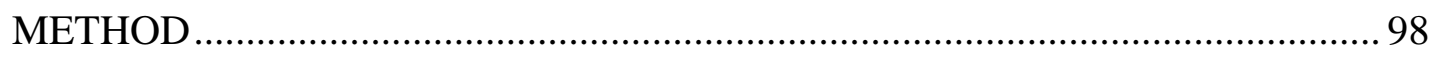

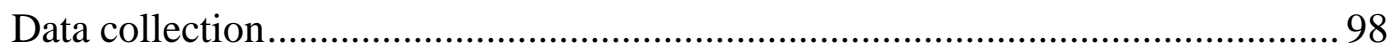

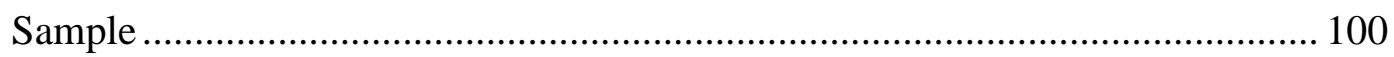

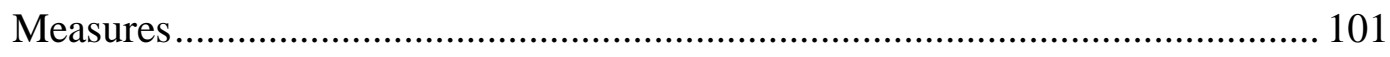

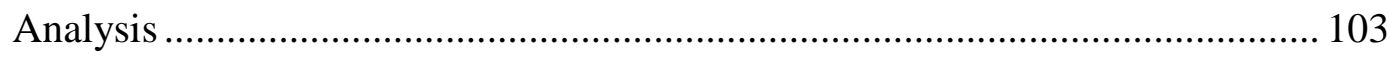




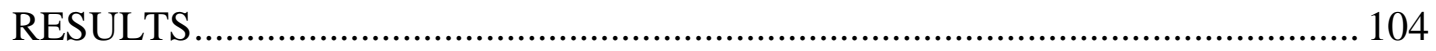

Research question 1: How do people deal with their multiple work goals? ....... 104

Research question 2: What determines how people work on their goals? .......... 121

Research question 3: What are the consequences of individual multiple goal

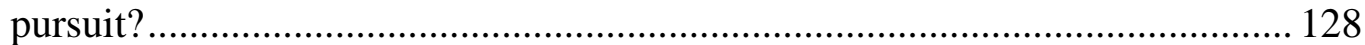

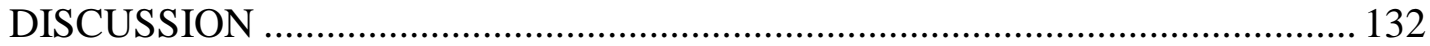



Possible determinants of multiple goal pursuit .................................................. 135

Consequences of multiple goal pursuit patterns ............................................... 138

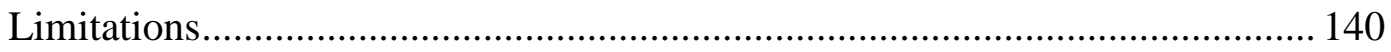



\section{CHAPTER 5}

POLYCHRONICITY AND MULTITASKING:

A DIARY STUDY AT WORK..................................................................................... 144

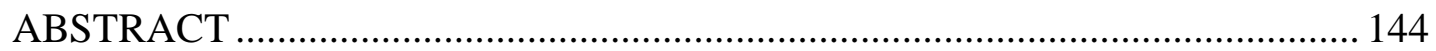

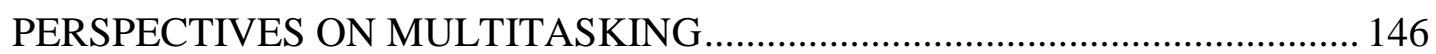

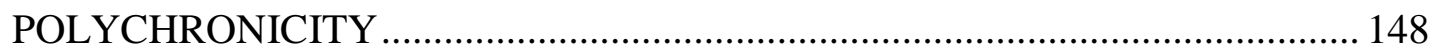

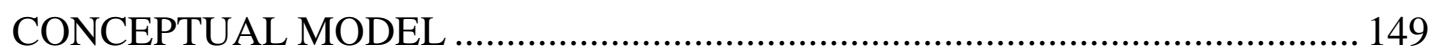

ANTECEDENTS OF MULTITASKING ......................................................... 150

CONSEQUENCES OF MULTITASKING AND AFFECTIVE WELLBEING

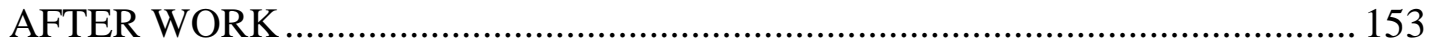

DAY-LEVEL MULTITASKING AND PERFORMANCE ................................ 154

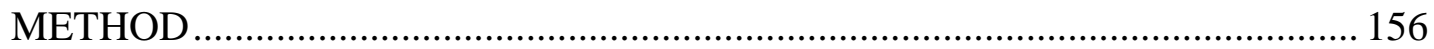

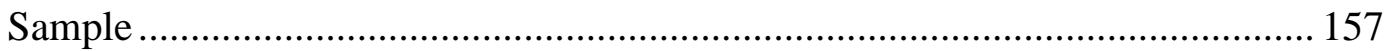

Questionnaire Measures at Person Level ....................................................... 158

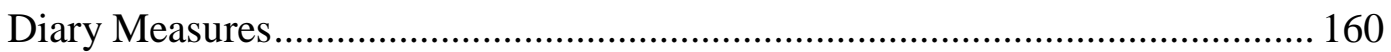

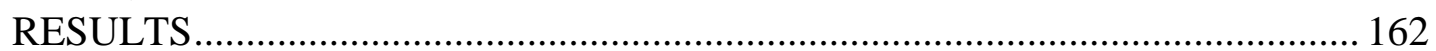

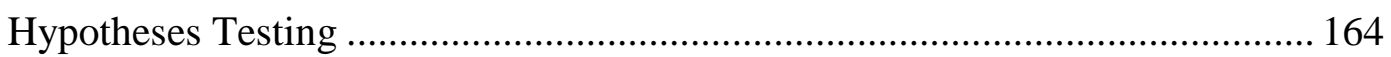

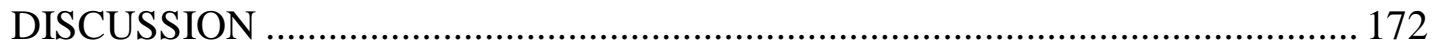

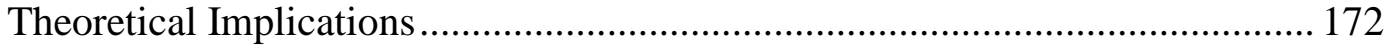

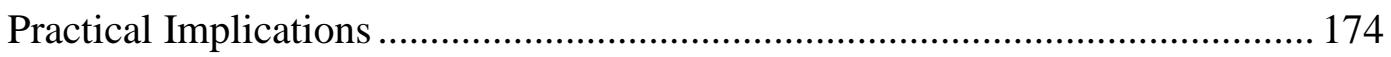

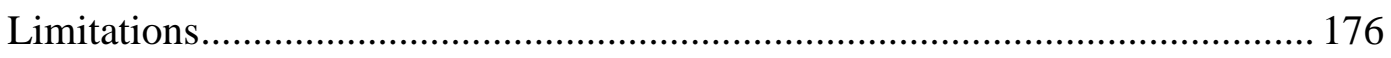

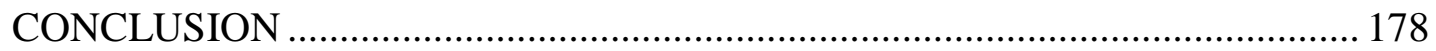

CHAPTER 6

CONCLUSIONS \& RECOMMENDATIONS ...................................................... 180

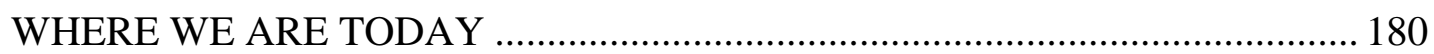

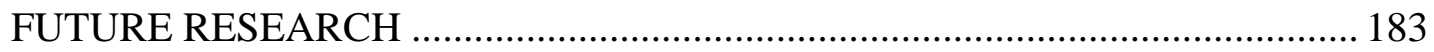

PRACTICAL IMPLICATIONS OF MULTIPLE GOAL MANAGEMENT......... 184

SUMMARY ........................................................................................................... 187

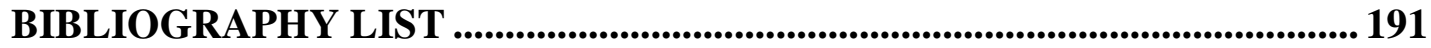

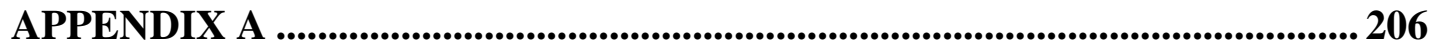




\section{CHAPTER 1}

\section{INTRODUCTION}

\section{A SHORT HISTORY OF WORK MOTIVATION}

The concept of motivation has been around for centuries and first appeared among the Greek philosophers who tried to explain what drives human beings' actions. The word motivation has its root in Latin language and means movement (movere). The Greek philosophers introduced the notion of hedonism, which implies that people are motivated by pleasure (Steers, Mowday, \& Shapiro, 2004). Since hedonism was considered not testable and insufficient for explaining people's behavior, psychological scholars advanced other approaches and began studying motivation empirically. In the early $20^{\text {th }}$ century behaviorist researchers such as Thorndike (1911), Hull (1943), and Allport (1937) suggested that rewards associated with past behavior are shaping motivation and driving action (Steers et al., 2004). Taylor (1911) applied this notion to the field of work, making pay-for-performance into a crucial part of his scientific management approach. This laid the basis for what would later be called 'extrinsic work motivation'. Inherent in Taylor's approach is the assumption that people "can be motivated", that is, that organizations influence the behavior of people at work by controlling the factors that motivate them - an idea that characterizes much of the later thinking about work motivation.

In the early 1930s social scientists such as Mayo (1933) drew attention to the importance of human relations for motivation at the work place, thereby broadening the perspective on motivation and recognizing the multiplicity of motivational factors influencing 
employee behavior. In the middle of the $20^{\text {th }}$ century a new stream of research emerged that identified many other factors that could "motivate " people. Theories developed in this time became known as content theories. The most cited theories in this category are the 'hierarchy of needs' theory by Maslow (1954) and need for achievement theory by McClelland (1971). These theories focused to a large extent on the differences in motivation between individuals. Deci (1975) acknowledged the fact that not all employees are solely driven by extrinsic rewards. He introduced the notion of intrinsic work motivation - the tendency of people to perform tasks that they like or that challenge them - standing in sharp contrast to the tenets of scientific management.

In the beginning of the 1960s another type of study appeared on the agenda of motivation researchers. The focus shifted from the content of motivation, i.e., the motivating factors, towards the processes by which people's motivation is evoked or changed, thereby heralding the era of motivational process theories. Cognitive theories became the center of process theories. The most prominent among them are Vroom's (1961) expectancy theory, Adam's equity theory (1963), Bandura's social cognitive theory (1977), Campion and Lord's control theory (1982), Hacker's action regulation theory (1986), and Locke and Latham's goal setting theory (1990b). All these theories postulate that cognitive processes are important in generating motivation, and have been used to explain the direction and level of people's motivation at work. Some of them, in particular the theories by Vroom and by Locke and Latham have mainly been used to actually "motivate" people.

During the 1990s the interest in motivation research diminished (Steers et al., 2004). Small adaptations were made in established theories and well-known concepts such as goal setting were tested empirically at length. More recently, the notion of self-regulation brought 
back the interest in motivation research and with it new aspects to study (Carver \& Scheier, 1998). Many new publications appeared that advanced self-regulation notions and tested certain propositions empirically (e.g., Baumeister \& Vohs, 2004; Kanfer, 2005). Central in this more recent research is the idea that work is goal-directed behavior and that processes related to establishing and pursuing goals are crucial for understanding motivation.

Recently there have also been calls to change the perspective of motivation research and to pay more attention to the aspect of time (Donovan \& Williams, 2003; Fried \& Slowik, 2004; Kanfer, Chen, \& Pritchard, 2008; Mitchell \& James, 2001; Roe, 1999a; Roe, 2008; Steers et al., 2004; Wood, 2005) and to the pursuit of multiple goals rather than single goals (Diefendorff \& Lord, 2008; Lord, Diefendorff, Schmidt, \& Hall, 2010; Louro, Pieters, \& Zeelenberg, 2007; Mitchell, Harman, Lee, \& Lee, 2008). This thesis can be considered to be a response to these calls.

\section{THE ROLE OF GOALS IN WORK MOTIVATION}

In the literature on motivation, which spans diverse areas of research (e.g., cognitive psychology, work psychology, social psychology), goals have been defined in various ways. Often referred to are Austin and Vancouver (1996), who define a goal as the "internal representation of a desired state". Pinder (1998; p. 368) defines a work goal as "something that a person tries to attain, achieve or accomplish". In action regulation theory work is defined as goal-directed action (Frese \& Zapf, 1994; Hacker, 1986) and goals are conceived as anticipated results as defined by tasks (Hacker, 1986). More precisely, work goals are derived from tasks and attained by means of actions. An action is defined as "the smallest unit of behavior that is related to a conscious goal" (Hacker, 1986, p.73). Thus, work goals are not only a point of comparison for the outcomes of an action, but also "pull" the action necessary 
to complete the goal. In this dissertation we generally adopt the definition of work goals in accordance with action regulation theory.

In recent years work motivation and work goals have mainly been studied from a selfregulation perspective. Self-regulation has been defined as "the ability to control and determine one's behavior consciously and intentionally" (Fitzsimons \& Bargh, 2004, p. 151). In the context of work motivation, self-regulation is considered responsible for initiating and carrying out the actions by which a previously set work goal are achieved. The processes associated with self-regulation are manifold. A well-investigated process is goal-setting (Locke \& Latham, 1990b). Research has shown that specific, difficult but still reachable goals lead to the best results. However, the focus in in goal-setting theory is slightly different from what was defined above. Goals in action regulation theory are aimed-for states of the work object, which can be reached by activities such as writing an email or making a business phone call. Goals in goal-setting theory are rather targets, that is, they are often quantitative and indicate a certain level of achievement. Examples are: writing a certain number of emails or making a certain number of pone calls per day. To put it simple, in terms of goal setting theory people who face the same task may have different goals (targets) attached to it.

The activities performed to achieve goals are referred to as goal striving (Diefendorff \& Lord, 2008; Vancouver \& Putka, 2000) or goal pursuit (Gollwitzer \& Brandstätter, 1997; Louro et al., 2007; Riediger \& Freund, 2004). Goal striving is described as the processes that are necessary to maintain or reach a goal once it has been set (Vancouver \& Putka, 2000). Part of this is forming 'implementations intentions' (Gollwitzer \& Brandstätter, 1997), which from the view of action regulation theory are necessary to determine when an action should be initiated. There is an extensive literature on goal striving, showing that goals are indeed very important for understanding the motivational basis of human behavior. 


\begin{abstract}
AIM OF THE DISSERTATION
Although the literature and the empirical work in the field of work motivation and especially self-regulation is overwhelmingly rich, only a small part of it has been conducted in real-life work settings and involved employees as subjects. As a consequence, the theories as well as the empirical results tell little about how people set and pursue their goals at work. The aim of this dissertation is to take a new perspective on the processes involved in generating and executing goals, by looking beyond well-established theories and observing people's activities in real-life work settings. To do so we add two important focal points to the study of work motivation, namely multiple goals and temporal dynamics.
\end{abstract}

\title{
Multiple goals at work
}

In present-day work places people are fulfilling roles that continuously confront them with multiple goals. Even if a person may seem to have only work goal to achieve in a certain day, he may have many other goals that should be worked upon and that are just put on hold. Having multiple goals to achieve makes it necessary to engage in processes such as prioritizing and rescheduling goals, particularly if new goals emerge or requirements change.

Acknowledging the existence of multiple goals in the workplace is of vital importance since it bears consequences for all theories and concepts that have been developed and researched over the past decades. However, little research has been conducted with regard to the actual pursuit of multiple goals and possible strategies for effectively handling them. The lack of research stands in stark contrast with current organizational practices, which increasingly encourage employees to perform multiple work goals at their own initiative, and often give them more discretion to decide which goals they should pursue and how and when 
they should pursue them. Over the past two decades researchers started to point out that there is a need to study the effect of multiple goals (Austin \& Vancouver, 1996; Kernan \& Lord, 1990; Locke \& Latham, 1990c; Lord et al., 2010; Roe, 1999b; Shah, Friedman, \& Kruglanski, 2002).

In this dissertation we will elaborate on the theoretical implications of acknowledging that people are normally working on multiple goals and we will explore the way in which people engage in multiple goals at work.

\section{The dynamics of goal processes}

Besides multiple goals we will also address the notion of time. Roe (1999b) and Fried and Slowik (2004) acknowledged that time is a crucial variable in the study of work motivation and called for further research. Although early approaches to motivation did account for time (Roe, 2014), the bulk of motivation research has largely neglected the importance of time and time was occasionally incorporated in goal setting research for the purpose of addressing deadlines (Ariely \& Wertenbroch, 2002), distinguishing between distal and proximal goals (Latham \& Seijts, 1999), or planning of future goals with the help of present feedback (Locke \& Latham, 1990a).

Working on multiple goals implies a role for time. For instance, it is obvious that at any point in time goals will differ in the degree to which they have been reached. While some goals will be close to completion, others may not have been worked upon at all. The amounts of work that remain to be done - or the time till the respective deadlines - may have an influence on the overall goal pursuit of a person. Furthermore, it seems unrealistic to assume that motivation and behavior are stable over time. Both are changing continuously and need to 
be studied within a dynamic perspective. Goals might be redefined, strengthened or weakened along the process. There is also the risk that during the process other goals may require to be worked upon or people prefer to switch their attention to other tasks. Generally, during the course of ongoing action people face many opportunities to pursue other activities and get tempted to switch their actions. Thus, time is essential to study this and the flow of events may have an influence at every subsequent stage of the goal-striving process.

In conclusion, the starting point for the research to be presented in this dissertation is the view that more research is needed to investigate not only goal setting and time but also the dynamics of goal enactment, goal rescheduling and all steps along the process. Throughout the text we will acknowledge the role of time when looking at goal processes and suggest ways of studying multiple goal management with a time perspective.

\section{DISSERTATION OUTLINE}

In chapter 2, we present a review of studies that have included multiple goals. We classify these studies according to the number of goals looked at, the definition and operationalization of goals or tasks, the independent and dependent variables applied, the theoretical and methodological acknowledgement of time, the design and method used, and the characteristics of the sample. We note that multiple goals and dynamic aspects has been underrepresented and propose that more research be done on these issues in order to build better theory and derive useful implications for practice.

In chapter 3, we present a theoretical approach to multiple goal pursuit and the management of it. We distinguish between lower-order self-regulation (single goal pursuit) and high-ordered self-regulation (multiple goal pursuit) and put forward some propositions. 
This chapter provides the grounds for the studies in chapter 4 and 5 in which some of the propositions are empirically addressed.

The aim of chapter 4 is to provide an exploratory investigation of how people pursue multiple goals across time in a real-life work setting. This chapter links to the propositions put forward in chapter 3. Using data from a three-week diary study, we show how people work on multiple goals over time and the ways in which they differ from each other. Furthermore, we show that goal pursuit patterns are not only varying between people but also show large variation over time, which makes it difficult to group them into types of goal management that consistently distinguishes people from each other. We will describe differences in multiple goal pursuit and look for relationships personal antecedents and consequences.

Some studies related to multiple goal pursuit have looked into polychronicity, defined as a preference for multitasking, and conceived as a stable personality characteristic. As we demonstrate in chapter 4, people do not show consistent patterns of goal pursuit that match the monochronic vs polychromic dichotomy. In chapter 5, we present a one-week diary study looking at polychronicity in relation to its behavior counterpart, multitasking. We report actual patterns of multitasking, their relations with daily performance and well-being, and the role of polychronicity as a moderator of their dynamic relationships.

In chapter 6, we will present an overall discussion and conclusion summarizing the main findings of the dissertation and giving recommendations for future research and for practice. 
CHAPTER 2

MULTIPLE GOALS AND DYNAMICS IN WORK MOTIVATION:

A CRITICAL REVIEW AND SUGGESTIONS FOR THE FUTURE

\begin{abstract}
Despite the vast amount of empirical and theoretical studies on work motivation there has been little coverage of multiple goals in motivational research. We review 27 empirical studies on work motivation that acknowledge the existence of multiple goals, theoretically or methodologically. Although the concept of goal has remained poorly defined and has been applied quite differently across studies, the interest in multiple goals is clearly growing and researchers more often use longitudinal designs (e.g., in combination with diaries) to study temporal facets of goal pursuit. Yet, most of the research has been conducted in the laboratory and used assigned goals, which leaves us with a need to study the dynamics of multiple goal pursuit and the effects on people's performance and wellbeing in everyday work life.
\end{abstract}




\section{INTRODUCTION}

Work motivation has been defined as "a set of energetic forces that originate both within as well as beyond an individual's being, to initiate work-related behavior, and to determine its form, direction, intensity, and duration" (Pinder, 1998). Although work motivation has been studied from different perspectives, e.g. focusing on drives, needs, rewards etc., the more recent literature has considered goals as a major origin of motivating forces (Pinder, 1998; Kanfer et al., 2008). Numerous studies have studied the processes involved in goal setting and goal striving. For instance, studies of goal-setting have demonstrated the motivating effect of setting a specific, challenging and time-bound goal on the direction, intensity and persistence of people's behavior (Latham \& Locke, 1991; Locke \& Latham, 1984; Locke \& Latham, 1990). Studies of goal striving have revealed details of how previously set goals actually direct individuals' behavior (Austin \& Vancouver, 1996 ; Diefendorf \& Lord, 2008). Surprisingly, most of this research has focused on single goals, in spite of the fact that people hardly ever pursue single goals at work. While this state of affairs has been noted in several reviews (Abraham \& Sheeran, 2003; Austin \& Bobko, 1985; Austin \& Vancouver, 1996; Locke \& Latham, 1990; Steers, Mowday \& Saphiro, 2004), little has changed and we still have little knowledge about how multiple goals influences motivation, how multiple goals influence each other, which strategies people employ to pursue multiple goals, how effective these strategies are, and so on. We also don't know why certain goals are being pursued and others are neglected, forgotten or abandoned. Thus, the role of multiple goals in work motivation has remained unclear, and specific processes like goal selection, activation, striving, revising, and completion, have remained undisclosed. 
Another gap in motivation research is the lack of studies considering time, which is noteworthy since time is a scarce resource that inevitably affects people's choices and possibilities to carry out actions, and time is an essential dimension of motivational processes (Fried \& Slowik, 2004; Locke \& Latham, 2004). Although many authors refer to goal "processes" (cf. Gollwitzer, 1990) few empirical studies have in fact addressed goal-directed behavior over time - even with single goals. We have minimal knowledge about temporal aspects such as meeting deadlines when facing many goals at once (Mitchell, Harman, Lee, \& Lee, 2008). With the increased use of longitudinal designs and diary methods, some facets of multiple goal pursuit or related phenomena such as goal disengagement or procrastination have meanwhile been investigated (Pychyl, Lee, Thibodeau, \& Blunt, 2000). However, the conceptualization and hypothesis building have largely remained a-temporal.

In this chapter, we provide an overview of empricial studies on work motivation with the aim to identify what we already know (and do not know), about the dynamics of multiple goal pursuit at work. The term work motivation is used in a broad way as to include diverse theoretical approaches, such as goal setting theory, action regulation theory, control theories, and self-regulation. We begin this chapter with reviewing the conceptualization and definition of goals. Next, we conduct a structured literature review to ascertain what is currently known about multiple goal management and to what degree research has investigated the temporal dynamics of goal pursuit. Before describing the various studies, we will describe the method used for identifying the studies to be included and the criteria applied to identify relevant empirical work on the dynamics of multiple goal management.

The review is directed towards the following questions: (1) To what extent has existing empirical research studied multiple goals? (2) How have goals been conceptualized? 
(3) Which methods have been used to study goal pursuit, and to what degree have they addressed its temporal dynamics ? With regard to methods, we look at sample characteristics (e.g. students vs. employees), research settings (e.g. laboratory vs. field studies), the research design, and dependent and independent variables. Moreover, we identify whether goal processes have been studied with differential (cross-sectional) or temporal (longitudinal) methods. The identified studies are categorized according to these guiding questions and the answers are summarized in a table. This will help us to establish the state of the art regarding multiple goal pursuit over time, and allows us to put forward a research agenda and suggestions for future research methods.

\section{CONCEPTUALIZATION AND DEFINITION OF GOALS}

The concept of motivation has always been hard to grasp, as there are no direct measures to assess the 'degree of motivation' of an employee at a certain moment in time. Due to the hypothetical nature of motivation can only make inferences about it by looking at observable indicators, such as the direction, intensity, and duration of behavior under varying conditions - either manipulated experimentally or observed in real life conditions. We focus on research in which people perform goals that are related to the tasks people are expected to fulfill in their work.

Goals can be defined as internal representations of desired states such as outcomes, processes and events (Austin \& Vancouver, 1996). However, over the decades many definitions and conceptualizations of goals have evolved, with little integration among the various research domains. For instance, a definition from the domain of personality research refers to goals as "Desired states that people seek to obtain, maintain, or avoid" (Emmons, 1998). In other words, goals may relate to states of the human being or actual outcomes of behaviors. This is 
only one example; other definitions of goals to be found in the literature on counseling (Klinger, 1975), health (Karoly, 1993), cybernetics (Campion \& Lord, 1982), or social psychology (Gollwitzer, 1993). Austin and Vancouver (1996) describe the danger of having many diverse goal concepts and associated micro-theories, and Elliot and Niesta (2009, p. 56) point out that "without clear definitional and conceptual separation between constructs, motivational analyses of behavior lack clarity, precision, and ultimately generativity, and utility". In response to this comment and in order to better structure this review of empirical studies we provide a short overview of goal notions and their definitions in table 1.

Even though there are so many different concepts and definitions around goals almost all have in common that they direct human behavior and provide our lives with purpose. Goals steer our behavior and connect the desires of people with action (Moskowitz \& Grant, 2009). Goals can be found at very different levels in terms of how many resources such as time and energy is necessary to reach the goal. While a life task is kept for a long time and acted upon continuously a task goal can be reached in a defined shorter time frame. Furthermore, goals vary in terms of abstractness, remoteness, interconnectedness to other goals, and so on. Elliot and Niesta (2009) define a goals as "a cognitive representation of a future object that an organism is committed to approach or avoid" (p.58). The difference between approach and avoidance goals has been introduced by Carver \& Scheier (1998) and will be discussed later in this chapter (also see table 2). 
Table 1: Goal constructs and definitions

\begin{tabular}{|c|c|c|c|}
\hline Goal constructs & Authors \& Year & Definition & $\begin{array}{l}\text { Research } \\
\text { domain }\end{array}$ \\
\hline \multirow[t]{2}{*}{ Goal } & $\begin{array}{l}\text { Austin \& Vancouver, } \\
1996\end{array}$ & $\begin{array}{l}\text { Goals are internal representations of } \\
\text { desired states such as outcomes, processes } \\
\text { and events. }\end{array}$ & I/O psychology \\
\hline & Emmons and King (1988) & $\begin{array}{l}\text { Desired states that people seek to maintain, } \\
\text { obtain, or avoid }\end{array}$ & Personality \\
\hline Task goal & $\begin{array}{l}\text { Locke (2000); Locke \& } \\
\text { Latham (1994) }\end{array}$ & $\begin{array}{l}\text { The aim of action within a specified time } \\
\text { frame }\end{array}$ & I/O psychology \\
\hline \multirow[t]{2}{*}{ Intention } & $\begin{array}{l}\text { Gollwitzer (1999); } \\
\text { Frese \& Zapf (1994); } \\
\text { action specific intention }\end{array}$ & $\begin{array}{l}\text { A desired endpoint that may be a } \\
\text { performance or outcome }\end{array}$ & $\begin{array}{l}\text { Social } \\
\text { (cognitive) } \\
\text { Psychology }\end{array}$ \\
\hline & $\begin{array}{l}\text { Ajzen, (1991) } \\
\text { Theory of planned } \\
\text { behavior }\end{array}$ & $\begin{array}{l}\text { The amount of effort } \\
\text { one is willing to exert to attain a goal }\end{array}$ & $\begin{array}{l}\text { Social } \\
\text { (cognitive) } \\
\text { Psychology }\end{array}$ \\
\hline Free fantasies & $\begin{array}{l}\text { Oettingen, Pak, Schnetter, } \\
(2001)\end{array}$ & $\begin{array}{l}\text { "Free fantasies are thoughts and images of } \\
\text { future events or behaviors that appear in } \\
\text { the mind, independent of the likelihoods } \\
\text { that these events or behaviors will actually } \\
\text { occur" }\end{array}$ & $\begin{array}{l}\text { Social } \\
\text { Psychology }\end{array}$ \\
\hline $\begin{array}{l}\text { Short-fuse } \\
\text { behaviors }\end{array}$ & $\begin{array}{l}\text { Dholaki \& Bagozzi } \\
(2003)\end{array}$ & $\begin{array}{l}\text { Everyday low level goals with limited time } \\
\text { window (e.g. train must be caught at a } \\
\text { certain time, library books must be } \\
\text { returned until their due date) }\end{array}$ & $\begin{array}{l}\text { Social } \\
\text { Psychology }\end{array}$ \\
\hline Life task & Cantor \& Fleeson (1990) & $\begin{array}{l}\text { Represents a goal that individuals see } \\
\text { themselves as working on in their } \\
\text { particular age-graded context; "getting } \\
\text { along with others" and "doing well } \\
\text { academically" }\end{array}$ & $\begin{array}{l}\text { Social } \\
\text { Psychology }\end{array}$ \\
\hline Personal project & $\begin{array}{l}\text { Little (1983) } \\
\text { Wallenius (2000) }\end{array}$ & $\begin{array}{l}\text { Personal projects are interrelated } \\
\text { sequences of actions intended to achieve } \\
\text { some personal goals }\end{array}$ & Personality \\
\hline Current concern & Klinger (1975) & $\begin{array}{l}\text { An internal state corresponding to each } \\
\text { goal for which an individual is striving }\end{array}$ & $\begin{array}{l}\text { Personality and } \\
\text { clinical }\end{array}$ \\
\hline Personal strivings & Emmons \& King (1988) & $\begin{array}{l}\text { Characteristic, recurring goals that a } \\
\text { person is trying to accomplish }\end{array}$ & Personality \\
\hline Possible selves & Markus \& Nurius (1986) & $\begin{array}{l}\text { Possible selves derive from representations } \\
\text { of the self in the past and they include } \\
\text { representations of the self in the future. } \\
\text { They are individualized or personalized, } \\
\text { but they are also distinctly social. }\end{array}$ & $\begin{array}{l}\text { Personality / } \\
\text { Social } \\
\text { psychology }\end{array}$ \\
\hline Goal construals & Karoly (1993) & $\begin{array}{l}\text { Motivational or value preference, i.e. the } \\
\text { specification of what is personally } \\
\text { desirable or undesirable such as wants, } \\
\text { passions, wishes, hopes, and strivings. }\end{array}$ & $\begin{array}{l}\text { Clinical } \\
\text { Psychology }\end{array}$ \\
\hline
\end{tabular}


We have decided not to include subconscious goals (Lord, Diefendorff, Schmidt, \& Hall, 2010), which have been investigated in research on priming and automotive goal pursuit (Fitzsimons \& Bargh, 2004; Stajkovic, Locke, \& Blair, 2006). Although subconscious goal pursuit and motives are interesting fields of studies and can certainly influence behavior, we will not further consider them since they are not subject to direct self-regulation. We refer to Action Regulation Theory (Hacker \& Sachse, 2014) for an account of the role that subconscious subgoals (and related mental models) can play in the context of self-regulation in work settings. Thus, we are also not looking into reflexive responses or unintended responses. Our focus is on those goals that are intentionally formed and pursued and on which human beings exert self-regulation behavior to attain them.

Overall it is obvious from Table 1 that the various goal notions refer to quite different states, which vary in scope, content, and level, and therefore in the time needed to accomplish them. In order to distinguish between the states aimed for, researchers have introduced additional notions, which make it possible to define different types of goals (see Table 2). It should be noted that these notions have mainly been applied in laboratory studies and typically refer to goals assigned by researchers. They are therefore of limited interest in the study for work motivation. First, goals can be framed with a prevention or promotion focus. People are supposed to have a general tendency to be either more promotion or prevention focused (Higgins, 1998). Those with a promotion focus strive to minimize the differences between their actual and desired selves. They feel happy when goals are reached and are determined during goals striving since they derive personal growth from attained goals. On the contrary, people with a prevention focus try to minimize the gap between their actual and ought to be selves. They feel relaxed when goals are reached and feel obliged to attain goals. Depending on how performance goals are framed during laboratory studies different emotions 
will be attached to them, which will in turn influence the self-regulatory behavior. Second, goals can be pursued with an orientation towards learning or producing particular results. Therefore, goals have been divided in learning goals, which aim at gaining knowledge, skills or competences, and performance goals, which focus on outcomes (Dweck, 1999; Seijts, Latham, Tasa \& Latham, 2004). Third, a distinction has been proposed between approach and avoidance goals (Carver \& Scheier, 1998). This is similar to the concept of promotion versus prevention focus. An approach goal resembles realizing something positive. Contrary to this people with an avoidance focus try to prevent negative effects and failures.

Table 2: Types of performance goals

\begin{tabular}{|l|l|l|}
\hline $\begin{array}{l}\text { Special forms of performance } \\
\text { goals }\end{array}$ & Authors \& Year & Definition \\
\hline Promotion vs. prevention focus & Higgins (1998) & $\begin{array}{l}\text { Promotion focus: Focus is on } \\
\text { realizing positive events, winning } \\
\text { and self-realization } \\
\text { Prevention focus: Focus is on } \\
\text { minimizing losses and maximizing } \\
\text { security }\end{array}$ \\
\hline Learning vs. performance goals & Dweck (1999) & $\begin{array}{l}\text { Learning goal orientation: } \\
\text { Focus on the acquisition of } \\
\text { knowledge and the perfecting of } \\
\text { competence; approach challenging } \\
\text { tasks and see mistakes as a source } \\
\text { of learning } \\
\text { Performance goal orientation: } \\
\text { View ability as fixed, and choose } \\
\text { tasks that allow to demonstrate } \\
\text { proficiency and avoid goals that } \\
\text { they believe to be incompetent in }\end{array}$ \\
\hline Approach vs. avoidance goals & $\begin{array}{l}\text { Approach: focus is on success and } \\
\text { outperforming others } \\
\text { Avoidance: focus on avoiding } \\
\text { failure or performing poorly } \\
\text { relative to others }\end{array}$ \\
\hline & Carver \& Scheier (1998) & \\
\hline
\end{tabular}

In the study of work motivation it is important to know what kind of goals people are aiming at and what really drives their behavior. This is especially important when thinking about goal setting in the work context. People who get assigned avoidance goals but who are 
actually more driven by approach goals will not feel comfortable and probably perform less well. While it is important to bear this in mind, it is not of utmost importance we will not focus on these distinctions as this stage. We are interested in the actual goal striving process and the dynamics involved when people are pursuing multiple goals at once.

Also important for the work domain is the distinction between assigned goals and selfset goals. Some research suggests that self-set goals are more motivating compared to assigned goals as people are more emotionally attached to self-set goals (Hollenbeck, 1987). Early and Kanfer (1985) found that performance and goal commitment is higher when individuals chose their goals themselves. Action regulation Theory (Hacker \& Sachse, 2014) makes a similar distinction, contrasting objective tasks as assigned to the person with the subjective task as understood by the person. To clarify their relationship, Roe (1999b) speaks of the task-as-given and the task-as-taken. The subjective task is the outcome of what is known as task-redefinition (Hackman, 1969) and defines the personal goal the person will be working on.

Many theorists have distinguished between higher and lower order goals, and proposed that goals be considered as hierarchically ordered (Austin \& Vancouver, 1996). In interpreting the structures that they have proposed, it is helpful to keep the distinction between objective and subjective goals in mind. Some researchers have tried to categorize objective goals in a certain life domain and arrange these in taxonomies, which span the goals that people might select and pursue (e.g., Ford \& Nichols, 1987; Chulef, Reed \& Walsh, 2001; Bateman, O'Neill \& Kenworthy, 2002). Others have focused on hierarchy in people's subjective goals, aiming to understand the means-end relations between higher and lowerorder goals, and their relationship to the structure of action (Hacker \& Sachse, 2014; 
Kruglanksi, 1996; Uithol, Van Rooij, Bekkering \& Haselager, 2012). The second approach acknowledges the idiosyncratic character of their cognitive structures.

In the following section we will discuss studies that have dealt with these various types of goals, in as far as they seem relevant for behavior in work settings.

\section{METHOD}

\section{Boundary conditions}

There are countless studies that investigate the motivational effect of goal setting (cf. Locke and Latham, 1990), the processes involved during goal pursuit (Vancouver \& Putka, 2000), goal disengagement (Wrosch, Scheier, Miller, Schulz, \& Carver, 2003), implementation intentions of a goal (Brandstätter, Lengenfelder, \& Gollwitzer, 2001; Gollwitzer \& Brandstätter, 1997), procrastination (Van Eerde, 2000) and many more related phenomena. Entering the key word motivation into the search engine of the database PsychINFO revealed over 12,000 articles. Since the field of work motivation is so large and many articles have been published throughout the years we need to set some boundary conditions to narrow the focus of this review.

First, we searched only for articles that are published in English peer-reviewed journals, but excluded those that are either practitioner oriented (e.g. Academy of Management Executive) or purely conceptual (e.g. Academy of Management Review). Although, conceptual papers have advanced the knowledge of the field tremendously, the scope in this review is limited to empirical work only. Thus, we neither considered book chapters on motivation (cf. Erez, Kleinbeck, \& Thierry, 2001; Latham, 2007; Mitchell et al., 
2008) nor earlier reviews (cf. Ambrose \& Kulilk, 1999; Latham \& Pinder, 2005; Mitchell et al., 2008) nor theoretical articles (cf. Lord et al., 2010). Second, we ignored studies that were not related to the field of work motivation, e.g. education research, sport research, or health studies. Third, we left out studies including motivation as one explanatory variable among many. Fourth, we focused on research studies that used goals or related concepts for studying motivation as described previously. Finally, the main criterion is the focus on multiple goals. Thus, we did not include studies that focus on one goal or task exclusively. Thus, the theory and/or the study needed to acknowledge multiple goals. We did not make any restriction regarding time, but simply investigate in how temporal facets of multiple goals have been dealt with.

\section{Article identification}

Our method of searching the literature for the review of empirical studies was threefold. First, we searched in the databases EBSCO and PsychINFO for relevant studies. Our focus was on empirical papers published since 1980. The keywords used for the search were motivation, (multiple) goal(s), goal hierarchy, goal setting, goal establishment, goal striving, goal prioritizing, competing goals, conflicting goals, goal enactment, goal execution, intentions, goal shielding, rescheduling, goal disengagement and procrastination. In addition we used search terms such as dynamic, longitudinal, diary, and time to reflect our interest of identifying temporal studies on work motivation and goal striving. To make sure that all relevant literature was included, synonyms of the above stated keywords were also used. Instead of only using "goal" as a keyword we also included search terms such as "task goal ", “current concern” (Klinger, 1975), "personal projects” (Little, 1983), “personal strivings” and "appointments" (see also table 1). Second, we searched in the reference lists of the articles 
found via the search engine for further relevant studies. Third, we browsed through all publications in distinguished journals embracing cognitive and $\mathrm{I} / \mathrm{O}$ psychology, as well as economics and business studies since $2000^{1}$. The journals studied included: Journal of Management, Journal of Applied Psychology, Organizational Behavior and Human Decision Process, Organizational Behavior and Human Performance, Academy of management Journal, Journal of Occupational and Organizational Psychology, Journal of Personality and Social Psychology, Applied Psychology an international review.

\section{RESULTS}

In total we analyzed 27 articles that included 39 empirical studies of work motivation in which multiple goals had been studied. Besides the conceptualization of goals, we identified for each study the number of goals, the underlying process or concept, the consideration of time, the design and method used, as well as the sample size and type.

The major findings are structurally presented in Table 4. On the following pages we will look at some specific facets of the studies included in Table 4, i.e., the number of goals and the types of goals, the methods and samples used, and the coverage of multiple goals and time. By means of this we are able to look into the questions raised at the beginning of this chapter: How have goals been conceptualized? Which methods in terms of sample, setting and temporal focus haven been used?

\footnotetext{
${ }^{1}$ We initially used the 2010 as the final for the search, but later searched the literature for additional publications - up to late 2013.
} 
Table 4: Results literature review

\begin{tabular}{|c|c|c|c|c|c|c|}
\hline $\begin{array}{l}\text { Author } \\
\text { Journal }\end{array}$ & $\begin{array}{c}\text { Number } \\
\text { of goals }\end{array}$ & Type of task or goal & Process / Concept & Time & Design \& Method & Sample \\
\hline $\begin{array}{l}\text { Byrd, } 2003 \\
\text { Master thesis }\end{array}$ & 2 tasks & $\begin{array}{l}\text { Performance goals; } 2 \text { computerized } \\
\text { tasks (scheduling and form- } \\
\text { processing task) }\end{array}$ & $\begin{array}{l}\text { Goal -performance discrepancies } \\
\text { DV: goal revision and effort } \\
\text { allocation }\end{array}$ & Temporal & $\frac{\text { Experiment }}{\text { Multiple trials }}$ & $\begin{array}{l}156 \text { undergraduate } \\
\text { students }\end{array}$ \\
\hline $\begin{array}{l}\text { Cheng, } \\
\text { Luckett, } \\
\text { Mhama(2007) } \\
\text { Accounting and } \\
\text { Finance }\end{array}$ & 5 goals & $\begin{array}{l}\text { Performance goals: call time, net } \\
\text { sales, adherence-to-schedule, process } \\
\text { accuracy and call quality }\end{array}$ & $\begin{array}{l}\text { Goal conflict } \\
\text { DV: Task Performance }\end{array}$ & No & $\frac{\text { Cross-sectional }}{\text { Survey }}$ & $\begin{array}{l}42 \text { call centre } \\
\text { workers }\end{array}$ \\
\hline $\begin{array}{l}\text { Claessens, } \\
\text { van Eerde, } \\
\text { Rutte, Roe } \\
(2010) \\
\text { Applied } \\
\text { Psychology: An } \\
\text { international } \\
\text { review }\end{array}$ & $\begin{array}{l}\text { On } \\
\text { average } \\
3.7 \text { tasks } \\
\text { per day }\end{array}$ & $\begin{array}{l}\text { Participants listed "planned tasks to } \\
\text { do today" at the beginning of the } \\
\text { work day }\end{array}$ & $\begin{array}{l}\text { Goal planning and striving } \\
\text { DV: task completion (percentage } \\
\text { for each planned task of the day) } \\
\text { Task characteristics, personality } \\
\text { characteristics, and time } \\
\text { management skills }\end{array}$ & Temporal & $\begin{array}{l}\text { Longitudinal Design } \\
\text { Paper based diary study: } 2 \\
\text { preselected days of a week over a } \\
\text { period of five weeks and pre- } \\
\text { questionnaire }\end{array}$ & $\begin{array}{l}29 \text { R\&D engineers } \\
\text { from a Dutch } \\
\text { semiconductor } \\
\text { company }\end{array}$ \\
\hline $\begin{array}{l}\text { DeShon, } \\
\text { Kozlowski, } \\
\text { Schmidt, } \\
\text { Milner, } \\
\text { Wiechmann } \\
\text { (2004) } \\
\text { Journal of } \\
\text { Applied } \\
\text { Psychology } \\
\end{array}$ & $\begin{array}{l}2 \text { goals: } \\
\text { individua } \\
1 \text { and } \\
\text { team } \\
\text { goal }\end{array}$ & $\begin{array}{l}\text { PC-based radar-tracking task; before } \\
\text { each trial participants stated } \\
\text { individual and team performance } \\
\text { goals }\end{array}$ & $\begin{array}{l}\text { Feedback, striving for } \\
\text { (competing) individual and team } \\
\text { goals } \\
\text { DV: resource allocation }\end{array}$ & $\begin{array}{l}\text { Methodologi } \\
\text { cally } \\
\text { temporal } \\
\text { (exception: } \\
\text { one } \\
\text { theoretically } \\
\text { temporal } \\
\text { hypothesis) }\end{array}$ & $\begin{array}{l}\text { Simulation } \\
\text { Team event-based adaptive } \\
\text { multilevel simulation: Multiple } \\
\text { trials ( } 3 \text { blocks of } 2 \text { trials each; } \\
\text { ca. } 10 \text { minute performance phase } \\
\text { per trial) }\end{array}$ & $\begin{array}{l}237 \text { undergraduate } \\
\text { students formed } \\
\text { into } 79 \text { teams of } 3 \\
\text { members }\end{array}$ \\
\hline $\begin{array}{l}\text { Dewitte, } \\
\text { Vergust, Lens } \\
\text { (2003) } \\
\text { Current } \\
\text { Psychology: } \\
\text { developmental, } \\
\text { learning, } \\
\text { personality, } \\
\text { social }\end{array}$ & $\begin{array}{l}10 \text { goals } \\
\text { or } \\
\text { behaviors }\end{array}$ & $\begin{array}{l}\text { Study } 1 \& 2 \text { : half of the participants } \\
\text { indicated goals ("give } 10 \text { goals you } \\
\text { have for the following week") and the } \\
\text { other half actions ("list } 10 \text { predictions } \\
\text { of your behavior for the coming } \\
\text { week") } \\
\text { Study 3: participants listing either } 10 \\
\text { goals (outcome focus) or } 10 \text { future } \\
\text { actions }\end{array}$ & $\begin{array}{l}\text { Focus(outcome or action), goal } \\
\text { difficulty, gaol importance, } \\
\text { presence or absence of } \\
\text { implementation intentions } \\
\text { DV: Goal enactment }\end{array}$ & $\begin{array}{l}\text { Methodolog } \\
\text { ically } \\
\text { temporal }\end{array}$ & $\begin{array}{l}\text { Short longitudinal design } \\
2 \text { sessions (1 week apart) in } \\
\text { which participants filled in } \\
\text { questionnaires }\end{array}$ & $\begin{array}{l}\text { Study 1: } 15 \\
\text { Study 2: } 14 \text { students } \\
\text { Study 3: } 16 \text { students }\end{array}$ \\
\hline
\end{tabular}




\begin{tabular}{|c|c|c|c|c|c|c|}
\hline $\begin{array}{l}\text { Author } \\
\text { Journal }\end{array}$ & $\begin{array}{c}\text { Number } \\
\text { of goals }\end{array}$ & Type of task or goal & Process / Concept & Time & Design \& Method & Sample \\
\hline $\begin{array}{l}\text { Donovan \& } \\
\text { Williams } \\
\text { (2003a) } \\
\text { Journal of } \\
\text { Applied } \\
\text { Psychology } \\
\end{array}$ & $\begin{array}{l}\text { Up to } 3 \\
\text { proximal } \\
\text { goals, } 1 \\
\text { distal } \\
\text { goal }\end{array}$ & $\begin{array}{l}\text { Proximal and distal achievement } \\
\text { goals }\end{array}$ & $\begin{array}{l}\text { Goal revision } \\
\text { also DV }\end{array}$ & Temporal & $\begin{array}{l}\text { Longitudinal Design } \\
100 \text { initial and } 287 \text { progress } \\
\text { surveys following each } \\
\text { competition and observation (over } \\
8 \text { weeks) }\end{array}$ & $\begin{array}{l}100 \text { varsity level } \\
\text { college track and } \\
\text { field athletes }\end{array}$ \\
\hline \begin{tabular}{l} 
Downie, \\
Koestner, \\
Horberg, \\
Haga (2006) \\
\multicolumn{1}{c}{ The } \\
Journal of Social \\
Psychology
\end{tabular} & 4 goals & $\begin{array}{l}\text { Participants listed } 4 \text { personal goals } \\
\text { that people intended to carry out } \\
\text { during the week the study took place }\end{array}$ & $\begin{array}{l}\text { Goal striving } \\
\text { DV: Goal progress } \\
\text { Self construal, implementation } \\
\text { intentions, and goal harmony }\end{array}$ & $\begin{array}{l}\text { Methodolog } \\
\text { ically } \\
\text { temporal }\end{array}$ & $\begin{array}{l}\text { Longitudinal Design } \\
4 \text { surveys; } 1 \text { week: } \\
1^{\text {st }} \& 2^{\text {nd }} \text { paper based, completed } \\
\text { in initial meeting } \\
3^{\text {rd }} \text { and } 4^{\text {th }} \text { via email or telephone; } \\
4^{\text {th }} \text { questionnaire divided into } \\
\text { interim follow-up and final follow- } \\
\text { up }\end{array}$ & $\begin{array}{l}85 \text { psychology } \\
\text { students }\end{array}$ \\
\hline $\begin{array}{l}\text { Elliot, } \\
\text { Sheldon, } \\
\text { Church } \\
\text { (1997) } \\
\text { Personality and } \\
\text { Social } \\
\text { Psychology } \\
\text { Bulletin }\end{array}$ & $\begin{array}{l}\text { Study } 1: \\
10 \\
\text { personal } \\
\text { striving } \\
\text { Study } 2 \text { : } \\
6 \\
\text { personal } \\
\text { projects }\end{array}$ & $\begin{array}{l}\text { Study 1: Participants listed } 10 \\
\text { personal strivings defined as: things } \\
\text { that you typically or } \\
\text { characteristically are trying to do in } \\
\text { your daily life; purpose or goals that } \\
\text { you seek in your everyday behavior; } \\
\text { the approach avoidance distinction } \\
\text { was explicitly explained to } \\
\text { participants } \\
\text { Study 2: Participants listed } 6 \text { of their } \\
\text { most relevant personal projects } \\
\text { defined as: goals and concerns that } \\
\text { people thing about, plan for, carry } \\
\text { out, and sometimes though not } \\
\text { always complete or succeed at; no } \\
\text { approach avoidance distinction } \\
\text { mentioned }\end{array}$ & $\begin{array}{l}\text { Antecedents(neuroticism, } \\
\text { extraversion, expected progress) } \\
\text { and consequences (well-being) of } \\
\text { adopting avoidance goals over } \\
\text { approach goals } \\
\text { DV1: proportion of avoidance } \\
\text { striving \& subjective well-being } \\
\text { DV2: perceived progress, } \\
\text { retrospective well-being and } \\
\text { current well being }\end{array}$ & $\begin{array}{l}\text { Methodolog } \\
\text { ically } \\
\text { temporal }\end{array}$ & $\begin{array}{l}\text { Longitudinal } \\
\text { Study 1: Multiple sessions during } \\
\text { the semester in which } \\
\text { questionnaires had to be filled in } \\
\text { (1. Neuroticism \& extraversion; } 2 \text {. } \\
\text { List of personal strivings; } 3 .-5 . \\
\text { Progress on strivings; } 6 . \\
\text { Retrospective subjective well- } \\
\text { being for the semester long } \\
\text { period) } \\
\text { Study 2: similar to study } 1 \\
\text { multiple sessions with } \\
\text { questionnaires. (1. Personal } \\
\text { projects, expected progress, } \\
\text { importance, current well-being; } \\
\text { 2.-4. Perceived progress; } 5 \text {. } \\
\text { Current well-being; } 6 \text {. } \\
\text { Retrospective measure of well- } \\
\text { being for the semester long period }\end{array}$ & $\begin{array}{l}\text { Study 1: } \\
166 \text { undergraduate } \\
\text { students } \\
\text { Study } 2: \\
65 \text { undergraduate } \\
\text { students }\end{array}$ \\
\hline
\end{tabular}




\begin{tabular}{|c|c|c|c|c|c|c|}
\hline $\begin{array}{l}\text { Author } \\
\text { Journal }\end{array}$ & $\begin{array}{l}\text { Number } \\
\text { of goals }\end{array}$ & Type of task or goal & Process / Concept & Time & Design \& Method & Sample \\
\hline $\begin{array}{l}\text { Emmons \& } \\
\text { King (1988) } \\
\text { Journal of } \\
\text { Personality and } \\
\text { Social } \\
\text { Psychology }\end{array}$ & 15 goals & $\begin{array}{l}\text { Study } 1 \& 2 \text { : Participants listed } 15 \\
\text { personal strivings (objectives that the } \\
\text { person typically is trying to } \\
\text { accomplish or attain) } \\
\text { Study } 3 \text { : Same as study } 1+\text { current } \\
\text { thought and activity }\end{array}$ & $\begin{array}{l}\text { Goal conflict } \\
\text { DV1 and 2: psychological and } \\
\text { physical well-being; } \\
\text { DV3: number of times thought or } \\
\text { worked on personal strivings }\end{array}$ & Temporal & $\begin{array}{l}\text { Longitudinal } \\
\text { Study 1: surveys (one at the } \\
\text { beginning, follow up one year } \\
\text { later) } \\
\text { Study 2: diary } \\
\text { Study3: Experience sampling } \\
\text { method }\end{array}$ & $\begin{array}{l}\text { Study 1: } \\
40 \text { undergraduate } \\
\text { students } \\
\text { Study 2: } \\
48 \text { undergraduate } \\
\text { students } \\
\text { Study 3:40 (same as } \\
\text { in study 1) } \\
\text { undergraduate } \\
\text { students }\end{array}$ \\
\hline $\begin{array}{l}\text { Emsley } \\
(2003) \\
\text { Journal of } \\
\text { Managerial } \\
\text { Psychology }\end{array}$ & $\begin{array}{l}\text { Max. } 3 \\
\text { goals }\end{array}$ & $\begin{array}{l}\text { Managers were asked to list a } \\
\text { maximum of three goals (in terms of } \\
\text { outcomes) used to determine the } \\
\text { department's performance }\end{array}$ & $\begin{array}{l}\text { Multiple goals \& goal importance } \\
\text { DV: Job related tension and } \\
\text { performance }\end{array}$ & No & $\begin{array}{l}\text { Cross-sectional } \\
\text { Questionnaire data generated } \\
\text { during face-to-face interviews }\end{array}$ & $\begin{array}{l}47 \text { production } \\
\text { managers }\end{array}$ \\
\hline $\begin{array}{l}\text { Erez, Gopher, } \\
\text { Arzi (1990) } \\
\text { Organizational } \\
\text { Behavior and } \\
\text { Human Decision } \\
\text { Processes }\end{array}$ & 2 tasks & $\begin{array}{l}\text { Dual task performance with two } \\
\text { simultaneous computerized tasks: } \\
\text { letter writing with right hand and } \\
\text { digit classification with left hand; for } \\
\text { each task easy, moderate, and } \\
\text { difficult goal }\end{array}$ & $\begin{array}{l}\text { Goal difficulty (easy, moderate, } \\
\text { difficult goals) } \\
\text { Monetary vs. non-monetary } \\
\text { reward } \\
\text { DV: Goal performance }\end{array}$ & No & $\begin{array}{l}\text { Cross sectional Experiment : } \\
\text { 2(self-set vs. assigned goal) x2 } \\
\text { (present vs. absent contingent } \\
\text { monetary rewards) x3 (easy, } \\
\text { moderate, difficult) design }\end{array}$ & $\begin{array}{l}32 \text { undergraduate } \\
\text { students }\end{array}$ \\
\hline $\begin{array}{l}\text { Fleeson \& } \\
\text { Cantor (1995) } \\
\text { Motivation and } \\
\text { Emotion }\end{array}$ & 2 goals & $\begin{array}{l}\text { Life tasks ( getting along with others } \\
\text { \& doing well academically) }\end{array}$ & $\begin{array}{l}\text { Goal pursuit } \\
\text { DV: Affect while working on the } \\
\text { goal } \\
\text { The influence of situational, } \\
\text { interpersonal, and temporal } \\
\text { contexts }\end{array}$ & Temporal & $\begin{array}{l}\text { Longitudinal Design } \\
\text { Diary study with experience } \\
\text { sampling }\end{array}$ & $\begin{array}{l}54 \text { undergraduate } \\
\text { students }\end{array}$ \\
\hline
\end{tabular}




\begin{tabular}{|c|c|c|c|c|c|c|}
\hline $\begin{array}{l}\text { Author } \\
\text { Journal }\end{array}$ & $\begin{array}{l}\text { Number } \\
\text { of goals }\end{array}$ & Type of task or goal & Process / Concept & Time & Design \& Method & Sample \\
\hline $\begin{array}{l}\text { Fulford, } \\
\text { Johnson, } \\
\text { Llabre, Carver } \\
\text { (2010) } \\
\text { Psychological } \\
\text { Science }\end{array}$ & 3 goals & $\begin{array}{l}\text { Participants listed } 3 \text { goals they would } \\
\text { be striving for in the coming weeks. } \\
\text { Participants should be committed to } \\
\text { the goals and the goals should be } \\
\text { reachable within the time frame of } \\
\text { the study, approach instead of } \\
\text { avoidance related, and demanding. } \\
\text { Examples: "spend } 2 \text { hours each day } \\
\text { on a certain project" or "spend } 1 \\
\text { hour of quality time with my child" }\end{array}$ & $\begin{array}{l}\text { Goal pursuit } \\
\text { DV: Goal effort } \\
\text { IV: Goal progress and the } \\
\text { influence of bipolar disorder }\end{array}$ & Temporal & $\begin{array}{l}\text { Longitudinal Design } \\
\text { Diary study over } 3 \text { weeks with } 3 \\
\text { assessments per day }\end{array}$ & $\begin{array}{l}24 \text { people (12 with } \\
\text { and } 12 \text { without } \\
\text { bipolar disorder) }\end{array}$ \\
\hline $\begin{array}{l}\text { Harris, } \\
\text { Daniels, } \\
\text { Briner (2003) } \\
\text { Journal of } \\
\text { Occupational and } \\
\text { Organizational } \\
\text { Psychology }\end{array}$ & 5 goals & $\begin{array}{l}\text { Participants rated daily goal } \\
\text { attainment and importance of } 5 \text { goals } \\
\text { at work: } \\
\text { 1.getting on with people at work } \\
\text { 2.being able to influence work } \\
\text { 3.good performance, } \\
\text { 4. high status at work, } \\
\text { 5. having a sense of purpose at work }\end{array}$ & $\begin{array}{l}\text { Daily attainment of work goals } \\
\text { and the moderating effect of goal } \\
\text { importance } \\
\text { DV: Affective well-being at the } \\
\text { end of the day }\end{array}$ & Temporal & $\begin{array}{l}\text { Longitudinal } \\
\text { Diary study (paper based) over } 2 \\
\text { weeks; daily questionnaires } \\
\text { before and after work }\end{array}$ & $\begin{array}{l}22 \text { Call-centre } \\
\text { workers }\end{array}$ \\
\hline $\begin{array}{l}\text { Koo \& } \\
\text { Fishbach, } \\
(2008) \\
\text { Journal of } \\
\text { Personality and } \\
\text { Social } \\
\text { Psychology }\end{array}$ & $\begin{array}{l}2 \text { goals } \\
\text { (but only } \\
\text { in study } \\
\text { 1) }\end{array}$ & $\begin{array}{l}\text { Study1: core and elective course } \\
\text { Study 2: motivation to participate in } \\
\text { a loyalty program } \\
\text { Study 3: motivation to purchase } \\
\text { merchandise } \\
\text { Study 4: Donation to charity }\end{array}$ & $\begin{array}{l}\text { Goal commitment and focus (to- } \\
\text { date vs. to-go information on goal } \\
\text { progress) } \\
\text { DV1: studying time } \\
\text { DV2: subjective interest in } \\
\text { using loyalty card } \\
\text { DV3: amount of money planned } \\
\text { to be spent on merchandise } \\
\text { DV 4: Charity contribution } \\
\text { Study 1: focus and importance } \\
\text { Study 2: focus and reward type } \\
\text { Study 3: desire vs. need and focus } \\
\text { Study 4: focus and commitment }\end{array}$ & No & $\begin{array}{l}\text { Cross-sectional } \\
\text { Study 1-3: Experiment with } \\
\text { scenarios; surveys } \\
\text { Study 4: Field experiment }\end{array}$ & $\begin{array}{l}\text { Study 1: } 92 \text { students } \\
\text { Study 2: } 92 \text { students } \\
\text { Study 3: } 77 \text { students } \\
\text { Study 4: } 122 \\
\text { potential donors }\end{array}$ \\
\hline
\end{tabular}




\begin{tabular}{|c|c|c|c|c|c|c|}
\hline $\begin{array}{l}\text { Author } \\
\text { Journal }\end{array}$ & $\begin{array}{c}\text { Number } \\
\text { of goals }\end{array}$ & Type of task or goal & Process / Concept & Time & Design \& Method & Sample \\
\hline $\begin{array}{l}\text { Locke, Smith, } \\
\text { Erez, Chah, } \\
\text { Schaffer } \\
\text { (1994) } \\
\text { Journal of } \\
\text { Management }\end{array}$ & $\begin{array}{l}2 \text { goals } \\
\text { for one } \\
\text { task }\end{array}$ & $\begin{array}{l}\text { Different types of goals (quantity vs. } \\
\text { quality) on a single task } \\
\text { Study1: group production of models } \\
\text { for fictitious art products company; } \\
\text { either produce many or pieces with } \\
\text { high quality } \\
\text { Study 2: doing research and teaching }\end{array}$ & $\begin{array}{l}\text { Goal conflict } \\
\text { DV: performance } \\
\text { Performance in goal conflict } \\
\text { situations }\end{array}$ & No & $\begin{array}{l}\text { Cross-sectional } \\
\text { Study 1: experiment } \\
\text { Study 2: field study, correlational }\end{array}$ & $\begin{array}{l}\text { Study 1: } 132 \\
\text { undergraduate } \\
\text { students (44 } \\
\text { groups) } \\
\text { Study 2: } 274 \\
\text { college professors }\end{array}$ \\
\hline $\begin{array}{l}\text { Louro, } \\
\text { Pieters, } \\
\text { Zeelenberg } \\
\text { (2007) } \\
\text { Journal of } \\
\text { Personality and } \\
\text { Social } \\
\text { Psychology }\end{array}$ & 2 goals & $\begin{array}{l}\text { Study 1: Weight loss goal and } \\
\text { personal goal (financial or study } \\
\text { related) } \\
\text { Study 2: Scenario with the goal to } \\
\text { earn some money (possibility to } \\
\text { accept a side job) and athletic } \\
\text { performance (hours spent practicing } \\
\text { to win } 110 \text { m sprint) } \\
\text { Study 3: primed goals of dieting and } \\
\text { other goal }\end{array}$ & $\begin{array}{l}\text { Goal striving } \\
\text { DV: Effort weight loss and effort } \\
\text { other goal } \\
\text { Changes in goal expectancies that } \\
\text { are influenced by goal proximity } \\
\text { and goal related emotions } \\
\text { determine effort allocation. }\end{array}$ & Temporal & $\begin{array}{l}\text { Longitudinal Design } \\
\text { Study 1: diary study over } 3 \text { weeks } \\
\text { Cross-sectional } \\
\text { Study 2: scenario with decision to } \\
\text { make } \\
\text { Cross-sectional } \\
\text { Study 3: Experiment }\end{array}$ & $\begin{array}{l}\text { Study 1: } 82 \text { female } \\
\text { undergraduate } \\
\text { students } \\
\text { Study 2: } 96 \\
\text { undergraduate } \\
\text { students } \\
\text { Study 3: } 165 \text { female } \\
\text { undergraduate } \\
\text { students }\end{array}$ \\
\hline $\begin{array}{l}\text { Madjar \& } \\
\text { Shalley } \\
\text { (2008) } \\
\text { Journal of } \\
\text { Management }\end{array}$ & 3 tasks & $\begin{array}{l}\text { Two creative tasks (computerized; } \\
\text { thinking and idea generation) and one } \\
\text { intervening task (lexical); multiple } \\
\text { goals for tasks }\end{array}$ & $\begin{array}{l}\text { Scheduling of multiple tasks; } \\
\text { discretion to switch between tasks } \\
\text { DV: individuals' creativity, } \\
\text { cognitive exhaustion, focus of } \\
\text { attention }\end{array}$ & No & Cross-sectional Experiment & $\begin{array}{l}263 \text { undergraduate } \\
\text { students }\end{array}$ \\
\hline $\begin{array}{l}\text { Pychyl, Lee, } \\
\text { Thibodeau, } \\
\text { Blunt (2000) } \\
\text { Journal of Social } \\
\text { Behavior \& } \\
\text { Personality }\end{array}$ & $\begin{array}{l}\text { Current } \\
\text { activity }\end{array}$ & $\begin{array}{l}\text { Participants indicated their current } \\
\text { activity/ task } 8 \text { random times a day } \\
\text { over a five day work week } \\
\text { proceeding a due date of either an } \\
\text { essay, project or exam }\end{array}$ & $\begin{array}{l}\text { Procrastination } \\
\text { DV: affect (also included in scale } \\
\text { as items: guilt and motivation) }\end{array}$ & $\begin{array}{l}\text { Methodolog } \\
\text { ically } \\
\text { temporal }\end{array}$ & $\begin{array}{l}\text { Longitudinal Design } \\
\text { Experience sampling procedure } \\
\text { (paper-based) with } 8 \text { random } \\
\text { beeps a day (between } 91 \mathrm{~m} \text { and } 10 \\
\text { pm) over a five day period; and } \\
\text { end of the study questionnaire } \\
\text { (but correlational analysis) }\end{array}$ & $\begin{array}{l}45 \text { undergraduate } \\
\text { students }\end{array}$ \\
\hline
\end{tabular}




\begin{tabular}{|c|c|c|c|c|c|c|}
\hline $\begin{array}{l}\text { Author } \\
\text { Journal }\end{array}$ & $\begin{array}{c}\text { Number } \\
\text { of goals }\end{array}$ & Type of task or goal & Process / Concept & Time & Design \& Method & Sample \\
\hline $\begin{array}{l}\text { Riediger \& } \\
\text { Freund (2004) } \\
\text { Personality and } \\
\text { Social } \\
\text { Psychology } \\
\text { Bulletin }\end{array}$ & $\begin{array}{l}\text { Study 1: } \\
4 \text { goals } \\
\text { Study } 2 \text { : } \\
1 \text { goal } \\
\text { Study } 3 \text { : } \\
\text { Goals of } \\
\text { study } 1\end{array}$ & $\begin{array}{l}\text { Study 1: Participants listed four } \\
\text { personal goals they have for the near } \\
\text { future, currently judged to be } \\
\text { important (definition as used } \\
\text { resembles life tasks) } \\
\text { Study 2: Goal to start regular physical } \\
\text { exercise } \\
\text { Study 3: Participants listed personal } \\
\text { goals (sse study 1) and activities } \\
\text { involved in during the preceding } \\
\text { hours }\end{array}$ & $\begin{array}{l}\text { Interference among goals(time, } \\
\text { financial or energy constraints, } \\
\text { and incompatible strategies) and } \\
\text { intergoal facilitation } \\
\text { (instrumental relations among } \\
\text { goals and overlapping goal } \\
\text { attainment strategies) } \\
\text { DV: well-being (habitual } \\
\text { positive/negative affect and life } \\
\text { satisfaction) \& goal pursuit }\end{array}$ & $\begin{array}{l}\text { No (Study } \\
\text { 1) Temporal } \\
\text { (Study } 2 \& 3 \text { ) }\end{array}$ & $\begin{array}{l}\text { Cross-sectional } \\
\text { Study 1: questionnaire } \\
\text { Longitudinal Design } \\
\text { Study 2: questionnaire (t1) and } \\
\text { five months information on } \\
\text { exercising after } \mathrm{t} 1 \\
\text { Longitudinal Design } \\
\text { Study 3: diary study ( } 3 \text { dairy } \\
\text { periods with } 3 \text { consecutive days } \\
\text { and } 6 \text { days between the next diary } \\
\text { period; } 3 \text { entries per day at noon, } \\
\text { at } 6 \text { pm and before going to bed) }\end{array}$ & $\begin{array}{l}\text { Study 1: } 111 \text { adults } \\
\text { Study 2: } 145 \text { adult } \\
\text { exercise beginners } \\
\text { Study } 3: \text { subsample } \\
\text { of study } 2=81 \\
\text { adults }\end{array}$ \\
\hline $\begin{array}{l}\text { Schmidt \& } \\
\text { DeShon } \\
\text { (2007) } \\
\text { Journal of } \\
\text { Applied } \\
\text { Psychology }\end{array}$ & 2 tasks & Scheduling task for two colleges & $\begin{array}{l}\text { Goal progress } \\
\text { DV: resources allocated } \\
\text { Resource allocation across } \\
\text { competing demands }\end{array}$ & No & Experiment & $\begin{array}{l}252 \text { undergraduate } \\
\text { students }\end{array}$ \\
\hline $\begin{array}{l}\text { Schmidt \& } \\
\text { Dolis (2009) } \\
\text { Journal of } \\
\text { Applied } \\
\text { Psychology }\end{array}$ & $\begin{array}{l}2 \text { tasks } \\
\text { with } \\
\text { specific } \\
\text { goals for } \\
\text { each task }\end{array}$ & $\begin{array}{l}\text { Computer administered concurrent } \\
\text { dual task paradigm; } \\
\text { First task: non-redundant class } \\
\text { scheduling } \\
\text { Second task: requisition task } \\
\text { (processing and validating equipment } \\
\text { requests) }\end{array}$ & $\begin{array}{l}\text { Dual-goal difficulty, goal } \\
\text { progress, and expectancies } \\
\text { DV: resource allocation (time } \\
\text { spent on each task during trial) }\end{array}$ & $\begin{array}{l}\text { Methodolog } \\
\text { ically } \\
\text { temporal }\end{array}$ & $\begin{array}{l}\text { Experiment } \\
5 \text { trials per person (each trial lasts } \\
7 \text { min. in which } 5 \text { schedules and } 5 \\
\text { requisition forms have to be } \\
\text { completed) }\end{array}$ & $\begin{array}{l}70 \text { undergraduate } \\
\text { students }\end{array}$ \\
\hline $\begin{array}{l}\text { Schmidt, } \\
\text { Dolis, Tolli } \\
\text { (2009) } \\
\text { Journal of } \\
\text { Applied } \\
\text { Psychology }\end{array}$ & 2 tasks & $\begin{array}{l}\text { Dual-task; Computer administered; } \\
\text { Class-scheduling for two colleges } \\
\text { with the goals to have all students } \\
\text { scheduled for each college } \\
\text { respectively }\end{array}$ & $\begin{array}{l}\text { Individuals differences and } \\
\text { contextual factors in goal- } \\
\text { performance discrepancy } \\
\text { situations } \\
\text { DV: Time allocation among } \\
\text { competing demands }\end{array}$ & $\begin{array}{l}\text { Methodologi } \\
\text { cally } \\
\text { temporal }\end{array}$ & $\begin{array}{l}\text { Experiment } \\
5 \text { segments (trials) of } 6 \text { minutes } \\
\text { each after which the simulation } \\
\text { continued from where participants } \\
\text { left off }\end{array}$ & 64 students \\
\hline
\end{tabular}




\begin{tabular}{|c|c|c|c|c|c|c|}
\hline $\begin{array}{l}\text { Author } \\
\text { Journal }\end{array}$ & $\begin{array}{c}\text { Number } \\
\text { of goals }\end{array}$ & Type of task or goal & Process / Concept & Time & Design \& Method & Sample \\
\hline $\begin{array}{l}\text { Strickland \& } \\
\text { Galimba } \\
\text { (2001) } \\
\text { The Journal of } \\
\text { Psychology }\end{array}$ & 3 tasks & $\begin{array}{l}3 \text { tasks: Anagram puzzles, solving } \\
\text { simple algebraic equations, spatial- } \\
\text { relations task; } \\
\text { Goals for each task were asked }\end{array}$ & $\begin{array}{l}\text { Goal setting } \\
\text { DV: switching, cognitive } \\
\text { interference, performance } \\
\text { Setting performance goals vs. no } \\
\text { goals on multiple tasks }\end{array}$ & No & Cross-sectional Experiment & $\begin{array}{l}116 \text { undergraduate } \\
\text { students }\end{array}$ \\
\hline $\begin{array}{l}\text { Wallenius } \\
2000 \\
\text { European } \\
\text { Journal of } \\
\text { Personality }\end{array}$ & $\begin{array}{l}8 \\
\text { personal } \\
\text { projects }\end{array}$ & $\begin{array}{l}\text { Participants listed } 8 \text { personal projects } \\
\text { (as defined by Little, 1983). } \\
\text { Participants were asked: "All of us } \\
\text { have a number of personal projects at } \\
\text { any given time that we think about, } \\
\text { plan for, and sometimes (though not } \\
\text { always)complete. Think about what } \\
\text { kind of projects you have in your life } \\
\text { at the moment." }\end{array}$ & $\begin{array}{l}\text { Level of abstractness, goal } \\
\text { conflict } \\
\text { DV: well-being in terms of life } \\
\text { satisfaction and depression }\end{array}$ & No & $\begin{array}{l}\text { Cross-sectional: } \\
\text { Questionnaire data generated } \\
\text { during face-to-face interviews } \\
\text { (length of interview: between } 1 \\
\text { and } 2 \text { hours) }\end{array}$ & 167 adults \\
\hline $\begin{array}{l}\text { Wiese \& } \\
\text { Freund } \\
\text { (Wiese \& } \\
\text { Freund) } \\
\text { Journal of } \\
\text { Occupational and } \\
\text { Organizational } \\
\text { Psychology } \\
\end{array}$ & $\begin{array}{l}\text { Up to } 5 \\
\text { goals }\end{array}$ & $\begin{array}{l}\text { Long-term goals in the work domain; } \\
\text { e.g. founding a company, making } \\
\text { progress in one's career, job security }\end{array}$ & $\begin{array}{l}\text { Goal progress } \\
\text { DV: well-being }\end{array}$ & Temporal & $\begin{array}{l}\text { Longitudinal Design } \\
\text { Over } 3 \text { years; } \\
2 \text { questionnaires: at beginning } \\
\text { and three years later }\end{array}$ & $\begin{array}{l}82 \text { that used to be } \\
\text { employed young } \\
\text { adults (after } 3 \text { years } \\
68 \text { still employed) }\end{array}$ \\
\hline
\end{tabular}




\section{Types of goals studied}

As discussed earlier and demonstrated in table 1 there are many diverse concepts of goals being used in the literature. In the majority of the identified studies computerized tasks were used as a unit of analysis, especially those conducting an experiment. In most studies, performance goals of the tasks to be conducted are set by the researcher or the participant. Often these goals refer to the percentage or number of correctly done tasks or the time needed to solve the task (e.g. an anagram or puzzle). The time needed to fulfill the given tasks varies between a few minutes in case there are multiple trials involved up to 2 hours.

Table 6: Types of goals studied

\begin{tabular}{|l|l|c|}
\hline Concept & Construct & Frequency of concepts used \\
\hline \multirow{4}{*}{ Performance Goals } & Goals related to computerized task(s) & 7 \\
\cline { 2 - 3 } & Goals related to tasks & 4 \\
\hline \multirow{4}{*}{ Personal strivings/goals } & Personal goals & 3 \\
\cline { 2 - 3 } & Goals (athletic, dieting, work) & 9 \\
\cline { 2 - 3 } & Personal strivings & 4 \\
\cline { 2 - 3 } & Personal projects & 2 \\
\cline { 2 - 3 } & Life tasks & 3 \\
\hline Current activity & & 1 \\
\hline Planned tasks of the day & 1 \\
\hline Primed goals & & 1 \\
\hline
\end{tabular}

In some studies researchers looked at personal strivings or personal goals. Here the focus was on longer term goals that had been set by the participants themselves. Generally, none of the studies used goals $t$ representative of typical goals people pursue in a work situation. Thus, the studies applied a variety of different definitions and conceptualizations of goals. In line with the proposition of Elliot and Niesta (2009) we found that very few empirical articles include a clear definition of goals. The conceptualization however is often included in the work of researchers (e.g. solve an anagram). The lack of clear definitions 
indicates that comparing results across studies is difficult and to a certain extent not valid. Concluding, we can say that none of the empirical studies investigated work related goals which points out the need to engage in research focusing on this area in more detail. We cannot assume that laboratory tasks teach us about the effects of pursuing multiple goals in a work setting and the attached behavior and consequences on work results.

\section{Number of goals studied}

Next, we counted the number of goals or tasks investigated in each study and noted that the mean number of goals was 4,93 goals time with a standard deviation of $4,07^{2}$. Many studies, especially experimental studies, include only two goals or tasks. Some studies include multiple goals, but the goals are not necessarily competing with each other due to different time frames (e.g. Donovan \& Williams, 2003b). Studies using diary or survey methods covered on average 6,37 goals. The rather high standard deviations indicate that there were large differences concerning the number of goals examined between studies. Again we see that there is little research looking at the effects multiple goals will have on each other in a work setting.

Table 5: Number of goals studied

\begin{tabular}{|l|c|c|c|c|}
\hline & Experiments & Surveys & $\begin{array}{l}\text { Diary } \\
\text { Method }\end{array}$ & All studies \\
\hline Mean of goals/tasks & 2.17 & 6.86 & 5.63 & 4.93 \\
\hline SD & 0.39 & 3.70 & 5.44 & 4.07 \\
\hline Min & 2 & 2 & $1^{3}$ & 1 \\
\hline Max & 3 & 15 & 15 & 15 \\
\hline Median & 2 & 5.5 & 3.7 & 3 \\
\hline Mode & 2 & 10 & 15 & 2 \\
\hline
\end{tabular}

\footnotetext{
${ }^{2}$ Seven articles listed in table 2 include numerous studies of which not all look at multiple goals. For the sake of completion we listed all studies. However, calculating the average number of goals investigated we neglected those studies that did not include 2 or more goals or tasks.

${ }^{3}$ The current activity was measured five times a day.
} 


\section{Methods and samples}

We categorized the studies along two dimensions. First, we looked at the method used, which could either be an experiment (simulation), surveys (cross-sectional or longitudinal), or diaries. Second, we differentiated between student, non-student, and employee samples. The results are listed in table 4 . Most of the studies, namely 30 out of 39 (table 4), conducted either experiments in laboratory settings or surveys to study multiple goals. The other 9 studies employed diary methods to get a more dynamic picture of multiple goal management. The average sample size varied according to the methods applied. While the average sample size for experiments was highest $(\mathrm{N}=131)$ diary methods had a much lower average sample size $(\mathrm{N}=47)$. This is not surprising as diary methods usually are longitudinal (often with multiple survey entries per day) and more demanding on participants, which in turn lower participant compliance.

Table 7: Methods and samples used

\begin{tabular}{|l|c|c|l|c|c|}
\hline & Experiments & Surveys & $\begin{array}{l}\text { Diary } \\
\text { Method }\end{array}$ & Total & $\begin{array}{l}\text { Average } \\
\text { Sample size }\end{array}$ \\
\hline Student sample & 14 & 8 & 5 & $27(69 \%)$ & 97 \\
\hline Non-student sample & 1 & 3 & 2 & $6(15 \%)$ & 108 \\
\hline Employees sample & 0 & 4 & 2 & $6(15 \%)$ & 83 \\
\hline \hline Count of studies & $15(38 \%)$ & $15(38 \%)$ & $9(23 \%)$ & 39 & \\
\cline { 1 - 5 } Average sample size & 131 & 91 & 47 & 96 & \\
\cline { 1 - 5 } SD sample size & 71.00 & 72.38 & 22.25 & 70.35 & \\
\cline { 1 - 4 } & & & &
\end{tabular}

Remarkably, nine (23\%) of the identified studies used diary methods to investigate goal pursuit over time. About $70 \%$ of the studies that we have taken into account in this 
literature review are characterized by samples composed of undergraduate students. Only six studies used employees as a sample but they were not chosen to study goals at work.

\section{WHAT WE KNOW AND DON'T KNOW - IMPLICATIONS FOR FUTURE RESEARCH}

As can be seen from the results described above there are some studies that look into the effects of multiple goal pursuit over time. However, there is no empirical study looking into the effects of multiple goal pursuit and the dynamics of this in a work setting. In the following part we will discuss what we know and do not know about multiple goal pursuit over time. At the same time we will derive the implications of our findings and propose an agenda for future research.

\section{Single vs. multiple goal pursuit}

The foregoing makes clear that the articles reviewed are not looking at multiple work goals and their effects on working people. Most studies used performance goals in a lab setting with undergraduate students as sample. However, everyday observation tells that many people at work have multiple goals to reach in the same period of time, that their goals often contradict each other, that only few goals may be activated at a given moment in time while others are cued in working memory, etc. This calls for research revealing how people reprioritize, postpone, or even abandon goals (Roe, 1999).

There have been numerous studies - not considered in this review - of multitasking, the processing of multiple lower-level often subconcious tasks at the same time (see Meyer \& Kieras, 1997; Salvucci \& Taatgen, 2008). People engage in multitasking in our everyday life 
and sometimes do not even take notice of it - typical examples are walking while talking or talking on the phone while doodling. We consider multitasking studies as highly important and regard them as the foundation for shifting the study of multitasking to the next level - that of goals. There is an urgent need to get to know more about multitasking of conscious, midlevel task goals, which we refer to as 'multi-goaling' or 'multiple goal management'. In line with other authors (Austin \& Vancouver, 1996; Fried \& Slowik, 2004; Lord et al., 2010; Mitchell et al., 2008; Steers, Mowday, \& Shapiro, 2004) we argue that research should address conscious, parallel goal pursuit. Thus, there is a need to conceptualize goals in a way that empirical research grasps the mechanisms involved in pursuing multiple goals at work. A goal in this context may be to write a proposal, prepare a presentation or on the more quantitative goal conceptualization to reach a certain sales number. The results of the empirical studies do show that in a multiple goal situation people have to decide on resources allocation. We are rarely able to work and proceed on multiple goals at the same time. Thus, there is a need to decide which goal to pursue. Another important area of research is the switching between goals. We barely start working on one goal until it is completed. To the contrary, we engage in regular switches between goals.

\section{Capturing the dynamics of goal pursuit}

The dynamics of single goal pursuit, so the process of being motivated and working towards a goal have been addressed in some theoretical pieces (Fried \& Slowik, 2004). People do not work on either goal with the same consistency and intensity all the time. Atkinson and Birch (1970) were among the first to acknowledge and study dynamic components in human behavior. They state that "the behavioral life of an individual is a constant flux of activity. There are no behavioral vacuums except when the individual is literally inactive and 
unconscious - yet still alive in a medical sense - as in the case of extreme illness or after a severe blow on the head. Otherwise, his behavioral life is, as Barker (1963) has described it: a continuous stream characterized by change from one activity to another without pause from birth until death" (p.1).

A substantial number of studies we looked at (11) used a temporal approach. This means that the method applied was longitudinal (e.g. diary method) as well as the method of analysis. In total 10 studies used a completely non-temporal approach. There were seven studies that used a methodological temporal approach but that lacked either the theoretical aspect of dynamics and/or used non-temporal methods of analysis (e.g. correlations). Generally, there is a problem that although temporal methods are more and more often applied the temporal thinking is lacking behind. We have the tendency to think about differences between people rather than looking at the differences within people. In other words, we need to start thinking about how goals and the associated behavior of people (e.g. work or not work on them) changes as time goes by.

However and as described above, there are also pauses and people will also be busy with working on other goals. Thus, time should be an inherent part of the study of goal striving. However, most of the empirical studies looked at have not used a temporal perspective. Even though some researchers are aware of the highly dynamic component of goal pursuit they fail to use proper methodologies to capture these effects.

Recently, several authors have pointed out the importance to address work motivation with a dynamic perspective (Kanfer, Chen, \& Pritchard, 2008; Latham, 2007; Mitchell et al., 2008; Roe, 1999; Roe, 2008; Roe, 2014). This must not only be done by means of temporal thinking and model development, but also by employing temporal methodologies such as 
diaries or time series. Although the number of diaries seems to increase, the use of methods for temporal analyses is still limited.

Without doubt, we need to study the dynamics of working behavior and the variations of time and other resources such as cognitive capability spend on the various work goals. This cannot be achieved by means of cross-sectional studies with a classical questionnaire approach. The aspect of time is important in several ways when studying work motivation. First, we need to identify when things are happening. Under what circumstances do we set goals, when do we start working on our goals, when do we interrupt goal pursuit, or when do we abandon goals? Second, how long does each phase along the goal process last? Depending on the goal or task at hand, people need more or less time for goal pursuit. The time needed to make a phone call may range from about a minute to a couple of hours, but we can hardly finish our goal of completing a $\mathrm{PhD}$ within a couple of years. Although, we are aware of these time differences due to goal characteristics it is also true that not every pursuit of the same goal takes the same amount of time. There may be interruptions of goal pursuit causing a delay and increasing the amount of time needed for the goal striving phase. Third, we need to identify the time lag between two goal phases. Roe (1999) describes a time lag between goal setting and the actual pursuit of that same goal. Indeed, we sometimes set goals that we store in memory but wait for its execution until the right circumstances are in place such as time, place, resources, or people necessary for goal striving. The length of time lags between the different phases along the goal process possibly bares important implications for (timely) goal completion, goal revision, or goal abandonment. Fourth, we have very limited knowledge about the dynamic interplay between changing phenomena of work motivation. As we proceed in goal pursuit of one goal we may accept new goals that put demands on our limited resources as well. The effect of continuous new goal acceptance on current and 
planned goal striving and ultimately on goal completion is not yet known. Related to this, we suggest studying the practice of goal prioritization and its related outcomes along the entire, often in parallel existing goal processes. Well-known theories such as control theory (Campion \& Lord, 1982) and self-efficacy (Bandura, 1991) suggest feedback loops, but up till now there has been limited empirical temporal field research looking at these effects using employee samples.

Thus, in order to appropriately study the dynamics of multiple goal pursuit we need to apply - besides temporal thinking - suitable methods and samples. Although, experiments that are conducted in lab settings are necessary and very helpful for theory testing, we argue that we need to study peoples' multiple goal management in situ and over time. Diary methods and experience sampling are very good methods that allow studying behaviors as they are exposed. Diary methods will help to understand when people are pursuing their goals and for how long.

Besides the method of data gathering the chosen sample is very important. In the studies that we looked at most of the time student samples have been used. There are seldomly studies that ask employees about their daily behavior at work. We advocate recruiting employees to participate in work motivation studies to increase the validity of implications for the work setting. Studying students as they solve anagram puzzles in a lab setting will tell us little about the behavior of people at work and the goals they are pursuing in everyday life. 


\section{CONCLUSION}

In sum, we know a lot about single goal setting and pursuit. Even though researchers have pointed out the urge to study multiple goals in the context of work motivation, there is little and very diverse research in which more than one goal has been studied.

Borrowing from the literature on multitasking, we need to develop theories and models that address multiple goal management over time and test related hypotheses empirical. 


\title{
CHAPTER 3
}

UNDERSTANDING HOW PEOPLE MANAGE MULTIPLE GOALS AT WORK: A THEORETICAL MODEL AND ITS IMPLICATIONS

\begin{abstract}
An assessment of past and current literature on work motivation shows that multiple goal management has received scant attention. We propose a dynamic model of multiple goal management with lower and higher ordered self-regulation processes. Our model addresses the interdependence between goal processes, resource allocation, and other critical issues in goal management. We present propositions to guide future research and discuss potential implications for theory and managerial practice.
\end{abstract}

The paper has been presented at the Annual Meeting of the Academy of Management in Chicago, August 2009 


\section{INTRODUCTION}

As many workers are increasingly held responsible for effectively managing their work, the juggling of multiple goals has become one of the biggest challenges of the modern workplace. Limited personal resources such as time and energy require employees to engage in multiple goal management, including for instance prioritizing, scheduling, and goal (de-) activation, to attain satisfying overall performance.

Although the necessity to manage multiple goals is an everyday phenomenon in the work life of many, we know very little about the processes involved and their motivational implications. As the strategies that people use to manage multiple goals could be considered to be an inherent part of motivated behavior (Strickland \& Galimba, 2001), it is rather surprising that hardly any research has focused on multiple goal pursuit and its motivational aspects (for notable exceptions see: Kernan \& Lord, 1990; Louro, Pieters, \& Zeelenberg, 2007). As a consequence, several questions remain unanswered. Why can some people effectively manage multiple goals and deliver their results in time, while others have trouble in meeting deadlines or fail to accomplish their goals? Why do people switch their activity to another goal while the current goal is seemingly more important or urgent? How, and especially why, do people reschedule goal- related actions and change their activity when time is running out, when circumstances change, or when new goals emerge? Several authors have expressed the need to study multiple goal management (Austin \& Bobko, 1985; Austin \& Vancouver, 1996; Fried \& Slowik, 2004; Kanfer, 2005; Locke \& Latham, 2004; Louro et al., 2007; Roe, 1999; Steers, Mowday, \& Shapiro, 2004) and to clarify how pursuing one goal may hinder the attainment of another goal. However, the amount of theoretical and empirical research, especially in real life work settings, devoted to this area has been minimal. 
The aim of this paper is to develop a model of multiple goal management and corresponding propositions as a basis for future research. We will begin by discussing some notions from goal theory, and provide a review of what the literature on work motivation and self-regulation offers with regard to multiple goal management. Next, we present a model of multiple goal management and derive according propositions. Last, we discuss the implications of our approach for existing theories, managerial practice, and future research.

\section{GOAL THEORY}

In line with Frese and Sabini (1985) we regard "human action as being fundamentally goal-directed" (Carver \& Scheier, 1990: 5). Goals focus attention, direct energy towards what is desired, and exert major influence on current and future behavior. Not surprisingly, many motivational theories have adopted the notion of "goal" to study individuals' purposeful behavior. Lewin was among the first researchers to acknowledge the importance of goals in the study of motivation (1926; 1935). Austin and Vancouver (1996) define a goal as an internal representation of a desired state. However, the capacity of a goal to produce an action does not only depend on cognition alone, but on an intention to act and a commitment to achieve the desired state. Goals have cognitive and motivational facets; in the words of Frese and Zapf: "the goal is a point of comparison for the action (the cognitive aspect), and the action is 'pulled' by the general goal (the motivational aspect)" (1994: 274). ${ }^{4}$ Given the importance of goals within motivation research, we will discuss goal theories in more detail below, paying special attention to situations in which multiple goals are present.

\footnotetext{
${ }^{4}$ Besides goals, similar constructs have been used that combine cognitive and motivational elements, such as 'personal projects' (Palys \& Little, 1983) or 'current concerns' (Klinger, 1975).
} 
At this stage it is important to lay out the boundaries of our review of the literature in a few words. Due to the immense volume of publications on goal theory and motivation it is impossible to cover all of it. We skip topics such as goal content taxonomies, goal orientation, and goal commitment. For an elaborate review on goal theories in psychology we refer to Austin and Vancouver (1996), who discuss these and other topics. On the other hand, we highlight particular aspects of goals to direct the focus to work motivation and time. First, we distinguish several dimensions of goals, such as the level of complexity, temporal perspective, and types of goals. Second, we focus on goal processes to address the dynamic component.

\section{Dimensions of goals}

The distinctions made in the literature between types of goals indicate very well the diversity of goals and point at differences in underlying motivational processes. First, complex goals tend to have more linkages to other goals than simple goals and can be divided into several subgoals. As a consequence, "more complex goals have greater potential for conflict" (Austin et al., 1996). While interrelated goals may impede each other, the contrary may happen as well. Complex but interrelated goals can also facilitate the successful pursuit of each other due to dependencies or overlap in activities or resources needed. In addition, the levels of complexity imply that different degrees of consciousness are involved in thinking about the goals and enacting them (Austin et al., 1996). On the highest level are superordinate goals, which are abstract and not continuously consciously experienced. They resemble general life achievement goals that are directing peoples' long term endeavors. Prominent examples are the goals of "getting rich" and "living a healthy life". Goals at the lowest level are often described as states to be achieved by sensorimotor processes, such as proprioception and muscle contractions. Again, these goals may not be consciously experienced and many of 
them may be enacted in parallel since they are not constrained by limited working memory (Austin et al., 1996) . Mid-level goals are consciously defined and normally represented in a person's working memory. Such mid-level goals, usually labeled "task goals" (Locke et al., 1990), are often investigated in connection to work motivation.

Second, the distinction between proximal (or short term) and distal (or long term) goals is important because the achievement of proximal goals require less planning than distal goals, and do not rely as much on long-term memory. For long term goals, planning is indispensable since the events and actions occurring in the meantime make it impossible for people to remember the goals and the necessary actions. Unlike short term goals, long term goals are also sensitive to distraction by events that happen in the time interval towards their execution. In a multiple goal setting the way proximal goals influence the pursuit of distal goals and vice versa is interesting to further investigate.

Third, there are work and non-work goals. The goals that people are supposed to pursue in work contexts are often outcome goals rather than process goals. They represent some desired end-state demanded by the organization to further its purposes, that is, they must lead to some tangible outcome at some point in time. These goals are typically characterized by moderate levels of abstraction and complexity. Although it must be acknowledged that work and non-work goals can influence each other, we focus on work related goals, that is to say, on task goals with moderate levels of proximity, abstraction, and complexity.

\section{Goal processes}

As depicted in Table 1, several researchers have proposed a temporally segmented process to explain the transition from cognition to action (Frese et al., 1994; Gollwitzer, 1993; 
Heckhausen \& Kuhl, 1985; Karoly, 1993; Roe, 1999). Generally, the goal process has been defined as behaviors and cognitions related to the striving towards the attainment of a goal (Austin et al., 1996). While the most basic view is that the goal process consists of only two phases, that is goal setting and goal striving, proposals from the self-regulation literature (e.g. Austin et al., 1996; Karoly, 1993) suggest more phases, namely goal establishment (volition), planning (cognition), acting, and evaluating (feedback). Researchers have argued that goalsetting represents the motivational part of the goal process whereas the other phases, which involve regulating and realizing the goal intention, represent the volitional part (Heckhausen \& Heckhausen, 2006).

The first phase of most goal processes is known as goal establishment or goal-setting. This has both cognitive and volitional aspects: the person identifies the goal's content, evokes an intention to act, as well as a commitment to keep acting till the end-result is achieved (Roe, 1999).

In the second phase of the goal process, the planning of goals, alternative paths by which the goal can be obtained are generated and evaluated (Hacker, 1998). Generally, planning connects the goal to action (Tubbs \& Ekeberg, 1991) and is the stage at which individuals ponder and decide about a sequence of tasks - thus prioritizing - by which the goal can be reached. Some researchers differentiate between goal intention and implementation intention (Gollwitzer \& Brandstätter, 1997). This is a typical assumption for single goal research, which may not hold for situations with multiple goals. In multiple goal settigs a goal intention may be formed at one moment and considerable time may pass necessary to work on other goals - before the goal is ready for enactment and implementation intentions are being built. In the view of Gollwitzer and Brandstätter, the planning process is 
the phase when goal intentions turn into implementation intentions. Planning defines when, where and how a certain action should be taken.

Table 1: Goal process models

\begin{tabular}{|c|c|c|c|c|c|c|}
\hline $\begin{array}{l}\text { Action } \\
\text { Research } \\
\text { (Lewin, } \\
\text { Dembo, } \\
\text { Festinger, \& } \\
\text { Sears, 1944) }\end{array}$ & $\begin{array}{l}\text { Rubikon } \\
\text { Model } \\
\text { (Heckhause } \\
\text { n et al., } \\
1985 \text { ) }\end{array}$ & $\begin{array}{l}\text { Self- } \\
\text { regulation } \\
\text { (Karoly, } \\
\text { 1993) }\end{array}$ & $\begin{array}{l}\text { Action } \\
\text { theory } \\
\text { (Gollwitz } \\
\text { er, 1993) }\end{array}$ & $\begin{array}{l}\text { Action } \\
\text { Regulation } \\
\text { Theory } \\
\text { (Frese et al., } \\
\text { 1994) }\end{array}$ & $\begin{array}{l}\text { Self- } \\
\text { regulation } \\
\text { process } \\
\text { (Austin et al., } \\
1996 \text { ) }\end{array}$ & $\begin{array}{l}\text { Calendar } \\
\text { Model } \\
\text { (Roe, 1999) }\end{array}$ \\
\hline \multirow[t]{5}{*}{ Goal setting } & Goal setting & \multirow[t]{5}{*}{$\begin{array}{l}\text { Goal } \\
\text { selection }\end{array}$} & \multirow[t]{3}{*}{ Wishing } & \multirow[t]{3}{*}{ Task Goal } & \multirow[t]{3}{*}{$\begin{array}{l}\text { Goal } \\
\text { establishment }\end{array}$} & $\begin{array}{l}\text { Goal } \\
\text { generation }\end{array}$ \\
\hline & \multirow[t]{4}{*}{$\begin{array}{l}\text { Intention } \\
\text { formation }\end{array}$} & & & & & \\
\hline & & & & & & Filtering \\
\hline & & & \multirow[t]{2}{*}{ Planning } & \multirow[t]{2}{*}{$\begin{array}{l}\text { Plan } \\
\text { Generation }\end{array}$} & \multirow[t]{2}{*}{ Planning } & Scheduling \\
\hline & & & & & & Preserving \\
\hline \multirow[t]{6}{*}{ Goal striving } & \multirow[t]{2}{*}{$\begin{array}{l}\text { Initiation of } \\
\text { intention }\end{array}$} & \multirow[t]{3}{*}{$\begin{array}{l}\text { Goal } \\
\text { cognition }\end{array}$} & \multirow[t]{6}{*}{ Acting } & \multirow[t]{5}{*}{ Execution } & \multirow[t]{4}{*}{ Striving } & \\
\hline & & & & & & Enactment \\
\hline & $\begin{array}{l}\text { Crossing the } \\
\text { "Rubicon" of } \\
\text { action } \\
\text { enactment }\end{array}$ & & & & & \\
\hline & \multirow[t]{2}{*}{ Action } & $\begin{array}{l}\text { Directional } \\
\text { Maint- } \\
\text { enance }\end{array}$ & & & & \\
\hline & & $\begin{array}{l}\text { Directional } \\
\text { change or } \\
\text { reprioritizati } \\
\text { on }\end{array}$ & & & \multirow[t]{2}{*}{ Revision } & \\
\hline & $\begin{array}{l}\text { Postactional } \\
\text { evaluation }\end{array}$ & $\begin{array}{l}\text { Goal } \\
\text { termination }\end{array}$ & & Feedback & & $\begin{array}{c}\text { Backrelating } \\
\text { Factor }\end{array}$ \\
\hline
\end{tabular}

Goal enactment, or goal striving is the third phase in most goal process models. In this phase, previously set goals are (re)activated and put into action. Building implementation 
intentions can also be located here. In this phase, goal-directed behavior is produced until the goal is completed. This phase can extend over a longer period of time and can involve various recurrent cycles.

Goal process models generally propose that the last phase comprises goal evaluation and feedback (cf. Gollwitzer, 1990). Information about the progress towards the goal and its ultimate attainment or non-attainment is used to decide about the continuation of goal-striving and can provide input for the next goal setting and striving cycle. During this phase individuals evaluate whether they have achieved the intended outcome, and whether the actual value of the goal striving outcome matches previous expectations (Gollwitzer, 1990). In some cases it is easy to identify the attainment of a goal, e.g. making a phone call or attending a class. However, there are goals that lack a precisely defined end point, which makes the correct timing of goal evaluation more difficult, e.g. developing a product or improving one's social competence.

In contrast to the previously described phases, a revised process model of cognitive goal-setting and striving process was proposed by Roe (1999). It is composed of five major phases, designated as goal generation, filtering, scheduling (cf. planning), preserving, and enactment of the goal (see Table 1). The first two phases can be seen as subdivisions of the goal-setting phase from previous models. Goal generation is seen as producing and evaluating goals that might possibly be pursued. The filtering phase entails comparisons among these possible goals and an evaluation of their implications, but it also includes the compatibility or incompatibility with previously established goals. Here, the existence of multiple goals is explicitly acknowledged. A conspicuous difference with other models is the introduction of a 
"preservation" phase, which reflects that there is usually delay (time gap) between goal generation and enactment. During this phase the goal is "dormant", that is, present in longterm memory rather than in work memory.

This model represents a dynamic approach to goal processes in a multi-goal setting since it assumes that new goals may enter, or existing goals may change. Also, the time gap in one goal process may be filled with parts of another, simultaneously occurring goal process (from work or another life domain, e.g. family, leisure), or with recovery.

Phase models generally describe how people act with regard to a single goal. Although they may be relevant for multi-goal situations, they do not describe what happens when people have multiple (assigned or self-set) goals, which is typical in organizations. It seems reasonable to expect that people cannot work equally well on multiple goals, as required resources may not be available at the same time and inter-goal interference may occur. Yet, existing theories provide little guidance regarding the kinds of effects to expect. Another general limitation of phase models is their rudimentary treatment of time and hence of processes involved (Roe, 2008). They apparently imply a temporal flow, as a certain amount of time is supposed to pass from the moment in which a goal is set until the moment in which it is accomplished, but they do not indicate whether these phases immediately succeed each other, nor what their duration is. The models seem to suggest that phases represent an undivided stream of events, and that a new goal process will only start when the first has ended. But from practical experience we know that people do not work on a goal without cessation. For instance, they stop working on the goal at lunchtime or at the end of the working day and resume the activity when they return. Goal pursuit may be interrupted when difficulties are encountered, or it may be halted and postponed to accommodate a new and 
more urgent goal (Eyrolle \& Cellier, 2000; Zijlstra, Roe, Leonova, \& Krediet, 1999). Some goals may even be abandoned for the sake of a more attractive goal (Van Eerde, 2000). All this suggests that, in the case of multiple goals, goal processes do not necessarily occur sequentially but possibly also in parallel. The model by Roe (1999) acknowledges this by postulating a gap during which other goals may be pursued.

Given the current state of the literature on goal theory we must look for other theoretical work to clarify how multiple goals and a dynamic view on these processes influence work motivation and subsequent performance. Thus, we will now focus on selfregulative theories of goal management and evaluate to what extent the effects of multiple goals have been considered.

\section{GOAL MANAGEMENT THEORIES}

Since the literature on motivation and goal management is vast, we focus on a few theories relevant to our model development. Even though there is an apparent link between time management and the juggling with multiple goals, we do not discuss time management at length since the amount of empirical research is limited and its theory is still its infancy (Claessens, Roe, \& Rutte, 2008; Claessens, Van Eerde, Rutte, \& Roe, 2007; Macan, 1994). Moreover, we do not address all motivational theories that have been related to work activity (for a recent overview see Latham, 2007; Pinder, 2008), but confine ourselves to theories that deal with processes by which people develop and enact goals. Most of them can be considered self-regulation theories, although this term is not always explicitly used. They include goal setting theory and action regulation theory. We explore the main tenets of these theories and see how they can help to understand multiple goal management. 
According to Fitzsimons and Bargh (2004: 151), self-regulation refers to the way in which people control and determine their behavior consciously and intentionally. Selfregulation represents the internal processes that enable individuals to guide their goal directed behavior over time and across situations (Karoly, 1993). Thus, self-regulation comprises the exercising of control over functions, states, and inner processes (Baumeister \& Vohs, 2004). Human beings possess the ability to execute reasoned behavior which makes the resultant purposeful action volitional (Latham \& Locke, 1991). In line with this, Karoly (1993) describes self-regulation as voluntary action management in which people must choose which goals to pursue and decide by which means to achieve these goals. Without goals, human behavior would be determined by external factors and would be in constant flux, changing direction according to whatever influence on them is strongest in a given moment (Atkinson \& Birch, 1970; Bandura, 1991). The essential role of goals within self-regulation theories has been explicitly acknowledged by goal setting theory.

\section{Goal setting theory}

An assumption of goal setting theory is that all cognitive human behavior is purposeful and that goals regulate individuals' actions (Latham \& Locke, 1991). The central proposition of goal setting theory is, that given ability and commitment to the assigned goal, specific and difficult goals result in higher performance compared to "no goal" or "do your best" goals (Locke et al., 1990).

Goal setting theory does not make a clear distinction between assigned goals and selfset goals. The theory assumes that assigned goals are generally accepted and turned into personal goals without major discrepancies. Under this assumption, goal setting theory (in the sense of assigning particular goals) can be seen as part of the self-regulation process, as it 
induces the motivational discrepancy existing between a desired and actual state and mobilizes actions towards the goal (Latham et al., 1991). As long as there is a discrepancy between the actual state and the goal, corrective actions are required that ultimately result in goal achievement (DeShon, Kozlowski, Schmidt, Milner, \& Wiechmann, 2004). If no corrective action is taken or is found necessary, the evaluation influences future expectations and leads to an adaptation of self-efficacy which is defined as the belief in one's capacity to perform some behavior or some level in a task (Bandura \& Cervone, 1986).

Unfortunately, goal setting theory pays little attention to the pursuit of multiple goals. In 1990 Locke and Latham acknowledged the existence of multiple goals at a macro level. They mentioned that organizations generally pursue multiple, contradictory, and often complex goals and that research on strategic management and organization theory has focused on macro goal setting. They considered this an important area for research and proposed to investigate the question "What are the contextual factors that influence the optimal number, type, and mix of organizational goals?" (Locke et al., 1990: 333). However, they did not extend their interest to the individual level. They state that "of course, individuals in real organizational settings have multiple goals, but these have rarely been examined in micro studies" (1990: 323). Until today this does not only apply to the work of other researchers, but also to their own research. Apparent issues such as the fact that multiple goals may compete for attention or priority, and that their mere existence may influence the motivation to execute other goals, have been acknowledged, but left unaddressed in goal setting theory. Latham (2007) recently argues that although there might be more than one goal and thus goal conflict may arise, the positive effect of goal setting on performance is still in place when people prioritize their goals effectively. 


\section{Self-regulation theory}

In our discussion of goal theory, we indicated that researchers tend to see the goal process as a series of phases that starts with goal setting and ends with an evaluation of the enacted goal. A number of theories have moved beyond this way of theorizing and looked at the underlying cognitive and motivational processes that produce this sequence of events (Bandura, 1991; Karoly, 1993). While some research has concentrated on goal setting (Heckhausen \& Kuhl, 1985) and planning (Gollwitzer, 1996), other work has also considered the enactment phase or the goal striving process (Vancouver \& Putka, 2000).

Self-regulation researchers have acknowledged the existence of multiple goals and their motivational impacts in several ways. For instance, Shah and Kruglanski (2003) have pointed out that people are frequently juggling with multiple goals in everyday life and that "goal shielding" is required along the process to obtain desirable outcomes. Wrosch et al. (2003) have emphasized the importance of deciding which goal to pursue. Decisions may be revised or goals may be abandoned in favor of a new or previously accepted goal. When people realize that they will not manage to attain a goal they may disengage from it. The real action taken by people is shaped by the "best means to a goal [...] defined collectively in terms of the entire system of currently active goals" (Shah \& Kruglanski, 2000: 96). In spite of this general recognition of the fact that multiple goals may be present, the way in which people handle multiple goals has not explicitly been addressed.

\section{Action regulation theory}

Action regulation theory is a comprehensive theory about the cognitive and motivational processes that underlie goal directed activity involved in work (Frese et al., 
1985; Frese et al., 1994; Hacker, 1998). It is similar to and in several ways complementary to self-regulation approaches. The key assumption is that behavior at work is largely intentional and goal directed. The way in which goals are developed and, through a series of steps, turned into action, is central in the theory. Building on action regulation theory Roe (1999) defines action regulation as "a complex self-regulating process in which the person initiates and fulfills an action in accordance to a self-generated cognitive representation of the goal" (p.237). He refers to action as "the smallest unit of behavior that is related to a conscious goal" (Hacker, 1986: 73). Similar to self-regulation theories, goals are viewed as the drive behind the action and as the point of reference that provides feedback. The goal has a cognitive component but also directs the action and thus exerts a motivational force (Frese et al., 1994). Goals are broken down in subgoals and subordinate parts, which form a hierarchical structure (cf. Austin et al., 1996; Volpert, 1982) that is executed in top-down and sequential manner.

The main difference with self-regulation theory is that goals in action regulation theory are seen as stemming from work tasks. A clear distinction is made between assigned (objective) tasks and self-defined (subjective) tasks, and it is assumed that subjective tasks are derived from objective tasks by a process of redefinition (Hackman, 1969). Assigned task goals that are "translated" into personal task goals (Hacker, 1986) may differ in significant respects (amount, quality, and timing). The distinction between objective and subjective goals is crucial in action regulation theory (Frese \& Zapf, 1994; Roe, 1999). In contrast to selfregulation theory and goal setting theory, the assumption is that only subjective goals direct a person's action. As goals are linked to tasks, they are also referred to as "task goals". Goals in action regulation theory are typically mid-level outcome goals, which have to be reached within a specified amount of time. Action regulation theory postulates that people can 
perform the same work tasks in different ways depending on the amount of experience with carrying out the required work activities - this is referred to as regulation levels (Hacker, 1998). At the highest level work goals are executed in a conscious manner using explicit action plans. At the intermediate level, reached by continued practice, the goal is represented by signs and pursued by following a work plan that consists of rules. And at the lowest level the goal is represented by signals and achieved by automated routines. These levels of regulation imply different degrees of consciousness. A similar distinction has been made by Rasmussen (1986). In recent years the idea of varying degrees of consciousness has also been adopted by self-regulation researchers (e.g. Stajkovic, Locke, \& Blair, 2006). Action regulation theory, like other goal theories, has concentrated on actions pertaining to a single goal and has given limited consideration to environmental influences (Dörnyei \& Ottó, 1998; Frese et al., 1994). However, action regulation theory explicitly acknowledges that work involves multiple goals and that regulatory processes involve changes of action (heterarchic regulation; Hacker, 1998).

Our review of the extant literature shows that little is as yet known about how people deal with multiple work goals and how they manage them within time. The necessity to incorporate multiple goals in work motivation theory has been acknowledged by many researchers, but there is very little theoretical and empirical work to build on. In the following section, we propose a model for studying multiple goal management that integrates parts of previously described theories and adds ideas about the dynamics of underlying cognitive and motivational processes as well as social and situational events. 


\section{TOWARDS A MODEL OF MULTIPLE GOAL MANAGEMENT}

We believe that in order to understand the management of multiple goals and to contribute to the motivation literature, we need to move beyond theoretical models that relate to single goals. In order to account for such processes as detecting conflicts between goal processes, scheduling goals vis-à-vis each other, allocating resources to them, giving priority to one goal while putting others on hold, we need to postulate a higher-order self-regulation process that does not aim at the fulfillment of a single goal but rather of a set of goals. We introduce the notion of goal portfolio to refer to a set of goals accepted by a person, and define multiple goal management (MGM) as the self-regulation processes by which the person aims to fulfill the goals in the portfolio over a certain time span.

The model of multiple goal management developed below differs from single goal models in a number of respects. First, it is based on the assumption that people are expected to fulfill multiple work goals within certain deadlines on a continuing basis. Second, it departs from the postulate of limited resources. Not only are there limits to the time available for setting, planning and executing goals, the cognitive and energetic resources that people can rely on within any time interval are also limited (Wickens \& McCarley, 2008). Third, it assumes that, as a consequence of these limitations, goals that remain inactive while other goals are being executed are exposed to the risk of decay, especially if the time gap until their execution is long. Fourth, it postulates that people rely on certain meta-cognitive, metamotivational, and meta-volitional processes in pursuing their multiple goals within external constraints and personal resource limitations, and that they apply a variety of strategies. Fifth, it acknowledges that environmental events and changes in goal related demands, actual progress in goal achievement, and changes in personal states give the person's MGM an 
ongoing character - which implies an explicit focus on time. The model is not meant to replace single goal models but rather to supplement them and explain how self-regulation processes regarding single goals may enhance or interfere with each other.

The model will be developed in a number of steps. First, we will describe the distinct but highly interlinked lower and higher order self-regulation processes. However, we will concentrate on the multiple goal process and be brief on single goal models. For these, we refer to the literature in the previous section. Second, we introduce the notion of individual goal portfolios and put forward a number of propositions regarding the way they function. Third, we discuss various aspects of higher-order self-regulation, including adding goals, prioritizing and scheduling goals, shielding goals, (re-)activating goals, and removing goals. Along with the model, we present propositions to be tested in future research.

\section{Lower and higher order self-regulation}

Multiple goal contexts offer ample opportunities for self-regulated behavior. To address MGM, we need to distinguish between self-regulation at two levels.

As depicted in Figure 1 at the lower part, the first level which we refer to as the lower order self-regulation is focusing on the direction, intensity, and persistence of actions across time and situations to reach a single goal. Regarding this lower level self-regulation we follow earlier models suggesting that every goal puts forward a dynamic goal generationstriving process comprised of a number of phases such as goal generation, goal planning, goal enactment, and evaluation (cf. Austin et al., 1996). In the case of multiple goals, we have to assume that several of such processes can take place serially or in parallel. Due to capacity and motivational limitations as well as time constraints there are interactions and interferences 
between goals. Some goals that are accepted need to be put on hold to give room for other goals to be executed first. Sometimes goals are worked upon, put aside and resumed at a later moment. Accordingly, and similar to Roe (1999), we postulate a time gap between the planning of the goals and their performance, during which previously set goals may be pursued, revised or lost, or new goals may be added. During these time gaps, goals are inactive. When inactive, resources can be used to activate and pursue other goals. As we will discuss later, time gaps may lead to motivational decrements and they increase the likelihood of accepting new goals.

The second level referred to as higher order self-regulation is similar to a definition of work motivation given by Kanfer, Chen, and Pritchard (2008): "the set of processes that determine a person's intentions to allocate personal resources across a range of possible actions" (p.4). There are some important differences between lower and higher order self-regulation processes. While the lower order process has a limited time span, ending with accomplishment of a particular goal, the higher order self-regulation process is ongoing as people accept new goals while existing goals are completed. There is a continual process of monitoring "what has to be done by what time" with "what has been achieved". A periodic assessment of the discrepancy between the goals a person has accepted to pursue with achievements made leads to a series of measures affecting the portfolio and the goals it comprises. As shown in Figure 1 these measures comprise: (1) adding new goals to the portfolio, balancing the demands from the work setting and possibilities for execution; (2) prioritizing goals vis-à-vis each other and scheduling them in time; (3) selectively activating and de-activating goals, as to achieve optimal results given demands and opportunities from the work setting and available resources; (4) shielding selected goals against disturbances, 
raising the likelihood of their timely completion; and (5) removing goals from the portfolio as they are no longer relevant or to create room for other, more important goals.

It is important to note that higher order self-regulation operates alongside lower order self-regulation. While the higher order process determines which goals are to be admitted to the portfolio and which of them are to be worked upon and when, the lower order process is responsible for suggesting goals for admission, and for executing goals in a timely fashion. 
Figure 1: Multiple Goal Management by Higher and Lower Order Self-Regulation

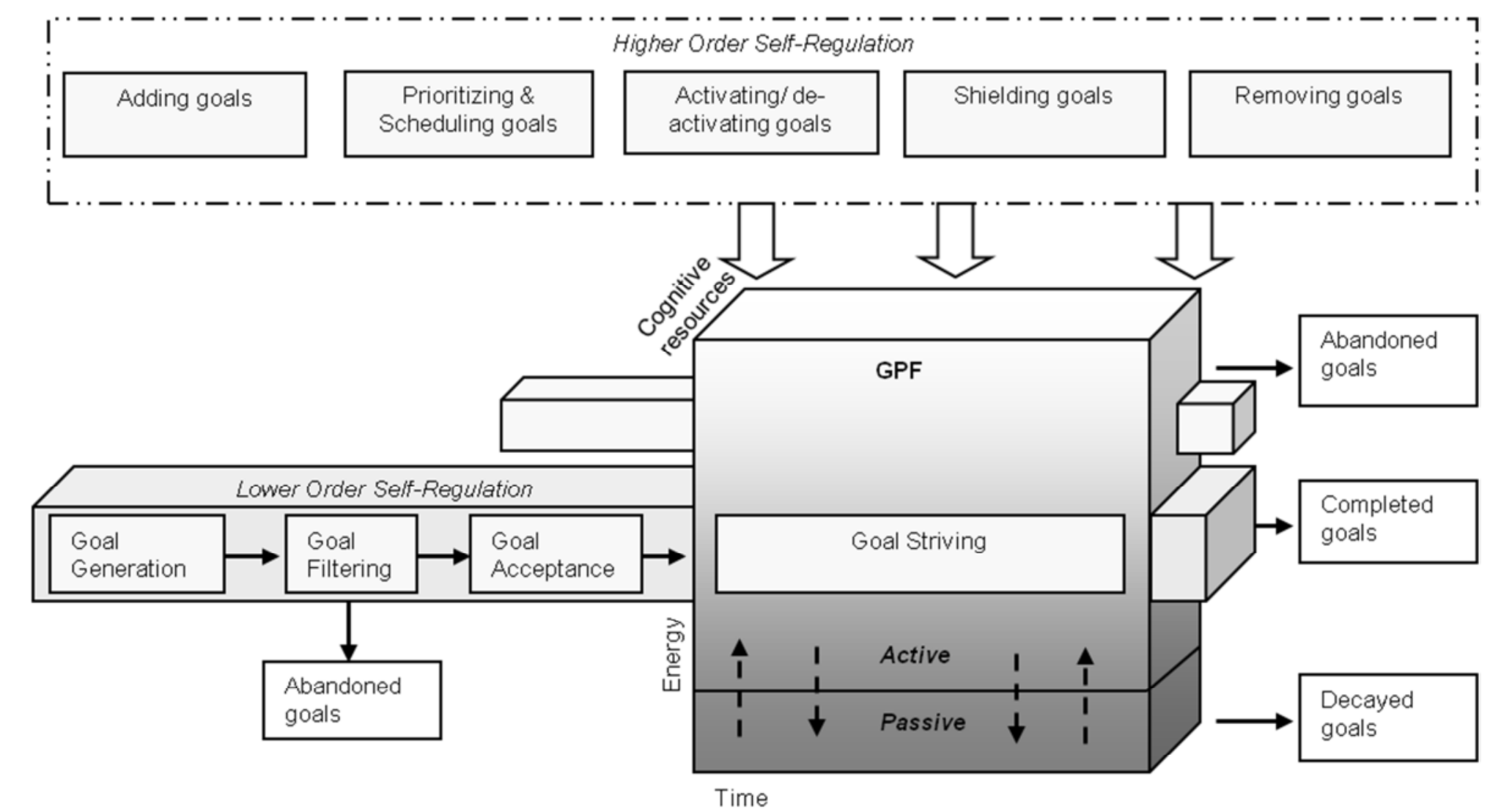




\section{Goal portfolios}

As mentioned earlier, we define a goal portfolio (denoted as GPF in Figure 1) as consisting of all goals a person has accepted for future execution at a given point in time. Usually a goal portfolio of an individual is a subset of all goals a person can or would like to pursue. Similarly, Altmann and Trafton (2002) assume that goals are stored in a distinct kind of memory, which they label "goal stack", influenced by higher-level control. The content of the goal portfolio will differ from person to person depending on, for example, the type of work and personal preferences, and it will change over time. In contrast to the goal stack, the goal portfolio is inherently dynamic: through their work and as time passes people enact, progress on, and accomplish certain goals, which then disappear from the portfolio, while they add new goals. As a result, the number of goals stored in the goal portfolio will differ between persons and change within person as time passes.

Even though people tend to complete their goals, some goals may leave the portfolio without being completed. As depicted in Figure 1 there are two main options: goals either leave the portfolio after having been completed to a satisfactory degree, or being unaccomplished. In the latter case they may be consciously abandoned or simply be forgotten (cf. decay).

Like separate goals, goal portfolios have various attributes that differ within and between individuals. The first is goal density, defined as the ratio between the time needed for executing all goals to the total time available to pursue these goals. We assume that goal density is affected by individual preferences. Some people are known to prefer very busy schedules - these so-called 'workaholics' (McMillan, O'Driscoll, \& Burke, 2003; Schaufeli, Taris, \& Van Rhenen, 2007) constantly add new goals to their portfolios. Secondly, 
goal portfolios may show a greater or lesser degree of compatibility between goals, depending on the goal structure, that is, the interrelationships between goals (Austin \& Vancouver, 1996). Compatibility refers to the degree to which the execution of goals requires the same resources. We put forward that the goal portfolio can be seen as a three dimensional space composed of time available, cognitive resources, and energy (see Figure 1). Goals that make similar demands on these resources can be executed simultaneously, while incompatible or conflicting goals cannot (cf. Locke et al., 1994). The degree of goal compatibility within the portfolio is assumed to have an influence on overall MGM performance, not only in terms of the number of goals accomplished but also their timeliness.

Following Wickens and McCarley (2008) we postulate that goals requiring the same resources cannot be executed simultaneously. In most cases only one or a few goals within the portfolio may be active at the same time and determine current behavior. We consider goals to be active if the person thinks about them (cognitively active) or works upon them (performatively active). All other goals within the goal portfolio are passive, so held in the background, involving long-term memory.

As shown in Figure 1, goals can be (re-)activated or put in the background at any time, and may be activated repeatedly. Figure 2 provides a 'zoomed in' picture of the goal portfolio over a time interval to illustrate an example of goal activation patterns. The lower area, marked with dark grey, represents the background of the portfolio, in which goals are stored while being passive. The lighter the shade the more active the goal is. Often goal pursuit is interrupted and people start working on an alternative goal (Goal 1 in Figure 2). This interruption may not have been planned by the individual, but occur due to changes in 
the environment and/or a rising awareness of a competing goal that seems more important or attractive at the moment.

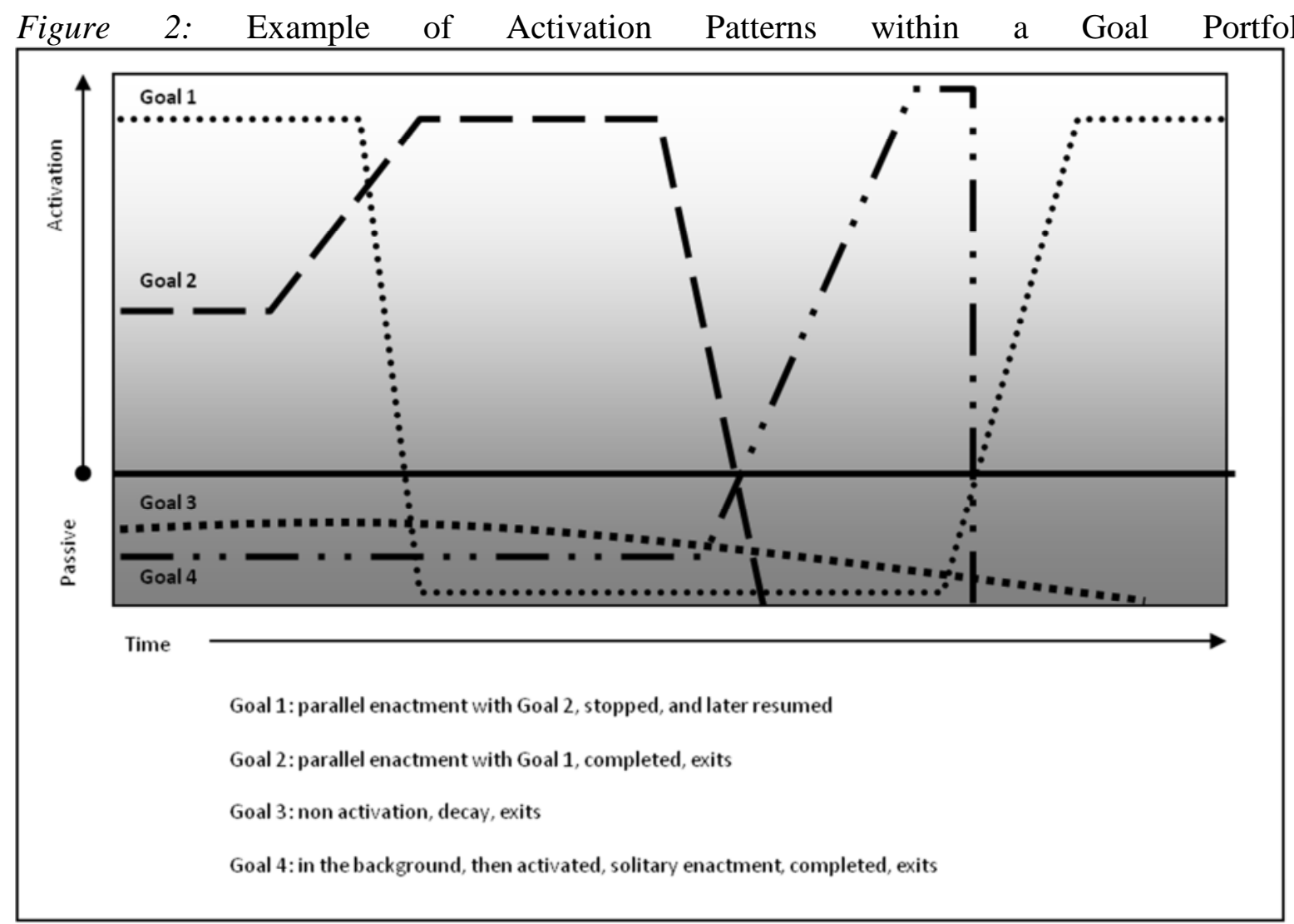

Altmann \& Trafton (2002) introduced the notion of an interference level that any goal has to cross in order to get enough attention to influence current behavior. They define the interference level as "the expected (mean) activation of the most active distractor" (p.45). Similarly, we put forward the notion of a threshold that a goal needs to pass when being reactivated from the background of the goal portfolio. The example of Goal 1 in Figure 2 shows that interrupted goals can be activated at a later point in time when the necessary resources become available again. Elaborating on the notion of goal portfolio and assumptions of limited resources and goals' active and passive states, we now come to a number of propositions. These are grouped into major categories. We will first discuss some basic 
processes that are supposed to happens in the goal portfolio. Next, we will focus on the higher order self-regulation process and the way in which people strive to manage multiple goals.

\section{BASIC PROCESSES IN THE GOAL PORTFOLIO}

\section{Goal strategy}

People may deal with the goals in the portfolio in a number of ways, which we will designate as "strategies". We distinguish between three main possibilities: a person may work continuously on one goal before starting to work on another goal (serial strategy), or work simultaneously on multiple goals (parallel strategy), or work on some goals and adding a new goal whenever an old goal is about to be completed (overlapping strategy). Due to the limited resources an individual has available and therefore his or her restricted ability to work on two or more goals concurrently, the goal strategy used will depend on the degree of compatibility between the goals within the portfolio. Incompatible goals have a lower likelihood of being activated simultaneously. In contrast, highly compatible goals often share common tasks which implies that work on these tasks create goal synergies (e.g. Goal 1 and 2 in Figure 2). Goal 4 in Figure 2 is supposed to be very resource consuming and to allow only for solitary enactment at a later time, when necessary resources have been freed. In short, the type of goal strategy used (serial, parallel, and overlapping) depends on the compatibility between goals in the portfolio.

Proposition 1: Goals will be executed serially (if compatible), in parallel (if incompatible), or overlapping depending on the compatibility among goals in the portfolio until completion or abandonment. 


\section{Goal decay}

We propose that if a goal is passive for a longer time, meaning that the person does neither think about the goal, nor plan for it, or actively pursue it, there is a strong likelihood that this goal will be forgotten, decay, and ultimately vanish from the goal portfolio (Goal 3 in Figure 2). This notion is strongly linked to research about prospective memory and the recall of goals (Fiore, 2008). As time passes and goal activation is not renewed, the strength of the goal diminishes. Also, it becomes more unlikely that relevant cues in the environment (event based) are recognized or self-initiated (time based) retrieval will have an effect on goal activation. A goal that is active, no matter whether due to performative or cognitive activation, will show progress in one or the other way. If, for example, a person thinks about a goal (cognitive activation), new ideas of how to reach that goal may be generated (cf. implementation intentions, Gollwitzer et al., 1997), or the goal may be adjusted to better meet available resources or circumstances. In short, goal activation helps to keep the goal in the portfolio. If regularly activated, goals will at least survive and stay within the goal portfolio and retain the chance of being completed at some point in time.

Proposition 2: Goals will decay, unless they are being activated.

\section{Time gaps}

Due to resource limitations and the presence of multiple goals, there will often be time gaps, e.g. between the generation of a goal and its enactment. Actually, there may be time gaps throughout the whole lower level self-regulation process. For instance, while one goal is passive, thus pausing (time gap), another goal may be pursued. It follows from the previous paragraph that the duration of the time gap - the time the goal is held in the background - 
influences the likelihood of goal decay. The longer the goal is passive the more likely it is that it is forgotten and ultimately vanishes, thus leaving the goal portfolio. We propose that this will be particularly visible for the time gap between goal generation and execution.

Proposition 3: Goal decay is faster, the longer the time gap between goal generation and execution.

\section{Goal progress}

We assume that goal progress has a general effect on the likelihood of goal activation. If people have accomplished a large part of the goal to be reached, there are more cues that trigger further goal activation. Working upon a goal enriches episodic memory - the memory of our past and personally relevant experiences (Fiore, 2008) - by promoting the recall of past experiences. Goal activation depends to a large extent on environmental factors that serve as cues for priming (Altmann et al., 2002). The more a person has worked upon the goal the more contextual cues will have developed, which in turn increases the chance of goal activation when faced with distractors. Besides priming of goals, volitional aspects are to be considered. The more progress has been made, the more the person has invested in completing this goal in terms of time and energy spent on the goal. As a consequence, the volition to activate the goal will increase (cf. proximity of goal completion, Louro et al., 2007). For example, it is not very likely that a person will discontinue reading a book if only a few pages are left compared to stopping after a few pages. As a consequence, goal decay will be stronger the less goal progress there has been and greatest if the goal has only been planned for and no actual goal enactment has taken place yet.

Proposition 4: Goal decay is less with greater progress on the goal. 


\section{HIGHER ORDER SELF-REGULATION AND MULTIPLE GOAL MANAGEMENT}

Higher order self-regulation is an ongoing process aiming at the management of the goal portfolio in its entirety by means of deciding which goals may enter the portfolio, as well as by prioritizing, scheduling, activating, shielding, and removing goals. Here we describe these five components of the higher order self-regulation process and postulate that they define the way in which people conduct MGM.

\section{Adding goals}

In work settings people regularly generate goal options - possible goals either on their own initiative or because given work tasks incite them to do so. Like other researchers (e.g. Heckhausen \& Kuhl, 1985), we assume that people engage in cognitive appraisal and higher order self-regulation to decide which of the potential goals to accept (see Figure 1). As Roe (1999) states, people may filter the potential goals they generate, ponder about their implications, and decide about their acceptance, adjournment, or abandonment. Acknowledging that goal acceptance should be seen in relation to previously made goal commitments (Klein, Austin, \& Cooper, 2008), we assume that higher order self-regulation implies an evaluation of possible goals against the existing goal portfolio. More specifically, we propose that this process involves a consideration of the resource requirements of present goals and the goal to be accepted. In addition, we assume that people will add a goal to their goal portfolio if they expect that enactment can take place in available time, with concurs with the idea of Kanfer (2005) that goal choice needs to be studied as a function of individuals, settings and time. Besides the assessment of available resources, the decision to add a new goal likely depends on an examination of the goal's attributes such as importance and attractiveness (cf. the 'OTIUM check' by Heckhausen \& Kuhl, 1985: opportunity, time, 
importance, urgent, and means). People will feel more inclined to accept an additional goal if they fancy it as important, attractive or pleasurable to execute, that is, if it corresponds to their personal preferences.

Proposition 5a: A goal will be added to the portfolio if there is enough capacity and the goal attributes accord with personal preferences.

Even though we assume that the decision to add a goal is based on an assessment of available resources and preferences, there are many occasions demonstrating that individuals are frequently not rational when it comes to such assessments. We propose that the tendency to reject or accept a goal is influenced by individual characteristics such as optimism, naïveté, or experience. Some people may accept goals although they do not have enough time and energy to accomplish it, unless other previously accepted goals get delayed or abandoned. One explanation for such non-rational goal acceptance is given by the planning fallacy, defined as the tendency to underestimate task completion time (Kahneman \& Tversky, 1979). When evaluating task completion time, people tend to rely on their previous experiences. However, people often have an elusive definition of task similarity and as a consequence base their plans on wrong assumptions. Another explanation is "people's natural inclination is to generate forecasts by focusing on details of a specific case rather than on distributional information about a related set of cases" (Buehler, Griffin, \& Ross, 1994: 379). As a result, goal portfolios sometimes get overcrowded requiring individuals to reschedule, postpone or abandon certain goals.

Although generally speaking the acceptance of new goals becomes unlikely if the number of goals and the resources required for their enactment exhaust the person's capacity, people differ in their preferences for goal density. Some are wary about the consequences of 
having too much to do and fear the risks of stress and poor performance. They prefer a low density and are reluctant to take on additional goals. Others like the challenge and the variety of multiple goals, and are attracted by the idea that taking on more goals increases the likelihood that more goals will be completed. They prefer a high density and are willing to accept additional goals.

Proposition 5b: A goal will be added to the portfolio if there is enough capacity and the addition matches with the person's preferred goal density.

The content of the goals in the portfolio also matters, as new goals may be more or less compatible with goals in the portfolio. We propose that people assess the compatibility of an optional goal with already accepted goals and determine whether it is possible to pursue them with the given resources. The higher the compatibility among the goals, the more likely it is that the same resources are used to reach these goals. This idea has been elaborated by Wallenius (2000) in her "personal project cross impact matrix", which shows different relations among goals. Projects may be mutually supportive, mutually detrimental, or neutral to each other ( ++ very positive, +positive, 0 neutral, - negative, -- very negative). People who already juggle multiple goals are generally assumed to avoid adding new goals. However, individuals may be more prone to add an additional goal if it creates synergies that allow for parallel enactment with existing goals, increasing overall MGM performance. Otherwise, this goal option will be abandoned during goal filtering (see Figure 1).

Proposition 5c: A goal will be added to the portfolio if it is compatible with goals already in the goal portfolio. 


\section{Prioritizing and scheduling goals}

As there will always be a number of goals in the portfolio, it is necessary to prioritize them, i.e. to decide which goal is to be pursued first, which next, and so on. In this sense, prioritizing can also be viewed as taking a decision about the order in which goals will receive the resources needed for their execution. Kahneman (in Wickens et al., 2008) argues that automatic, non-conscious attentional processes are responsible for the allocation of resources, without prioritizing as a necessary intermediary step. Schneider and Schiffrin (1977) view prioritizing as a dynamic process that is not necessarily conscious. Karniol and Ross (1996) posit that there are unconscious as well as conscious processes - they refer to emotions, goal hierarchies, current concerns, and self-control processes - that have an influence on prioritizing.

Building on this research we assume that goal prioritizing can be conducted consciously and deliberately. We see it as a higher order self-regulation process, involving an assessment of social, contextual, and organizational factors, as well as individual preferences. Similar to adding goals, goal attributes such as perceived importance, urgency and attractiveness may play a major role in goal prioritizing (cf Claessens, Van Eerde, Rutte \& Roe, 2010). For instance, when a goal is made more salient by contextual factors, such as receiving feedback from the supervisor, this may stimulate the appraisal of goal attributes and accordingly prioritizing (Abraham \& Sheeran, 2003).

Closely linked to prioritizing is scheduling a process that has previously been studied under labels such as planning behavior (Abraham et al., 2003; Claessens, Van Eerde, Rutte, \& Roe, 2004) and building implementation intentions (Brandstätter, Lengenfelder, \& Gollwitzer, 2001; Gollwitzer et al., 1997). We conceive scheduling as a higher order self- 
regulation process in which people assess resource demands of all goals in the portfolio to formulate an overall schedule or plan, including times for enactment of all goals, to ensure their (timely) completion. The progressive enactment of goals and the continual entry and exit of goals from the portfolio, make scheduling an ongoing process. As people change the priority of goals in response to changing demands or opportunities they will also reschedule the goals.

We posit that changes in goal demands, such as a shifted deadline or an adjustment of other peoples' expectations may initiate a reprioritization of the goal. Often the objective task that has to be done is modified in such a way that the goal needs to be reprioritized. Whenever, a deadline changes other goal characteristics such as importance and urgency are adapted as well. A previously not so important and urgent task may - due to changing external demands - become priority.

Proposition 6a: Goals in the portfolio will be reprioritized and rescheduled in response to changes in demands.

The execution of goals is often dependent on opportunities and constraints. Some goals involve short-fuse behaviors that are defined as "behaviors that must be initiated and executed within some limited window of opportunity in order to realize the intention successfully" (Dholaki \& Bagozzi, 2003: 889). If for example the time window to execute a goal has changed, the goals within the portfolio will be reprioritized vis à vis each other, as to enhance the chance of the goal to be completed within the limited time frame. Reprioritizing will also be triggered by changes in information, dependence on other people or location, and the availability of resources, such as money. Changes in legal or ethical opportunities may 
also incite people to reprioritize their goals. Again, we assume that reprioritization will be accompanied by rescheduling.

Proposition 6b: Goals in the portfolio will be reprioritized and rescheduled in response to changes in opportunities and constraints.

In addition to changes in demands, opportunities and constraints, goals will be reprioritized due to experiences. Many goals are carried out repeatedly and will be prioritized according to previous success and failure. The effect of previous success and failure may follow the theory of self-efficacy which "refers to beliefs in one's capabilities to mobilize the motivation, cognitive resources, and courses of action needed to meet given situational demands" (Wood \& Bandura, 1989: 408). Previous performance on a goal influences the expectancy of future successful execution. Accordingly, the commitment to the goal as well as goal intentions may change and call for a reprioritizing of goals within the goal portfolio. Moreover, some goals are reprioritized along the process due to an increase or decrease in the pleasure of executing the goal. Again we assume that re-prioritization will come with rescheduling.

Proposition 6c: Goals in the portfolio will be reprioritized and rescheduled in response to experiences of success and failure and the pleasure of executing the goal.

\section{Activating goals}

Individuals can counteract goal decay and thus increase the likelihood of goal completion by goal activation. The activation of goals is seen as a higher order self-regulation process, which implies that individuals consciously decide about resource allocation among goals within the portfolio. Goal activation is dependent on the previously described dynamic 
process of goal prioritizing. Since goals are constantly reprioritized vis à vis each other, goals will be activated and deactivated according to changes in priority, in such a way that high priority goals are activated first.

Proposition 7a: Goals are selectively (de-)activated according to priority.

Goals can be activated by means of enactment (performative activation) or merely thinking about it (cognitive activation), or both. Performative activation is likely to be more effective to counteract decay since it entails episodic memory increasing goal accessibility in the future.

Goals may also be activated by means of self-initiated cognition or external cues. Intentional reminders trigger planned actions through prospective and more specifically episodic memory (Brandimonte \& Passolunghi, 1994; Fiore, 2008). Often people use mnemonic and planning tools such as calendars, alarm clocks or post-it's to increase the likelihood of goal activation. If people are reminded of the goal through calendars, its activation is more likely to follow. Also, unintentional reminders may facilitate goal activation, e.g. a stack of papers on the desk or the execution of a different but interlinked goal.

In addition, the presence of others may increase the chance of goals being recalled since they act as social reminders. For example, every time an employee runs into her superior she is reminded of finishing a memorandum. Meacham (1988) has argued that tasks of a more social nature, such as meetings, are more likely to be remembered compared to more object-oriented tasks such as writing a report. Moreover, if a goal is made public to 
other people social pressures and expectations may facilitate goal activation due to elevated goal commitment.

Proposition 7b: Goal (de-)activation is enhanced by self-initiated cognition and the involvement or presence of others.

Another way to increase the likelihood of goal activation is forming implementation intentions (Brandstätter et al., 2001; Gollwitzer et al., 1997). This means that people define the condition under which the goal has to be activated manifested in "if this happens, I will do that". Implementation intentions were found to significantly increase the likelihood of goal achievement (Gollwitzer et al., 1997). It has been argued that specific goals have a greater chance of goal activation since they are "more likely to be remembered better given their richer memory traces and the strength of activation associated with the unique cues that have been associated with the goal" (Fiore, 2008: 545). As a consequence, people can reduce the risk of goal decay by means of specifying their goals and formulating implementation intentions.

Proposition 7c: Goal activation is enhanced by implementation intentions.

\section{Shielding goals}

An additional means for higher order self-regulation in goal portfolio management is shielding goals. Shah and his colleagues define goal shielding as a process that makes goal relevant information more accessible whereas competing information is suppressed (Shah, Friedman, \& Kruglanski, 2002). This bears resemblance with controlling and directing the focus of attention. People often engage in goal shielding to ensure that high priority goals are enacted first and to prevent goal switching; a reason may be that it is 
difficult to resume a goal after an interruption has occurred since the goal suffers retroactive interference and is 'buried' or 'masked' by its successors in terms of activation (Altmann, 2002). Goal shielding may also be used as a way to prevent the pursuit of fruitless or less important goals (Shah et al., 2002).

In our view goal shielding is a higher order self-regulation process by which people consciously suppress competing goals with the aim to prevent them from decay. A way to do this is formulating specific plans of goal attainment or raising the importance attached to a goal (Diefendorff et al., 2008). Goal shielding is a learnable skill to such an extent that some people internalized it so much that they exert goal shielding automatically without conscious awareness of it (Shah et al., 2002). Goal shielding is an important strategy in multiple goal situations especially when serial goal enactment is required and goal switching has to be suppressed.

Proposition 8a: Goal activation is maintained by goal shielding.

\section{Removing goals}

Besides goal shielding people can choose to intentionally remove goals from their portfolios. That is, an assessment of available resources such as time and energy as well as current and future obligations, may result in a decision to abandon a goal. This higherorder self-regulation process is likely to be used when people are faced with too many goals and corresponding resource requirements, they may drop a goal from the portfolio. Abandoning a goal frees resources that can be used to pursue other, higher valued goals. Sometimes, a goal becomes obsolete because it is being replaced by a newly added goal or because of a change in organizational demands. In addition, the opportunity for enacting the 
goal has disappeared, e.g. because a submission deadline has passed, a goal may also be removed from the portfolio.

Proposition 8b: The selective removal of goals will be used to manage the size of the goal portfolio in order to ensure progress of the remaining goals.

\section{Individual differences}

The MGM model describes regulation processes that are supposed to occur within individuals over time. The model focuses on the dynamics of the performance of multiple work goals under continually changing conditions. Although the model is not meant to portray individual differences, we acknowledge that people may differ in their reliance on and application of higher order self-regulation. Some people may be more inclined to explicitly manage their multiple goal performance than others, and there may be differences in, for example, the use of serial over parallel strategies, the preference for higher or lower goal density, and the tendency to apply goal shielding. Individual differences are also likely to show up in goal attributes, such as the attractiveness, importance or urgency attached to various goals. Such differences are potentially important and should be investigated after the propositions on the goal management process have been shown to be valid.

\section{FUTURE RESEARCH \& FUTURE IMPLICATIONS}

The notion of multiple goals raises a number of critical questions that need to be answered in future research and bears several consequences for specific theories. For instance, goal setting theory will have to be extended since the suggested positive effect of specific difficult goals may not hold in work settings where people have to perform multiple task goals, unless they engage in selective goal acceptance, goal prioritization, and 
appropriate deadline definition. Likewise, the positive effect of feedback on results that has been found for single goals may not be generalized to multiple goals.

In a similar way, self-regulation theory needs to broaden its focus as to include both the regulation of single goals (lower order self-regulation) over time and the higher order self-regulation of activities related to the management of the entire goal portfolio. This regulation will have to be modeled in such a way that the overall effectiveness of activity given a certain goal portfolio with a set of deadlines is optimized.

The explicit incorporation of multiple goals calls for a further development of action regulation theory as well. Although action regulation theory puts forward a sequence of continuous actions, it does not account for interruptions along the goal process or the abandonment of goals. The switching between task activities when confronted with interruptions, as studied by some researchers (Eyrolle et al., 2000; Zijlstra et al., 1999) is compatible with the theory, but a reformulation of the process and mechanisms of action regulation with multiple goals is still needed. In the following sections we address future research questions and considerations, followed by practical implications.

\section{Future research questions}

We believe that the MGM model allows to further develop motivational theories as to broaden their scope and to shed light on problems, such as procrastination, delays in goal attainment, goal decay, and overall underperformance in the presence of multiple goals, that are as yet poorly understood. To clarify MGM the following questions need to be addressed. 
First, the MGM model puts forward the assumption that people at work are typically engaged in multiple goals. However, there is little we know about basic facts, such as e.g. the number of goals people accept into their goal portfolio. This points at a need for descriptive research on the composition of peoples' goal portfolios. As a first step we need to know the quantity and nature of goals in the portfolios as well as how often goals are postponed, abandoned, or completed. Moreover, we ought to study how long the goal is kept in the portfolio, differentiating between back- and foreground, acknowledging the number of times the goal was stopped or interrupted and resumed. This will further our understanding of the nature and origin of goal conflict. We are not aware of research investigating the number of goals people usually pursue in parallel, and if there is an optimal number of goals.

Second, an assessment of the length of the time gap between goal generation of each goal and its actual enactment is required to better understand the MGM processes. Up to this moment, we only know about two preliminary studies that have investigated the length of this pause. Roe and Quist (2004) in a study of HR consultants found an average "time gap" of 18 days between setting a goal and enacting it, and a longest gap of 33 weeks. A study by Weckauf (2005) among academic staff at a university found an average time gap of 9 days. In less than $5 \%$ of all events the enactment followed within 24 hours of the goal's acceptance. We have postulated that the length of the time gap has a negative influence on the likelihood of goal execution. The longer the time gap the more likely it is that the goal is forgotten, because it is 'buried' in the goal portfolio underneath new and more ostentatious goals. Moreover, the retrieval of goals from memory may become more difficult as more time passes. The study by Roe \& Quist (2004) indeed shows that a longer time gap between setting and enacting the goal is associated with a lower rate of completion. However, there may be exceptions to this principle. In case of very attractive goals that have to be put aside for a 
longer time, the desire to reach the goal might increase over time and positively affect goal completion when the opportunity for enactment arises.

Third, and to the best of our knowledge, existing theories have not yet aimed at defining success in a multiple goal setting. Frequently, people need to make tradeoffs in their effort to juggle their multiple goals. We postulate that several factors such as timeliness, quality, and quantity determine overall success whenever people are faced with multiple goals. Simon (1955) stated that people usually do not optimize their outcome on one concern, but rather try to 'satisfice' them all, thus deliver satisfying result on the entire set of concerns. Future research should answer questions such as how much postponement of a goal is beneficial and under what circumstances, and when dropping goals or rejecting them is recommendable.

\section{Methodological consideration for future research}

As should be clear from our previous arguments, there is a need to integrate multiple goals into motivation theories with a temporal perspective. Longitudinal research designs are necessary to capture the effect of multiple goal processes acting in parallel and the influence they exert on each other over time. Therefore, we recommend tracking peoples' goals over time and using a within-person analysis to explain why motivation varies as time elapses. A within-person approach allows studying motivational problems in MGM, such as non initiation of goals, decay of goals, goal abandonment, and delay. Moreover, it will help to gain insight into the mechanisms responsible for persistence of an activity and factors influencing choice preferences among alternatives. 
In addition, there is clearly a need for studies executed in realistic work settings with real-life goals to gain better understanding of the complexity of MGM as employees encounter it (Austin et al., 1985; Steel \& König, 2006; Tubbs et al., 1991). Due to the difficulty of studying multiple goal processes in naturalistic settings we recommend the application of diary studies or experience sampling method (ESM). The latter technique allows capturing life in situ while minimizing memory biases. Other authors have recognized the importance of studying work motivation in realistic settings as well. Mitchell and his colleagues (Mitchell, Harman, Lee, \& Lee, 2008) recommend to simulate work settings to obtain data while people are actually working on goals.

\section{Practical implications}

People differ not only in their tendency and preference to manage multiple goals, but also in their effectiveness in it. Employees execute their goals with delays, procrastinate their work, revise their goals, refrain from further goal pursuit, redirect their attention to new goals, reengage in already abandoned goals, or accept unattainable or too many goals. The notion of multiple goals clearly challenges theories that assume single goal processes at a time.

Higher order self-regulation processes such as scheduling, prioritizing, and goal shielding are essential to be successful in multiple goal settings. These processes are similar to skills known from the time management literature which have been argued to be learnable (Claessens, Van Eerde, Rutte, \& Roe, 2007; Macan, 1996). To increase the effectiveness of MGM, people need to be trained in these apparently straightforward skills. In addition, mnemonic tools such as calendars can be applied. 
Another approach would be to define a "time management function" which comprises scheduling, reminding team members to keep track of deadlines, and temporal coordination. Mohammed (2008) addresses this by means of "temporal leadership" which implies that managers are aware of the effect of activities such as keeping in touch with their employees and offering them reminders in order to maintain the salience of the goal during the preservation phase. However, the time management function meant here could also be assigned to work teams and individuals themselves.

Furthermore, organizations need to provide enough room for their employees to successfully work on their multiple goals. Opportunities and constraints of goal enactment need to be actively managed, and tools to increase work time flexibility may be installed to improve the ability of employees to schedule their goals with discretion. Moreover, social reminders could be promoted to enhance the rate of successful goal completion. Explicit statements on what people try to achieve in the future and the setting of public deadlines will facilitate goal enactment. Last, thorough feedback on employees' MGM should be provided to maintain the motivation for future goal activation and enactment. It is important that feedback is not only directed towards a single goal, but that performance feedback addresses the management of all goals within the portfolio. If a person does not perform well on one goal, it does not necessarily mean that there is a lack of motivation, but it could simply suggest that another goal was more urgent or important and needed more resources.

\section{CONCLUSION}

Many researchers have investigated motivational theories, such as goal setting and striving processes, advancing our understanding of motivated human behavior. Yet, most of these studies have focused on single goals and neglected the dynamic processes underlying 
the pursuit of multiple goals. We introduced the notion of a dynamic goal portfolio consisting of all goals a person has accepted to pursue in the future. Due to limited resources, not all goals in the goal portfolio can be worked upon simultaneously. This requires people to engage in higher order self-regulation. We showed that people can actively manage their goal portfolios by means of multiple goal strategies such as selective goal (de-)activation, removal of goals, and goal shielding. The MGM model and the propositions that we have presented, as well as our considerations for future research are certainly only a starting point for further study. Nevertheless, we believe it is an important stream of research that calls for further theoretical and empirical work to solve the many unanswered questions concerning the dynamics of higher and lower order self-regulation that employees engage in every day at work to manage their multiple goals. 


\title{
CHAPTER 4
}

\section{MULTIPLE GOAL PURSUIT, A DESCRIPTIVE AND EXLORATORY STUDY}

\begin{abstract}
Even though our understanding of theoretical issues in multiple goal pursuit has evolved, there is a lack of studies describing how people actually deal with multiple goals in their everyday work life. Therefore, the aim of this study is to describe and explore multiple goal-pursuit in a work context. By means of a diary device, participants recorded their work experience and behavior with respect to five individually defined goals over a three-week period. We investigate when and for how long people work on their goals over time, and how they combine multiple goals, using graphical methods do describe their performance trajectories. We analyzed goal management patterns by categorization and examining attributes, and by exploring relationships with selected antecedents and consequences.
\end{abstract}

The paper has been presented at the $14^{\text {th }}$ congress of the European Association of Work and Organizational Psychology in Santiago de Compostella, May 2009 


\section{INTRODUCTION}

In contemporary organizations, employees are increasingly required to work on multiple goals. On a typical working day an employee may have to attend meetings, contact other people (such as clients, suppliers or colleagues) by email or telephone, work on a particular task, write a report, or travel to another location. What exactly should be done may change from day to day, as new goals are added, opportunities to work on tasks or contact people vary, or priorities or deadlines change. The multitude of goals, the changes in goals and the dynamics in the environment, require people to be self-reliant in managing and coordinating their work goals. They must decide which goals to work on, when to work on which goal, how long to work on each goal, and how much effort to spend, while simultaneously accomplishing their goals in a timely manner.

The processes involved in obtaining, maintaining and accomplishing goals have mainly been studied from a self-regulation perspective (Vancouver \& Day, 2005). Most research to date has focused on self-regulatory behaviors in single goal settings, but researchers have begun to acknowledge that people typically pursue multiple goals. Recognizing that self-regulation processes do not only involve deciding what to work on but also how many resources to allocate to which task or goal at what moment in time and for how long, researchers have proposed theoretical models of how people allocate resources to two conflicting goals (e.g. Louro, Pieters, \& Zeelenberg, 2007; Schmidt, Dolis, \& Tolli, 2009; Vancouver, Weinhardt, \& Schmidt, 2010). This work underlines the importance of time management as an inherent part of self-regulation in multiple goal settings (also Claessens, Roe, \& Rutte, 2009; Claessens, Van Eerde, Rutte, \& Roe, 2007a). Key time management activities are (re)prioritizing and (re)scheduling, since they allow people to reach multiple 
goals within the respective deadlines. The fact that people have limited resources (Wickens \& McCarley, 2008) has profound implications for the possibilities to accomplish multiple goals. For instance, when people decide to work on one goal, they also decide to not allocate our resources to another goal. Also, when making progress on one goal, it is likely that they will not make progress on the other goal. This turns multiple goal pursuit a very complex and highly dynamic process, particularly when new goals are added and requirements change. It is, in fact, a never-ending process in which some goals become obsolete and others are completed or abandoned (Wrosch, Scheier, Miller, Schulz, \& Carver, 2003), while new goals are added.

Vancouver et al. (2010) proposed a computational model of multiple goal pursuit based and investigated it with data gathered in a laboratory setting. The tasks were similar (making class schedules for students at two imaginary schools) but could not be carried out simultaneously due to lack of cognitive resources. This research shows the complexities of pursuing multiple goals, even with a limited set of well-defined task goals. Some researchers have studied certain facets of how people deal with multiple tasks they have to do. For example, Grawitch, Granda, \& Barber (2008) studied the impact of task appraisals at the beginning of a workday on affect and performance at the end of the workday, and Claessens et al. (2010) studied the influence of task and person characteristics on the completion of tasks over time. Fay and Sonnentag (2012) predicted proactive behavior and core task behaviors from experienced competence and affect across several days.

To the best of our knowledge no study has been conducted looking at multiple goal pursuit over time in a naturalistic work setting with a focus on the amount of time spent on several goals. The aim of the present study is to describe and explore multiple goal pursuit in 
real-life work, where people are in charge of managing their own goals. Thus, we investigate people performing goal-directed activities in a real-life occupational environment, where they are responsible for setting, changing and realizing work goals, deriving income from the successful accomplishment of these goals.

Our study is guided by three general research questions:

1. How do individual employees deal with their multiple work goals over time?

2. How do personal and environmental factors influence people's multiple goal pursuit over time?

3. Does people's performance effectiveness vary with the way in which they manage their multiple work goals over time?

Below, we will sketch the theoretical background of our study, incorporating ideas and findings from the research literature. Next, we present the design of the study and explain how we have addressed the three research questions. After that we present the results of our study and discuss the implications for further research on multiple goal management.

\section{THEORETICAL BACKGROUND}

\section{Multiple goal management}

As we have explained in Chapter 3, there are not many publications directly addressing multiple goal management. However, there are several studies that provide notions of evidence that is of relevance in designing our study. They relate, amongst others, to goal pursuit, goal conflicts and goal-switching. 
Goal pursuit (or goal striving) has mainly been studied with regard to single goals (Austin \& Vancouver, 1996), just like goal-setting. Vancouver and Putka (2000) define goal striving as "the processes involved in attaining and maintain goals once they are established". Goals differ remarkably in the amount of time and effort needed to accomplish them. For instance, goals in laboratory studies can typically be completed within an hour or less, whereas work goals often extend over days or weeks. Given the structure of the workday and the limited number of hours available, people have to interrupt and resume their goal striving, as often and as long as is needed to ultimately deliver the end-product. Thus, goal-pursuit reflects in what Roe (2014) calls the "temporal footprint of work". An example of a work goal that spreads out over days or weeks is organizing a workshop. Writing an academic paper is an example of a work goal that normally takes months or years to accomplish. Such work goals can be broken down in sub-goals, some of which may be achieved within the limits of a workday. Booking a location and sending out invitations would be examples of sub-goals of organizing a workshop that might fit within a single day. However, conducting a literature survey as a sub-goal of writing an academic paper would often span multiple workdays.

When goal striving processes are spread over longer time episodes, it is inevitable that they are influenced by other factors. In real-life work settings there are various external and internal changes as time passes by. Apart from interruptions, that draw attention away from the ongoing goal striving process and direct it towards alternative tasks or emerging conditions (Eyrolle \& Cellier, 2000; Jett \& George, 2003), the individual will engage in offtask behaviors such as e.g. eating, changing locations, or performing household duties. In addition, one is likely to see goal revision (Donovan \& Williams, 2003), e.g., due to changes in priorities or deadlines, or in resource availability. Fluctuations in personal states, such physical fitness, vitality or self-efficacy may also occur. Referring back to our example of 
organizing a workshop, goal revision might occur because of changes in the content requirements of the workshop, sudden illness of the trainer, or cancellations of participants. Moreover, goal pursuit is likely to be influenced because the individual is presented with new goals, which causes shifts in resource demands and sometimes the abandonment of the current goal (Roe, 1999; Wrosch et al., 2003). For instance, the person organizing the workshop or writing an academic paper may be required to teach a course or do committee work, necessitating her to postpone or abandon the workshop or writing the paper.

Although there may still be jobs in which the same task is performed repeatedly and uninterruptedly during a single workday, the majority of people today are performing multiple work tasks that extend over periods longer than a day. They are expected to engage in "multitasking", which implies a certain degree of interruption and task switching (Adler \& Benbunan-Fich, 2013; Czerwinski, Horvitz, \& Wilhite, 2004; König, Oberacher, \& Kleinmann, 2010). As a consequence, goal striving in real-life settings can no longer be studied without acknowledging that people pursue many goals at a time, and without paying attention to the impacts that the simultaneous pursuit of multiple goals has on the progress made with regard to each of these goals.

A number of studies have investigated the reasons for goal-switching and the consequences concerning work performance and well-being. In a diary study, Czerwinski, Horvitz, and Wilhite (2004) found that $40 \%$ of switches are self-initiated, $12 \%$ are caused by telephone calls, and $9 \%$ are due to appointments. These examples show that switching task goals is often caused by interruptions at work.

Jett and George (2003) define four types of interruptions at the workplace, namely intrusions, breaks, distractions, and discrepancies. An intrusion is "an unexpected encounter 
initiated by another person that interrupts the flow and continuity of an individual's work (Jett \& George, 2003, p.495). Examples of intrusions are telephone calls or unexpected chats with colleagues.

In their study Czerwinski et al. (2004) found that only $19 \%$ of all task switches are due to beginning the next task. Thus, the majority of task and possibly goal switches are not due to finishing the previous task or goal.

Some studies have looked into the effects of goal-switching on performance and found these to be negative, due to the cognitive resources involved in switching (Monsell, 2003) and the time lost in the resumption of tasks (Hodgetts \& Jones, 2006; Pashler, 2000). Research on interruptions, which also imply goal-switching, have shown that people may forget resuming the goal after a longer break or disruption. Forgetting about a goal is explained by limits of prospective memory retrieval (Altmann, 2002; Altmann \& Trafton, 2002; McDaniel \& Einstein, 2000). Overall, goal switching has been studied in terms of adaptation (König, van Eerde, \& Burch, 2010), but studies focusing on how often goals are switched at work are nearly absent. It is important to note that research on goal switching has largely been conducted in laboratory settings by cognitive psychologists interested in changes within short timeframes and measured in milliseconds. The occurrence and effects of goal switching in work settings will need timeframes covering days and hours, and time scales with units of minutes or seconds. Such research is virtually absent to date.

In studying the interaction and effects of multiple goals, it is important to consider the degree of compatibility of goals and the possibility of goal conflict. Goals can be said to conflict when they are competing for resources such as time and attention needed for completion. Most goal conflict studies are to be found in the literature on health (e.g. dieting 
and sporting), education (e.g. studying for a math exam or studying French), and work family conflict (e.g. spending time with one's children vs. writing business related email from home). However, there is little research in which the pursuit of work-related, multiple goals are investigated. While writing a paper and preparing a presentation of the paper are compatible with one another, writing a paper and teaching a course are not likely to be compatible. If goals are not compatible, people have to choose which goals to work on and how to allocate their resources over their goals. Emmons and King (1988) were among the first to look at conflict between personal strivings. They found a negative effect of goal conflict on psychological and physiological well-being. When people strive for multiple goals, switching between them often becomes a necessity in order to respond to changes in external requirements. Often, working on two goals simultaneously is not possible due to limited resources (Wickens \& McCarley, 2008) or goal conflict (Locke, Smith, Erez, Chah, \& Schaffer, 1994).

Although the general conclusion of this research is that goal-conflict leads to detrimental effects, one may also argue that non-conflicting goals may also facilitate one another (Riediger \& Freund, 2004). That is, goals may be compatible in terms of the resources used and the same activities can help to realize different goals at the same time. Wallenius (2000) studied the effect of compatibility of people's personal projects and found that more specific projects are more often in conflict. Goal compatibility enhances or reduces the resources allocated to the goal in terms of relative time spent on them. Moreover, it is more likely that people work on their goals in parallel if the goals are compatible with one another. Compatibility can also bring along synergies in terms of working on goal A will also yield results on goal B. The combined effects of multiple goals, possibly ranging from negative to neutral to positive, have not been examined systematically in a work setting. 
The foregoing shows that there is a gap in the literature with regard to the way in which people carry out multiple work-related goals over time. Self-regulation theory has been a fertile ground for proposing theoretical mechanisms involved in multiple goal management. A number of publications have given theoretical accounts of the processes of generating, planning and executing multiple work goals (Kanfer, Chen, \& Pritchard, 2008; Kirchberg, Roe, \& Van Eerde, 2008; Lord, Diefendorff, Schmidt, \& Hall, 2010; Mitchell, Harman, Lee, \& Lee, 2008; Roe, 1999). However, there remains a need to study multiple goal pursuit empirically and to see to which degrees the models meet reality.

\section{Determinants of multiple goal pursuit}

As has become already obvious from the casuistic description of multiple goal pursuit given above, there are many different factors that can exert an influence on the way in which people handle multiple goals. Although we are apt to look at the contemporary work ecology and the pressures for multitasking that stem from organizations and clients (Appelbaum, Marchionni, \& Fernandez, 2008; Salvucci \& Taatgen, 2011), we should not forget that people themselves may also be inclined to pursue multiple goals and that the human body is rather well prepared for simultaneous mental and physical activities. Thus, in order to examine what drives multiple goal pursuit, we shall look at a range of environmental and personal factors and ascertain which factors are likely to play a role given the results of earlier research.

The literature on environmental determinants of multiple goal pursuit is limited and the available publications mention overall trends at the level of organizations or occupations, rather than precise factors that operate at the level of the individual performing day-today work tasks. However, there are studies on multitasking (König et al., 2010) and individual time management (Claessens et al., 2009; Claessens, Van Eerde, Rutte, \& Roe, 2004b, 2007b, 
2010) hinting at potentially relevant factors. The first factor to look at is job content in terms of the number of tasks that have to be performed and their interconnectedness, as well as general requirements regarding deadlines, priorities, and simultaneity. The combination of having multiple tasks to attend to and temporal constraints, is likely to produce a setting in which people will be forced to work on multiple goals in parallel. However, the trigger to actual multitasking comes from the dynamic work demands, in the sense of emerging tasks, deadlines and priorities, as well as changes therein (König et al., 2010). This points at the importance of goal density, which was defined earlier as the planned dedicated time devoted to goals already accepted. This accords with the suggestion that people engage in multiple goal pursuit when they experience high workload (Waller, 2007) and want to complete more (Britton \& Tesser, 1991). A job characteristic that seems of immediate relevance in this context is the worker's discretion (job control, autonomy) with regard to the content and timing of activities. With greater discretion one would expect less direct impact of the dynamics of the work demands.

What also matters is the environment the job is embedded in. This includes the social environment, which other people, such as supervisor, colleagues, and clients, and the technical environment, with digital infrastructure and machines or tools. Both can be the source of numerous disruptions and interruptions, calling for the person's attention, response, or actions (Czerwinski et al., 2004; Jett \& George, 2003; Sykes, 2011; Wajcman \& Rose, 2011). However, disruptions and interruptions can also be self-initiated and originate from the need to free cognitive resources in order to give priorities to certain task activities (Adler \& Benbunan-Fich, 2013). 
In contrast, there is a more extensive literature on individual differences, pointing at the potential relevance of certain personal determinants of multiple goal pursuit. Often mentioned is polychronicity, which has been defined as "an individual's preference for shifting attention among ongoing tasks, rather than focusing on one task until completion and then switching to another task" (Poposki \& Oswald, 2010; p. 9). In line with this, Waller (2007) argues that polychronicity is best described as a preference to multitask. It seems likely that polychronicity is associated with a greater involvement in multitasking, and there is some evidence for this (Kaufman-Scarborough \& Lindquist, 1999; König et al., 2010; Zhang, Goonetilleke, Plocher, \& Liang, 2005). However, this does not mean that polychronicity also predicts multitasking performance. The evidence on this is inconsistent (Kantrowitz, Grelle, Beaty, \& Wolf, 2012; König, Bühner, \& Mürling, 2005; Zhang et al., 2005).

Two personality factors seem particularly relevant for multiple goal pursuit, i.e. extraversion and conscientiousness (König \& Waller, 2010). It has been found that conscientious people show low levels of polychronicity, but that people high on extraversion are also high on polychronicity (Conte \& Gintoft, 2005; Conte \& Jacobs, 2003). The role of abilities is as yet unclear. Although there are several studies showing that people with 'multitasking ability' (Morgan et al., 2013; van der Horst, Klehe, \& van Leeuwen, 2012) or with specific cognitive abilities, such as working memory perform better in settings where multiple tasks have to be performed (Hambrick, Oswald, Darowski, Rench, \& Brou, 2010; König et al., 2005; Logie, Trawley, \& Law, 2011), there is no direct evidence on whether these characteristics affect the degree of multitasking, or how they affect the way in which people manage multiple goals. 


\section{Consequences of multiple goal pursuit}

Studies into the effects of multiple goal pursuit have mostly focused on performance, and mainly used experimental designs, contrasting sequential with simultaneous execution of task goals (Adler \& Benbunan-Fich, 2012; Buser \& Peter, 2012). There are also some studies that have looked into the effects on creative performance (Madjar \& Shalley, 2008). Recently researchers have begun to address the impacts of media-multitasking (involving the use of Facebook, texting, computer applications etc.) on a variety of learning and performance indicators, showing negative effects (e.g., Judd, 2013; Junco \& Cotten, 2012; Karpinski, Kirschner, Ozer, Mellott, \& Ochwo, 2013; Levine, Waite, \& Bowman, 2012). Research on multiple goal performance in realistic work settings is scarce, though. One study examined multiple goals in managers and found differences between managers pursuing 1, 2 or 3 goals, showing that job-related tension increased and self-rated performance decreased (Emsley, 2003). Research on interruptions shows mostly negative effects on well-being and satisfaction (e.g., Baethge \& Rigotti, 2013; Roe, Leonova, Zijlstra, \& Krediet, 1996), but although interruptions are common in multiple goal settings, one cannot generalize these findings to multiple goal management in general.

An aspect that has drawn attention in the context of time management is the experienced control of time (Claessens et al., 2010; Macan, 1994), which is defined as "the extent to which individuals believe they can directly affect the way they manage their time" (Claessens, Van Eerde, Rutte, \& Roe, 2004a, p.943). It can be considered as an indicator of the effectiveness of multiple goal management from the individual's perspective, and thereby as an outcome of a certain way of working. However, in analogy with self-efficacy, it can also be treated as an antecedent of subsequent behavior. In this case one could expect two possible 
effects: people in control of time either work in a systematic and organized manner, without frequent switching and focusing on a limited number of goals at one time, or they feel free to use the time as they please, leading to unnecessary switches, possibly because only they prefer to do so (cf. Buser \& Peter, 2012). This topic remains open to future research on multiple goal pursuit.

It should be noted that the literature lacks a satisfactory definition of performance in multiple goal situations. The presence of multiple goals, each of which should be completed within a certain amount of time, while reaching certain standards of quality, implies that the customary uni-dimensional notion of performance is ill-suited. Given the trade-off functions between completion, quality and timeliness, one would either need some form of weighing these different performance attributes or use multiple performance indicators independently. We will address this issue when describing our own research study, in the next section.

\section{DESIGN OF THE STUDY}

To gain a better understanding of multiple goal pursuit in a real-life work environments, we have designed a study that empirically investigates the time that employees in a variety of jobs spend on five work goals during a period of three weeks. Examining how their work behavior unfolds and how they progress in their work while accommodating everyday events, allow us to describe the unique trajectories of their activities and to explore a number of possible determinants and consequences. In contrast to many other studies, our research does not commit itself to a particular theoretical approach but rather aims at describing and exploring the reality of work, in ways that can produce new insights. We feel that such an approach is justified because of the absence of factual evidence on multiple goal 
activity, and is to be preferred over the conventional approach of starting from extant theory, which runs the risk of premature theorizing.

Our study is directed towards the three research questions, presented in the introduction. Central is the first question, i.e., how do individual employees manage their multiple work goals over time? An important part of our study therefore is the account of how we have collected the observations needed to answer this question, and how we have tried to produce descriptions that allow studying the idiosyncratic performance trajectory of each person. Next, we will introduce the constructs and variables that we have used to explore possible determinants and consequences, aiming to answer the questions "How do personal and environmental factors influence people's multiple goal pursuit over time?" and "Does people's performance effectiveness vary with the way in which they manage their multiple work goals over time?"

\section{Model}

The study starts from a heuristic model that shows how have looked at people's multiple goal pursuit, and at which determining and consequent factors our explorations will be directed. The model is depicted in Figure 1, below. The central part shows a goal portfolio with a set of (five) goals that people at the start and the end of a certain time period (three weeks) and the state of the goals during each working day (green $=$ goal has been worked upon; red = goal has not been worked upon). We will use daily measurements, collected with a diary, to track people's activities and to construct goal trajectories. 
Figure 1: heuristic model of the study design

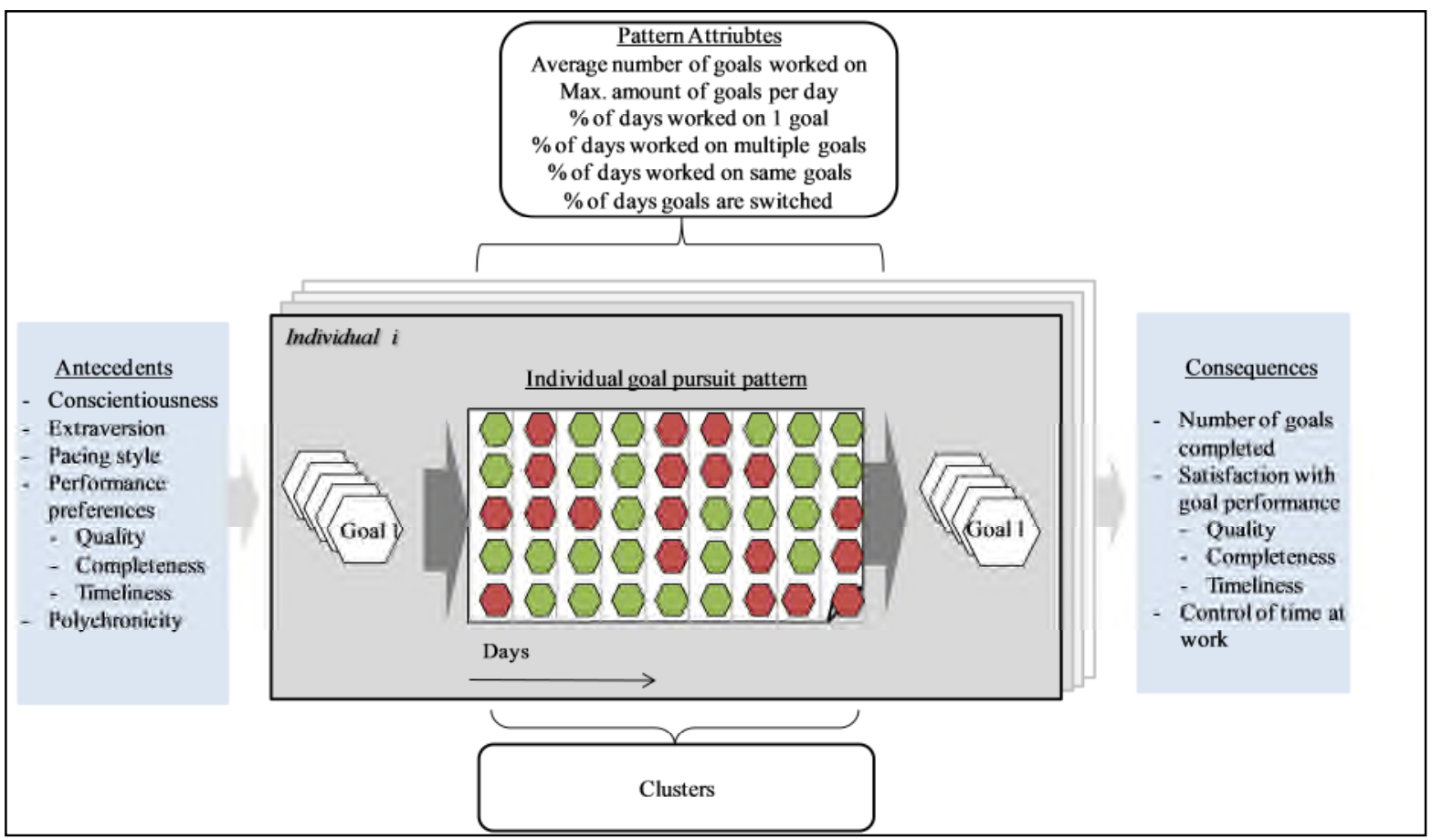

The very left part of the model shows the determinants that will be explored, and the very right part the consequences. The model also shows the two analytical strategies for examining the goal trajectories, one in terms of descriptive attributes (above) and one in terms of categorization (below).

Central in our study are is the simultaneous pursuit of multiple goals, taken from the people's personal goal portfolios (see Chapter 3). At the start we ask every person to select five goals and during the subsequent days we collect data about time spent on each goal using a digital diary. Since there are no standardized ways to describe multiple goal trajectories we will propose and compare three different graphing methods. The first method is a cumulative curve, which is analogous to the 'work curve' that was used in early studies of work performance (Poppelreuter, 1928; Roe, 2013, forthcoming). It shows the accumulated amount of time spent on each task over subsequent days of the time period. When a person works on a goal, the curve for that goal keeps rising. When a goal is not worked on, the curve for that 
goal remains flat. The second method is a distributive area graph, showing the relative amount of time spent on the five goals over time. It displays the distribution of time over the days and thereby reveals the goals that people work on simultaneously and sequentially, and the days on which they do so. The third method is a stacked bar chart showing the absolute time (in minutes per day) spent on each goal during every day. It provides more precise information and gives a clearer impression of the days on which the person does not work on any of the goals (e.g. weekend or holidays). An illustration of the three charts is given below, in Figure 2. 
Figure 2: Examples of a cumulative curve, distributed area graph and bar chart describing multiple goal pursuit.
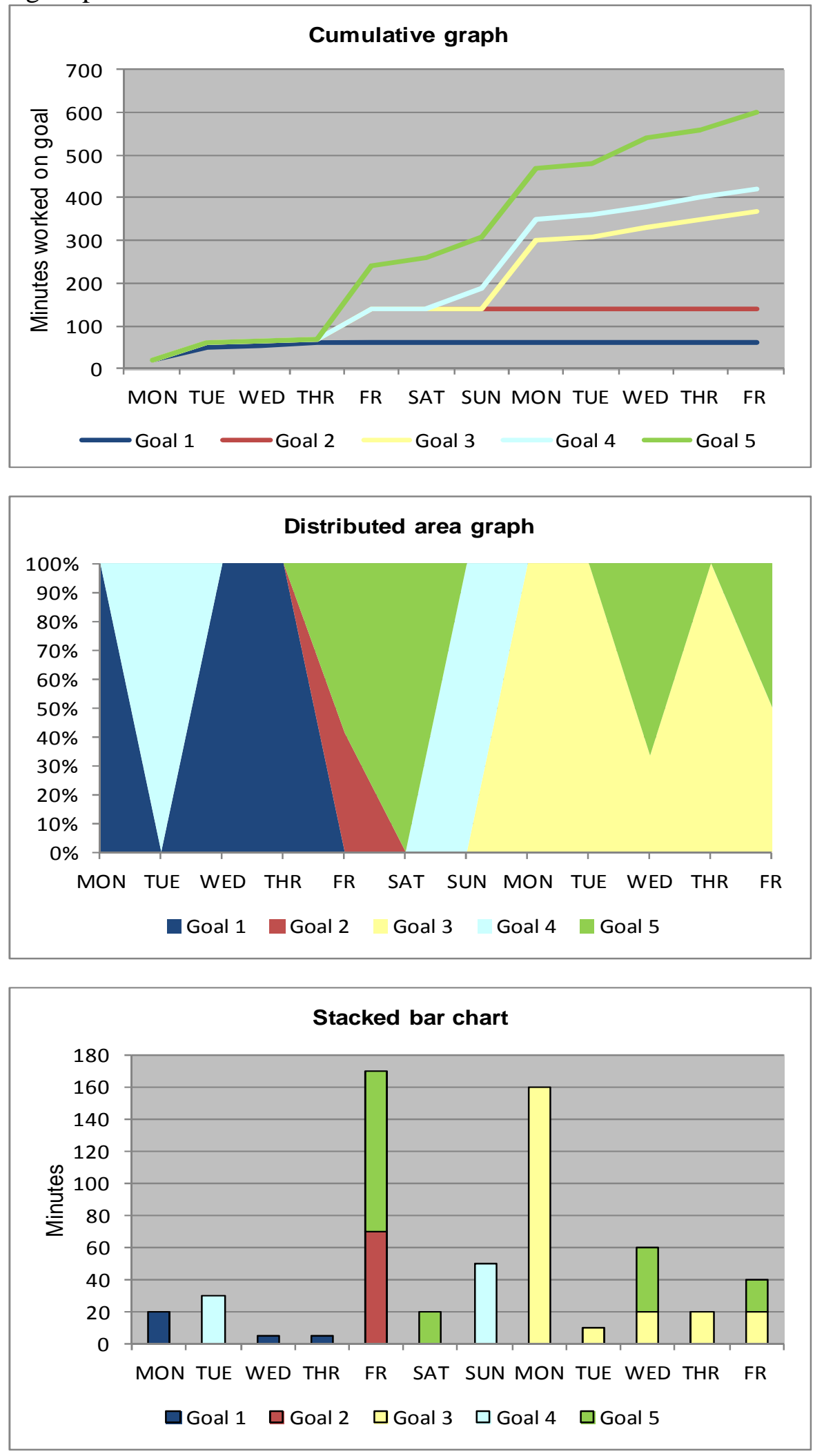
We analyze the differences between people in their multiple goal pursuit in two ways. First, we describe each set of goal trajectories with respect to a number of quantitative attributes. They can be used to directly describe a person's goal pursuit and they can serve as input to the second method, which is categorization by means of clustering. This method serves to identify whether the patterns of goal pursuit exhibit by different people fall into a small number of contrasting groups. More information about these methods will be given later on.

The research model in Figure 1 shows the potential determinants and consequences that will explored in this study. Our intention was to relate both to the attributes of the goal pursuit trajectories and to the clusters. Since we were not able to produce meaningful clusters, the second purpose could not be fulfilled. The specific variables will be introduced in the next paragraph.

\section{Possible determinants}

In the previous section (theoretical background) we mentioned a large number of factors that might be related to multiple goal pursuit in general and to the specific goals people work on, simultaneously and sequentially, during a certain time episode. The study presented here is confined to a number of personal characteristics that have also been involved in other research. The list starts with two personality traits, namely Conscientiousness, which might be associated with a more organized style of working, pursuing less goals and less frequent switching, and Extraversion, which might be related to the pursuit of many goals at the same time and frequent goal switching (König \& Waller, 2010; Poposki \& Oswald, 2010). Pacing style, refers to the way in which people tend to distribute their effort over time when pursuing a goal with a deadline - e.g. distributing the 
effort evenly over time, or concentrating it shortly before the deadline. It is "a relatively stable and general personal characteristic of how people tend to use their time under deadline conditions" (Gevers, Claessens, Van Eerde, \& Rutte, 2009). Since several studies have found pacing styles to differentiate individuals and teams with regard to performance over time (e.g., Gevers, Claessens, Van Eerde, Rutte, \& Roe, 2006; Mohammed \& Nadkarni, 2011), it seems worth investigating its role in multiple goal pursuit.

Since time constraints tend to make it impossible to meet the standards for every goal, and trade-offs exist between such outcomes as completing the work on time and delivering perfect quality (Wood, 2005), people are often forced to make choices as regards what to deliver. This brought us to introduce and explore a new notion, specific for multiple goal pursuit, namely performance preference. It is defined as the relative preference for quality, completeness or timeliness in cases where all three performance outcomes are impossible to achieve at the same time. Performance preference is measured with a forced choice instrument that will be introduced below. We also included Polychronicity, or the preference for multitasking, which has been used as an antecedent in many other studies (e.g, KaufmanScarborough \& Lindquist, 1999; König et al., 2010; Zhang et al., 2005).

\section{Possible consequences}

Since the goals people work on and the way in which they combine them is highly idiosyncratic, one would consider using personal consequences to evaluate the results of their work. Here, we limit ourselves to some more generic consequences that seem nonetheless suited to assess the outcomes of the work. A consequence that is of obvious importance in the context of multiple goal performance over time is the Number of goals achieved in the period covered by the study. In addition, we include the Satisfaction with goal performance, 
differentiated according to the three performance aspects mentioned before: Quality, Completeness and Timeliness. While these consequences have not been studied in previous research. However, Control of time has been studied before and has been found to be of relevance, mainly in the context of time management (Claessens et al., 2010; Macan, 1994).

\section{METHOD}

We will now describe the methods used in this study, starting with the data collection and the sample. Next, we discuss the measures used in answering the research questions. Given the descriptive and explorative purpose of the study, we will present the analytical methods in the Results Section.

\section{Data collection}

The study consisted of three phases (see Table 1 for an overview). In the first phase, every participant was asked for an appointment in which two paper based pre-questionnaires were administered and additional information concerning the study was provided. The questionnaire consisted of two parts.

The first part of the questionnaire consisted of an A3-sized paper on which participants were asked to name five work related goals. A requirement for all goals indicated was that the participant would need more than one day to complete it. To increase the likelihood that people would work on these goals longer, participants were asked to indicate two out of the five goals that would take even longer to accomplish (min. four weeks). Moreover, the paper-based goal inventory included the following definition of a goal and examples: "In this research, a goal is defined as something you want to accomplish in the future that is related to your work. This could be for example an event, outcome, task, or 
appointment that you already have or plan to put effort in, but which has not been accomplished yet. Examples of goals are preparing a presentation, organizing a course, or writing a paper."

The second part of the questionnaire was administered in a small booklet in which the personality traits conscientiousness and extraversion were assessed as well as pacing styles preferred performance outcomes in multiple goal settings, polychronicity and control of time at work. Moreover, we asked for some demographics such as age and gender. Either we collected the questionnaire or the participant returned it with a previously provided ID in a sealed envelope to one of the researchers' mailbox.

Table 1: Overview of study phases and data collection

\begin{tabular}{|c|c|c|c|c|}
\hline & $\begin{array}{l}\text { Pre-diary: Goal } \\
\text { Inventory }\end{array}$ & $\begin{array}{l}\text { Pre-diary: General } \\
\text { Questionnaire }\end{array}$ & Diary Study & $\begin{array}{l}\text { Post-diary: } \\
\text { Questionnaire }\end{array}$ \\
\hline Timing & $\begin{array}{l}\text { Thursday or Friday before } \\
\text { diary phase }\end{array}$ & $\begin{array}{l}\text { Thursday or Friday } \\
\text { before diary phase }\end{array}$ & $\begin{array}{lr}2 \text { week minimum; } & \text { start } \\
\text { at Monday after } \\
\text { inventory } & \text { and } \\
\text { questionnaire } & \end{array}$ & $\begin{array}{l}\text { When PDA was } \\
\text { collected }\end{array}$ \\
\hline Method & Paper based & Paper based & PDA Diary & Paper based \\
\hline Constructs & $\begin{array}{lll}\text { 1. Participants list } 5 \\
\text { Goals }\end{array}$ & $\begin{array}{l}\text { 1. Conscientiousness } \\
\text { 2. Extraversion } \\
\text { 3. Pacing Styles } \\
\text { 4. Performance } \\
\text { preferences } \\
\text { 5. Polychronicity } \\
\text { 6. Demographics }\end{array}$ & $\begin{array}{l}\text { 1. Percentage of days } \\
\text { worked on only } 1 \\
\text { goal } \\
\text { 2. Percentage of days } \\
\text { worked on multiple } \\
\text { goals } \\
\text { 3. Percentage of days } \\
\text { worked on the same } \\
\text { goals } \\
\text { 4. Percentage of days } \\
\text { goals have been } \\
\text { switched } \\
\text { 5. Average number } \\
\text { of goals per day }\end{array}$ & $\begin{array}{l}\text { 1.Number of } \\
\text { goals completed } \\
\text { 2.Overall } \\
\text { satisfaction with } \\
\text { all goals } \\
\text { 3.Satisfaction } \\
\text { with quality, } \\
\text { quantity, and } \\
\text { timeliness of } \\
\text { indicated goals } \\
\text { 4.Control of time } \\
\text { at work }\end{array}$ \\
\hline
\end{tabular}


In the second phase of the study, we used an experience sampling technique to gather longitudinal data of goal pursuit. Experience sampling allows studying the dynamics of behaviors in real life settings as they unfold over time (Bolger, Davis, \& Rafaeli, 2003). We distributed the handhelds the Monday after the appointment in which the questionnaires were administered. All palmtops were exclusively programmed to include the work related goals stated by each participant respectively in phase 1. Every participant was instructed individually how to use the handhelds until the handling of the device and the procedure was completely understood. Every day five trials randomly spread across equally spaced intervals of the work day were signaled by a beep. Participants kept the handhelds a minimum of two weeks and a maximum of three weeks (at least 10 and at most 15 working days).

During every trial participants were asked whether they had been working on any of their indicated goals (name of the goal appeared on the screen) since the last trial they had answered. If they had been working on any of their indicated goals, they were asked which goal(s) they had been working on and for how long.

Although some people filled in the questionnaires longer than 19 days, we used this as the overall time frame for all participants and deleted the observations that were gained after theses 19 days. Weekends are included in the 19 days and occur on days 6,7,13, and 14 .

\section{Sample}

We recruited participants among employees working at a Dutch university. We sent out an invitation email in which we shortly described the purpose and procedure of the study, and asked people for their voluntary participation. We did not provide any monetary compensation for participating in the study, but participants received an overview of their individual results. 174 invitational emails were sent out, and 52 employees agreed to 
participate in the study (response rate of 29,89\%). All participants filled out the initial questionnaire in which they indicated five personal work goals. Throughout the diary phase, all participants filled in at least 22 trials on the Palm top, with an average of 44,54 trials across the three weeks, and a maximum of 69 trials. In total, we obtained 2316 data points of 52 participants out of a possible 3900 (59\%).

On average, participants were about 32 years old, approximately $42 \%$ were female, and almost $95 \%$ had a full time contract. The sample consisted of 16 professors, 4 researchers, and $32 \mathrm{PhD}$ students.

\section{Measures}

\section{Individual goal pursuit pattern}

Whenever the device prompted participants to fill out the questionnaire, the first question was if they had been working on any of their previously indicated goals (yes/no). If they had been working on any of their goals, participants were asked to indicate for how long they had been working on their goal since the last time they answered the PDA. The answers were categorical in nature and ranged from 1-10 minutes to more than 120 minutes. The time worked on each goal was aggregated to the day level. This allowed us to construct graphs for each individual that depict which goals had been worked on for how long on which day. These graphs were later used to clustering individuals and identify common goal pursuit patterns. They also provided the data for further analyses, involving the antecedents and outcome variables indicated in the model.

\section{Antecedents}

Conscientiousness \& extraversion. We used the items developed by Hendriks, Hofstee, \& De Raad (1999) to assess extraversion and conscientiousness. An exemplary item of extraversion is "I like to chat" and of conscientiousness "I like to follow a regular 
schedule". There are six items of extraversion and conscientiousness respectively all assessed on a five point Likert scale from $1=$ almost never to $5=$ almost always. We checked for the reliability of both scales. After deleting the item "I slap people on the back" from the extraversion scale Cronbach's alpha was .722. No items were deleted from the conscientiousness scale $(\alpha=.798)$.

Pacing style. Participants were asked to indicate on a five point Liker scale ( $1=$ almost never to $5=$ almost always) to what extent the pacing style graphs adapted from Gevers, Rutte, and van Eerde (2006) represent the way they generally organize their time when performing a task or project. Each graph represents a different style of working on activities towards a deadline. Four graphs were presented: 1) a graph that indicates an early start or very late start before a deadline, a 2) a constant style 3) an inverted $\mathrm{u}$-shape and 4) u-shape pacing style graph.

Performance preferences. Since no research considers performance in a multiple goal setting, we constructed a measure to capture the different aspects of what good performance in a multiple goal setting would entail. Participants were asked to distribute 100 points among three categories according to their preferred work outcome when faced with several work goals. The categories to allocate the points to were "the work is finished in time" (timeliness), "the work is fully completed" (completeness), and "the work is perfect" (quality).

Polychronicity. Instead of using a scale to assess polychronicity we used a graphical method. Participants were presented with four different graphs, namely working on one goal only, working on two goals in parallel, working on a few goals in parallel, and working on 
many goals in parallel on a day. We asked participants to think of a typical work day and checkmark the graph that represents best the way they prefer to work on their goals.

\section{Consequences}

Number of goals completed. After the diary phase participants indicated if they completed their goals by means of dichotomous answer $(0=$ not completed, $1=$ completed $)$. We aggregated the answers to the individual level referring to the number of goals completed per person.

Satisfaction with goals. Participants were asked how satisfied they were with their overall performance on their goals. This was assessed on a 1-item five point Likert scale from $1=$ very unsatisfied to $5=$ very satisfied. After completing the diary phase participants were asked to indicate on a five point Likert scale how satisfied they were with the three dimensions of goal performance, namely the completeness, timeliness and quality of their five indicated goals.

Control of time at work. We adapted the control of time scale by Claessens et al. (2004) . We used eight items of the original scale, but refined them by taking out any frequency identifying terms, such as 'usually' or 'often'. The items "Things at work go differently from what was planned" and "I start working on tasks that I intended to do when the workday is almost over" have been added to the original scale. The reliability of the scale was satisfactory $(\alpha=.802)$.

\section{Analysis}

For describing and exploring patterns of goal pursuit we used graphical methods, which will be described below. The clustering of goal pursuit patterns was done on the basis of quantitative parameters derived from the graphs, using the Quick Cluster procedure from 
SPSS. Relationships between antecedents, goal pursuit parameters, and consequences were generally investigated with Pearson product-moment correlations. Comparisons involving categorical variables were carried out with Analysis of Variance. Given the explorative purpose of the study significance tests were usually conducted with an alpha of .10 and a twosided evaluation of $\mathrm{p}$.

\section{RESULTS}

We will now present the results of our study, addressing the three research questions formulated in the introduction.

\section{Research question 1: How do people deal with their multiple work goals?}

To describe how people work on their goals we chose to conduct three different methods of analysis. First, we examined each individual goal pursuit pattern graphically, using three different techniques. Second, we looked into attributes that best describe the way people pursue their multiple goals over time. To this end we used parameters of the patterns, such as, e.g., the average or maximum number of goals per day. Third, we tried to form meaningful cluster from the data to see whether we can categorize people into a certain goal pursuit style.

\section{Graphical examination of individual goal pursuit patterns}

As described in the Design section we have chosen three ways of depicting the individual's goal pursuit over time (see Figure 2). First, we used cumulative curves to show the amount of time spent on the five goals over the 19 days of the study. These graphs demonstrate the progress a person makes on each goal. They clearly show that as the person progresses on one goal (increasing line) there is often no progress on other goals (the level of 
the line is constant), which can be seen as exhibiting the limited resources available for performing work tasks. Second we used distributive area graphs, which show the amount of time dedicated to each of the five goals under the assumption that these goals are the only ones the person is currently pursuing. In drawing these graphs, we deleted the days the person did not work on any of the indicated goals. Third, we plotted the absolute amount of time spent on each goal per day in stacked bar charts. These graphs also include the days that the person did not work on any of the indicated goals. On the X-axis the days are depicted and on the $\mathrm{Y}$-axis the minutes spent on each of the goals. The bar charts allow simultaneous depiction of the time spent on all five goals per day. Using a different color for each goal, the charts show the total amount of time spent on each of the goals and the total amount of time spent on the five goals for every single day. In addition, the graphs include the accumulated number of goals accepted throughout the study and the number of times of rescheduling the original plan. Since the stacked bar graphs reveal the most information about multiple goal pursuit we included such a graph for each participant in Appendix A.

Our exploration aims at identifying the different goal pursuit patterns that people exhibit. To show the variety of these patterns we have selected examples of rather different patterns in which people pursue one goal at the time, multiple goals in parallel, and multiple goals with a partial overlap. These patterns resemble three ideal-types of goal-pursuit which we introduced in earlier work (Kirchberg \& Roe, 2009). However, we present two patterns of parallel goal pursuit, to illustrate the variety of possible action trajectories.

Single goal pursuit. As the literature of polychronicity suggests that some people prefer working on one task at a time without switching, we explored if we would find people who would actually work on a single goal throughout the whole time period. The sample did 
not reveal one case of "pure" single goal pursuit in this sense. However, some participants did indeed work on only one goal per day for most of the time (e.g. ID 13, 25, 41 or 43 in the Appendix). Yet, there was hardly any case where people completed such a single goal before starting the next goal. To the contrary, we found quite some people engaging in only goal per day, but switching to another goal on the next day. Some work on goal A on day one, goal B on the second day, and then switch back to goal A on day three.

A graphical examination of a case of single goal pursuit is provided in figures $3.1-$ 3.3 below. Figure 3.1 displays the accumulated time participant ID 27 spent on the five indicated goals. This graph allows to recognize overall progress made on each of the goals. In addition, it clearly shows that most of the time was spent on goal 4 throughout the whole time period, indicating single goal pursuit. Towards the end of the time period the person started working on goals 1 and 3, while stopping to work on goal 4.

Graph 3.2 depicts goal pursuit in a relative format by means of a distributive area graph. The days the person did not work on any of the indicated goals are not taken into account. This graph also shows that the person spent most of the time to goal 4 . In contrast to graph 3.1 one can see how much time is spent on the goals in relation to one another. While the participant only spent a couple of minutes working on goal 5 during the first days (5 and 20 minutes respectively) it is still depicted as a rather large area in the graph. Since we are interested in the relative distribution of peoples' resources among the five indicated goals the actual amount of time spent on each goal is intentionally neglected in this graph.

Figure 3.3 shows the absolute amount of time spent on each goal per day in stacked bars. We included the number of goals added to the person's goal portfolio over the length of the study, and the accumulated number of goals that needed to be rescheduled. The figure 
shows that the person accepted ten more goals and had to reschedule goals four times throughout the study. Although the stacked bar chart provides the most detailed information about the goal pursuit of the individual it does not show the single goal pattern pursuit as clearly as Figures 3.1 and 3.2. 
Figure 3.1: Example of a cumulative graph of single goal pursuit



Figure 3.2: Example of a distributive area graph of single goal pursuit

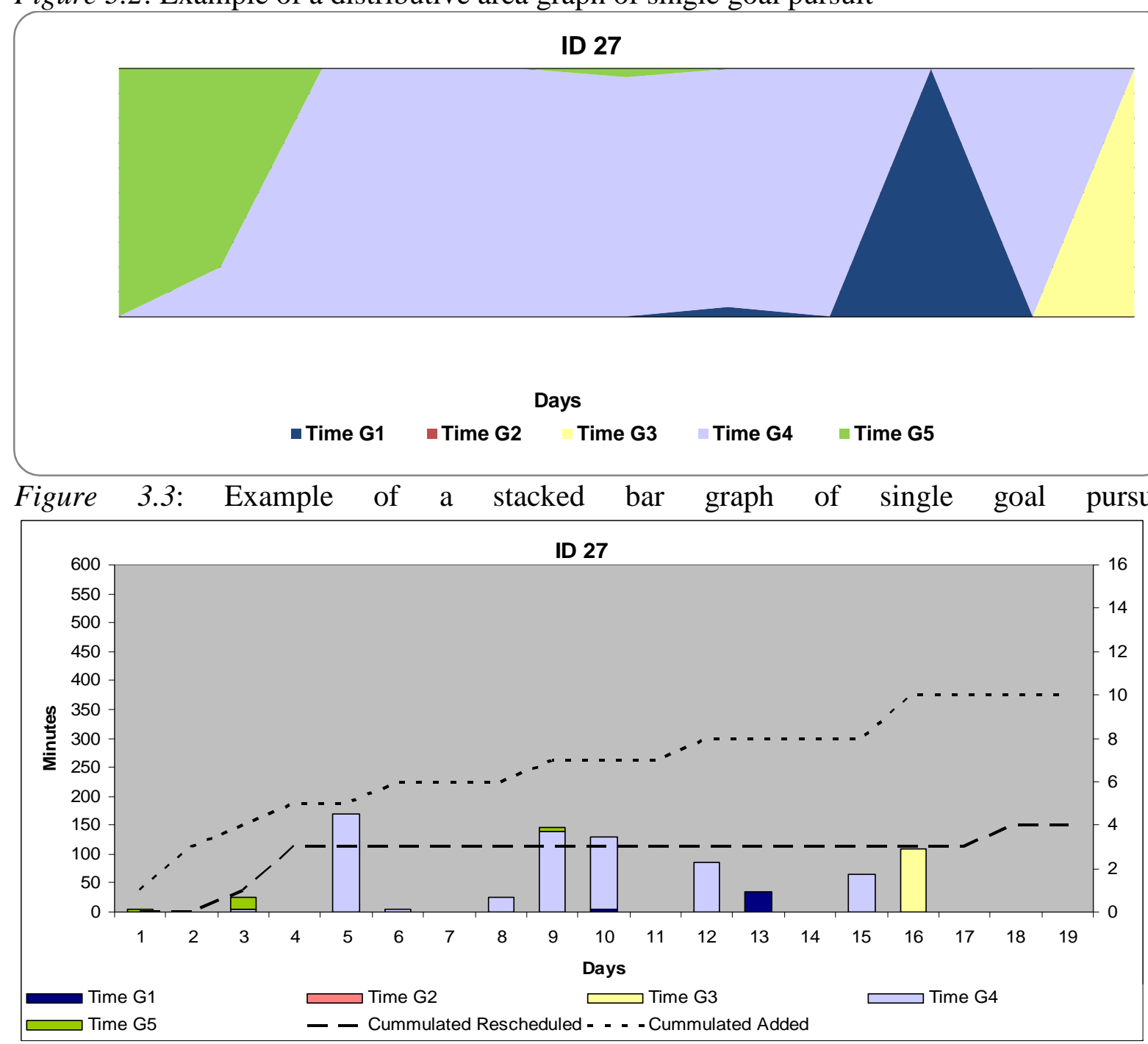


Parallel goal pursuit. We were also interested to see whether we would find people working on two or more goals in parallel, throughout the period of the study. In contrast to the case of single goal pursuit, we found many examples of parallel goal pursuit (e.g., ID 1,3, 2, 9, 14, 20 in the Appendix). As in single goal pursuit we find some cases of parallel goal pursuit that are rather "pure" and others that are more "mixed". Pure parallel goal pursuit is present when participants always pursue the same two or more goals in parallel and spend almost equal amounts of time on them. Figures 4.1-4.3 relate to a case of rather "pure" parallel goal pursuit. The person spent six days working on the same two goals in parallel. On four other days the person worked on these two goals plus an additional goal. The two main goals received an almost equal share of time.

Figure 4.1 shows the cumulative curve for this case. The time spent on goal 2 and 4 is almost equal throughout the study so that the two lines are overlapping each other. In the end the person starts working on goal 3 and spends more time on goal 2 compared to goal 4 . The parallel goal pursuit of participant ID 20 can best be seen in graph 4.2. The person focuses on goals 2 and 4 for almost the whole period of the study. Again the stacked bar chart (figure 4.3.) provides most information. Yet, one can best see the parallel goal pursuit and the relative time spent on each goal in the previous figure. 
Figure 4.1: Example of a cumulative graph of "pure" parallel goal pursuit

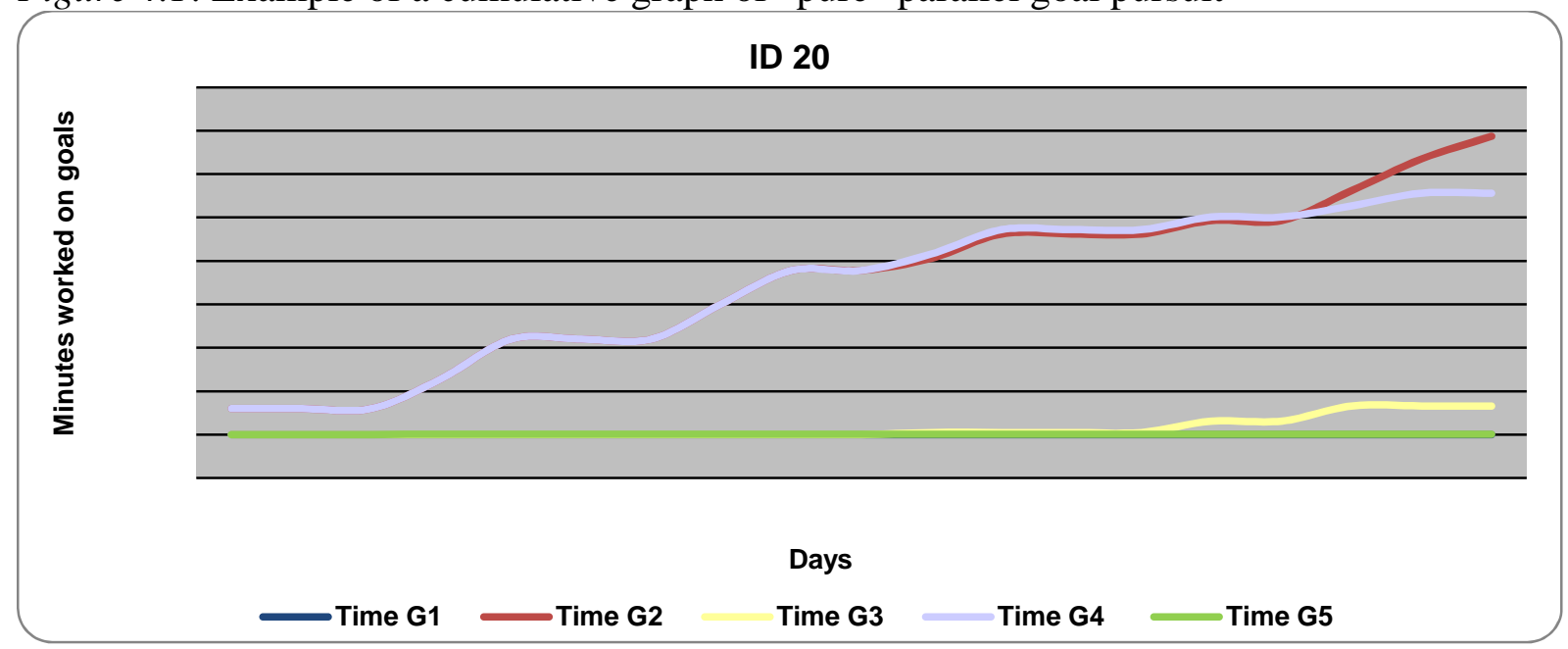

Figure 4.2: Example of a distributive area graph of "pure" parallel goal pursuit

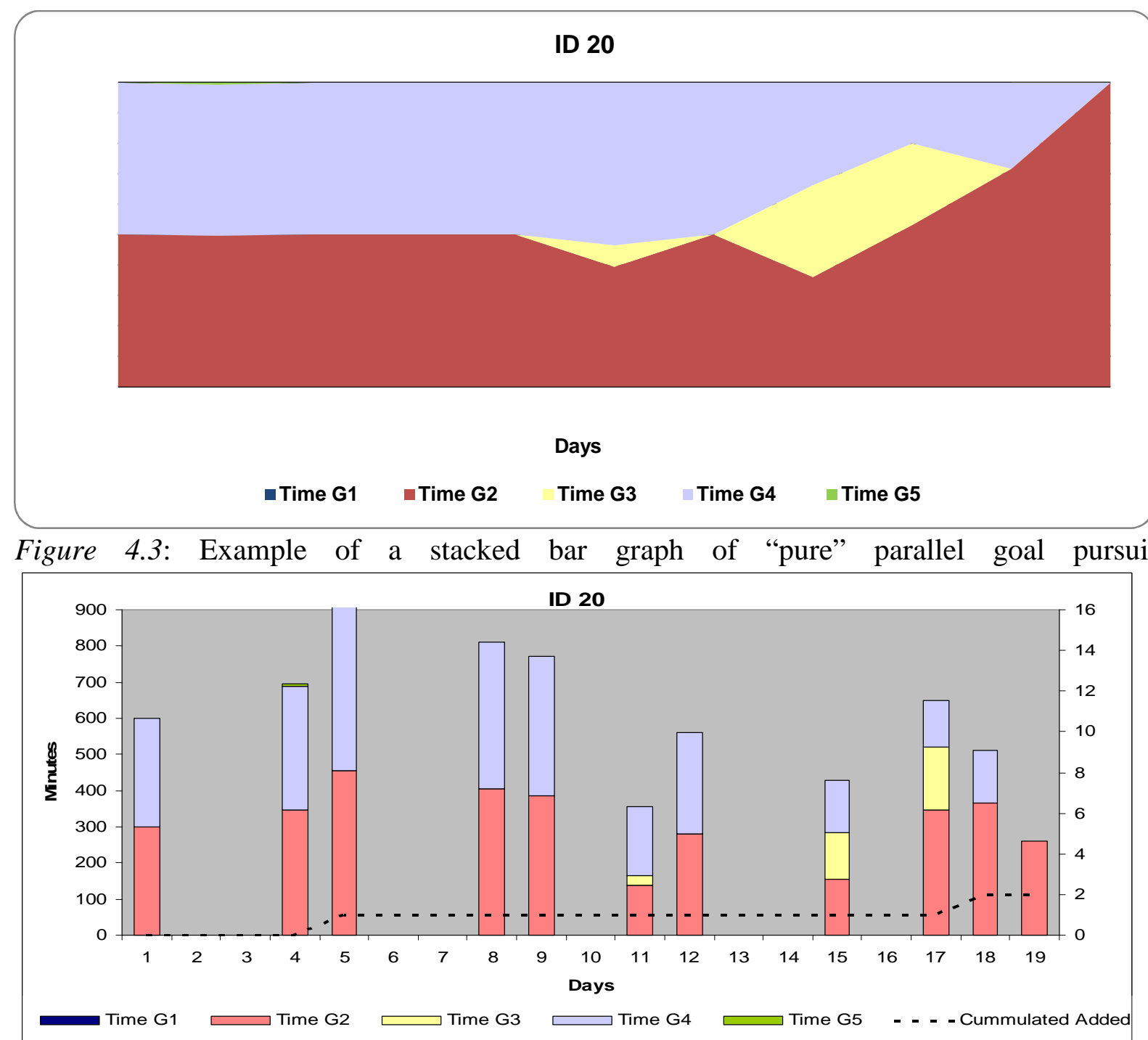


As previously stated, the sample contained many cases of people working on their goals in parallel but also frequently switching the combination of goals worked upon. Moreover, the relative time spend on the five goals may vary substantially. Thus, we decided to include an example of a more "impure" parallel goal pursuit style (figures $5.1-5.3$.) to contrast it with the relatively clear two-goal pursuit that we have just described (figures 4.14.3). Further examples of "impure" parallel goal pursuit patterns can be found in the Appendix (e.g., ID 17 and 26).

The cumulative work curve of participant ID 19 (figure 5.1) shows the progress on each of the five goals. However, the graph can be misleading as it seems as if the person made continuous progress every day on each goal. Figures 4.2 and 4.3 show more clearly that the person did not work on any of the previously indicated goals during seven days.

In such a case of impure parallel goal pursuit, the distributed area graph seems to give a rather chaotic presentation. Nevertheless, one can quickly grasp the main features: the person is almost always working on at least two goals in parallel and is frequently switching the combination of goals.

In figure 5.3 the stacked bar chart of the impure parallel goal pursuit of participant ID 19 is depicted. In contrast to Figure 5.1 one can easily see that the person did not work on any of the indicated goals from the $16^{\text {th }}$ day onwards. Figure 5.2 visibly demonstrates the parallel goal pursuit. In Figure 5.3 one has to carefully look to identify the parallel goal pursuit since some goals got worked upon for a couple of minutes per day only, which is hard to recognize in the stacked bar chart (e.g. day 2 or day 6 ) as it provides the time worked on each goal in absolute and not relative terms. 
Figure 5.1: Example of a cumulative graph of "impure" parallel goal pursuit

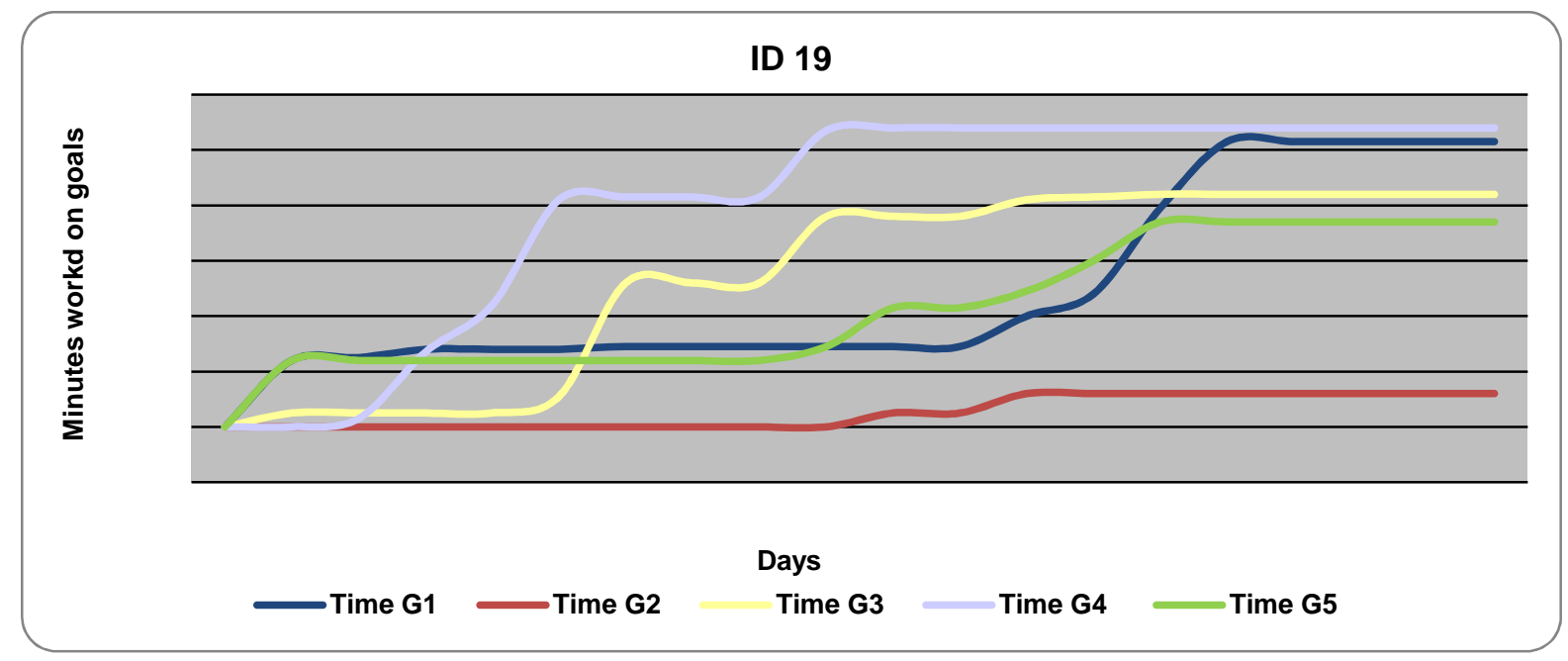

Figure 5.2: Example of a distributive area graph of "impure" parallel goal pursuit

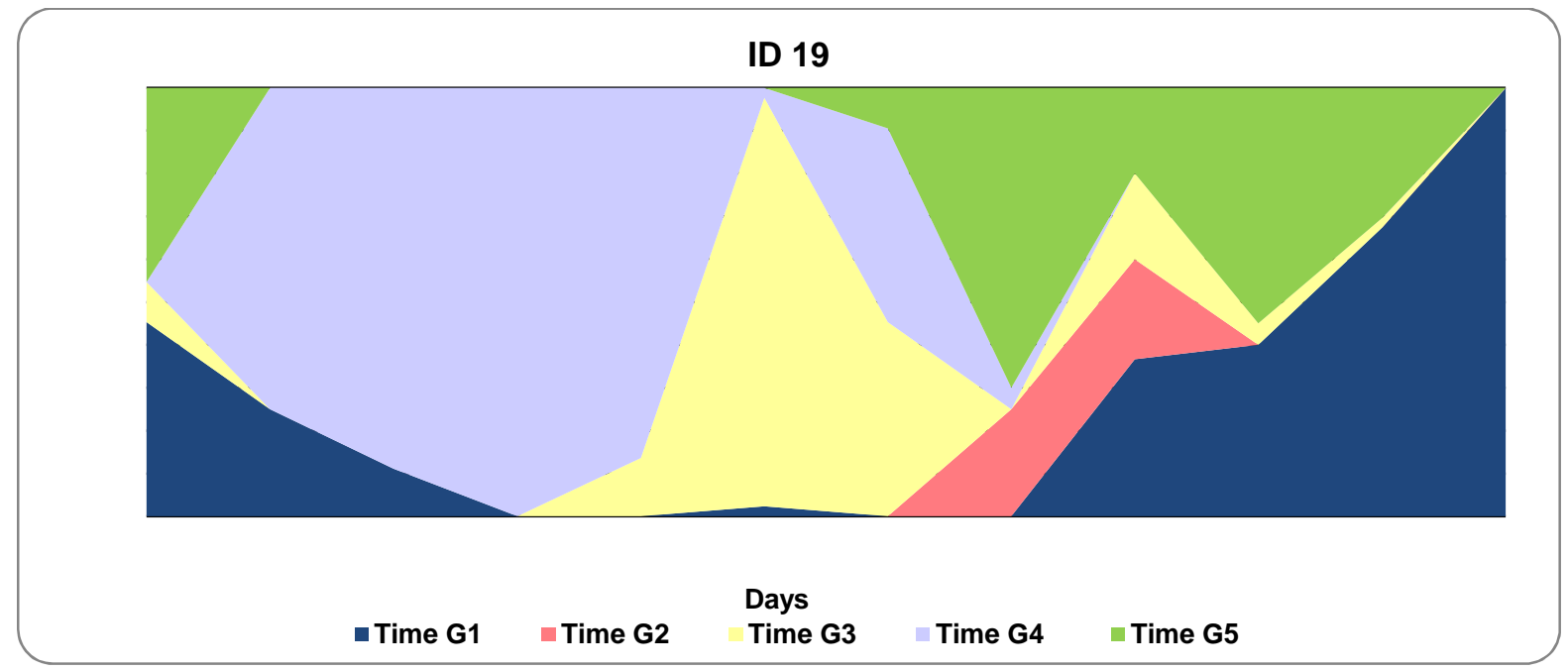

Figure 5.3: Example of a stacked bar graph of "impure" parallel goal pursuit

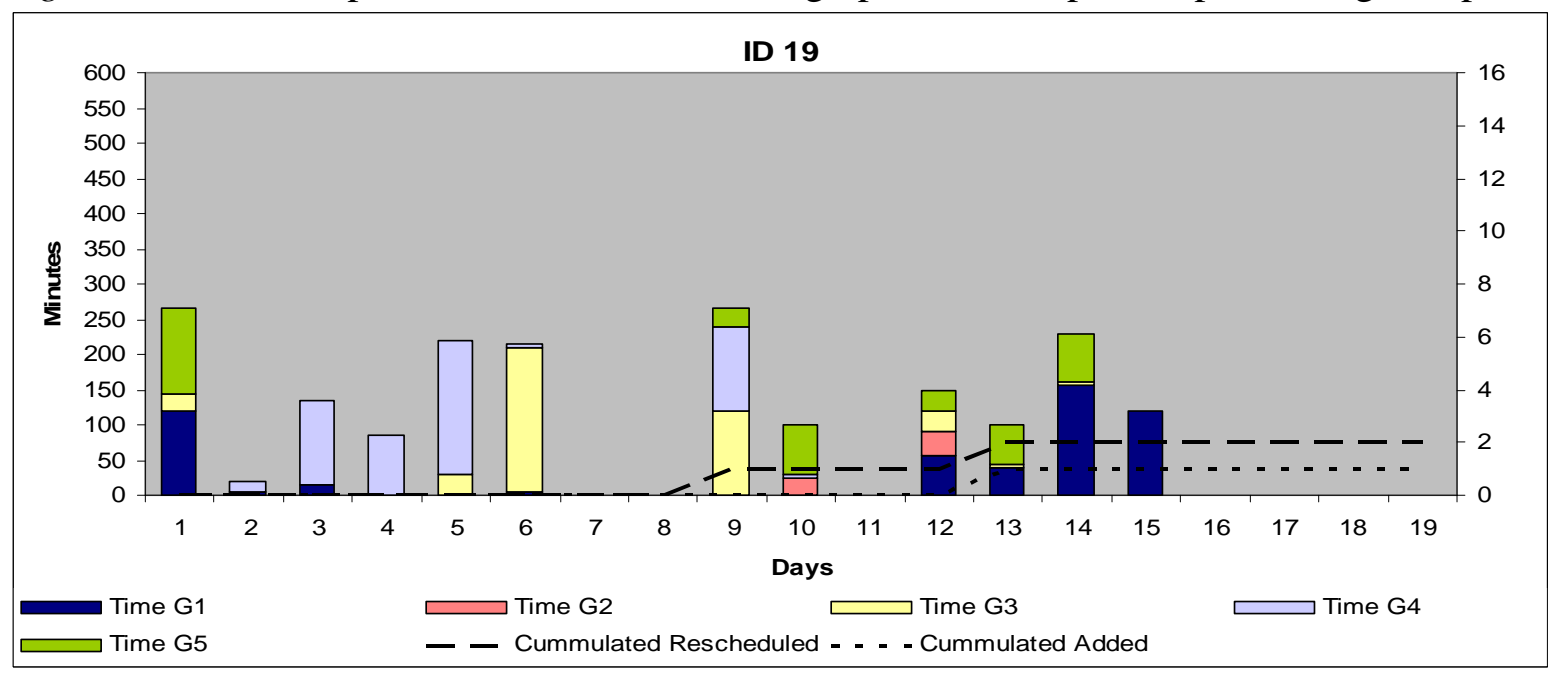


Overlapping goal pursuit. Besides single and parallel goal pursuit, there were also some cases of overlapping goal pursuit. An overlapping goal pursuit means that the person starts working on the next goal when the first goal is almost completed. This pattern is similar to the parallel one, but goals worked upon are in different stages of completion and there is not much goal switching. In figures $6.1-6.3$ we depict the goal pursuit of participant ID 10 . In the beginning, goal 2 was pursued exclusively. Then, the person stopped working on this goal and started to work on goal 4. After pursuing goal 4 for a while exclusively, the person began also working on goal 5 . This pattern means that people start working on the next goal while the previous goal is "fading out". The cumulative graph (figure 6.1) does not show the overlapping pattern very clearly, but rather suggests a single goal pursuit pattern.

The distributive area graph (figure 6.2) is showing the overlapping goal pursuit in a clearer way compared to the cumulative graph. Here, the "fading out" of one goal while starting the next one is well visible.

Again, the stacked bar graph (figure 6.3) is showing the most detailed information. However, the overlapping style is not as quickly recognizable in the stacked bar graph compared to the distributed area graph. 
Figure 6.1: Example of a cumulative graph of overlapping goal pursuit

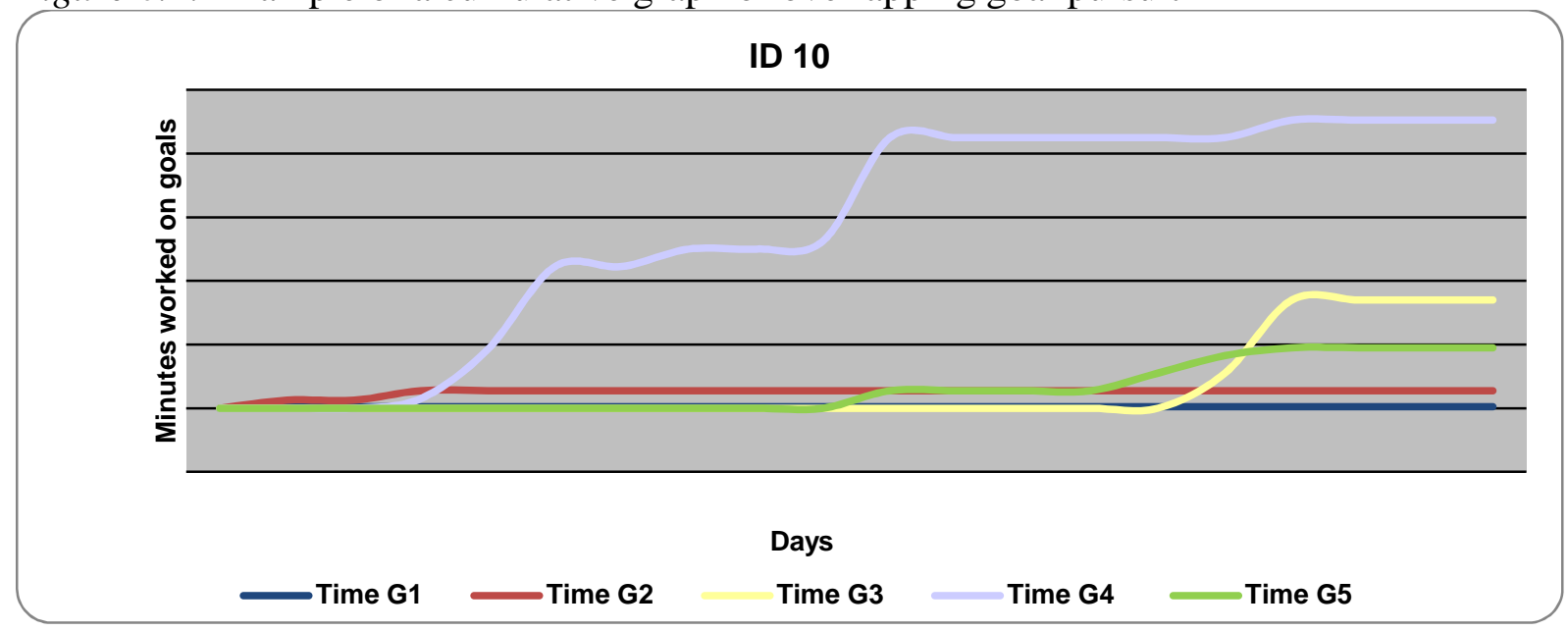

Figure 6.2: Example of a distributive area graph of overlapping goal pursuit

ID 10

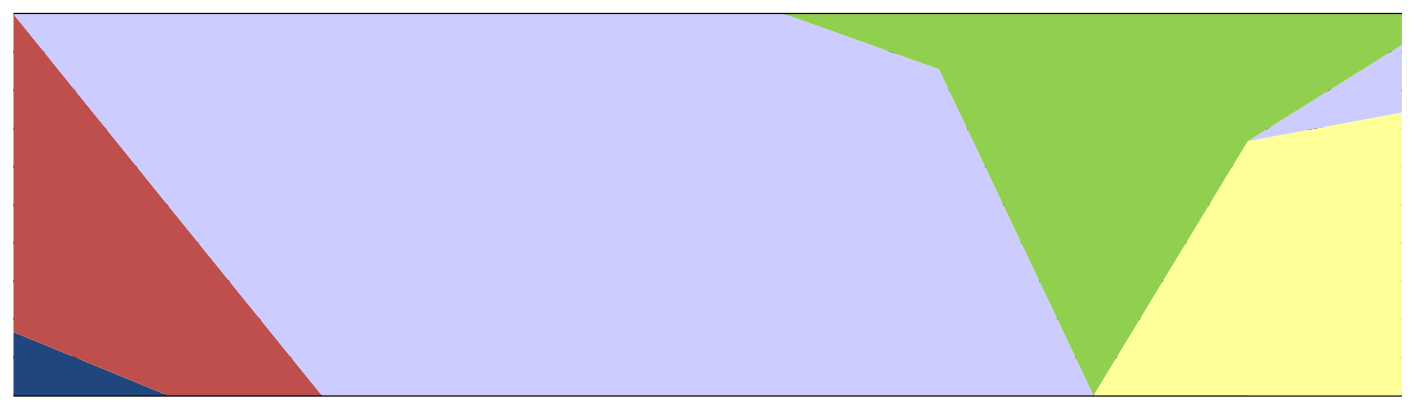

Days

- Time G1 $\quad$ Time G2 Time G3 $\quad$ Time G4 $\quad$ Time G5

Figure 6.3: Example of a stacked bar graph of overlapping goal pursuit




Conclusion. When examining the graphs of all persons (Appendix 1), we do recognize the differences between single, parallel and overlapping goal pursuit. However, the majority of graphs reveal mixtures of such goal pursuit patterns. For example, one person (ID 34) starts working on two goals in parallel, but on the third and fourth day works on one of these goals exclusively. He then works on three and four goals in parallel before working on one goal only in the end again. This example shows a great deal of dynamics in the goal pursuit patterns, and a dependence on the periods of measurement. This may reflect the impact of frequent externally induced task switches (e.g. telephone calls or meetings), shifts in demands (e.g. new goals are added and others become obsolete), and the limited time available. The apparent variety of patterns makes their categorization difficult and limits their predictability from personal characteristics.

\section{Attributes of individual goal pursuit}

After describing the goal pursuit patterns in their entirety, we looked at attributes that best describe the differences between peoples' way of pursuing their goals. Table 2 lists descriptive statistics for the individual goal pursuit patterns. To compare the descriptive results between people, we aggregated the data from the 19 days to the person level. The most straightforward measure is the average number of goals a person works on per day. On average people pursued about 1,2 goals per day. Due to the fact that sometimes people did not work on any of their indicated goals or at least did not respond to the questions on these particular days (e.g. missed data entries), we included a second measure indicating the average number of goals worked on during the days the person worked on any of the indicated five goals. Referring to this measure, people worked on average on two (1.99) goals per day. This confirms the finding from the graphical analysis that most people do not engage in single goal pursuit, but instead work on their goals in parallel. 
Table 2: Descriptive statistics of goal pursuit attributes

\begin{tabular}{|c|c|c|c|c|}
\hline & Mean & SD & Min & Max \\
\hline $\begin{array}{l}\text { Average number of goals worked on per day (without days } \\
\text { not worked on any goal) }\end{array}$ & 1.99 & 0.48 & 1 & 3.33 \\
\hline Maximum number of goals worked on per day & 3.31 & 0.12 & 1 & 5 \\
\hline Days with single goal pursuit (in \%) & 0.21 & 0.15 & 0 & 0.67 \\
\hline Days with parallel goal pursuit (in \%) & 0.64 & 0.25 & 0 & 1.00 \\
\hline $\begin{array}{llllllll}\begin{array}{l}\text { Days } \\
\text { (in \%) }\end{array} & \text { with } & \text { same } & \text { goal } & \text { (composition) } & \text { in } & \text { a } & \text { row } \\
\end{array}$ & 0.18 & 0.12 & 0 & 0.58 \\
\hline Days on which person switched goal(s) (in \%) & 0.11 & 0.08 & 0 & 0.32 \\
\hline Number of goals accepted & 5.48 & 5.80 & 0 & 29 \\
\hline
\end{tabular}

$\mathrm{N}=52$

The average amount of goals pursued may not be a very sensitive measure of multiple goal pursuit. We therefore included the maximum number of goals people pursue on a given day. As can be seen in Table 2 some people never worked on more than one goal per day while others would work on five goals per day. We also looked at the percentage of days that people worked on one goal only. Thus, we developed the attribute "days with single goal pursuit" by counting the days people work on one goals only over all days worked on any of the goals. On average people worked on only one goal on $20 \%$ of the days. However, there are people who work on only one goal on $67 \%$ of the days. Thus, there is quite a large variation between people in this respect.

Next, we counted the number of days people work on more than one goal in parallel. This goal pursuit attribute is called "days with parallel goal pursuit". The results show that participants worked on average on $64 \%$ of the days on their goals in parallel. However, as discussed previously, there are huge differences in the degree of "parallelity" of individual goal pursuit. While some people always worked on the same goals, others frequently switched between goals. To capture this statistically we also counted the days that each participant worked on the same goal or goal compositions for more than one day in a row. Thus, if a 
person worked from Monday up to and including Wednesday on the same single goal it would mean three days over the total amount of days. This goal pursuit attribute is called "days with same goal (composition)". It turned out that people spent on average $18 \%$ of their time working on the same goal(s) in parallel for more than one day. Furthermore, we were interested in the number of days on which people switched their goal(s). Thus, we included the goal pursuit attribute "days on which person switched goal(s)". On average people switched their goal(s) on one third of the days.

Even though these attributes give an indication of multiple goal pursuit, there are large differences between people (see min and max as well as standard deviations in Table 5). This is in line with the results of the graphical examination and confirms the finding that individual multiple goal pursuit patterns are not only different between people but are also highly dynamic over time.

Besides looking at the number of days participants worked on a single goal or goals in parallel we also asked people to indicate how many new goals they had been adding. On average people accepted 5,48 new goals over the three week period in addition to the five that they indicated at the beginning of the study. Again, the spread is quite large. While some people did not add any goals during the time of the study, others added up to 29 goals! The number of goals added might, of course, influence the goal pursuit displayed, since less time is available to be spent on the indicated goals when new goals are added.

\section{Categorization of goal pursuit patterns}

Using the individual goal pursuit attributes described above we tried to form meaningful clusters of goal pursuit and to ascertain to which degree they exhibit single, parallel and overlapping goal pursuit (Kirchberg \& Roe, 2009). Given the great variety of 
patterns, clustering people into a small number of categories is not easy. To identify clusters we used the goal pursuit attributes given in Table 2. We applied Quick Cluster analysis (hierarchical cluster analysis) in SPSS 21 and examined a three, four, and five cluster solution. We limited the iteration process to 10 . In the end only three iterations were needed to reach the final solution. Results showed that the five cluster solution is superior to the three and four cluster solution. Therefore, we focus on the five cluster solution. Table 3 shows the centers of the goal pursuit attributes for each of the five clusters and the number of participants in each cluster. The average number of goals pursuit in the first indicated cluster are 2,57 in comparison with e.g. only 1,34 goals on average in cluster 4 . Interesting to see is also the percentage of days people pursued either only one goal or more in parallel. Table 4 presents the respective ANOVA results providing an indication of the suitability of the chosen attributes to discriminate between multiple goal pursuit patterns. Results indicate that the formed clusters are significantly different from each other with respect to the average number of goals worked on, the maximum amount of goals a person works on a day, the percentage of days worked on single goals only, and the percentage of days one worked on multiple goals in parallel. The two attributes percentage of days with goal switches and the percentage of days one sticks to the same goal (combination) are not significantly different between the five clusters.

Table 3: Cluster centers of five cluster solution

\begin{tabular}{|l|l|l|l|l|l|}
\hline & \multicolumn{3}{|l}{ Cluster } & \multicolumn{3}{l|}{} \\
\cline { 2 - 6 } & $\mathbf{1}$ & $\mathbf{2}$ & $\mathbf{3}$ & $\mathbf{4}$ & $\mathbf{5}$ \\
\hline Average number of goals per day & 2.57 & 1,90 & 2.34 & 1.34 & 1.97 \\
\hline Maximum number of goals worked upon a day & 4 & 3 & 5 & 2 & 4 \\
\hline Days with single goal pursuit (\%) & .08 & .21 & .21 & .37 & .23 \\
\hline Days with parallel goal pursuit (\%) & .87 & .67 & .69 & .32 & .60 \\
\hline Days with same goal (composition) (\%) & .14 & .18 & .14 & .21 & .20 \\
\hline Days on which person switched goals (\%) & .15 & .10 & .09 & .14 & .10 \\
\hline N per cluster & 11 & 21 & 4 & 9 & 7 \\
\hline
\end{tabular}


Table 4: ANOVA five cluster solution

\begin{tabular}{|l|l|l|l|l|l|l|}
\hline & \multicolumn{2}{|l|}{ Cluster } & \multicolumn{2}{l|}{ Error } & \\
\cline { 2 - 7 } & $\begin{array}{l}\text { Mean } \\
\text { Squares }\end{array}$ & df & $\begin{array}{l}\text { Mean } \\
\text { Squares }\end{array}$ & df & F & Sig. \\
\hline Average number of goals per day & 2,062 & 4 &, 073 & 47 & 28,101 &, 000 \\
\hline $\begin{array}{l}\text { Maximum number of goals worked upon a } \\
\text { day }\end{array}$ & 10,047 & 4 &, 019 & 47 & 531,236 &, 000 \\
\hline Days with single goal pursuit (\%) &, 100 & 4 &, 015 & 47 & 6,704 &, 000 \\
\hline Days with parallel goal pursuit (\%) &, 383 & 4 &, 036 & 47 & 10,717 &, 000 \\
\hline Days with same goal (composition) (\%) &, 009 & 4 &, 015 & 47 &, 576 &, 681 \\
\hline Days on which person switched goals (\%) &, 008 & 4 &, 007 & 47 & 1,138 &, 350 \\
\hline
\end{tabular}

Furthermore, the Euclidean distance of each individual was calculated (Table 5) to see how well the participant is represented by the goal pursuit attributes of that cluster. This information is useful in evaluating the individual patterns presented in Appendix A

Table 5: Cluster membership per ID

\begin{tabular}{|l|l|l|l|l|l|l|l|l|l|l|l|}
\hline ID & Cluster & Distance & ID & Cluster & Distance & ID & Cluster & Distance & ID & Cluster & Distance \\
\hline 1 & 1 &, 779 & 14 & 3 &, 388 & 27 & 4 &, 205 & 40 & 5 &, 339 \\
\hline 2 & 2 &, 175 & 15 & 1 &, 166 & 28 & 5 &, 279 & 41 & 4 &, 196 \\
\hline 3 & 2 &, 269 & 16 & 1 &, 334 & 29 & 2 &, 269 & 42 & 1 &, 291 \\
\hline 4 & 1 &, 218 & 17 & 1 &, 345 & 30 & 4 &, 582 & 43 & 4 &, 197 \\
\hline 5 & 2 &, 264 & 18 & 2 &, 155 & 31 & 4 &, 544 & 44 & 2 &, 301 \\
\hline 6 & 2 &, 349 & 19 & 1 &, 282 & 32 & 2 &, 102 & 45 & 1 &, 343 \\
\hline 7 & 2 &, 136 & 20 & 2 &, 482 & 33 & 2 &, 280 & 46 & 2 &, 399 \\
\hline 8 & 2 &, 317 & 21 & 2 &, 300 & 34 & 5 &, 254 & 47 & 4 &, 456 \\
\hline 9 & 2 &, 255 & 22 & 3 &, 259 & 35 & 2 &, 289 & 48 & 4 &, 204 \\
\hline 10 & 2 &, 419 & 23 & 3 &, 770 & 36 & 3 &, 301 & 49 & 5 &, 148 \\
\hline 11 & 2 &, 500 & 24 & 1 &, 165 & 37 & 2 &, 227 & 50 & 5 &, 200 \\
\hline 12 & 2 &, 297 & 25 & 4 & 1,020 & 38 & 5 &, 282 & 51 & 2 &, 644 \\
\hline 13 & 4 &, 592 & 26 & 1 &, 253 & 39 & 5 &, 674 & 52 & 1 &, 128 \\
\hline
\end{tabular}

Looking at the five different clusters we note that there are 11 people in cluster one. The goal pursuit pattern of these people is best described as engaging on average in many goals $(2,57)$ and spending only a small amount of their time on single goal pursuit $(8 \%$ of all 
days). Furthermore, this cluster is characterized by a high degree of working on goals in parallel (on average $87 \%$ of all days worked on goals in parallel).

People in cluster two also prefer working on their goals in parallel (67\% of the days) but they do not engage in too many goals at a time (maximum amount of goals per day is three). Furthermore, they tend to stick to the same goal combination. Thus, this group could be probably best described as showing "pure" parallel goal pursuit (see also stacked bar charts of participants of cluster two in Appendix A).

Participants in cluster three usually work on many goals in parallel (67\% of the days) with an average number of goals of 2,34. A distinguishing characteristic is that these participants would work on up to five goals a day.

In contrast to cluster one, people best described by cluster four engage on average in 1.34 goals with a maximum of two goals a day and work more often on a single goal, compared to the other clusters (37\% of the days). These people also stick most often to the same goal (composition) compared to the other clusters. This cluster could be best described as resembling a single goal pursuit pattern.

Participants of cluster five do not exhibit a straightforward multiple goal pursuit pattern. Also looking at the graphs (Appendix A) of these participants we find that they tend to work on a single goal on some of the days ( $23 \%$ of the days) and then spend some days working on multiple goals in parallel (60\% of the days). There is a tendency to stick to the same goal combination ( $20 \%$ of the days). 


\section{Research question 2: What determines how people work on their goals?}

Since there are different ways of working on multiple goals that even vary within people, we are interested to examine if we are able to predict the individual goal pursuit of people. To do this, we looked at personality characteristics and individual preferences and their relationship with goal pursuit attributes. Table 6 shows the pertinent correlations.

Table 6: Correlation of goal pursuit attributes with personality characteristics, pacing styles, and preferences

\begin{tabular}{|c|c|c|c|c|c|c|}
\hline & $\begin{array}{c}\square \text { number } \\
\text { of goals per } \\
\text { day }\end{array}$ & $\begin{array}{l}\text { Maximum } \\
\text { number of } \\
\text { goals per day } \\
\text { worked on }\end{array}$ & $\begin{array}{c}\text { Days with } \\
\text { single goal } \\
\text { pursuit (in \%) }\end{array}$ & $\begin{array}{c}\text { Days with } \\
\text { parallel goal } \\
\text { pursuit (in \%) }\end{array}$ & $\begin{array}{c}\text { Days with } \\
\text { same goal } \\
\text { (composition) } \\
\text { in a row (in } \\
\% \text { ) }\end{array}$ & $\begin{array}{l}\text { Days on which } \\
\text { person } \\
\text { switched } \\
\text { goal(s) (in } \%)\end{array}$ \\
\hline $\begin{array}{l}\text { Per sonality Characteristics } \\
\text { Conscientiousness (1-5) } \\
\text { Extraversion (1-5) }\end{array}$ & $\begin{array}{rl}-0,246 & * \\
0,075 & \\
\end{array}$ & $\begin{array}{r}-0,196 \\
0,043 \\
\end{array}$ & $\begin{array}{rr}0,330 & * * \\
-0,028 & \\
\end{array}$ & $\begin{array}{r}- \\
0,152 \\
0,003 \\
\end{array}$ & $\begin{array}{l}0,244 * \\
0,147\end{array}$ & $\begin{array}{rl}-0,253 & * \\
0,044 & \\
\end{array}$ \\
\hline $\begin{array}{l}\text { Pacing Styles } \\
\text { Deadline pacing style (1-5) } \\
\text { Constant pacing style (1-5) } \\
\text { Early pacing style (1-5) } \\
\text { U-shape pacing style (1-5) } \\
\text { Inverted U-shape pacing style (1-5) }\end{array}$ & $\begin{array}{r}0,004 \\
0,118 \\
-0,038 \\
0,170 \\
0,120 \\
\end{array}$ & $\begin{array}{r}-0,100 \\
0,078 \\
0,020 \\
0,039 \\
0,045 \\
\end{array}$ & $\begin{array}{r}-0,244 * \\
0,079 \\
0,207 \\
-0,223 \\
-0,036\end{array}$ & $\begin{array}{r}0,052 \\
0,095 \\
- \\
0,054 \\
0,223 \\
0,172 \\
\end{array}$ & $\begin{array}{rl}-0,243 & * \\
0,142 & \\
0,278 & * * \\
-0,094 & \\
0,155 & \\
\end{array}$ & $\begin{array}{r}0,245 \\
-0,285 * \\
-0,114 \\
0,050 \\
-0,286 * *\end{array}$ \\
\hline $\begin{array}{l}\text { Preferences } \\
\text { The work is finished in time } \\
\text { The work is fully completed (1-100) } \\
\text { The work is perfect (1-100) } \\
\text { Polychronicity (4 categories) }\end{array}$ & $\begin{array}{r}0,001 \\
0,149 \\
-0,120 \\
0,189\end{array}$ & $\begin{array}{r}-0,102 \\
0,130 \\
-0,005 \\
0,149\end{array}$ & $\begin{array}{l}-0,030 \\
-0,178 \\
0,170 \\
-0,222 *\end{array}$ & $\begin{array}{r}0,067 \\
0,066 \\
- \\
0,121 \\
0,195\end{array}$ & $\begin{array}{r}0,189 \\
-0,132 \\
-0,035 \\
-0,094\end{array}$ & $\begin{array}{r}-0,044 \\
0,105 \\
-0,052 \\
-0,063\end{array}$ \\
\hline
\end{tabular}

* Correlation is significant at the 0.10 level (2-tailed). ** Correlation is significant at the 0.05 level (2-tailed).

$* * *$ Correlation is significant at the 0.01 level (2-tailed). $N=52$

Conscientiousness and extraversion. Conscientiousness relates to several attributes of goal pursuit, namely as the average number of goals worked on, days with single goal pursuit, days with the same goal composition in a row, and days on which goals were switched. We found a significant negative relationship of conscientiousness with the average number of goals pursued $(\mathrm{r}=-, 246 ; p<.10)$ and the number of days on which the person switched goals 
$(\mathrm{r}=-, 253 ; p<.10)$. The relationships with the maximum amount of goals a person pursued on a day and days with parallel goal pursuit are also negative, but not significant $(r=-, 196 ; r=-$ ,152). As conscientious people are likely to be more concerned with the quality of goal performance and sticking to deadlines, it is not surprising that they allocate their time to less goals to achieve more timely and better results. In line with this we also find a significant and positive relationship between conscientiousness and the number of days worked on a single goal $(\mathrm{r}=, 330 ; p<.01)$ and conscientiousness with the number of days worked on the same goal composition $(\mathrm{r}=, 244 ; p<.05)$.

Surprisingly, we did not find any significant relationship between extraversion and the goal pursuit attributes. One would probably expect a positive relationship between the average number of goals and extraversion, as people scoring high on extraversion have been found to be more prone to be high in polychronicity (Poposki \& Oswald, 2010).

We also ran statistical tests (univariate and cross tables) to check if we can predict cluster membership by means of conscientiousness and extraversion, however results were insignificant. There are no distinctive personality characteristics that predict the goal pursuit pattern cluster.

Pacing styles. The deadline pacing style was significantly and negatively related to the percentage of days worked on one goal only $(\mathrm{r}=-, 244 ; p<.10)$ as well as to the percentage of days worked on the same goal composition $(\mathrm{r}=-, 243 ; p<.10)$. The constant pacing style was negatively and significantly related to the percentage of days on which the person switched goals $(\mathrm{r}=-, 285 ; p<.10)$. People who are pursuing a constant pacing style are thus less prone to switch between goals back and forth, but rather continuously work on their goals without interferences. In addition, there were positive and significant relationships between the early 
pacing style and the percentage of days working on the same goals $(\mathrm{r}=, 278 ; p<.05)$. In a multiple goals setting some people may engage in a parallel goal pursuit and stick to the same goal combination in order to prevent themselves from starting to work on a goal too late.

The U-shape pacing style was negatively related to the percentage of time the person engaged in single goal pursuit $(r=-, 223)$ and positively to the percentage of days worked on goals in parallel $(\mathrm{r}=, 223)$, but these correlations did not reach significance; $p<.10)$. People with a U-shape pacing style are expected focus on a single goal at the start and the end but distribute effort on other goals in the meantime. This seems to be in agreement with the overall tendency to work on multiple goals. We found a significant negative relationship between the inverted U-shape pacing style and the number of days with goal switching $(\mathrm{r}=$ ,286; $\mathrm{p}<.05)$. People with an inverted U-shape are expected to spend a lot of time on a single goal in the middle of a given period. Thus, the degree of switching to other or between goals will be less likely.

We also checked if pacing styles predict membership of a certain multiple goal pursuit cluster. Even though we did not find significant results we looked at the modes of the diverse pacing styles (scale 1-5 for every pacing style) according to the five clusters presented earlier. One would expect that pacing styles which represents the usual pursuit of a single goal influences the way people work in a multiple goal setting. As can be seen in Figure 7 people often do not indicate to have a certain pacing style. They indicate to use different pacing styles. As a result, there are no significant differences between the five clusters and the modes of the pacing styles. However, people of cluster five most often indicated to use a U-shape pacing stlyle (mode is 4) and almost never the early and inverted U-shape (mode is 1 respectively). People in cluster 1 seem to use every kind of pacing style a bit (modes range 
from 2-4 across pacing styles). This again shows that there are many people who cannot be classified to be working in a certain manner and thus the ability to predict behavior and compare it between people is rather difficult.

Figure 7: Modes of pacing styles for each cluster

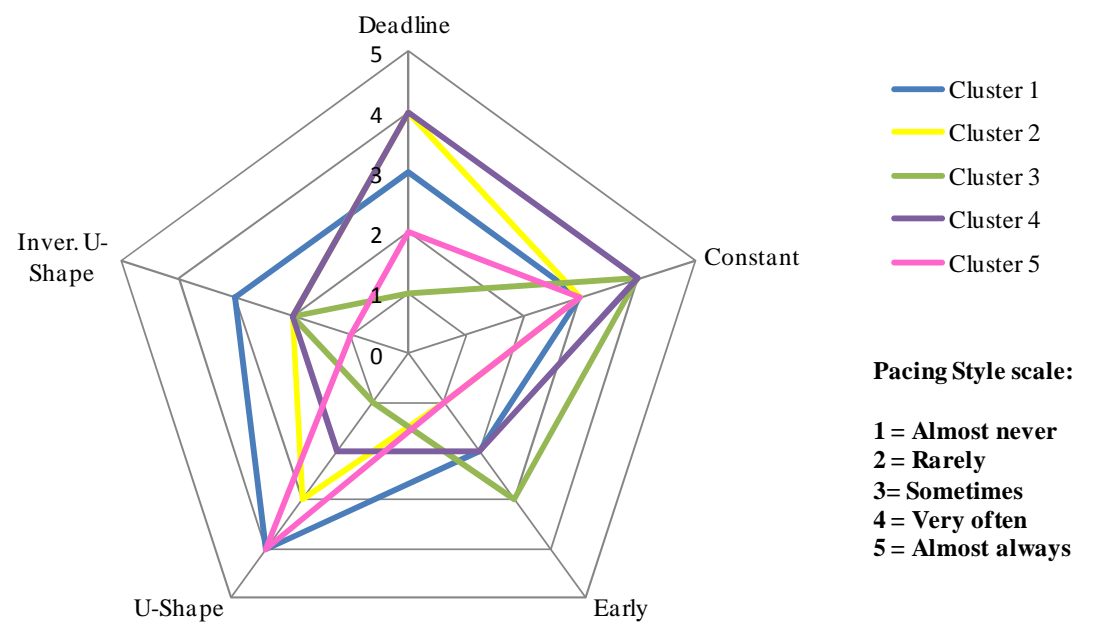

Performance preferences. As previously discussed, we assumed that there is an effect on the way people pursue their goals depending on their preferences in terms of outcome in a multiple goal setting. People who value the timely completion of their goal the most, tend to work more often on the same goals $(r=, 189)$. This makes sense the more time one spends on the same goal the more likely it is that the goal gets accomplished in the time provided. The correlation is not significant, though. There is a slight tendency to work more often on a single goal among people who prefer to complete their work in time $(\mathrm{r}=0,178)$ and those who prefer to deliver perfect work $(r=0,170)$. However, these correlations are not significant.

Polychronicity. The result indicate that polychronic people have fewer days on which they work on a single goal $(\mathrm{r}=0,222 ; \mathrm{p}<.10)$. There is also a non significant tendency for polychronic people to work on more goals per day $(r=0,189)$ and to work on more goals in 
parallel $(r=0,195)$. Since polychronicity is defined as the preference of people to switch between tasks rather than continuously working on one task (Poposki and Oswald, 2010) these findings are in agreement with what one would expect.

Demographics. Besides personality characteristics, pacing styles and individual preferences we also investigated if there is an effect of gender or age on the goal pursuit attributes displayed by the participants. To test this we run Anova tests. The descriptives and the test results for gender are reported in Table 7 and 8 . There was no effect of gender on the way people worked on their goals. Although females tend to work more days on one goal exclusively (24\% vs. $19 \%$ ) this effect was not significant (Table 8 ).

Table 7: Descriptive statistics of gender and goal pursuit attributes

\begin{tabular}{|c|c|c|c|c|c|c|c|}
\hline & & $\mathrm{N}$ & Mean & Variance & SD & Min & $\operatorname{Max}$ \\
\hline \multirow{2}{*}{$\begin{array}{l}\text { Average number of goals } \\
\text { per day }\end{array}$} & Male & 30 & 2,02 & 0,49 & 0,09 & 1,00 & 3,33 \\
\hline & Female & 22 & 1,95 & 0,48 & 0,10 & 1,08 & 2,63 \\
\hline \multirow{2}{*}{$\begin{array}{l}\text { Maximum number of goals } \\
\text { pursued per day }\end{array}$} & Male & 30 & 3,33 & 0,84 & 0,15 & 1,00 & 5,00 \\
\hline & Female & 22 & 3,27 & 0,98 & 0,21 & 2,00 & 5,00 \\
\hline \multirow{2}{*}{$\begin{array}{l}\% \text { of days worked on a } \\
\text { single goal }\end{array}$} & Male & 30 & 0,19 & 0,11 & 0,02 & 0,00 & 0,44 \\
\hline & Female & 22 & 0,24 & 0,19 & 0,04 & 0,00 & 0,67 \\
\hline \multirow{2}{*}{$\begin{array}{l}\% \text { of days worked on goals } \\
\text { in parallel }\end{array}$} & Male & 30 & 0,65 & 0,22 & 0,04 & 0,00 & 1,00 \\
\hline & Female & 22 & 0,63 & 0,29 & 0,06 & 0,08 & 1,00 \\
\hline \multirow{2}{*}{$\begin{array}{l}\% \text { of days same goal } \\
\text { (composition) }\end{array}$} & Male & 30 & 0,16 & 0,11 & 0,02 & 0,00 & 0,58 \\
\hline & Female & 22 & 0,20 & 0,13 & 0,03 & 0,05 & 0,53 \\
\hline \multirow{2}{*}{$\begin{array}{l}\% \text { of days on which person } \\
\text { switched goal(s) }\end{array}$} & Male & 30 & 0,11 & 0,07 & 0,01 & 0,00 & 0,26 \\
\hline & Female & 22 & 0,11 & 0,10 & 0,02 & 0,00 & 0,32 \\
\hline
\end{tabular}


Table 8: Anova results for gender and goal pursuit attributes

\begin{tabular}{|c|c|c|c|c|c|c|}
\hline & & $\begin{array}{l}\text { Sum of } \\
\text { Squares }\end{array}$ & df & $\begin{array}{l}\text { Mean } \\
\text { Square }\end{array}$ & $F$ & Sig. \\
\hline Average number of goals per day & $\begin{array}{l}\text { Between } \\
\text { Within } \\
\text { Overall } \\
\end{array}$ & $\begin{array}{l}, 072 \\
11,626 \\
11,698 \\
\end{array}$ & $\begin{array}{l}1 \\
50 \\
51 \\
\end{array}$ & $\begin{array}{l}0,072 \\
0,233\end{array}$ & 310 &, 580 \\
\hline $\begin{array}{l}\text { Maximum number of goals } \\
\text { pursued per day }\end{array}$ & $\begin{array}{l}\text { Between } \\
\text { Within } \\
\text { Overall }\end{array}$ & $\begin{array}{l}, 047 \\
41,030 \\
41,077\end{array}$ & $\begin{array}{l}1 \\
50 \\
51\end{array}$ & $\begin{array}{l}1,000 \\
50,000 \\
51,000\end{array}$ &, 057 & 813 \\
\hline$\%$ of days worked on a single goal & $\begin{array}{l}\text { Between } \\
\text { Within } \\
\text { Overall } \\
\end{array}$ & $\begin{array}{l}, 030 \\
1,069 \\
1,098 \\
\end{array}$ & \begin{tabular}{|l|}
1 \\
50 \\
51 \\
\end{tabular} & $\begin{array}{l}0,030 \\
0,021\end{array}$ & 1,380 &, 246 \\
\hline $\begin{array}{l}\% \text { of days worked on goals in } \\
\text { parallel }\end{array}$ & $\begin{array}{l}\text { Between } \\
\text { Within } \\
\text { Overall }\end{array}$ & $\begin{array}{l}, 003 \\
3,212 \\
3,215\end{array}$ & \begin{tabular}{|l|}
1 \\
50 \\
51
\end{tabular} & $\begin{array}{l}0,003 \\
0,064\end{array}$ &, 053 & ,819 \\
\hline $\begin{array}{l}\% \text { of days same goal (composition) } \\
\text { in a row }\end{array}$ & $\begin{array}{l}\text { Between } \\
\text { Within } \\
\text { Overall }\end{array}$ & $\begin{array}{l}, 017 \\
, 736 \\
, 753\end{array}$ & \begin{tabular}{|l|}
1 \\
50 \\
51
\end{tabular} & $\begin{array}{l}0,017 \\
0,015\end{array}$ & 1,183 &, 282 \\
\hline $\begin{array}{l}\% \text { of days on which person } \\
\text { switched goal(s) }\end{array}$ & $\begin{array}{l}\text { Between } \\
\text { Within } \\
\text { Overall }\end{array}$ & $\begin{array}{l}, 000 \\
, 342 \\
, 342 \\
\end{array}$ & \begin{tabular}{|l|}
1 \\
50 \\
51
\end{tabular} & $\begin{array}{l}0,000 \\
0,007\end{array}$ & ,001 & ,973 \\
\hline
\end{tabular}

Next we tested if there are differences in the goal attributes referring to age. Thus, we ran Anovas again to see if the goal pursuit attributes depend on age categories. The descriptive statistics and the test results are displayed in Table 9 and 10.

There was a significant difference in the maximum amount of goals pursued per day with respect to age $(\mathrm{F}=5,2(49,2) ; p<.01)$. Generally, older employees in the sample tend to work on fewer goals. Actually nobody aged above 41 worked on more than four goals a day. In contrast to this, the age group 31-40 worked on a maximum of three to five goals a day. All other goal attributes were not significantly different among the three age categories. The data suggest that younger people tend to work on average on more goals simultaneously $(2,03 \mathrm{vs}$. 1,72 goals) but switch less frequently between goals. While the people from 41-65 switched their goals on average on $17 \%$ of the days, the younger participants only switched goals on $10 \%$ of the days. 
Table 9: Descriptive statistics of age and goal pursuit attributes

\begin{tabular}{|c|c|c|c|c|c|c|}
\hline & $\mathrm{N}$ & Mean & Variance & SD & Min & Max \\
\hline $\begin{array}{ll}\text { Average number of goals } & 20-30 \text { years } \\
\text { per day } & 31-40 \text { years } \\
& 41-65 \text { years } \\
\end{array}$ & $\begin{array}{l}29 \\
15 \\
8 \\
\end{array}$ & $\begin{array}{l}2,03 \\
2,05 \\
1,72 \\
\end{array}$ & $\begin{array}{l}0,51 \\
0,33 \\
0,55 \\
\end{array}$ & $\begin{array}{l}0,10 \\
0,09 \\
0,20\end{array}$ & $\begin{array}{l}1,08 \\
1,50 \\
1,00\end{array}$ & $\begin{array}{l}3,33 \\
2,63 \\
2,71 \\
\end{array}$ \\
\hline $\begin{array}{lrl}\text { Maximum number } & \text { of } & 20-30 \text { years } \\
\text { goals pursued per day } & & 31-40 \text { years } \\
& & 41-65 \text { years } \\
\end{array}$ & $\begin{array}{l}29 \\
15 \\
8 \\
\end{array}$ & $\begin{array}{l}3,34 \\
3,67 \\
2,50 \\
\end{array}$ & $\begin{array}{l}, 897 \\
, 617 \\
, 926 \\
\end{array}$ & $\begin{array}{l}, 167 \\
, 159 \\
, 327\end{array}$ & $\begin{array}{l}2 \\
3 \\
1\end{array}$ & $\begin{array}{l}5 \\
5 \\
4\end{array}$ \\
\hline $\begin{array}{ll}\% \text { of days worked on a } & 20-30 \text { years } \\
\text { single goal } & 31-40 \text { years } \\
& 41-65 \text { years }\end{array}$ & $\begin{array}{l}29 \\
15 \\
8 \\
\end{array}$ & $\begin{array}{l}0,22 \\
0,19 \\
0,23\end{array}$ & $\begin{array}{l}0,16 \\
0,12 \\
0,16\end{array}$ & $\begin{array}{l}0,03 \\
0,03 \\
0,06\end{array}$ & $\begin{array}{l}, 00 \\
, 00 \\
, 00\end{array}$ & $\begin{array}{l}, 67 \\
, 44 \\
44\end{array}$ \\
\hline $\begin{array}{llll}\% \text { of days worked in } & 20-30 \text { years } \\
& 31-40 \text { years } \\
\text { parallel } & & 41-65 \text { years }\end{array}$ & $\begin{array}{l}29 \\
15 \\
8\end{array}$ & $\begin{array}{l}0,68 \\
0,64 \\
0,52\end{array}$ & $\begin{array}{l}0,24 \\
0,22 \\
0,33\end{array}$ & $\begin{array}{l}0,04 \\
0,06 \\
0,12\end{array}$ & $\begin{array}{l}, 08 \\
, 20 \\
, 00\end{array}$ & $\begin{array}{l}1,00 \\
1,00 \\
1,00\end{array}$ \\
\hline 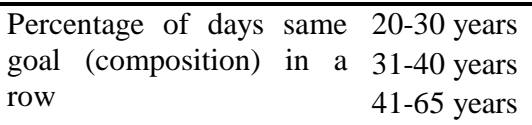 & $\begin{array}{l}29 \\
15 \\
8\end{array}$ & $\begin{array}{l}0,20 \\
0,16 \\
0,11\end{array}$ & $\begin{array}{l}0,14 \\
0,09 \\
0,06\end{array}$ & $\begin{array}{l}0,03 \\
0,02 \\
0,02\end{array}$ & $\begin{array}{l}, 05 \\
, 00 \\
, 05\end{array}$ & $\begin{array}{l}, 58 \\
, 37 \\
, 21\end{array}$ \\
\hline $\begin{array}{lll}\% \text { of days on which } & 20-30 \text { years } \\
\text { person switched goal(s) } & 31-40 \text { years } \\
& 41-65 \text { years }\end{array}$ & $\begin{array}{l}29 \\
15 \\
8\end{array}$ & $\begin{array}{l}0,11 \\
0,10 \\
0,17\end{array}$ & $\begin{array}{l}0,08 \\
0,08 \\
0,10\end{array}$ & $\begin{array}{l}0,01 \\
0,02 \\
0,03\end{array}$ & $\begin{array}{l}, 00 \\
, 00 \\
, 05\end{array}$ & $\begin{array}{l}, 26 \\
, 21 \\
, 32\end{array}$ \\
\hline
\end{tabular}

Table 10: Anova results for age and goal pursuit attributes

\begin{tabular}{|c|c|c|c|c|c|c|}
\hline & & \begin{tabular}{|ll}
$\begin{array}{l}\text { Sum } \\
\text { Squares }\end{array}$ & of \\
\end{tabular} & df & $\begin{array}{l}\text { Mean } \\
\text { Square }\end{array}$ & $\mathrm{F}$ & Sig \\
\hline $\begin{array}{l}\text { Average number of goals } \\
\text { per day a }\end{array}$ & $\begin{array}{l}\text { Between } \\
\text { Within } \\
\text { Overall }\end{array}$ & $\begin{array}{l}, 697 \\
11,001 \\
11,698\end{array}$ & $\begin{array}{l}2 \\
49 \\
51\end{array}$ & $\begin{array}{l}349 \\
, 225\end{array}$ & 1,553 &, 222 \\
\hline $\begin{array}{l}\text { Maximum number of } \\
\text { goals pursued per day }\end{array}$ & $\begin{array}{l}\text { Between } \\
\text { Within } \\
\text { Overall }\end{array}$ & $\begin{array}{l}7,192 \\
33,885 \\
41,077\end{array}$ & $\begin{array}{l}2 \\
49 \\
51\end{array}$ & $\begin{array}{l}3,596 \\
, 692\end{array}$ & 5,200 & ,009 \\
\hline $\begin{array}{l}\% \text { of days worked on a } \\
\text { single goal }\end{array}$ & $\begin{array}{l}\text { Between } \\
\text { Within } \\
\text { Overall }\end{array}$ & $\begin{array}{l}, 011 \\
1,087 \\
1,098 \\
\end{array}$ & $\begin{array}{l}2 \\
49 \\
51\end{array}$ & $\begin{array}{l}, 005 \\
, 022\end{array}$ & ,242 & ,786 \\
\hline $\begin{array}{l}\% \text { of days worked in } \\
\text { parallel }\end{array}$ & $\begin{array}{l}\text { Between } \\
\text { Within } \\
\text { Overall }\end{array}$ & $\begin{array}{l}, 148 \\
3,068 \\
3,215\end{array}$ & $\begin{array}{l}2 \\
49 \\
51\end{array}$ & $\begin{array}{l}, 074 \\
, 063\end{array}$ & 1,178 &, 316 \\
\hline $\begin{array}{l}\% \text { of days same goal } \\
\text { (composition) in a row }\end{array}$ & $\begin{array}{l}\text { Between } \\
\text { Within } \\
\text { Overall }\end{array}$ & $\begin{array}{l}, 053 \\
, 700 \\
, 753 \\
\end{array}$ & $\begin{array}{l}2 \\
49 \\
51 \\
\end{array}$ & $\begin{array}{l}027 \\
, 014\end{array}$ & 1,867 &, 165 \\
\hline $\begin{array}{l}\% \text { of days on which } \\
\text { person switched goal(s) }\end{array}$ & $\begin{array}{l}\text { Between } \\
\text { Within } \\
\text { Overall }\end{array}$ & $\begin{array}{l}, 030 \\
, 312 \\
, 342\end{array}$ & $\begin{array}{l}2 \\
49 \\
51\end{array}$ & $\begin{array}{l}015 \\
, 006\end{array}$ & 2,384 &, 103 \\
\hline
\end{tabular}




\section{Research question 3: What are the consequences of individual multiple goal pursuit?}

With regard to this research question we find the following results.

Level of completion and satisfaction with goals. Participants indicated at the end of the study how many goals they had accomplished and indicated how satisfied they are with all of their goals. Furthermore, they stated how satisfied they are with the quality, completeness and timeliness of their indicated goals. We used correlation analysis to explore the relationship between number of goals completed and satisfaction with goal pursuit attributes (see Table 11).

Table 11: Correlation analysis of goal pursuit attributes with number of goals completed and satisfaction of goal pursuit

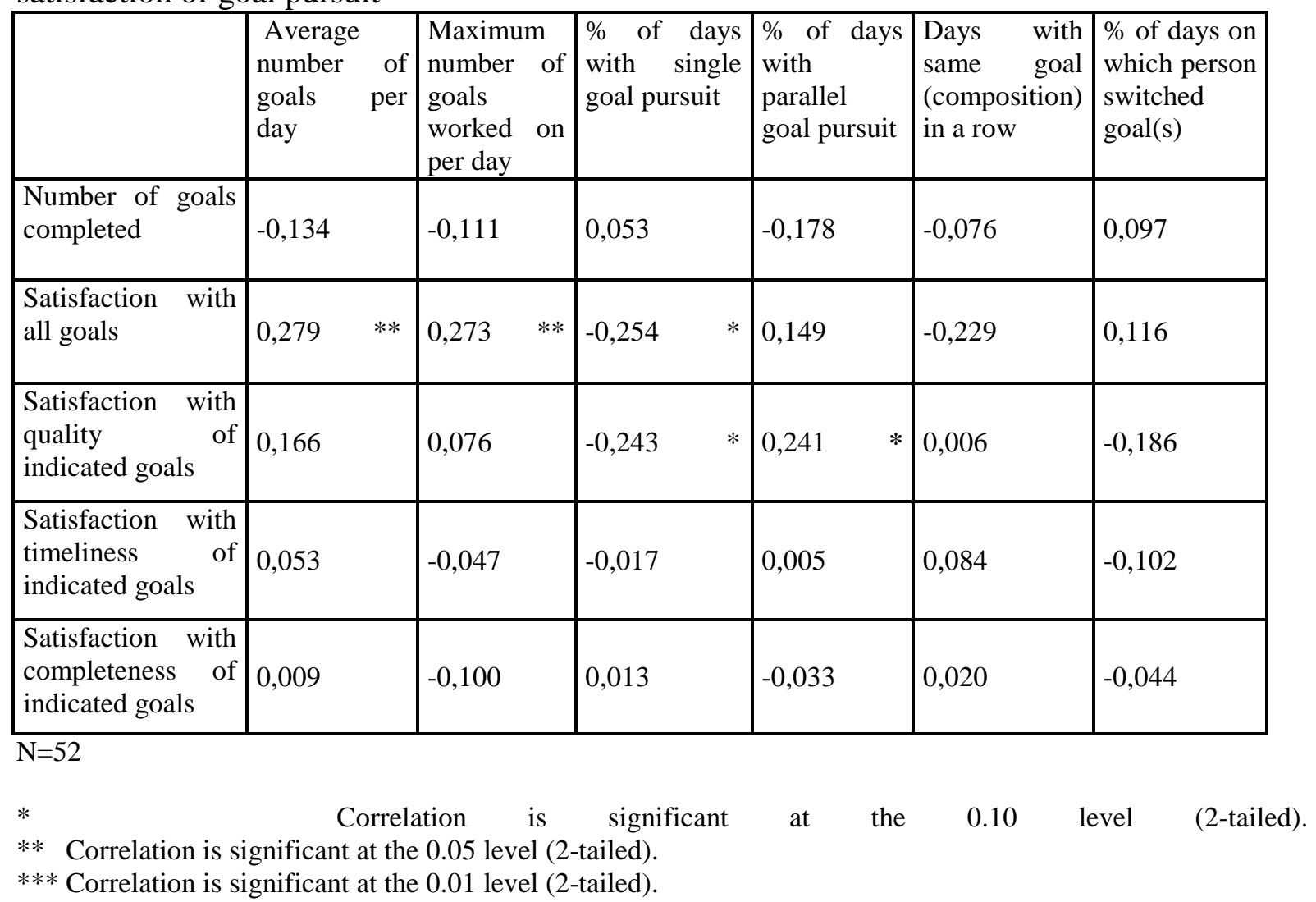


Somewhat remarkably, we did not find any relationship of the number of goals completed with the goal pursuit attributes. There is a slight tendency for days with parallel goal pursuit to be associated with fewer goals completed $(\mathrm{r}=-, 178)$. Overall satisfaction with all goals did relate to several attributes. It related positively with the average number of goals $(\mathrm{r}=, 279 ; p<.05)$ and the maximum number of goals worked upon $(\mathrm{r}=, 273 ; p<.05)$, and negatively with the number of days worked on one goal only $(\mathrm{r}=-, 254 ; p<.10)$. The relationship with working on the same goals is also negative, although not significant $(\mathrm{r}=-$ ,229). If a person keeps working on the same goal over a longer period of time the chance that other goals will be completed decreases.

Next, we looked at the satisfaction with respect to the quality, completeness and timeliness of goal achievement. We did not find any significant relationship of timeliness or completeness with goal pursuit attributes. However, contrary to expectations, the percentage of days worked on a single goal was significantly and negatively related to the perceived satisfaction with quality $(\mathrm{r}=-0,243 ; p<.10)$. We would have expected to find a positive relationship assuming that people are more satisfied with the quality of the goals if they spend more time on it exclusively. However, we asked participants to indicate their satisfaction concerning the quality of all five goals together and not for each goal individually. Thus, even if a person may be very satisfied with the quality of one goal the overall satisfaction with the quality of goals can be low. In line with this is the result that satisfaction with quality of all goals was positively related to the percentage of days a person worked on multiple goals in parallel $(\mathrm{r}=0,241 ; p<.10)$.

Besides examining the effect of goal pursuit attributes of individuals, we also explored if the membership of a certain cluster of goal pursuit predicts the outcomes. We depict the 
means and according ranges of each cluster for the outcome variables in Table 12 below. To see if there are differences in outcomes with respect to the five clusters defined we ran an analysis of variance (Table 13).

Table 12: Mean and range of each outcome variables per goal pursuit cluster

\begin{tabular}{|l|l|ll|l|l|ll|ll|l|l|}
\hline & $\mathrm{N}$ & \multicolumn{2}{|l|}{$\begin{array}{l}\text { Number of goals } \\
\text { completed }\end{array}$} & $\begin{array}{l}\text { Satisfaction } \\
\text { with all goals }\end{array}$ & \multicolumn{2}{l|}{$\begin{array}{l}\text { Satisfaction } \\
\text { with quality of } \\
\text { indicated goals }\end{array}$} & $\begin{array}{l}\text { Satisfaction with } \\
\text { timeliness of } \\
\text { indicated goals }\end{array}$ & $\begin{array}{l}\text { Satisfaction with } \\
\text { completeness of } \\
\text { indicated goals }\end{array}$ \\
\hline Cluster 1 & 11 &, 91 & $(0-3)$ & 4,00 & $(0-5)$ & 3,73 & $(3-5)$ & 2,91 & $(2-5)$ & 3,00 & $(2-5)$ \\
\hline Cluster 2 & 21 &, 71 & $(0-3)$ & 3,38 & $(2-4)$ & 3,90 & $(2-5)$ & 2,95 & $(1-4)$ & 2,90 & $(1-4)$ \\
\hline Cluster 3 & 4 &, 50 & $(0-1)$ & 4,00 & $(4)$ & 4,25 & $(4-5)$ & 3,00 & $(2-4)$ & 3,00 & $(2-4)$ \\
\hline Cluster 4 & 9 & 1,11 & $(0-2)$ & 3,56 & $(2-4)$ & 3,44 & $(2-4)$ & 2,89 & $(1-4)$ & 3,22 & $(2-4)$ \\
\hline Cluster 5 & 7 & 1,00 & $(0-3)$ & 3,86 & $(3-4)$ & 3,14 & $(2-4)$ & 2,43 & $(2-4)$ & 2,57 & $(2-3)$ \\
\hline
\end{tabular}

Table 13: Anova results for goal pursuit cluster and outcome variables

\begin{tabular}{|c|c|c|c|c|c|}
\hline & $\begin{array}{l}\text { Sum of } \\
\text { Squares }\end{array}$ & df & $\begin{array}{l}\text { Mean } \\
\text { Square }\end{array}$ & $\mathrm{F}$ & Sig. \\
\hline $\begin{array}{lll}\begin{array}{l}\text { Number of } \\
\text { completed }\end{array} & \text { goals } & \text { Between } \\
& & \text { Within } \\
& & \text { Overall }\end{array}$ & $\begin{array}{l}1,686 \\
39,084 \\
40,769\end{array}$ & $\begin{array}{l}4 \\
47 \\
51\end{array}$ & $\begin{array}{l}, 421 \\
, 832\end{array}$ & ,507 & ,731 \\
\hline $\begin{array}{lll}\text { Satisfaction with all } & \text { Between } \\
\text { goals } & & \text { Within } \\
& & \text { Overall }\end{array}$ & $\begin{array}{l}3,737 \\
20,032 \\
23,769\end{array}$ & $\begin{array}{l}4 \\
47 \\
51\end{array}$ & $\begin{array}{l}934 \\
, 426\end{array}$ & 2,192 & 084 \\
\hline 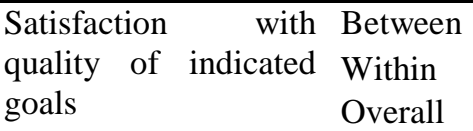 & $\begin{array}{l}4,852 \\
23,821 \\
28,673\end{array}$ & $\begin{array}{l}4 \\
47 \\
51\end{array}$ & $\begin{array}{l}1,213 \\
, 507\end{array}$ & 2,394 & ,064 \\
\hline $\begin{array}{lrl}\text { Satisfaction } & \text { with } & \text { Between } \\
\text { timeliness } & \text { of } & \text { Within } \\
\text { indicated goals } & & \text { Overall }\end{array}$ & $\begin{array}{l}1,593 \\
36,465 \\
38,058\end{array}$ & $\begin{array}{l}4 \\
47 \\
51\end{array}$ & $\begin{array}{l}, 398 \\
, 776\end{array}$ & ,513 & $\overline{7,726}$ \\
\hline $\begin{array}{lrl}\text { Satisfaction } & \text { with } & \text { Between } \\
\text { completeness } & \text { of } & \text { Within } \\
\text { indicated goals } & & \text { Overall }\end{array}$ & $\begin{array}{l}1,748 \\
39,079 \\
40,827\end{array}$ & $\begin{array}{l}4 \\
47 \\
51\end{array}$ & $\begin{array}{l}, 437 \\
, 831\end{array}$ & ,525 & 9718 \\
\hline
\end{tabular}

There were significant differences in terms of satisfaction with all goals $(F=2,19$ $(47,4) ; p<.10)$ and the satisfaction with the quality of the indicated goals $(\mathrm{F}=2,39(47,4) ; p<$ .10) with respect to the five different clusters. The mean values in Table 8.1 and a post-hoc analysis showed that the differences concerning the satisfaction with all goals are largest 
between cluster two compared to clusters one and three. While people in cluster one and three indicated on average a high degree of satisfaction with their goals (mean value 4) people in cluster two indicated a much lower score (mean value 3,38). The respective post-hoc tests showed significant levels of differences of $p<.05$ and $p<.10$ respectively.

Moreover, the goal pursuit clusters were significantly different with respect to the satisfaction of the quality of the indicated goals. While people in cluster three had a rather high score with respect to the satisfaction of the quality of the indicated goals (mean value of 4,25 ) people in cluster five were less satisfied (mean value 3,14). People of cluster three were characterized by a high degree of goals worked upon a certain day (average amount of goals per day was 2,34) while people of cluster five pursue on average 1,97 goals.

Control of time at work. In the literature review we addressed control of time and suggested that it can be viewed as a measure of the effectiveness of multiple goal pursuit. The results (see Table 14) do not show any relationship between any of the goal pursuit attributes and control of time.

Table 14: Correlation: Control of time \& multiple goal pursuit attributes

\begin{tabular}{|l|l|l|l|l|l|l|}
\hline & $\begin{array}{l}\text { Average } \\
\text { number of } \\
\text { goals per } \\
\text { day }\end{array}$ & $\begin{array}{l}\text { Maximum } \\
\text { amount of } \\
\text { goals } \\
\text { pursued per } \\
\text { day }\end{array}$ & $\begin{array}{l}\text { \% of days } \\
\text { with } \\
\text { single } \\
\text { goal } \\
\text { pursuit }\end{array}$ & $\begin{array}{l}\% \text { of days } \\
\text { worked in } \\
\text { parallel }\end{array}$ & $\begin{array}{l}\text { of days } \\
\text { worked of days } \\
\text { the same goal } \\
\text { (composition) }\end{array}$ & $\begin{array}{l}\text { on of } \\
\text { onhich } \\
\text { person } \\
\text { switched } \\
\text { goal(s) }\end{array}$ \\
\hline $\begin{array}{l}\text { Control of } \\
\text { time at work }\end{array}$ &,- 153 &,- 097 &, 195 &,- 190 &, 067 &,- 009 \\
\hline
\end{tabular}

$\mathrm{N}=52$ 


\section{DISCUSSION}

\section{Multiple goal pursuit over time}

This study started from a need to get a better understanding of multiple goal management in everyday work life. The data gathered with a self-kept diary with five randomly determined moments on a day on five work goals executed during a three-week period allows us to answer to answer the first research question: How do individual employees deal with their multiple work goals over time? All evidence presented shows that people typically pursue multiple goals in parallel and rarely opt for working on a single goal. It seems that people hardly have the "luxury" of working on one goal only, and if it occurs it is usually imited to a short period. The general pattern emerging from the goal pursuit trajectories is what has been described as an 'interleaving of actions' (Frisch, Förstl, Legler, Schöpe, \& Goebel, 2012). People are putting one task on hold to pursue another or to react to interruptions and changes in demands. They move back and forth between goals using the varying opportunities to bring each of them forward. This may not only happen among employees in academia, like those who participated in our study, but also among other professions, like e.g. management, consultancy, advertising, secretarial services, nursing, etc. If it is a more general phenomenon indeed, one wonders whether it is really a new phenomenon or something that already existed in earlier decades, and why it has received so little attention in motivation research. The discrepancy between the major motivation theories with their focus on single goals and the complexities of the multiple goal pursuit in real-life setting is truly amazing. The gap underlines the importance of studying the phenomenon of multiple goal-pursuit in naturalistic environments in order to learn more about the 
determinants and consequences of multiple goal pursuit, and to develop self-management strategies that help to foster good multiple goal performance.

We asked participants to indicate and describe five of their current work goals since we wanted to track their vicissitudes over time. However, we assumed that participants of the study would be pursuing more than five goals throughout the three-week period. Therefore, we also asked participants to indicate whether they had been adding additional work goals to their portfolios. The results were surprising: participants added more than five new goals on average during the measurement period, with a maximum of 29 goals! Besides, there were also many unforeseen activities (accounting for $36 \%$ of the daily working time, one average), more than in the sample of R\&D engineers studied by Claessens (2004). All this was accompanied by a substantial amount of rescheduling, apparent from the charts in Appendix A, which points at the interconnectedness of goal pursuit with other aspects of multiple goal management. Our aim of the study was to explore the way people work on multiple goals over time. The graphical examination revealed that although participants differed in their patterns, there was also a substantial amount of variation within participants. In an earlier paper we had heuristically introduced three "stylized" patterns of single, parallel, and overlapping goal pursuit (Kirchberg \& Roe, 2009). The results show that it is not easy to recognize these patterns in the graphs. The differences do exist but they are not consistent over time. Hence, we conclude that most employees vary in how they approach and work on their goals over time. We see for example some people pursuing the same single goal for a couple of days and later changing their working behavior to parallel goal pursuit with frequent switching between goals. The observed goal pursuit of people seems to vary along the chosen time frame. There are busy times at work (peak times or end of the year) with frequent interruptions and high amounts of unplanned tasks and there are more slow times at work 
(e.g. during vacation season or off season). The implication is that there is little room for stable personal characteristics to show up within the time frame of this study. For instance, it seems hard to reconcile the simple distinction between mono- and polychronicity (Bluedorn, 2002) with the complexities of multiple goal dynamics. The high degree of intrapersonal variability makes it difficult to cluster goal pursuit patterns into stable groups and to predict which people will be found in which group. This underlines the importance of studying the pursuit of multiple goals from a temporal instead of a differential perspective.

An interesting observation emerged from using different graphs to describe the multiple goal pursuit patterns. Each graph provided a different image of goal pursuit over time, highlighting different features. While the bar charts provide the most accurate data, the distributive area graph quickly shows the general pattern of how people have been working on their goals. The cumulative curve nicely demonstrates the concept of limited resources in terms of cognitive capabilities and attention (Wickens \& McCarley, 2008). It is nearly impossible to make progress on each goal simultaneously. Differences also reflected in the pattern attributes; e.g., in the maximum number of goals per day (ranging from 1 to 5).

Clustering the goal pursuit patterns on the basis of their attributes lead to five clusters that show different ways of working on the multiple goals over time: working on a single goal or a few goals, working on parallel goals with few or with many switches, working on a growing number of goals, and working in a highly dynamic way. The exact patterns in each cluster are nonetheless quite diverse. For instance, a person may pursue one goal per day and then move to multiple goals in parallel. This again indicates that multiple goal pursuit is much more dynamic than previously assumed. We do not know how the clusters will hold out over 
longer time spans, e.g., when the three-week period would be extended to four, five, or more weeks. This is clearly a matter for future research.

\section{Possible determinants of multiple goal pursuit}

With regard to the second research question "How do personal and environmental factors influence people's multiple goal pursuit over time?" our study shows that there are indeed some personality characteristics and preferences that differentiate forms of actual multiple goal pursuit. Using the separate goal pursuit attributes we found that highly conscientious employees engage more often in single goal pursuit and stuck more often to the same goal composition on consecutive days. In line with this, they also pursued a lower number of goals per day. This reflects the general tendency of conscientious people to be more precise and the need to do things accurately. In contrast, Extraversion did not significantly relate to any goal pursuit characteristic. This finding is rather surprising since extraversion has been linked to a variety-seeking (e.g., Hill, 1975) and some studies (e.g., Conte \& Gintoft, 2005; Conte \& Jacobs, 2003) found a positive link between polychronicity and extraversion, but we could not confirm this with the current sample as the two concepts were not significantly related.

Even though polychronicity theory puts forward that people have a certain preference of working on their goals and tasks either in parallel or sequentially (Bluedorn, 2002; also Stephens, Cho, \& Ballard, 2012), in a real work setting people frequently change how they pursue their goals. Even though we found a positive relationship between polychronicity and the average number of goals pursued this relationship was rather weak and will not allow to accurately predict actual behavior of people on a given day. Thus, some people may be more prone to engage in certain behavior due to their preferences, but polychronicity and 
monochronicity fail to accurately predict actual behavior. Adopting a temporal approach, with a focus on intraindividual change (Roe, 2013, forthcoming) will help understanding the dynamics of goal pursuit and may also clarify whether polychronicity itself is open to change.

In designing out study we wondered how people would deal with the lack of clarity about "good performance" in multiple goal situations, and how the trade-offs between dimensions of performance would affect their behavior. We postulated that they would have certain 'performance preferences', that is, preferences for goal quality, quantity and timeliness. We would have expected to find a positive relationship between e.g. the number of times people focus on a single goal and the preference to deliver good quality. However, people's preferences were not related to the way in which they worked on their multiple goals. This lack of relationship might be due to the fact that people are taking into account the whole goal portfolio. Even though a person might have a general preference for quality, this preference applies might not to be active for a specific goal. It is also conceivable that the assumed preferences are not stable over time and vary with the content of the goal portfolio. We must conclude that the existence of stable performance preferences has not been proven and the potential role of preferences deserves further study.

In addition to personality characteristics and performance preferences we explored if there is a relationship between pacing styles and the way people pursue multiple goals. Generally, pacing styles determine how we work on a single goal over time (Gevers et al., 2009). We found some significant relationship between the multiple goal pursuit attributes and the pacing styles. However, in retrospect it seems that the concept of pacing style is premised on the notion of a single goal and that its role in a multiple goal context is unclear. For instance, does a U-shaped pacing style mean that a person will start to work on all goals 
simultaneously in the beginning then stop working on them all together before resuming all goals? Since this is unlikely it would be interesting to see how the pacing styles of individual goal pursuit overlap with one another in a multiple goal setting as time unfolds. It is likely that a person with a shape pacing style starts working on goal one, then stops and starts working on goal two before resuming one and stop working on two (see Figure 8). We recommend looking at the effect of pacing styles in a multiple goal setting in future research.

Figure 8: Example of pacing styles in a multiple goal setting

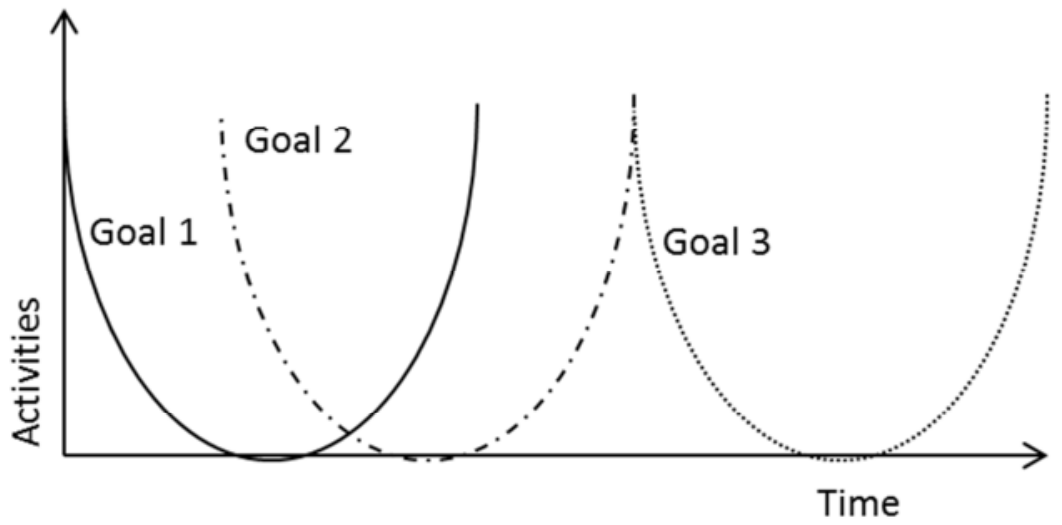

In designing our study we also considered the possible role goal characteristics, and we actually gathered data to ascertain their effect on, for example which goals get worked upon first and which ones are postponed or are not worked upon at all. The analysis of these rather extensive data is beyond the scope of this chapter. However, we suggest to address the effects of goal characteristics in future research since it is possible that goal attributes such as an urgent deadline or the importance of a goal determine the amount of time spent on it or influence its place in the overall goal pursuit pattern. Also, if a goal needs to be completed, for example the next two days a person is more likely to engage in single goal pursuit on that goal than in multiple goals. in order to reach completion. If goal characteristics determine our 
behavior we need to also tackle the question if the person is managing the goals over time choosing/setting goals and deciding what to work on when and for how long - or whether he is managed by the goals?

\section{Consequences of multiple goal pursuit patterns}

We explored the consequences of goal pursuit and answered the third research question: "Does people's performance effectiveness vary with the way in which they manage their multiple work goals over time?" Probably the most pertinent consequence was the number of goals completed after the three week period. We found that none of the goal pursuit attributes were significantly related to the number of goals completed. Thus, none of the pursuit patterns applied seems to have been superior in terms of number of goals accomplished. One reason for this insignificant relationship could be the fact that the specific goals may take longer to be completed than the time of the study.

We found a positive relationship between the satisfaction with all goals and the average number of goals pursued and the maximum amount of goals worked on per day. People tend to be more satisfied with their performance if they work on many goals and thus make progress on multiple goals. Applying the single goal pursuit bears the risk of only making progress on one goal while neglecting the other goals. If people switch too late to another goal they risk that the goal will not be accomplished within the given deadline or they produce lower quality. Thus, people need to find the right balance between concentrating on one goal and aiming at good results and at the same time not forgetting their other goals. Previous research focused on the outcome of single goals but we suggest that future research should look at the result of goal portfolios, as there are tradeoffs of working on one goal and not the other. 
In line with these results were the findings when predicting outcomes by means of the clusters. One reason for the limited predictive power of goal pursuit clusters on outcomes variable is the low number of people in each cluster. Cluster number four was only represented by four people (characterized by single goal pursuit). Another reason for the limited amount of predictive power is the finding that the clusters as such are not clear cut and sometimes show substantial within-variation.

Not much light was shed on how goal pursuit influences control of time. People who more often engage in single goal pursuit might have more sense of control of time, and there was a tendency into this direction. However, none of the other goal pursuit patterns revealed any relationship. It may be that control of time is more matter of correspondence between planned and actual activities, which we did not examine in this study. It is important to clarify its role since it may moderate other outcomes, such as stress or well-being.

In this exploratory study we included a limited amount of possible consequences of multiple goal pursuit patterns. We believe that future research should address more consequences of multiple goal pursuit, preferably with a focus on intra-individual effects. There needs to be congruence between goal pursuit and related consequences in time as they unfold in individual people. We suggest, for example, to look at the effect of certain changes in the pattern of multiple goal pursuit (possibly because of interruptions or accumulating work tasks) on changes in well-being or the level of stress. Previous research has mainly explored the inter-individual effect of polychronicity on well-being (Hecht \& Allen, 2005) and the effect of multitasking on the level of stress experienced (Robinson \& Smallman, 2006), but this line of research might well be complemented by studies looking at what happens over time at the individual level. 
A conceptual and methodlogical issue is that, unlike in the present study, the consequences emerging from multiple goal pursuit should also be studied over time. The number of goals achieved is always a number of goals achieved at a particular point in time, and the same is true for any other outcome. Acknowledging this implies that future research should opt for time series and temporal analysis (Roe, 2008).

\section{Limitations}

The distinctive features of our study's design can be seen as strengths and weaknesses at the same time. The participants were people in diverse jobs at an academic institution in the Netherlands, willing to participate in a rather time-intensive diary study, in a particular time episode. While being a useful source of information they are rather specific group in a specific corner of the labor market. We did not plan and we could not possibly generalize our findings to other professionals in other countries or to other time periods. We have argued that the multiplicity of goals and the high degree of dynamics may well apply to other professions, but this needs to be investigated.

Having a three-week period to study the unfolding of goal pursuit is an attractive and unique feature of our study, but we are well aware - and our data emphasize this - that results may be different if longer or shorter timeframes would be adopted. Again, this is something to investigate empirically in the future. Since the focus of this study was on describing and exploring patterns of goal pursuit, we opted for a limited range of antecedent and consequences. We have, e.g., not included psychological well-being and stress, although these would certainly deserve attention. In line with the prevailing custom among other researchers we have given priority to antecedents and consequences at the individual level and analyzed 
these differentially. Our findings make us believe that future research could profit from choosing a temporal rather than a differential perspective.

There are several other limitations, some of which relate to small but nonetheless important technicalities. For instance, aiming to capture peoples' self-defined working goals over time, we have asked participants to indicate and write down their goals. These are idiosyncratic which limits their comparability and it may have increased their commitment of reaching the goals. This issue was brought to out attention by participants who stated that they liked being part of the experiment since their "effectiveness" had been elevated. They indicated that being constantly reminded of their work goals had a positive effect of their working style - which suggests that the number of goals worked upon and the dynamics of pursuit might even be greater than we have found. Furthermore, the data obtained is based on self-reports thus there might be a common method bias, self-serving bias, and the wish to answer consistently. Although these are issues that can have an impact on differential analysis, particularly with variables that are measured at a single point in time, there is little evidence to suggest that this has indeed happened in our rather time-extensive design.

We should also note that some participants missed quite significant amounts of data entries, which might have affected the recorded goal pursuit variables. In other words, a person may have missed to enter the data due to pressure at work to complete many goals being totally absorbed in work. To counterbalance this effect as well as possible, we accounted for the days missed and the ratios were adapted accordingly. However, certainly this caused some variables to be skewed (e.g. average number of goals worked on). 


\section{Future research}

We believe that our study shows the need for further study of multiple goal pursuit over time. We have shown trajectories that, to our knowledge, have never been published before, and our descriptive and exploratory analyses have shown many questions that call for an answer. It is tempting to suggest that future research should study people in other occupations and work settings, and with other demographic characteristics. However, we feel that it would also be worthwhile to conduct further explorations with people from the same or similar population. Rather than zooming out and looking for generalization across jobs and people, we would suggest to zoom in on the time dimension and focus further research on the intra-individual dynamics in order to understand what drives the process of accepting new goals, rescheduling goals, and stopping, resuming, and prioritizing goal pursuit. In such an approach one would like to look beyond the goals per se and include the person's interactions with the organizational environment, in order to find the sources of motivational change that can explain the goal management process. Here, one might follow the logic of Atkinson and Birch (1970; also Revelle, 1989) that changing motives may affect the behavioral stream. Research might profit from acknowledging and examining the idiosyncratic, path-dependent nature of individual goal trajectories. Dropping the idea that people do the same kind of tasks and that their goal pursuit trajectories are essentially replications of the same process, researchers might accept that peoples' actual goal portfolios and the ways in which they carry out tasks over time, interacting with clients and colleagues, accommodating environmental events, and responding to the success and failure of the work process, are unique. Given a focus on a person's individual's goal pursuit, research might investigate alternative ways of managing multiple tasks with experimental methods, in order to find which options would give the best results. Nesting sets of alternative goal management options within a person's 
work trajectory over time, thus using $\mathrm{N}=1$ with a large number of successive observations, might be an alternative to the conventional approach of looking for variables that moderate people's work trajectories over time.

It is interesting to think of how such research could be designed and what methods it would require. One would minimally need to develop methods for visualizing goal management trajectories, building on our explorations of goal pursuit with different graphs. Ideally, one would find a method that would be informative and easy to understand, and that could be used in to depict ongoing goal management in a real-time manner, as to allow monitoring the process as it unfolds. While it would enable researchers to simultaneously collect information about possible determinants and consequences and build time-series to analyze their co-variation, there might also be opportunities for developing practical applications. We are thinking of using visualization and monitoring tools for selfmanagement, which might enhance the range of current time-management techniques, which are largely based on general principles derived from differential research. We are aware that all this will require a large research effort and that it may not immediately lead to useable results, but we feel that breaking away from the doctrine that research should be based on existing theory even in areas that were hardly ever charted and creating room for fresh theorizing, based on novel observations, description and exploration is worth trying and has the potential of producing new insights. 


\title{
CHAPTER 5
}

\section{POLYCHRONICITY AND MULTITASKING:}

\section{A DIARY STUDY AT WORK}

\begin{abstract}
Polychronicity and multitasking have been described as being indispensible in work today because they enable people to use their time flexibly and effectively. We conducted a diary study among 93 employees during the mornings and evenings of five consecutive workdays ( $n=418$ observations). The study used hierarchical linear modeling with polychronicity and other personal characteristics at the person level, and multitasking behavior along with multitasking opportunities, interruptions, and unplanned work as antecedents, and affective wellbeing and self-rated performance as outcomes at the day level. We found several relations between antecedents and multitasking as well as between multitasking and consequences. Polychronicity interacts with these relationships, such that polychronic individuals' affective wellbeing and self-rated performance are less affected on days with much multitasking compared to monochronic individuals.
\end{abstract}

The paper has been presented at the $15^{\text {th }}$ congress of the European Association of Work and Organizational Psychology in Maastricht, May 2011

The paper has been accepted for publication in the Journal of Human Performance (forthcoming February 2015) 


\section{INTRODUCTION}

The continuingly changing demands in today's interconnected workplaces, the concentration of multiple duties in the same jobs, and the growing emphasis on speed and flexibility have made multitasking a necessity in the work of many (Appelbaum, Marchionni, \& Fernandez, 2008). Current job descriptions often ask for multitasking ability. Regardless of the business area, a job search with the keyword "multitasking" as requirement reveals thousands of hits. Despite the trend of recruiting "super multitaskers", there has been surprisingly limited research on multitasking in everyday work settings. Previously, multitasking has been conceived as a cognitive ability or as a cognitive process and has mainly been studied in laboratory environments within very short time windows (seconds, minutes). Studies aiming to understand multitasking in everyday work-life are rather scarce, but they are highly needed because of the growing prevalence and significance of multitasking in organizations. As far as we are aware, this study is the first study to investigate multitasking in the workplace, looking at variations in multitasking across working days. Our aim is twofold: first, better understanding of multitasking, its personal and workplace antecedents and its consequences for performance and affective wellbeing; second, clarifying the role of polychronicity, people's preference for multitasking. We hope to advance both our theoretical understanding of multitasking and to extend this knowledge to practice.

Although polychronicity and multitasking are often seen as related, they are quite different phenomena (König \& Waller, 2010). Polychronicity is a stable individual difference variable that describes how people differ in their general preference for multitasking. Multitasking is a dynamic phenomenon, something which "happens" (Roe, 2008) as people perform two or more tasks simultaneously. Since differential (between-subjects) analyses are 
unable to provide information about dynamic phenomena, and temporal analyses (withinsubjects) do not provide information about differences between people (Molenaar, Huizenga, \& Nesselroade, 2003; Roe, 2013), we adopt a multi-level approach that allows studying “interindividual differences in intraindividual variation”, namely hierarchical linear modeling. This enables us to examine the dynamics of multitasking, along with antecedents and consequences, as it varies over subsequent workdays, and to determine whether there are differences in this variation between people with different degrees of polychronicity. That is, we examine whether polychronicity has a moderating effect on the relation between multitasking and outcomes on a daily basis. Thus, our study contributes to the literature in three ways: 1) we investigate multitasking in a workplace setting; 2) we focus on variations of multitasking across working days, and 3) we study polychronicity as a moderator of the relation between multitasking and its consequences.

\section{PERSPECTIVES ON MULTITASKING}

Multitasking can be defined as simultaneously carrying out two or more tasks within a certain period of time. The term originates from computer science, where it refers to handling parallel processes that require the same resources. Simultaneity does not mean that all resources are fully used and shared from the beginning till the end of the period. It is possible to work intermittently on overlapping tasks during the same period, switching from one to the other. Thus, task switching is inherent in multitasking, in computers as well as in people. Multitasking has been studied from different perspectives and in different contexts with differences in the scope of tasks and the period of time considered. Several studies have been conducted by selection psychologists, with the aim to identify job applicants who have the ability to carry out multiple tasks simultaneously (cf. Sanderson, Bruk-Lee, Viswesvaran, 
Gutierrez, \& Kantrowitz, 2013; van der Horst, Klehe, \& van Leeuwen, 2012). A present-day example is driving a car while navigating in an unknown city (Wu, Zhao, Lin, \& Lee, 2013). Cognitive and neuro-psychologists have studied multitasking from another angle, namely with a focus on mechanisms and processes involved in parallel cognitive activities, such as recognizing a visual or auditory pattern, retrieving memory content, choosing a motor response, or carrying out a tracking operation (e.g., Salvucci \& Taatgen, 2008). In both types of research the interest is in narrowly defined cognitive tasks presented in a controlled (assessment or laboratory) environment, and studied within limited time windows (rarely more than an hour) with units of milliseconds or seconds. Such research goes into great detail, measuring response times (in ms), error rates (Monsell, 2003), or brain functioning (Burgess, Veitch, de Lacy Costello, \& Shallice, 2000; Just, Carpenter, \& Miyake, 2003).

Following König and Waller (2010), we propose to study multitasking at the workplace, looking at the execution of work tasks within a broader time window. We define work tasks as goals to be accomplished in the context of a person's role in an organization. As for the time window, we propose to look at workdays in a workweek. It is important to note that the change of time window affects the meaning of simultaneity and multitasking, and can lead to different results (Roe, 2013, forthcoming; Zaheer, Albert, \& Zaheer, 1999). All tasks a person works on during certain parts of the day will be considered as happening simultaneously, and thus be captured by the term multitasking, regardless of the number of parts of the task being executed and their length. According to Pashler (2000), the frequent switching between multiple and different tasks is a substantial component of multitasking in work settings. In this study, we look at multitasking as varying from working on a single task per day (lower scale end) to working on many tasks throughout the day with frequent switching behavior between those tasks (higher scale end). 
Multitasking is often thought of as a differential variable, implying that when people are given the same tasks, some would finish one task before starting to work on a new task (low multitasking), while others would perform them in parallel (high multitasking). There is indirect evidence for such differences from a study that used a scale to inquire about typical behaviors within one a hour (König, Oberacher, \& Kleinmann, 2010). A possible ground for such differences could be people's general preference for a certain degree of multitasking, i.e., polychronicity. Little is known about the variability of multitasking over time. There are, to our knowledge, no studies that have conceived multitasking as a variable behavior over time and that studied it in a dynamic perspective. Considering the temporal footprint of work (Roe, 2013, forthcoming), that is, the way in which work activities unfold during the hours of the day, the days of the week etc., it is likely that multitasking fluctuates during the day and across days, just like is the case for performance (cf. Binnewies, Sonnentag, \& Mojza, 2009). This is the reason for us to study intra-individual differences in multitasking, as recommended by König et al. (2010).

\section{POLYCHRONICITY}

There is a considerable body of literature suggesting individual differences in the preference for multitasking, called polychronicity vs. monochronicity (e.g., Slocombe \& Bluedorn, 1999). Poposki and Oswald (2010) defined polychronicity as “an individual's preference for shifting attention among ongoing tasks, rather than focusing on one task until completion and then switching to another task" (p.9). Differential research has shown the importance of polychronicity in predicting job performance (Kantrowitz, Grelle, Beaty, \& Wolf, 2012). The moderating role of polychronicity in the (differential) relation between 
multitasking ability and performance at work has also been demonstrated (Sanderson et al., 2013).

Some researchers have treated the concepts polychronicity and multitasking as synonyms, assuming that a given level polychronicity implies a certain degree of multitasking (Bluedorn, 2002; Spink, Cole, \& Waller, 2008). Like König and Waller (2010) and Poposki and Oswald (2010), we challenge this assumption, because of the conceptual differences between the two notions. We think that the relationship between polychronicity as a stable preference and multitasking as a dynamic phenomenon needs to be explored empirically.

\section{CONCEPTUAL MODEL}

Since we assume that multitasking changes over time while polychronicity is supposed to be a stable individual characteristic, the conceptual model for our study, as presented in Figure 1, is composed of two levels.

Figure 1: Conceptual Model

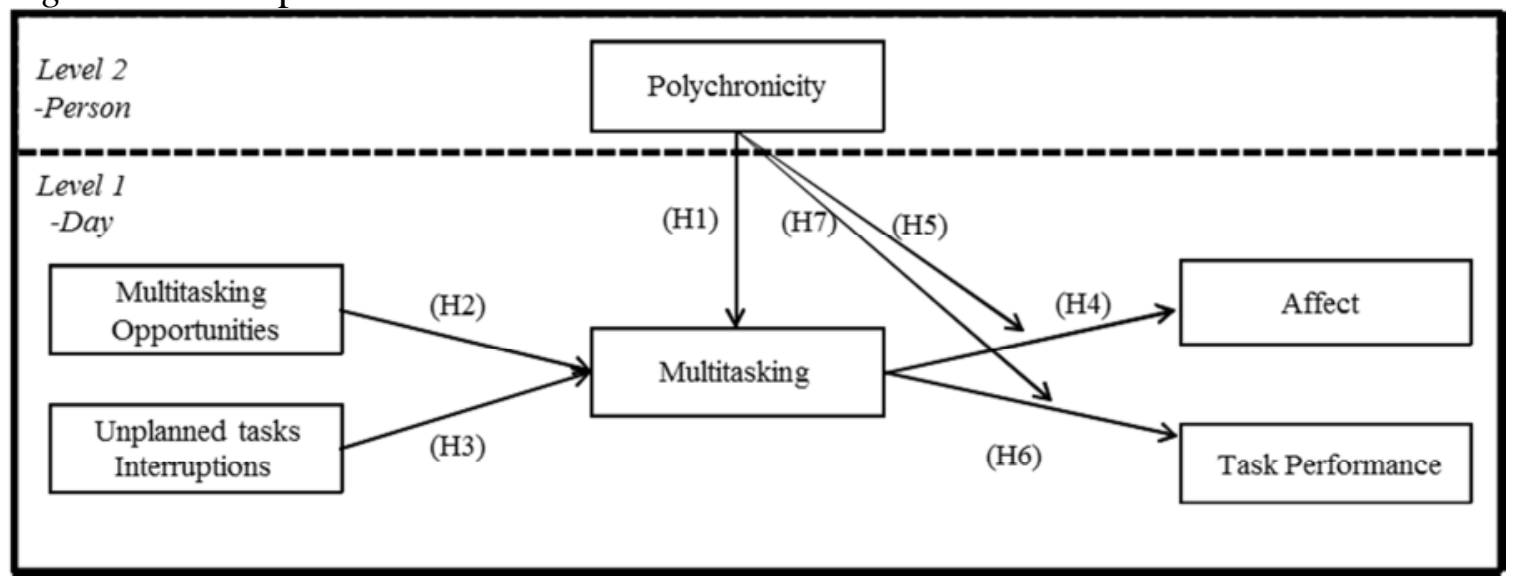

Level 1, the level of the day, comprises states and processes that are supposed to occur within each person across days. Level 2 is characterized by between-person differences in polychronicity and a number of control variables, namely gender, age, job autonomy, control of time, conscientiousness, and extraversion. We hypothesize that the degree of 
within-person change across days in multitasking depends on certain factors that can vary from day to day, i.e. multitasking opportunities and interruptions and unplanned tasks. In addition, we hypothesize that variations in multitasking will be related to variations in affective wellbeing and performance. As the model shows, we will also combine the person and day-level factors, postulating certain cross-level interactions, namely a moderating effect of polychronicity on the relationship between day-level multitasking and performance, as well as affective wellbeing, at the end of a working day.

\section{ANTECEDENTS OF MULTITASKING}

An increasing number of scholars have called for research addressing the dynamic nature of work-related phenomena by including time in theory and research designs (e.g., George \& Jones, 2000; Mitchell \& James, 2001; Roe, 2008). It is likely that variable circumstances will make people work in a particular way even though they may have a general preference to work on multiple goals in parallel or in a sequential manner (Kirchberg, Roe, \& Van Eerde, 2009). For example, an employee who is highly monochronic may find herself in a job, e.g., a secretarial job, where it is expected to engage in multiple tasks at the same time. While writing a document, the phone may ring, and an email may pop up that requires an immediate answer. Although the employee may prefer to finish the writing task first, she may feel a pressure to switch to picking up the phone and answer the email before returning to the original task. Thus, besides personal preferences for monochronic or polychronic working styles, external work conditions may influence the level of multitasking employees actually engage in.

Before elaborating on the role of these variable working conditions, we would like to state that polychronicity can still be seen as an antecedent of multitasking, in a differential 
sense. This is in line with findings by König et al. (2010) who in a cross-sectional study demonstrated that polychronicity is positively related to self-rated multitasking.

Hypothesis 1: People being high in polychronicity will show a higher average level of daily multitasking.

Thus, we do not assume that multitasking preference exclusively and always translates into the corresponding behavior as there are variations in external and internal demands across days. We put forward that multitasking varies across days, and that polychronicity is a person-level predictor of multitasking in general. Jobs such as receptionist or air traffic controller require the simultaneous execution of many tasks. However, multitasking behavior may vary due to variations in the opportunities for multitasking (e.g., actual variations in tasks) across working days. Also, many employees have a certain degree of job autonomy which allows them to decide how to work on their multiple goals - serially or in parallel.

Unlike previous research, which has assumed or at least implied that multitasking is a stable phenomenon we assume that multitasking varies over time. Not every working day is the same; as some working days are more hectic than others, they may expose the employee to conditions that vary in the room for multitasking. Such daily variations may lead to different degrees of multitasking behavior. Hecht and Allen (2005) studied the consequences of fit between individual polychronicity and 'polychronicity supplies' stemming from the job. Polychronicity supplies are defined as the opportunities to work on multiple tasks at once (Hecht \& Allen, 2005). We propose to simply use the term 'opportunities to multitask' to indicate the opportunities an employee is facing each working day. On days with many opportunities people may engage in multitasking because they have to or because they consider it useful (Kaufman-Scarborough \& Lindquist, 1999). Thus, we propose that daily 
multitasking will depend on daily changing multitasking opportunities stemming from the job - other things being equal, thus controlling for job autonomy and employees' perceived control of time.

Hypothesis 2. On days with many multitasking opportunities employees will engage more in multitasking than on days with few multitasking opportunities.

Further sources of multitasking can be interruptions and unplanned tasks encountered throughout the working day. Interruptions are defined as "incidents or occurrences that impede or delay organizational members as they attempt to make progress on work tasks" and are categorized into intrusions, breaks, distractions and discrepancies (Jett \& George, 2003, p. 494). Interruptions can be internal (self-initiated; e.g., a break) and external, which means that their occurrence is beyond the control of the employee (e.g., an intrusion). We propose that interruptions are likely to lead to more multitasking, as any onset of an activity that demands immediate attention causes a shift of attention from the focal task to a new one, and requires switching back at a later time (Eyrolle \& Cellier, 2000; Zijlstra, Roe, Leonova, \& Krediet, 1999). The more interruptions occur on a day, the more the employee may engage in multitasking, in response to the external needs or internal demands.

Employees are also frequently confronted with unplanned tasks during the work day which represent additional work to be done. In a diary study by Claessens, Van Eerde, Rutte, and Roe (2010), the average percentage of unplanned tasks employees worked on per day was about $15 \%$ with substantial variation. Employees are generally expected to carry out and complete these unplanned tasks. Following the same argument as above for interruptions, we expect that unplanned tasks also are likely to produce multitasking.

Hypothesis 3: On days with many interruptions and unplanned tasks, employees will engage more in multitasking than on days with few interruptions and unplanned tasks. 


\section{CONSEQUENCES OF MULTITASKING AND AFFECTIVE WELLBEING AFTER WORK}

Although the consequences of multitasking at work attract increasing attention, to our knowledge, no study investigated the relationship from a dynamic perspective. Yet, it is important to consider that multitasking can have negative effects. Experiments and differential studies suggest that multitasking can lead to a higher level of stress (Robinson \& Smallman, 2006), mood and anxiety problems (Becker, 2013), as well as irritation at the end of the working day (Baethge \& Rigotti, 2013), There are several reasons to expect such effects. The increased cognitive demands required by executing multiple tasks, and by task switching and resumption requires can lead to depletion of cognitive resources and produce negative emotions (Zijlstra et al., 1999). Besides these cognitive costs, people will realize that the time available for the remaining work is reduced, which in turn requires them to increase their work pace to finish essential tasks (Jett \& George, 2003). Moreover, the lack of predictability of task progress and of the tasks themselves may reduce people's perceived control of time, which can lead to stress and anxiety (Claessens, 2004; Macan, 1996). Considering these effects, which fit well into a conservation of resources framework (Hobfoll, 1989), we posit that multitasking is generally negatively related to perceived positive affective wellbeing after work.

Hypothesis 4: The more multitasking on a day, the lower affective wellbeing is experienced after work.

The effects of multitasking may not be the same for all people. Individuals who perceive their tasks as repetitive or who easily get bored may find satisfaction in changing work activity and managing the complexity associated with multitasking opportunities. Other employees rather wish to avoid such changes in their workplace or be unable to handle the 
juggling of multiple simultaneous tasks, experiencing decreased levels of affective wellbeing at the end of the working day. Hecht and Allen (2005) examined job-person fit in polychronicity and its relationship with wellbeing. They showed that there is a positive effect on wellbeing if an employee scores high on polychronicity and the job calls for multitasking. We expect the same for day-level multitasking. If polychronicity is high and the extent of day-level multitasking is also high, wellbeing is likely to be greater because there is a match between the allocation of resources that is preferred and actually needed. However, if an employee scores low on polychronicity, thus generally prefers not to engage in multitasking, but nevertheless needs to engage in multitasking, there will be a negative effect on affective wellbeing.

Hypothesis 5: Polychronicity moderates the relationship between day-level multitasking and affective wellbeing such that individuals low on polychronicity will experience lower wellbeing at the end of the work day than individuals high on polychronicity.

\section{DAY-LEVEL MULTITASKING AND PERFORMANCE}

Performance of employees varies across days for many reasons (e.g., Beal, Weiss, Barros, \& MacDermid, 2005; Roe, 1999, 2013, forthcoming). We propose that multitasking, as a facet of the way in which daily tasks unfold, is one of them. There are an increasing number of studies suggesting that multitasking is related to performance. While some studies point at positive effects of multitasking on performance, the preponderance of studies show negative relations between multitasking and performance. Positive effects are mainly due to progression on two or more tasks at the same time. However, these are constrained by cognitive resources required for executing the tasks (Wickens \& McCarley, 2008). It may be 
possible to read an email while talking on the phone, but it is not possible to get a presentation ready while preparing a travel expense report. As soon as task switching is required the time gain advantage disappears. Research on multitasking ability also seems to suggest that multitasking is positively related to performance, but the ability cannot be equated to actual multitasking behavior. It is rather an indication of fluid intelligence or other cognitive ability (Morgan et al., 2013; van der Horst et al., 2012).

In most cases negative effects of multitasking on performance have been found. Experimental studies found negative relationships with performance (Adler \& BenbunanFich, 2012, 2013; Buser \& Peter, 2012; Hodgetts \& Jones, 2006; Pashler, 2000), mainly attributed to performance decrements as a consequence of switching costs. Delbridge (2001) found that working on a single task or goal results in fewer errors and less time compared to working on multiple tasks or goals. There is also evidence showing negative performance impacts of interruptions, which are often implied in multitasking. For instance, Eyrolle and Cellier (2000) found that interruptions in work tasks increase the processing time of the focal task and increase the mean error rate. Similar results were obtained by Zijlstra et al. (1999). Research has shown that performance decrements can not only be explained by the cognitive costs of resuming the main task but also by prospective memory failure (Baethge \& Rigotti, 2013; Czerwinski, Horvitz, \& Wilhite, 2004; Dismukes, 2012; McDaniel \& Einstein, 2000): the person forgets what the next step to be executed is. This is particularly relevant in areas such as medicine and aviation. Crenshaw (2008), referring to aviation, dismisses multitasking as an effective way of working, arguing that it is generally damaging to work productivity. Depletion of resources during task switching, resulting in fatigue, offers an additional explanation for performance decline. This is likely to be the most salient part of performance 
on a daily basis. Thus, for daily time intervals, we put forward that multitasking generally lowers performance.

Hypothesis 6: The more multitasking on a day, the lower performance is.

Similar to our reasoning for Hypothesis 5, we expect that the negative effect of multitasking will be less in persons wirh high degrees of polychronicity. We derive our argument from the person-job fit literature (Kristof, 1996). Previous studies have shown that the fit between conditions favoring multitasking, i.e., demands or opportunities, and polychronicity is associated with job performance (Hecht \& Allen, 2005; Jansen \& KristofBrown, 2005). In other words, if the conditions are favorable for multitasking and people prefer working on multiple tasks simultaneously they will report higher performance. Yet, monochronic employees may choose not to multitask when confronted with such conditions. The moderating effect of polychronicity on the relation between multitasking ability and performance was also shown in a previous (differential) study (Sanderson et al., 2013). Thus, we state the following hypothesis:

Hypothesis 7. Polychronicity moderates the relationship between day-level multitasking and performance such that individuals low on polychronicity will perform less than individuals high on polychronicity.

\section{METHOD}

First, participants received a paper-based questionnaire. In this questionnaire we assessed participants' preferences, characteristics, and demographics. Next to the paper-based questionnaire we distributed handheld computers (palm tops z22) and asked participants to fill in daily questionnaires on these devices during their next working week. Attached to the questionnaire was a general invitation letter. The letter asked participants to fill in the paper- 
based questionnaire before starting the one week diary phase. We instructed the participants on how to use the handheld computers, either individually or in an group meeting. On Monday, people started the diary phase, which lasted for one work week (5 days of data collection). During the week, participants answered one questionnaire in the morning before starting to work and one after the work day was over. These daily questionnaires appeared on the screen of the handheld computers after a self-initiated start. Every participant obtained a one paging message on how to start the questionnaire to make sure that everyone was able to conduct the self-initiated start.

Participants were asked to note the identification number visible on their handheld computers on the general questionnaire for later matching. After the diary phase, participants put the paper questionnaire in an envelope and returned it to the researcher together with the handheld computers. The data were analyzed using hierarchical linear modeling.

\section{Sample}

The respondents were recruited through personal contacts to firms (12 in total), all located in Western Germany. The contact person of the respective firm provided us the opportunity to distribute questionnaires and handheld devices to other employees in the organization. Generally we met participants personally (individual or group meetings) and provided them with the paper based questionnaire. Among those who agreed to participate in the study we distributed palm tops. In total, we received 111 completed paper questionnaires. Missing data, incorrect diary entries (e.g., both questionnaires answered in the morning), and technical failure of the handheld devices (resulting of complete diary data loss in some cases), led to a reduced sample. The final sample consisted of 93 participants who had filled in the paper questionnaire and the daily diary. All questions were translated into German and back- 
translated, checked by bilingual speakers afterwards, and checked for understandability with five persons who were not involved in the study.

Participation was voluntary and no monetary or other reward was provided for study compliance. The participating employees were mostly (44\%) working for medium sized companies (100-499 employees) and had a full-time contract (83\%). Participants' work descriptions were quite diverse, with most people working in the following areas: accountancy and control (17\%), administration (14\%), and sales (12\%). Overall, 41 women participated and all age categories were represented (25\% younger than 30 and $15 \%$ older than 51 years). About $36 \%$ had a managing position and most people (39\%) had been employed in the company for 6-15 years.

\section{Questionnaire Measures at Person Level}

The measures included in the questionnaire assess preferences, personality traits, and demographic characteristics. Most of the questions of the questionnaire and the diary had to be answered on a five point Likert scale ranging from $1=$ strongly disagree to $5=$ strongly agree. Some questions used a frequency scale with anchors ranging from $1=$ almost never to $5=$ almost always. After participants agreed to participate in the study, they received the paper questionnaire and were asked to answer the questions before the start of the diary phase.

Polychronicity. This variable was measured with 14 items of a scale developed by Poposki and Oswald (2010). In contrast to previous scales of polychronicity, these authors emphasized that the preference for multitasking should be evaluated, not actual behavior. Moreover, they used the day-level as a time anchor reflecting our definition of multitasking. A sample item is: "I prefer to work on several projects in a day, rather than completing one project and then switching to another". The Cronbach's $\alpha$ was .84 . 
Conscientiousness and Extraversion. These variables were measured with 6 items each from the scale developed by Hendriks, Hofstee, and De Raad (1999). Since previous research had shown relations between personality characteristics such as conscientiousness and extraversion and polychronicity and related performance (Conte \& Gintoft, 2005; Poposki \& Oswald, 2010), we included these constructs as control variables. Exemplary items are "I like to follow a regular schedule" for conscientiousness and "I keep apart from others (reverse coded)" for extraversion. Both scales showed low reliabilities with Cronbach's $\alpha$ of .58 and .56 respectively. Deleting the items "I slap people on the back" and "I laugh aloud", which are socially less-desirable in Germany, were deleted from the extraversion scale leading to an improved Cronbach's $\alpha$ of .74. The reliability result also reflects the low factor loadings these two items originally had when the scale was developed (Hendriks et al., 1999). Deleting items from the conscientiousness scale did not improve its reliability, and the scale was not changed.

Control of time. This variable was measured with an adapted and extended version of a scale originally used by Macan (1994) and later further developed by Claessens, Van Eerde, Rutte, and Roe (2004). The five items are: 'I feel in control of my time' 'I find it difficult to keep to my schedule' (reverse coded) 'I feel that I have my work under control' 'I feel confident in that I am able to complete my work on time,' and 'I often have little control of what is happening at work.' Cronbach's $\alpha$ was .70 . Since individuals with more control of time are more likely to follow their preference and those with less control of time could not, we used control of time as a control variable.

Job autonomy. This variable was measured with 9 items taken from the job autonomy scale developed by Morgeson and Humphrey (2006). Originally, the scale was composed of three different factors, namely work scheduling autonomy, decision- making autonomy, and 
work methods autonomy. Exemplary items are "The job allows me to make my own decisions about how to schedule my work" or "The job allows me to make a lot of decisions on my own". The scale was highly reliable (Cronbach's $\alpha=.93$ ). Similar to control of time, we controlled for job autonomy to rule out the effect of being able to organize the work day and because we conducted the study within different firms and across diverse hierarchical levels and jobs.

Demographics. These included age and gender, measured in categories and on a dichotomous scale respectively. We control for the demographic factors age and gender, because these may be related to performance. For instance, an experiment showed that multitasking performance decreased with higher age as cognitive processing efficiency declines (Salthouse, Hambrick, Lukas, \& Dell, 1996). Moreover, we can investigate popular assumptions about gender, multitasking, and performance claiming that women are more prone to multitask than men.

\section{Diary Measures}

On the day-level we collected data concerning the antecedents and multitasking as well as on performance and affect. In total, 93 participants participated, providing 480 observations over the days. However, as previously mentioned, there was some loss of data since participants filled only the morning or the evening questionnaire. As a result we had 418 observations with complete general, morning, and evening questionnaires.

Multitasking opportunities. This variable was measured with four items in the morning. The items were taken from a scale measuring polychronicity supplies defined as opportunities for polychronic time use at work (Hecht \& Allen, 2005). We took four items of the original scale and rephrased them to reflect multitasking opportunities at the level of the day. An exemplary item is "Today, I have to spend a little bit of time on several tasks - 
moving back and forth from one thing to the other". Cronbach's $\alpha$ ranged between .70 and .78 across the five days.

Interruptions and unplanned tasks. Both variables were measured with a single item at the end of the work day to keep the questionnaire manageable. The extent of unplanned tasks was measured with the item "There were many unplanned tasks today" and the extent of interruptions with the item "Today, I was interrupted a lot".

Multitasking. This variable was assessed in the evening after work. We rephrased the four items from König et al.'s (2010) general multitasking scale to capture daily variations in multitasking. The items were "Today I worked on many tasks simultaneously" "Today I worked on more than one task," "Today I worked on tasks in a sequential manner', (reverse coded), and "Today I accomplished several tasks simultaneously.' The Cronbach's $\alpha$ across the five days ranged between .89 and .92 .

Affective wellbeing. We measured affective well-being with 10 adjectives representing five mood dimensions, namely anxiety-comfort, depression-pleasure, boredenthusiastic, tiredness-vigour and angry-placid (Daniels, 2000). For each dimension one negatively valenced and one positively valenced item was used. One example is "At the moment I feel tired" and "At the moment I feel active". Affective wellbeing was measured before and after the work day with the same scale. Cronbach's $\alpha$ for affective wellbeing in the morning ranged between .88 and .92 and for affective wellbeing in the evening between .83 and .93 .

Performance. We measured this variable after work with four items drawn from the scale developed by Roe, Zinovieva, Dienes, and Horn (2000), adapted to refer to the performance on the specific day. This instrument has also been used in other diary research (Binnewies, Sonnentag, \& Mojza, 2010). The items provide an indirect measure of 
performance that captures a person's appraisal of his/her performance in comparison with others with similar tasks. The items are: "Compared to the standards I got good results from my work today", "I think I deserve a very good evaluation by my boss today", "My performance today is not as good as required" (reverse coded), "There were no or few complaints about the quality of my work today". The item "today there were no or only a few complaints about my work" was deleted from the scale which improved the reliability of the scale significantly. Without this item, Cronbach's $\alpha$ ranged between .78 and .89 .

\section{RESULTS}

We used hierarchical linear modeling with observations on the day-level variables nested within persons (Raudenbush \& Bryk, 2002). Table 1 shows the means, standard deviations and zero-order correlations of all day-level and person-level variables. To correlate multilevel data, we aggregated the day-level data to the person-level.

Day-level predictors were centered around the person mean and person-level predictors were centered around the grand mean. To assess whether multilevel data analysis was appropriate we conducted one-way analyses of variance with random effects null models (Table 2). The percentage attributable to within-person variability ranged between $51 \%$ and 69\%. This substantial within-person variation allows for analyzing the data at the daily level using hierarchical linear modeling. 
Table 1: Means, Standard Deviations, and Zero-Order Correlations

\begin{tabular}{|c|c|c|c|c|c|c|c|c|c|c|c|c|c|c|c|c|c|}
\hline & Variable & M & $\mathrm{SD}$ & 1 & 2 & 3 & 4 & 5 & 6 & 7 & 8 & 9 & 10 & 11 & 12 & 13 & 14 \\
\hline 1 & Multitasking supplies & 3,04 & 0,82 & - & $.494 * * *$ & $.180 * * *$ & $.581 * * *$ & $.719 * * *$ & .017 & -.062 & .004 & & & & & & \\
\hline 2 & Extent of interruptions & 2,89 & 1,08 & $.582 * * *$ & - & $.662 * * *$ & $.450 * * *$ & $.656^{* * *}$ & -.050 & $-.152 * *$ & -.061 & & & & & & \\
\hline 3 & Extent of unplanned tasks & 2,78 & 1,08 & $.577 * * *$ & $.774 * * *$ & - & $.462 * *$ & $.604 * * *$ & -.040 & $.188^{* * *}$ & -.065 & & & & & & \\
\hline 4 & Number of goals to do & 6.00 & 2,51 & $.643^{* * *}$ & $.510 * * *$ & $.554 * * *$ & - & $.564 * * *$ & .084 & $\begin{array}{l}.013 \\
-\end{array}$ & $.151^{* *}$ & & & & & & \\
\hline 5 & Daily Multitasking & 3,23 & 0,99 & $.856^{* * *}$ & $.762 * * *$ & $.703 * * *$ & $.627 * * *$ & - & -.027 & $.183^{* * *}$ & $-.093 *$ & & & & & & \\
\hline 6 & Affect in the morning & 3,86 & 0,7 & $.276^{* *}$ & .046 & .112 & $.236 *$ & $.227 * *$ & - & $.602 * * *$ & $.404 * * *$ & & & & & & \\
\hline 7 & Affect in the evening & 3,64 & 0.80 & .062 & -.101 & -.106 & .138 & .009 & $.654 * * *$ & - & $.519 * * *$ & & & & & & \\
\hline 8 & Daily Task performance & 4.02 & 0.72 & $.206^{* *}$ & .033 & .113 & $.317 * *$ & .107 & $.378 * * *$ & $.466^{* * *}$ & - & & & & & & \\
\hline 9 & Job Autonomy & 3.75 & 0.80 & .096 & -.069 & -.118 & .050 & -.001 & .199 & .122 & .134 & - & & & & & \\
\hline 10 & Polychronicity & 2.78 & 0.55 & $.428 * * *$ & .150 & .108 & $.301 * *$ & $.380 * * *$ & .200 & $.267 * *$ & .109 & .172 & - & & & & \\
\hline 11 & Conscientiousness & 3.67 & 0.49 & -.065 & -.119 & -.009 & .112 & -.040 & .162 & -.053 & $.207 *$ & -.048 & $.282 * *$ & - & & & \\
\hline 12 & Extraversion & 3.69 & 0.68 & .053 & .155 & .136 & .126 & .166 & .001 & .160 & -.060 & -.179 & -.085 & -.023 & - & & \\
\hline 13 & Control of time at work & 3.75 & 0.47 & -.133 & $-.224 *$ & -.053 & .064 & -.145 & $.220^{*}$ & .188 & $.350 * * *$ & $.207^{*}$ & $-.199 *$ & $.624 * * *$ & .111 & - & \\
\hline 14 & Age & 2.33 & 1.01 & .051 & .025 & -.039 & .008 & .051 & $.293 * *$ & 0,12 & .064 & $.311 * * *$ & .102 & $.245^{*}$ & -.183 & .144 & - \\
\hline 15 & Gender & 1.44 & 0.5 & .001 & .072 & -.027 & -.037 & -.045 & -.048 & -.021 & -.029 & $-.263 * *$ & -.111 & .145 & .024 & .057 & -.068 \\
\hline
\end{tabular}

Note. Correlations below the diagonal are person-level correlations $(\mathrm{n}=93)$. Correlations above the diagonal are day-level correlations $(\mathrm{n}=418)$. 
Table 2: Variance component of Null Models for Day-level Variables

\begin{tabular}{llcr}
\hline \multicolumn{1}{c}{ Variable } & $\begin{array}{c}\text { Day-level } \\
\text { variance }\end{array}$ & $\begin{array}{c}\text { Person- } \\
\text { level } \\
\text { variance }\end{array}$ & $\begin{array}{c}\text { \% variability } \\
\text { within person }\end{array}$ \\
\hline $\begin{array}{l}\text { Multitasking opportunities } \\
\text { Extent of interruptions during work }\end{array}$ & 0.346 & 0.318 & $52.11 \%$ \\
$\begin{array}{l}\text { Extent of unplanned tasks during } \\
\text { work }\end{array}$ & 0.671 & 0.497 & $57.46 \%$ \\
Multitasking & 0.799 & 0.358 & $69.05 \%$ \\
Affect in the evening & 0.586 & 0.390 & $60.05 \%$ \\
Task performance & 0.399 & 0.236 & $62.83 \%$ \\
& 0.327 & 0.246 & $57.09 \%$ \\
\hline
\end{tabular}

\section{Hypotheses Testing}

In total, we estimated four nested multilevel models to predict each of the dependent variables. First, we calculated the respective null models with no predictors and only the dependent variables, for multitasking, affective wellbeing, and performance. For each dependent variable some additional models were calculated and compared. In the first models we entered person-level control variables, namely age, gender, job autonomy, control of time at work, conscientiousness, and extraversion. In the second set of models, we added the person-level predictor polychronicity. In the third set of models, we included the day-level predictors. In the fourth set of models we added the moderating effect of polychronicity, represented by the cross-level interaction term of polychronicity and multitasking. This allows us to asses how polychronicity moderates the within-person change in multitasking and its within-person relationships with wellbeing and performance. We tested the predicted improvement of models by means of a chi-square distribution with degrees of freedom equal to the number of parameters added to the model.

Person predictors of multitasking. Table 3 displays the results with estimates, standard errors, and t-values for all variables entered into the models. In Model 1, we entered 
gender, age, job autonomy, control of time, conscientiousness, and extraversion as control variables. Control of time showed a significant negative effect on multitasking $(\gamma=-0.443, S E$ $=0.222, t=-1.996, p<.05)$ and extraversion was positively related to day-level multitasking $(\gamma=0.242, S E=0.118, t=2.052, p<.05)$. The demographic control variables were not related to daily multitasking. The null model showed a better fit than Model 1. Thus, adding control variables to the model did not increase the variance explained in multitasking. In Model 2, we added the person level predictor polychronicity, explaining a significant amount of variance over Model 1 (difference of $-2 * \log =10.534, d f=1, p<.001$ ). Polychronicity was significantly and positively related to day-level multitasking $(\gamma=0.529, S E=0.134, t=3.962$, $p<.001)$. Thus, Hypothesis 1 stating that individuals who have higher polychronicity engage more in multitasking is supported by the data.

Daily predictors of multitasking. In model 3, we added multitasking opportunities, interruptions, and unplanned tasks. We included random effects for level 1 and 2 in all models. Multitasking opportunities showed a positive relation to day-level multitasking $(\gamma=$ $0.330, \mathrm{SE}=0.073, \mathrm{t}=4.516, p<.001)$.

Therefore, Hypothesis 2, stating that daily multitasking opportunities increase the likelihood of the behavior, was supported. Moreover, Hypothesis 3, predicting that interruptions $(\gamma=0.186, S E=0.051, t=3.663, p<.001)$ and unplanned tasks $(\gamma=0.278, S E=$ $0.047, t=5.913, p<.001)$ during the day are positively related to multitasking, was supported. Overall, Model 3 that included all day-level predictors of multitasking was significantly better than Model 2 (difference of $-2 * \log =253.408, d f=1, p<.001$ ). Thus, daily changing opportunities to multitask and the extent of unplanned tasks and interruptions during the day are significantly related to daily multitasking, in addition to the person-level variables. 
Table 3: Multilevel Estimates for Models Predicting day-level multitasking

\begin{tabular}{|c|c|c|c|c|c|c|c|c|c|c|c|c|}
\hline \multirow[b]{2}{*}{ Variable } & \multicolumn{3}{|c|}{ Null Model } & \multicolumn{3}{|c|}{ Model 1} & \multicolumn{3}{|c|}{$\underline{\text { Model } 2}$} & \multicolumn{3}{|c|}{ Model 3} \\
\hline & Estimate & SE & $\mathrm{t}$ & Estimate & SE & $\mathrm{t}$ & Estimate & SE & $\mathrm{t}$ & Estimate & SE & $\mathrm{t}$ \\
\hline Intercept & 3.232 & 0.075 & 42.964 & 3.232 & 0.075 & 43.317 & 3.233 & 0.069 & 46.870 & 3.233 & 0.068 & 47.592 \\
\hline Gender & & & & -0.037 & 0.160 & -0.23 & -0.031 & 0.148 & -0.211 & -0.091 & 0.124 & -0.735 \\
\hline Age & & & & 0.054 & 0.082 & 0.657 & 0.024 & 0.077 & 0.311 & 0.042 & 0.064 & 0.657 \\
\hline Job autonomy & & & & 0.080 & 0.114 & 0.701 & 0.021 & 0.106 & 0.194 & 0.009 & 0.090 & 0.099 \\
\hline Control of time at work & & & & -0.443 & 0.222 & $-1.996 *$ & -0.405 & 0.205 & -1.969 & -0.227 & 0.176 & -1.285 \\
\hline Conscientiousness & & & & 0.210 & 0.214 & 0.983 & 0.359 & 0.201 & 1.787 & 0.244 & 0.169 & 1.449 \\
\hline Extraversion & & & & 0.242 & 0.118 & $2.052^{*}$ & 0.236 & 0.109 & $2.161^{*}$ & 0.261 & 0.093 & $2.796 * *$ \\
\hline Polychronicity & & & & & & & 0.529 & 0.134 & $3.962 * * *$ & 0.516 & 0.113 & $4.559 * * *$ \\
\hline Multitasking opportunities & & & & & & & & & & 0.330 & 0.073 & $4.516^{* * *}$ \\
\hline Unplanned tasks & & & & & & & & & & 0.278 & 0.047 & $5.913 * * *$ \\
\hline Interruptions & & & & & & & & & & 0.186 & 0.051 & $3.663^{* * *}$ \\
\hline$-2 \times \log$ & & & 1090.5334 & & & 1096.6680 & & & 1086.1345 & & & 832.7265 \\
\hline Diff $-2 \times \log$ & & & & & & -6.1346 & & & $10.5335^{* *}$ & & & $253.408 * * *$ \\
\hline df & & & & & & 6 & & & 1 & & & 2 \\
\hline $\begin{array}{l}\text { Level 1: intercept } \\
\text { variance (SE) }\end{array}$ & & 0.5858 & $(0.7654)$ & & 0.5861 & $(0.7656)$ & & 0.5858 & $(0.7654)$ & & 0.2059 & $(0.6169)$ \\
\hline $\begin{array}{l}\text { Level 2: intercept } \\
\text { variance (SE) }\end{array}$ & & 0.3898 & $(0.6243)$ & & 0.3812 & $(0.6174)$ & & 0.3066 & $(0.5537)$ & & 0.3806 & $(0.4538)$ \\
\hline
\end{tabular}

Note. ${ }^{*} \mathrm{p}<.05, * * \mathrm{p}<.01, * * * \mathrm{p}<.001$. 
Multitasking and affective wellbeing. Hypothesis 4 predicts a negative relationship between day-level multitasking and affective wellbeing in the evening. Again, we calculated sets of models (see Table 4). In the first model, gender, age, job autonomy, control of time at work, conscientiousness, and extraversion were included as control variables. Only control of time at work was positively related to affective wellbeing in the evening $(\gamma=0.381, S E=$ $0.172, t=2.218, p<.05)$ and conscientiousness was negatively related to it $(\gamma=-0.347, \mathrm{SE}=$ $0.165, \mathrm{t}=-2.099, p<.05)$. In Model 2, we entered polychronicity. It was significantly and positively related to affective wellbeing in the evening $(\gamma=0.272, S E=0.109, t=2.506, p$ $<.01$ ), but adding this variable did not improve the variance explained in comparison to the previous model (difference of $-2 * \log =1.678, d f=1, n . s$. ). To test Hypothesis 4 , we entered day-level multitasking. As predicted, day-level multitasking was negatively related to affective wellbeing in the evening $(\gamma=-0.181, S E=0.062, t=-2.923, p<.01)$ and Model 3 was significantly better than Model 2 (difference of $-2 * \log =152.981, d f=1, p<.001$ ). In Model 4, we tested the moderating effect of polychronicity on the relationship between multitasking on affect, as proposed in Hypothesis 5. Although the interaction effect $(\gamma=$ $0.272, \mathrm{SE}=0.105, t=2.588, p<.01)$, day-level multitasking $(\gamma=-0.159, \mathrm{SE}=0.060, t=-$ 2.658, $p<.01)$, and polychronicity $(\gamma=0.275, \mathrm{SE}=0.107, t=2.57, p<.01)$ were significant predictors of affective wellbeing in the evening, there was no significant improvement between Model 3 and Model 4 (difference of $-2 * \log =1.70, d f=1$, n.s.). The moderating effect is depicted in Figure 2. While there is almost no difference in affective wellbeing in the evening if day-level multitasking is low, affective wellbeing is considerably lower if polychronicity is low and day-level multitasking is high. 
Table 4: Multilevel Estimates for Models Predicting Affective Well-being in the Evening

\begin{tabular}{|c|c|c|c|c|c|c|c|c|c|c|c|c|c|c|c|}
\hline \multirow[b]{2}{*}{ Variable } & \multicolumn{3}{|c|}{ Null Model } & \multicolumn{3}{|c|}{ Model 1} & \multicolumn{3}{|c|}{ Model 2} & \multicolumn{3}{|c|}{ Model 3} & \multicolumn{3}{|c|}{ Model 4} \\
\hline & Estimate & SE & $\mathrm{t}$ & Estimate & SE & $\mathrm{t}$ & Estimate & SE & $\mathrm{t}$ & Estimate & SE & $\mathrm{t}$ & Estimate & SE & $\mathrm{t}$ \\
\hline Intercept & 3.646 & 0.059 & 61.330 & 3.376 & 0.237 & 14.228 & 3.408 & 0.231 & 14.781 & 3.385 & 0.215 & 15.774 & 3.390 & 0.214 & 15.807 \\
\hline Gender & & & & 0.038 & 0.124 & 0.309 & 0.041 & 0.120 & 0.343 & 0.032 & 0.112 & 0.287 & 0.026 & 0.112 & 0.229 \\
\hline Age & & & & 0.092 & 0.064 & 1.442 & 0.077 & 0.062 & 1.235 & 0.092 & 0.057 & 1.601 & 0.094 & 0.057 & 1.639 \\
\hline Job autonomy & & & & 0.015 & 0.088 & 0.175 & -0.016 & 0.086 & -0.186 & -0.056 & 0.080 & -0.703 & -0.063 & 0.080 & -0.785 \\
\hline $\begin{array}{l}\text { Control of time at } \\
\text { work }\end{array}$ & & & & 0.381 & 0.172 & $2.218^{*}$ & 0.402 & 0.167 & $2.405^{*}$ & 0.383 & 0.156 & $2.458^{*}$ & 0.382 & 0.156 & $2.446^{*}$ \\
\hline Conscientiousness & & & & -0.347 & 0.165 & $-2.099 *$ & -0.272 & 0.163 & -1.666 & -0.269 & 0.152 & -1.767 & -0.269 & 0.152 & -1.765 \\
\hline Extraversion & & & & 0.130 & 0.092 & 1.418 & 0.126 & 0.089 & 1.423 & 0.129 & 0.083 & 1.556 & 0.124 & 0.083 & 1.494 \\
\hline $\begin{array}{l}\text { Polychronicity } \\
\text { Day level }\end{array}$ & & & & & & & 0.272 & 0.109 & $2.506^{* *}$ & 0.187 & 0.101 & 1.858 & 0.275 & 0.107 & $2.57 * *$ \\
\hline Multitasking & & & & & & & & & & -0.181 & 0.062 & $-2.923^{* *}$ & -0.159 & 0.060 & $-2.658 * *$ \\
\hline $\begin{array}{l}\text { Polychronicity X } \\
\text { Day level } \\
\text { Multitasking }\end{array}$ & & & & & & & & & & & & & 0.272 & 0.105 & $2.588^{* *}$ \\
\hline$-2 \times \log$ & & & 922.546 & & & 927.597 & & & 925.919 & & & 772.938 & & & 771.237 \\
\hline Diff - $2 \times \log$ & & & & & & -5.051 & & & 1.678 & & & $152.981 * * *$ & & & 1.701 \\
\hline df & & & & & & 6 & & & 1 & & & 1 & & & 1 \\
\hline $\begin{array}{l}\text { Level 1: intercept } \\
\text { variance (SE) }\end{array}$ & & 0.3990 & $(0.6317)$ & & 0.3986 & $(0.6313)$ & & 0.3987 & $(0.6314)$ & & 0.2107 & $(0.4590)$ & & 0.2118 & $(0.4603)$ \\
\hline $\begin{array}{l}\text { Level 2: intercept } \\
\text { variance (SE) }\end{array}$ & & 0.2360 & $(0.4858)$ & & 0.2182 & $(0.4671)$ & & 0.2002 & $(0.4474)$ & & 0.2402 & $(0.4901)$ & & 0.2383 & $(0.4882)$ \\
\hline
\end{tabular}

Note. ${ }^{*} \mathrm{p}<.05, * * \mathrm{p}<.01, * * * \mathrm{p}<.001$. 
Figure 2: Interaction between polychronicity and multitasking for affect in the evening

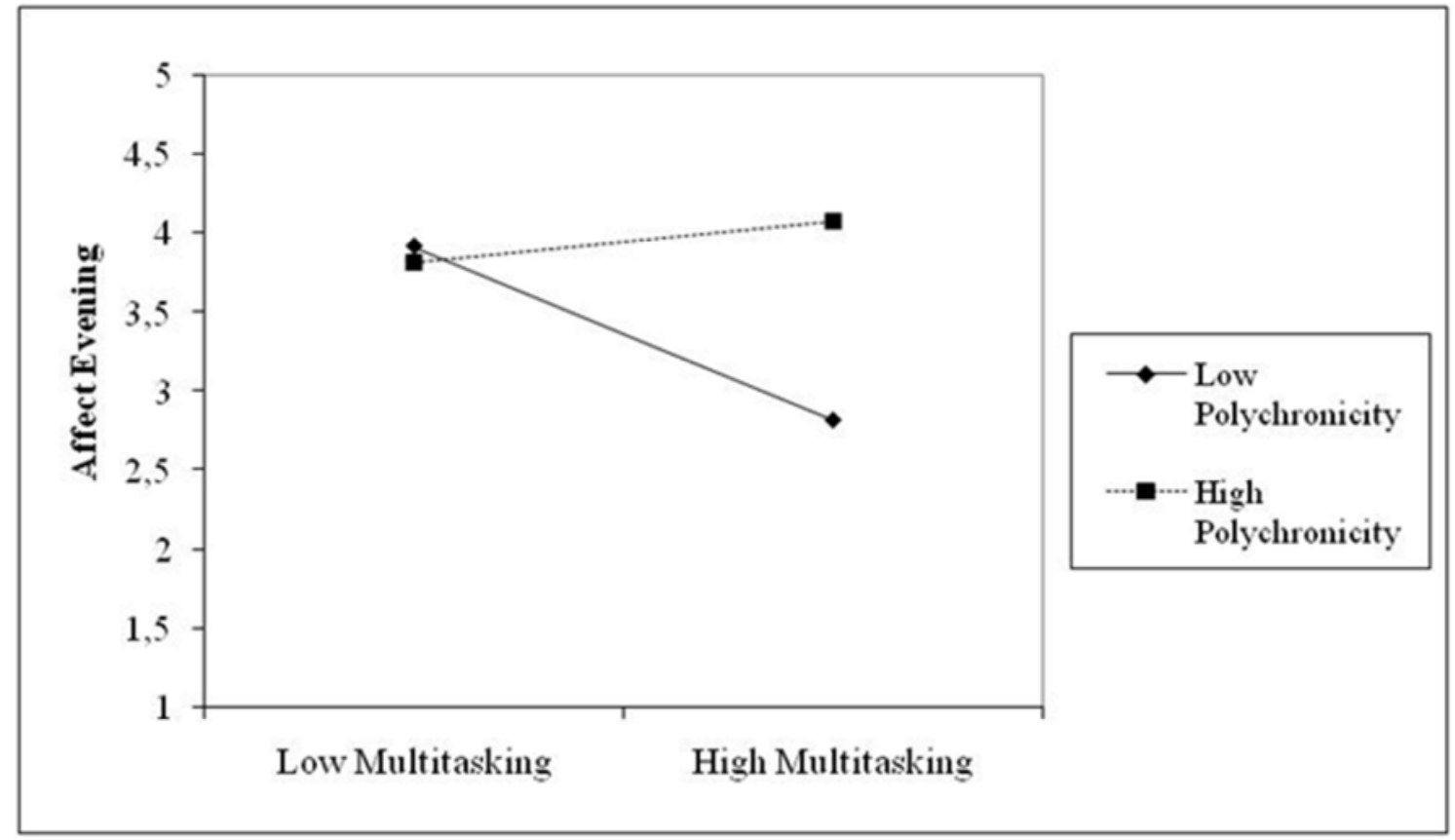

Multitasking and performance. Hypothesis 6 states that there is a negative effect of day-level multitasking on performance. Again, we calculated four models to assess the effect of multitasking on performance (see Table 5). The control variables that we entered in Model 1 were non-significant, except control of time $(\gamma=0.535, S E=0.167, t=3.197, p<.01)$. In Model 2, we added polychronicity that was significantly and positively related to performance $(\gamma=0.268, S E=0.105, t=2.541, p<.01)$. However, Model 2 was not significantly better than Model 1. When we added multitasking in Model 3 there was a significant improvement (difference of $-2 * \log =146.326, d f=1, p<.001$ ). Multitasking was negatively related to performance supporting hypothesis 6 . Next, we tested whether polychronicity moderated the relationship between multitasking and performance. Model 4 shows that multitasking $(\gamma=$ 0.111, $S E=0.052, t=-2.129, p<.05)$, polychronicity $(\gamma=0.243, S E=0.104, t=3.197, p$ $<.05)$ and their interaction $(\gamma=0.361, S E=0.091, t=3.950, p<.001)$ were all significantly related to performance in the hypothesized direction. 
Table 5: Multilevel Estimates for Models Predicting Task Performance

\begin{tabular}{|c|c|c|c|c|c|c|c|c|c|c|c|c|c|c|c|}
\hline \multirow[b]{2}{*}{ Variable } & \multicolumn{3}{|c|}{$\underline{\text { Null Model }}$} & \multicolumn{3}{|c|}{ Model 1} & \multicolumn{3}{|c|}{ Model 2} & \multicolumn{3}{|c|}{ Model 3} & \multicolumn{3}{|c|}{ Model 4} \\
\hline & Estimate & SE & $\mathrm{t}$ & Estimate & SE & $\mathrm{t}$ & Estimate & SE & $\mathrm{t}$ & Estimate & SE & $\mathrm{t}$ & Estimate & SE & $\mathrm{t}$ \\
\hline Intercept & 3.998 & 0.059 & 67.968 & 4.042 & 0.231 & 17.506 & 4.076 & 0.224 & 18.194 & 4.029 & 0.218 & 18.524 & 4.034 & 0.215 & 18.752 \\
\hline Gender & & & & -0.021 & 0.120 & -0.175 & -0.020 & 0.117 & -0.167 & -0.003 & 0.113 & -0.028 & -0.015 & 0.112 & -0.13 \\
\hline Age & & & & -0.006 & 0.062 & -0.1 & -0.021 & 0.060 & -0.353 & -0.012 & 0.058 & -0.197 & -0.006 & 0.058 & -0.111 \\
\hline Job autonomy & & & & -0.021 & 0.086 & -0.24 & -0.051 & 0.084 & -0.612 & -0.039 & 0.081 & -0.477 & -0.044 & 0.080 & -0.551 \\
\hline $\begin{array}{l}\text { Control of time at } \\
\text { work }\end{array}$ & & & & 0.535 & 0.167 & $3.197 * *$ & 0.556 & 0.162 & $3.426 * * *$ & 0.559 & 0.158 & $3.538 * * *$ & 0.556 & 0.156 & $3.556 * * *$ \\
\hline Conscientiousness & & & & -0.111 & 0.161 & -0.689 & -0.036 & 0.159 & -0.229 & -0.089 & 0.154 & -0.58 & -0.099 & 0.153 & -0.647 \\
\hline Extraversion & & & & -0.117 & 0.089 & -1.318 & -0.121 & 0.086 & -1.4 & -0.120 & 0.084 & -1.435 & -0.126 & 0.083 & -1.519 \\
\hline Polychronicity & & & & & & & 0.268 & 0.105 & $2.541 * *$ & 0.169 & 0.102 & 1.654 & 0.243 & 0.104 & $2.33^{*}$ \\
\hline Day level Multitasking & & & & & & & & & & -0.137 & 0.057 & $-2.4^{* *}$ & -0.111 & 0.052 & $-2.129 *$ \\
\hline $\begin{array}{l}\text { Polychronicity X } \\
\text { Day level } \\
\text { Multitasking }\end{array}$ & & & & & & & & & & & & & 0.361 & 0.091 & $3.95 * * *$ \\
\hline$-2 \times \log$ & & & 855.318 & & & 857.705 & & & 855.931 & & & 709.605 & & & 700.921 \\
\hline Diff $-2 \times \log$ & & & & & & -2.387 & & & 1.774 & & & $146.326^{* * *}$ & & & $8.684^{* *}$ \\
\hline df & & & & & & 6 & & & 1 & & & 1 & & & 1 \\
\hline $\begin{array}{l}\text { Level 1: intercept } \\
\text { variance (SE) }\end{array}$ & & 0.3265 & $(0.5714)$ & & 0.3263 & $(0.5712)$ & & 0.3264 & $(0.5714)$ & & 0.1716 & $(0.4142)$ & & 0.1736 & $(0.4166)$ \\
\hline $\begin{array}{l}\text { Level 2: intercept } \\
\text { variance (SE) }\end{array}$ & & 0.2456 & $(0.4955)$ & & 0.2182 & $(0.4671)$ & & 0.2001 & $(0.4473)$ & & 0.2337 & $(0.4834)$ & & 0.2316 & $(0.4812)$ \\
\hline
\end{tabular}

Note. ${ }^{*} \mathrm{p}<.05, * * \mathrm{p}<.01, * * * \mathrm{p}<.001$. 
Model 4 was significantly better than Model 3 (difference of $-2 * \log =8.684, d f=1, p$ <.01). As depicted in Figure 3, performance was highest when multitasking and polychronicity were low. The worst performance was related to high multitasking and low polychronicity. Thus, we found support for the moderating effect of polychronicity on the within-person relationship between multitasking and performance as stated in Hypothesis 7.

Figure 3: Interaction between polychronicity and multitasking for performance

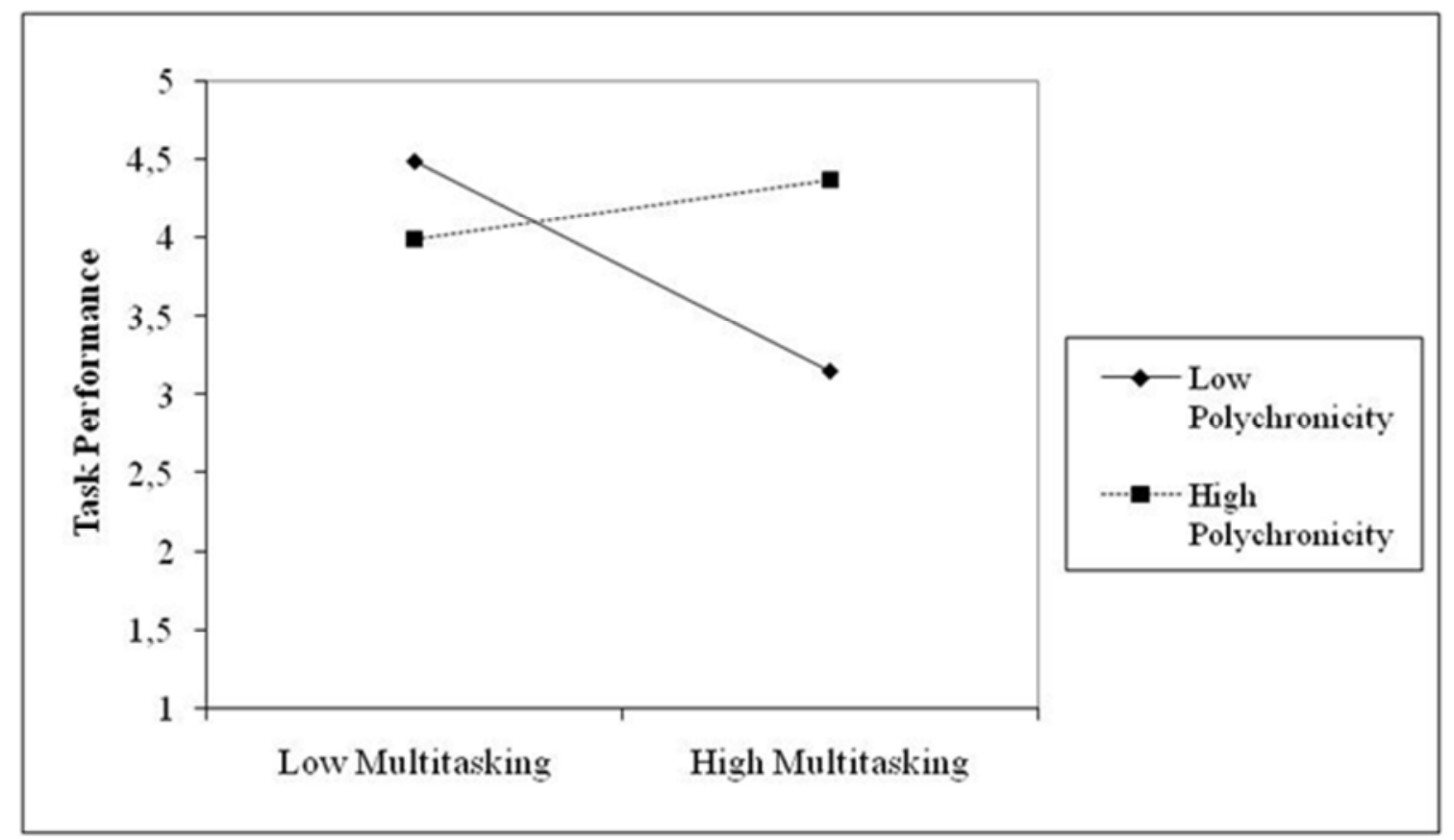

Person-level control variables. The control variables age and gender were not significant predictors in any of the models that we ran. Thus, we cannot support the popular assumption that there are gender differences in multitasking. Furthermore, there were no significant differences between men and women in polychronicity $(F(1,100)=1.256, p=$ $.265)$. 


\section{DISCUSSION}

Generally, the data supported our hypotheses. There was considerable variation of multitasking across the days, showing the difference between multitasking as a dynamic phenomenon that occurs within persons. We showed that people engage in multitasking for different reasons, although the degree of multitasking also reflects polychronicity, i.e. the preference for multitasking. As Poposki and Oswald (2010) have argued, work requirements and personality can influence polychronicity as well as multitasking. Our results show that multitasking opportunities, interruptions, and unplanned tasks predicted multitasking. This suggests that the degree of multitasking is determined by the external demands, interruptions and unplanned tasks inherent in the actual work setting. In the specific context investigated in our study the daily work demands explained more variance in multitasking than the level of polychronicity. Notwithstanding the commonly assumed positive effects associated with multitasking, our study shows that multitasking goes together with lower perceived performance and with lower affective wellbeing, particularly when the preference for multitasking is low. The results bear a number of theoretical and practical implications.

\section{Theoretical Implications}

In the past, polychronicity has sometimes been equated to multitasking, a practice that has been criticized on conceptual grounds (König \& Waller, 2010; Poposki \& Oswald, 2010). Our empirical analysis confirms the position of these authors that polychronicity is related but not identical to multitasking. As a personal characteristic, polychronicity is conceived to be stable over time, but multitasking changes from day to day. These changes do not seem incidental; they show a linear trend over the days of the week, which is congruent with trends in antecedents and consequences. 
An interesting finding from our study is that the consequences are on average negative, that is, on days with more multitasking lower wellbeing and performance were observed. This is in line with the observation that multitasking can impair affect, increase stress, and lower performance (Langfred \& Moye, 2004; Offer \& Schneider, 2011), and runs against the general belief that multitasking leads to better performance and makes work more attractive, since it adds to variety, autonomy and flexibility. We propose four reasons for these seemingly contradicting results.

First, former studies have often examined multitasking from a differential instead of a temporal angle, and produced evidence about between-person relationships that is irrelevant for within-person relations over time (Molenaar et al., 2003). Second, many studies of multitasking have been done in university laboratories and examined cognitive tasks lasting minutes rather than real work tasks lasting hours. We measured workers' multitasking and the consequences with regard to work tasks at the level of the workday. Third, there are some studies of multitasking at the workplace that have treated the construct as an ability or a typical behavior that characterizes individuals and shows little or no change over time. Our results indicate substantial variation within persons over time. This suggests that future research should not assume that multitasking is stable, but should rather investigate variations across days, and should determine to which degree the differences are compatible with the notion of multitasking ability. Fourth, some studies took polychronicity as a proxy of actual multitasking, which can also result in contradicting findings.

It is clear from our study that the degree of multitasking shown by a person at a certain moment depends on both external demands of that moment and a general personal preference. Employees who are confronted with many interruptions and unplanned tasks, are normally expected to respond to them in one way or another, and multitasking is one of the 
ways they can opt for. Thus, carrying out parts of the tasks simultaneously and switching inbetween to make optimal use of personal and workplace resources is a means to deal with disruptive factors that are beyond people's control. Opportunities for multitasking or interruptions cannot be equated to multitasking itself, though. Employees may engage in multitasking even when they are not required to do so because of external demands. There is an aspect of volition in multitasking that is indirectly addressed in this article by showing the moderating effect of polychronicity. However, further attention should be paid to voluntary versus required multitasking (Spink et al., 2008), and the different effect that they might have on wellbeing or performance.

\section{Practical Implications}

Considering variable work demands, the need for flexibility, and high work pace at the contemporary workplace, a certain degree of multitasking is inevitable - multitasking is not only a matter of choice, but also of necessity. However, there are limits to what can be done within a certain period of time. This is even so in the domain of computing from which the concept 'multitasking' originated: simultaneous processing of tasks by a computer is only possible to a limited extent and scheduling is needed to execute all tasks properly. If there are too many simultaneous processes, programs may jam due to limited storage and the computer may crash. Humans have limited capacities as well and cannot process too many tasks simultaneously (Wickens \& McCarley, 2008). As the human brains struggles to process multiple tasks in parallel, there are negative effects on work results as well as on wellbeing. Thus, employees who are confronted with multiple tasks and goals need to engage in scheduling, prioritizing, postponing, and decision making to avoid negative consequences on work performance and individual affective outcomes. 
Interruptions are antecedents of multitasking in that they force employees to stop working on their focal task. Resuming work after an interruption carries cognitive costs in that employees need to reorient themselves (Mark, Gonzalez, \& Harris, 2005; Zijlstra et al., 1999). When many interruptions occur during the workday, the cognitive costs accumulate, which can lead to overload, making employees lose track of the state of tasks. Simply put, employees end up asking themselves "where was I?". To limit this source of multitasking and its related negative consequences, management should decrease unwanted interruptions where possible.

The negative relation of daily multitasking with affective wellbeing and daily performance stands in sharp contrast to the positive connotation generally associated with multitasking in the business world. Thus, managers should be careful asking employees to engage in high levels of multitasking as this could actually backfire, particularly if employees are monochronic. Our results show that people who are highly polychronic do not suffer from multitasking as much as people having a preference for monochronic working. Thus, employers should recruit employees with high polychronicity for jobs in which multitasking is essential.

Polychronicity has been treated as a general and stable preference of people. In contrast to this assumption, König and Waller (2010) argue by means of cognitive dissonance theory (Festinger, 1957) that polychronicity can change over time to match the multitasking demands stemming from the work environment. In other words, employees may "learn to love" multitasking if they are constantly confronted with high levels of multitasking opportunities. If polychronicity can change due to external demands, this could mean that the detrimental effects of multitasking could be lessened. In one study, polychronicity was found to significantly change over time ( $\mathrm{Li}$, Waller, \& Roe, 2008). However, the scale used was 
partly reflecting activities and not just preferences. Thus, more research is needed to establish whether polychronicity may change over time and at what rate.

Britton and Tesser (1991) state that people can use multitasking as a time management tool in handling multiple task demands. Along the same line, others have argued that multitasking can be a coping behavior to handle work load in groups (Waller, Conte, Gibson, \& Carpenter, 2001). This does not imply that multitasking will have positive rather than negative effects, but rather that employees could learn how to minimizing the negative impacts. Future research on time management training could look into multitasking strategies in addition to gaining more control over disruptive factors at work such as unplanned tasks and interruptions - which would reduce the need for multitasking. It would also be worth examining the effects of training employees to refrain from multitasking, if not indispensable. There might well be a positive effect on affective wellbeing in the evening and performance at work. Previous studies found that time management training increases job satisfaction, control of time at work, health and decreases procrastination at work, worry and stress (Claessens, Van Eerde, Rutte, \& Roe, 2007; Van Eerde, 2003). Time management was positively related to supervisors' ratings of employee performance (Macan, 1996).

\section{Limitations}

A strength but also a limitation of this study is its temporal scope. We have looked at multitasking as happening in single working days using measurements from five consecutive days. This gives an insight into multitasking that was lacking from previous studies, but it does not show the occurrence and effects of multitasking over longer time spans. It is well conceivable that variable degrees of multitasking - with highs and lows over many days - or high levels of multitasking over extended periods of time would have different effects on performance and wellbeing. Research with different time windows, from hours to months, 
may improve our understanding of multitasking and may clarify when multitasking has positive or negative outcomes. A second limitation is that our HLM analyses assume the trajectories of multitasking, as well as antecedents and outcomes to be linear. Although this is a common assumption in longitudinal research using HLM, it may well be that changes are not linear and that upward and downward variations occur, particularly if longer time frames are considered. This is also something to be addressed in future research. A third limitation is that polychronicity has been assumed to be stable. Although this is in line with the theory as advanced by Slocombe and Bluedorn (1999) there are indications that polychronicity is open to changes over time. Thus it would be worth investigating in a multilevel design that uses days (or other episodes) nested within persons.

A fourth limitation has to do with the generalizability of our findings. We have studied subjects in a variety of (white collar) jobs in Germany in the year 2010, that is, within a particular work ecology bounded in time and space. Within these general limits we recruited participants from different organizations with diverse job descriptions, to make sure that our findings would not be limited to a specific type of work. In addition, we controlled for managerial position, age, gender, tenure, and job characteristics such as job autonomy to disentangle the effects that diverse types of work might have on multitasking, as well as on associated antecedents and outcomes. We are aware that not all types of work will necessarily show negative effects of multitasking on affective wellbeing and performance. For instance, it has been shown that for creative tasks, breaks may be beneficial to avoid impasses (Beeftink, van Eerde, \& Rutte, 2008), which suggests that the resumption of tasks may sometimes be beneficial as new ideas emerge and a fresh look is taken at the focal task. Even if the relationships identified in our study would appear among employees in other jobs, in similar work environments, we would not claim that they would extend to work in other (e.g., more 
dynamic) ecologies, and that they would continue to hold in later periods. We hope that our study, which was the first to address multitasking at the level of the workday across a single workweek, will inspire other researchers to conduct similar research. This would give a better insight in multitasking and make clear which aspects of our findings are generalizable or not.

A final issue is that our data are based on self-report and stem from the same source, which makes them vulnerable to common-source bias. Polychronicity and affective wellbeing are subjective phenomena that would be hard to assess via other sources than self-report. For measuring performance one would generally prefer objective measures or supervisor ratings, although the latter have their own limitations. In this study, where people in different jobs and organizations are involved, and each fulfills a unique set of tasks that unfolds over time in a completely idiosyncratic manner, neither objective measures nor supervisor ratings could possibly be obtained. Therefore, we adopted a method that is based on self-report but asks the person to compare with general performance expectations at the workplace (Roe et al., 2000). To counteract possible bias in self-assessments, we guaranteed participants confidentiality, used short questions, and included reversed coded items in the scales. Moreover, we used person mean centering for day-level variables and measured the constructs at two different points in time to reduce common method bias (Podsakoff, MacKenzie, Lee, \& Podsakoff, 2003).

\section{CONCLUSION}

In this study we investigated multitasking and related it to polychronicity, which both seem indispensible at the modern workplace. We have demonstrated that multitasking is related to but also different from polychronicity. While polychronicity is a preference, multitasking is a behavior that changes at the day level depending on opportunities, interruptions and unplanned tasks at work. 
Our findings show that across working days a greater degree of multitasking is associated with less affective wellbeing in the evening and lower self-rated performance. These results are in line with findings from cognitive psychology showing switching costs, such as higher error rates and increased response time. However, our study relates to multitasking as a behavior observable during the days people spend at the workplace work and not only in microseconds in the laboratory. Polychronicity seems to "absorb" the negative consequences of multitasking on performance and affective wellbeing to a large extent. Therefore, employers relying on multitasking should consider employees' polychronicity in order to prevent lower performance and negative affective wellbeing. This might be of special importance as negative affective wellbeing may have a cumulative impact on performance over time. The high demands on self-regulation and cognitive resources needed to multitask on a daily basis may lead to burnout symptoms, reduced job satisfaction, lowered commitment, and this may result in worsened performance. 


\section{CHAPTER 6}

\section{CONCLUSIONS \& RECOMMENDATIONS}

\section{WHERE WE ARE TODAY}

The aim of this dissertation was to develop a better understanding of a widespread but little investigated phenomenon, multiple goal management. The review of the pertinent literature on work motivation, presented in Chapter 2, shows a gradual change in the nature of work motivation theory over time with an increasing interest in goals and self-regulation. While the theoretical work and empirical research on goal-related motivation initially concentrated on goal setting, the emphasis gradually shifted to goal pursuit. Meanwhile, a considerable body of knowledge has accumulated regarding the setting and pursuit of single goals, but there is still little recognition of the fact that people at work have multiple goals to accomplish and that managing different goals has become a challenge for many in the present-day workforce. The role of time in motivation, although occasionally referred to, has also remain underexposed and very little is known about how the dynamics of goal management.

Multiple goal management has drawn some attention from a pragmatic perspective, largely under labels like 'time management' and 'work interruptions', and calls for multiple goal research have been for more than a decade (e.g., Emsley, 2003; Roe, 1999). Yet, researchers have only recently begun designing studies to clarify the cognitive and motivational processes involved in performing multiple goals and to disentangle the many factors involved. The studies on time management and interruptions and those proposing 
mechanisms in carrying out a small number of tasks simultaneously have been helpful to recognize the factors involved and the importance of temporal dynamics.

To our knowledge, the research presented here has been the first to investigate multiple goal management in a naturalistic work setting. It has screened the literature for relevant findings, developed a theoretical model, and studied multiple goal pursuit in the context of everyday work-life. The literature study (chapter 2) and our theoretical work (chapter 3) lead to the conclusion that the postulate of sequential processes underlying goalsetting and goal-pursuit, which was widely subscribed to until the late 1990s, is incapable of accounting for the typical interleaving of activities associated with different goals. This postulate is useful to understand the unfolding of a single goal, and the effects of incidental interruptions. However, one needs to distinguish a second, higher-order level of cognitive and motivational activity to account for the acceptance and discarding of goals, and the prioritizing, scheduling and activation of goals respective to each other. Thus, a distinction must be made between lower-order self-regulation at the level the goals and higher-order selfregulation at the level of what we called the 'goal-portfolio'.

We conducted two empirical studies in which we tracked the performance of multiple work goals in everyday life with the help of a diary method (see chapters 4 and 5). These studies, which covered work periods of three weeks and one week, lead to other important discoveries. They revealed the highly dynamic nature of goal pursuit and that stability, if it happens, is limited to short time episodes - confirming the view that "stability is a special form of change" (Roe, Gockel, \& Meyer, 2012). They also showed great differences between persons and the tendency for goal pursuit patterns to be quite idiosyncratic. Our conclusion from these studies is that the pursuit of multiple goals over time shows highly dynamic 
patterns that are unique to each individual. The high degrees of volatility and idiosyncrasy that were found imply that it is hard to predict how people will execute multiple goals, which contradicts the popular idea that people's preference for one vs. many goals (monochronicity - polychronicity (Bluedorn, 2002) will lead to corresponding ways of working. As we found in our last study (chapter 5), polychronicity may act as a moderator, that is, differentiate people with regard to the temporal goal trajectories. However, we must conclude that understanding the inherent dynamics of these trajectories and the factors and mechanisms involved in the many changes and their timing calls for a temporal research approach.

Our study of goal pursuit over time over two series of consecutive days has not only shown that "much is happening" as people carry out their everyday work, it also has a opened a 'Pandora's box', because it made clear that there are many, previously unknown questions to be addressed and answered. First, questions about the very dynamics of multiple goal management, which escape the limits of our study (with five goals selected upfront). For example: how often do people consider new goals and actually add goals to their goal portfolio?; how many goals do they add as time progresses and what are the properties of these goals?; how many goals do people keep in the portfolio and for how long?; how many work and which work goals completed and discarded as time progresses?

Second, questions about what drives the goal management process, which should include extraneous work place events, interactions with clients, colleagues and others (e.g., children, relatives, friends), and personal states such as anxiety or fatigue. One should also consider the degree of progress pursuing various goals, the amount of remaining effort needed, or the time till the deadline. For example: what makes people stop working on one goal, continue working on another goal, or start working on a new goal?; what determines the 
moment at which this happens?; what makes people take a break or rather continue working on the goal?; what makes people postpone certain goals and for how long?; what makes them forget about certain goals and ultimately abandon them? Next are questions about the cognitive and motivational mechanisms involved. The literature offers several useful ideas about this, e.g. regarding prospective and retrospective memory, and the executive function involved in planning, scheduling and activating or inhibiting goals (cf. Logie, Trawley, \& Law, 2011). However, the way in which these postulated mechanisms would be involved in producing the ongoing activity would still need to be exposed.

\section{FUTURE RESEARCH}

As regards the methodological approach needed to shed light on these matters, the conclusion of our research is that further research should preferably follow a temporal approach, that is, collect times-series data and conduct analyses of changes and processes occurring within persons over time. Analyses should thus focus on what happens over time and interlink unfolding goal trajectories with concomitant external events, organizational demands, social interactions, changing personal states etc. In an environment in which an increasing number of people are equipped with smart phones, tables, computers and other interactive devices and exposed to constant interconnectivity, events in the virtual environment, such as text messages and emails arriving should also be taken into account.

Although the dynamics of the everyday work environment is a sufficient ground for adopting a temporal approach there is an additional reason to opt for this approach and to avoid the more customary individual differences approach, namely the continuity of time itself. What we mean is that there is no natural end to the phenomenon of work that would define the timeframe of research. Real-life work is an on-going phenomenon that interrupted 
by evenings and nights, by weekends and holiday breaks, and for many people multiple goal management is an ongoing process as well. Understanding how people maintain their goal portfolio over longer periods, and how they effectively carry over their goals to the next days or week, is a phenomenon that deserves to be studied. Although it is conceivable that there are regularities in goal management in different episodes, it may well be that longer time windows of research than the 19 days of our studies will show different forms and facets of dynamics, with more rather than less idiosyncrasy.

\section{PRACTICAL IMPLICATIONS OF MULTIPLE GOAL MANAGEMENT}

Although the focus of our research has been on fundamental aspects of studying goal related activity and on conceptual and theoretical issues, our study has also implications for practice. While we admit that more evidence should be collected before we can give firm recommendations for goal management in practice, the insights gained allow us to give some suggestions to improve time management practices based on earlier research.

The first recommendation relates to the definition of good performance in a multiple goal setting. How should such good performance be defined? While some people strive for a timely completion of their goals adhering to given or self-set deadlines other people are striving for excellence and the best possible quality. To a certain extent there will always be some kind of tradeoff between timeliness, completeness and the delivered quality of goals. To be still able to reach the best possible results, two things seem to be important. First of all, goals need to be clearly set and clarified. Thus, a person accepting or setting a goal has to clarify amongst others what is expected (what is a good result), who is involved (e.g. the audience or the client) and when is the preferred and the latest deadline the goals has to be finished. Second, one has to define a roadmap of things to do over time. In the workplace 
often milestones are used to keep track of the progress made. The studies of this dissertation show that there are always interruptions and unplanned tasks that emerge along the goal striving process. A working day cannot be fully planned ahead as unexpected tasks appear that require immediate attention and action. Thus, rescheduling and postponing of tasks is not the exception but the rule. It is important for people to take this into account when formulating the roadmap and e.g. schedule "time buffers".

In addition, an explicit scheduling of each goal is recommended, as this is likely to increase the completion of the goals in time. In a multiple goal environment this is a true challenge. Assuming that every goal has been clearly defined and expectations are clarified, it is necessary to develop an overall plan of how to work on the multiple goals one currently has in the portfolio. One technique to keep track of the number of goals and the associated tasks that need to be carried out is the use of calendars or to-do-lists. With the help of such tools the sequencing of tasks can be better organized and their monitoring can be made easier.

Of crucial importance is higher-ordered self-regulation as defined in chapter 3. Being aware of these self-regulation processes and consciously applying them is of vital importance for successful multiple goal management. Of utmost importance is scrutiny in accepting new goals. At work people tend often accept additional goals too quickly, without considering the consequences this adding has on the goals already in the portfolio. Of course there are situations where there is no choice, but in general one has to carefully decide what to put in the portfolio and what to exclude. Adding a goal to the portfolio that requires substantial resources (e.g. time that needs to be spent on related tasks) one risks the survival or accomplishment of goals that are already in the portfolio. Also, the greater the number of tasks one is working on the more easily some tasks are forgotten. If an additional goal is 
accepted nonetheless a person should consider other options for higher order self-regulation, such as abandoning other goals in the portfolio, putting certain goals on hold (deactivation of goals), or reprioritizing them in order to free resources for the pursuit of the new goal and avoid an "overload". Similarly, one may engage in goal shielding which is defined as the process of making goal relevant information more accessible whereas information related to other goals is suppressed (Shah, Friedman \& Kruglanski, 2002). By means of this attention is focused on the most urgent and relevant goal in the portfolio. However, this higher-order selfregulation process is probably the most challenging one in the workplace where there is a growing amount of information.

Overall, our studies show that there is a large amount of time at work that cannot be planned for. This implies a necessity for people to be flexible and frequently engage in rescheduling and reassessing the goal portfolio. There is also need to recognize that people at work are often required to engage in multiple goal pursuit patterns that they did not plan for nor prefer, and to allow for this in work schedules, performance management schemes, and reward systems. 


\section{SUMMARY}

Although research on work motivation has a long history and an ample amount of studies have been conducted, little has as yet been said about the fact that people at work are constantly required to work on many goals, simultaneously adhering to multiple demands, preferences and desires. Nowadays work has to be delivered fast with frequent switches between goals. Employees are asked to demonstrate a high degree of flexibility due to unplanned tasks or interruptions at work. More and more people realize that the handling of multiple goals at work is a true challenge. It comes as no surprise that there is an increasing amount of trainings and self-help books offered that address issues such as time management. While the work environment has changed, the research on work motivation has hardly taken the concept of multiple goals into account. Moreover, work motivation has been approached from a rather static point of view - conceptually and empirically. However, work motivation clearly is a highly dynamic phenomenon that reveals changes over time. Goal setting and goal striving as the main processes in work motivation are both highly dynamic.

The dissertation aims to fill these gaps in the literature by exploring the way in which people deal with multiple goals and by taking the notion of time theoretically and empirically into account. After a general and short introduction to the field of work motivation, a structured literature review is presented. This review confirms that there is little we know about the effect of multiple goals on work motivation and related process models. Our focus is on empirical studies that either addressed the phenomenon of multiple goals theoretically and/or empirically. Furthermore, we examine if the studies have taken a temporal perspective on multiple goals. Results show that there is no coherent definition of the concept of goals across studies. Even though there is an increase in the number of studies looking into the 
effect of multiple goals by means of temporal designs little is still known about the basic processes taking place in a multiple goal work environment.

In chapter three we present a theoretical but dynamic model of multiple goal management at work. We introduce the notion of 'goal portfolio' acknowledging the fact that although everyone has a certain amount of goals accepted people cannot work on all our goals simultaneously. Instead they frequently activate and deactivate their goals by switching between our goals back and forth. To describe the processes taking place we introduce the concepts of lower- and higher ordered self-regulation. While the lower ordered self-regulation describes the individual goal process (setting, filtering, accepting and striving) the higherorder self-regulation describes the mechanisms involved in managing multiple goals. Thus, our model explains the interdependence of individual goal processes and the goal management strategies (including goal shielding or goal abandoning) that people apply to reach satisfactory results when confronted with multiple goals. Furthermore, we present a research agenda to address multiple goal management.

Since no study looked into the actual pursuit of multiple goals in a work environment we conducted an exploratory study. Our aim was to empirically investigate how people work on their goals over time. By means of a diary study we tracked the pursuit of five individually indicated and actual work goals of 52 employees over a period of three weeks. We graphically examined the goal striving of people on these five goals, which allowed us to explore between-persons as well as within-persons differences. Although we can establish meaningful attributes that describe the goal pursuit of each person, there appear to be substantial changes over time with regard to how people work on their goals. The goal pursuit patters are not only 
contingent on the chosen time window but also on external factors such as work demands, interruptions, and unplanned tasks. Furthermore, we explore possible determinants of certain multiple goal management patterns such as personality characteristics and personal preferences such as polychronicity. With the exception of conscientiousness almost none of the explored determinants appears to show a significant relationship.

Next, we conducted an empirical study of multitasking in a work environment. One aim of the study was to examine the effect of multitasking on performance and affective wellbeing. In a diary study with 93 employees answered two daily questionnaires (before and after work) over a one-week period. We applied hierarchical linear modeling for the analysis. We explicitly differentiated between the preference 'polychronicity' and the actual behavior of multitasking using the observations made in the exploratory study. We note that polychronicity has little predictive power with regard to actual behavior displayed. As in the previous study we find evidence for the need to study multiple goal or task performance applying temporal designs. There is substantial within-person variation in the extent to which people engage in multitasking behavior. It appears impossible to classify people as multitaskers or monotasks, since this the pattern of multitasking depends on the time frame, external demands, and the opportunities to engage in this behavior. Generally, there appears to be a negative effect of multitasking on affective well-being and task performance. Howver, we find a moderating effect of polychronicity lessening the negative effect of multitasking on the outcome variables. In other words, people with high polychronicity are less affected by multitasking compared to more monochronic people.

In the final chapter we discuss the results of all studies and give recommendations regarding for further research and practice. A main conclusion and advice for future research 
is the clear need to apply a temporal approach and focus on intra-individual differences when studying multiple goals pursuit. Noting the need for more research, we give some recommendations for practice that add to insights from the literature on time management. 


\section{BIBLIOGRAPHY LIST}

Abraham, C., \& Sheeran, P. 2003. Implications of goal theories for the theories of reasoned action and planned behavior. Current Psychology: Developmental, Learning, Personality, Social, 22(3): 264-280.

Adams, S. J. 1963. Towards an understanding of inequity. Journal of Abnormal and Social Psychology, 67: 422-436.

Adler, R. F., \& Benbunan-Fich, R. 2012. Juggling on a high wire: Multitasking effects on performance. International Journal of Human-Computer Studies, 70(2): 156-168.

Adler, R. F., \& Benbunan-Fich, R. 2013. Self-interruptions in discretionary multitasking. Computers in Human Behavior, 29(4): 1441-1449.

Ajzen, I. 1991. The theory of planned behavior. Organizational Behavior \& Human Decision Processes, 50: 179-211.

Allport, G. W. 1937. Personality: A psychological interpretation. New York: Holt.

Altmann, E. M. 2002. Functional decay of memory for tasks. Psychological Research, 66: 287-297.

Altmann, E. M., \& Trafton, J. G. 2002. Memory for goals: An activation-based model. Cognitive Science, 26: 39-83.

Ambrose, M. L., \& Kulilk, C. T. 1999. Old friends, new faces: Motivation Reserach in the 1960s. Journal of Management 25(3): 231-292.

Appelbaum, S. H., Marchionni, A., \& Fernandez, A. 2008. The multi-tasking paradox: Perceptions, problems and strategies. Management Decision, 46(9): 1313-1325.

Ariely, D., \& Wertenbroch, K. 2002. Procrastination, deadlines, and performance: Selfcontrol by precommitment. Psychological Science, 13(3): 219-224.

Atkinson, J. W., \& Birch, D. 1970. The dynamics of action. New York: John Wiley \& Sons.

Austin, J. T., \& Bobko, P. 1985. Goal-setting theory: Unexplored areas and future research needs. Journal of Occupational Psychology, 58: 289-308.

Austin, J. T., \& Vancouver, J. B. 1996. Goal constructs in psychology: Structure, process, and content. Psychological Bulletin, 120(3): 338-375.

Baethge, A., \& Rigotti, T. 2013. Interruptions to workflow: Their relationship with irritation and satisfaction with performance, and the mediating roles of time pressure and mental demands. Work \& Stress, 27(1): 43-63.

Bagozzi, R. P., Bergami, M., \& Leone, L. 2003. Hierarchical representation of motives in goal setting. Journal of Applied Psychology, 88(5): 915-943.

Bandura, A. 1977. Self-efficacy: Toward a unifying theory of behavioral change. Psychological Review, 84: 191-215.

Bandura, A. 1991. Social cognitive theory of self-regulation. Organizational Behavior and Human Decision Processes (50): 248-187.

Bandura, A., \& Cervone, D. 1986. Differential engagement of self-reactive influences in cognitive motivation. Organizational Behavior and Human Decision Processes, 
38: $92-113$.

Barker, R. G. 1963. The stream of behavior. New York: Appleton-Centruy-Crofts.

Baumeister, R. F., \& Vohs, K. D. 2004. Handbook of self-regulation: Research, theory, and applications. New York: Guilford Press.

Beal, D. J., Weiss, H. M., Barros, E., \& MacDermid, S. M. 2005. An Episodic Process Model of Affective Influences on Performance. Journal of Applied Psychology, 90(6): 1054-1068.

Becker, M. W. A. R. C. J. 2013. Media Multitasking Is Associated with Symptoms of Depression and Social Anxiety. CyberPsychology, Behavior \& Social Networking, 16(2): 132-135.

Beeftink, F., van Eerde, W., \& Rutte, C. G. 2008. The effect of interruptions and breaks on insight and impasses: Do you need a break right now? Creativity Research Journal, 20(4): 358-364.

Binnewies, C., Sonnentag, S., \& Mojza, E. J. 2010. Recovery during the weekend and fluctuations in weekly job performance: A week-level study examining intraindividual relationships. Journal of Occupational and Organizational Psychology, 83(2): 419-441.

Bluedorn, A. C. 2002. The human organization of time: Temporal realities and experience. Stanford, CA: Stanford Business Books.

Brandimonte M. A., \& Passolunghi, M. C. 1994. The effect of cue-familiarity, cuedistinctiveness, and retention interval on prospective remembering. The Quarterly Journal of Experimental Psychology, 47A: 565-587.

Brandstätter, V., Lengenfelder, A., \& Gollwitzer, P. M. 2001. Implementation intentions and efficient action initiation. Journal of Personality and Social Psychology, 81(5): 946-960.

Britton, B. K., \& Tesser, A. 1991. Effects of time-management practices on college grades. Journal of Educational Psychology, 83(3): 405-410.

Buehler, R., Griffin, D., \& Ross, M. 1994. Exploring the "Planning Fallacy": Why People Underestimate Their Task Completion Times. Journal of Personality and Social Psychology, 67(3): 366-381.

Burgess, P. W., Veitch, E., de Lacy Costello, A., \& Shallice, T. 2000. The cognitive and neuroanatomical correlates of multitasking. Neuropsychologia, 38(6): 848-863.

Buser, T., \& Peter, N. 2012. Multitasking. Experimental Economics, 15(4): 641-655.

Campion, M. A., \& Lord, R. G. 1982. A control systems conceptualization of the goalsetting and changing process. Organizational Behavior and Human Performance, 30: $265-287$.

Cantor, N., \& Fleeson, W. 1990. Life tasks and self-regulatory mechanisms. In M. L. Maehr, \& P. R. Pintrich (Eds.), Advances in motivation and achievement (Vol. 7): 327-369. Greenwich, CT: JAI Press.

Carver, C. S., \& Scheier, M. F. 1990. Principles of self-regulation: Action and emotion. In E. T. Higgins, \& R. M. Sorrentino (Eds.), Handbook of motivation and cognition: Foundations of social behavior: Vol. 2: 3-52. New York: The Guilford Press. 
Carver, C. S., \& Scheier, M. F. 1998. On the self-regulation of beahvior. New York, NY: Cambridge University Press.

Cheng, M. M., Luckett, P. F., \& Mhama, H. 2007. Effect of perceived conflict among multiple performance goals and goal difficulty on task performance. Accounting and Finance, 47: 221-242.

Claessens, B. J. C. 2004. Perceived control of time: Time management and personal effectiveness at work. Unpublished Dissertation, Technische Universiteit Eindhoven.

Claessens, B. J. C., Roe, R. A., \& Rutte, C. G. 2008. Time Management: Logic, Effectiveness and Challenges. In R. A. Roe, M. J. Waller, \& S. Clegg (Eds.), Time in Organizational Research: 23-41. London: Routledge.

Claessens, B. J. C., Roe, R. A., \& Rutte, C. G. 2009. Time Management: Logic, Effectiveness and Challenges. In R. A. Roe, M. J. Waller, \& S. Clegg (Eds.), Time in Organizational Research: 23-41. London / New York: Routledge.

Claessens, B. J. C., Van Eerde, W., Rutte, C. G., \& Roe, R. A. 2004. Planning behavior and perceived control of time at work. Journal of Organizational Behavior, 25(8): 637-950.

Claessens, B. J. C., Van Eerde, W., Rutte, C. G., \& Roe, R. A. 2007. A review of the time management literature. Personnel Review, 36(1/2): 255-276.

Claessens, B. J. C., van Eerde, W., Rutte, C. G., \& Roe, R. A. 2010. Things to Do Today . . . : A Daily Diary Study on Task Completion at Work. Applied Psychology: An International Review, 59(2): 273-295.

Conte, J. M., \& Gintoft, J. N. 2005. Polychronicity, Big Five personality dimensions, and sales performance. Human Performance, 18(4): 427-444.

Conte, J. M., \& Jacobs, R. R. 2003. Validity Evidence Linking Polychronicity and Big Five Personality Dimensions to Absence, Lateness, and Supervisory Performance Ratings. Human Performance, 16(2): 107-129.

Crenshaw, D. 2008. The myth of multitasking: How 'doing it all' gets nothing done. San Francisco, CA US: Jossey-Bass.

Czerwinski, M., Horvitz, E., \& Wilhite, S. 2004. A diary study of task switching and interruptions. Paper presented at the CHI, Vienna, Austria

Daniels, K. 2000. Measures of five aspects of affective well-being at work. Human Relations, 53(2): 275-294.

Deci, E. L. 1975. Intrinsic motivation. New York: Plenum.

Delbridge, K. A. 2001. Individual differences in multi-tasking ability: Exploring a nomological network. ProQuest Information \& Learning, US.

DeShon, R. P., Kozlowski, S. W. J., Schmidt, A. M., Milner, K. R., \& Wiechmann, D. 2004. A multiple-goal, multilevel model of feedback effects on the regulation of individual and team performance Journal of Applied Psychology, 89(6): 1035-1056.

Dewitte, S., Verguts, T., \& Lens, W. 2003. Implementation intentions do not enhance all types of goals: the moderating role of goal difficulty. Current Psychology: developmental, learning, personality, social 22(1): 73-89. 
Dholakia, U. M., \& Bagozzi, R. P. 2003. As time goes by: How goal and implementation intentions influence enactment of short-fuse behaviors. Journal of Applied Social Psychology, 33(5): 889-922.

Diefendorff, J. M., \& Lord, R. G. 2008. Goal-Striving and Self-Regulation Processes. In R. Kanfer, G. Chen, \& R. D. Pritchard (Eds.), Work Motivation: Past, Present, and Future: 151-196. New York: Routledge.

Dismukes, R. K. 2012. Prospective memory in workplace and everyday situations. Current Directions in Psychological Science, 21(4): 215-220.

Donovan, J. J., \& Williams, K. J. 2003. Missing the mark: Effects of time and causal attributions on goal revision in response to goal-perfromance discrepancies. Journal of Applied Psychology, 88(3): 379-390.

Dörnyei, Z., \& Ottó, I. 1998. Motivation and action: A process model of L2 motivation. Working Papers in Applied Linguistics, 4: 43-69.

Downie, M., Koestner, R., Horberg, E., \& Haga, S. 2006. Exploring the Relation of Independent and Interdependent Self-construals to why and how people pursue personal goals The Journal of Social Psychology 146(5): 517-531.

Dweck, C. S. 1999. Self-theories: Their role in motivation, personality, and development. Philadelphia: PA: Psychology Press.

Earley, P. C. R. K. 1985. The influence of component participation and role models on goal acceptance, goal satisfaciton, and performance. Organizational Behavior \& Human Decision Processes, 36: 378-390.

Elliot, A. J., \& Niesta, D. 2009. Goals in the context of the hierarchical model of approachavoidance motivation. In G. B. Moskowitz, \& H. Grant (Eds.), The psychology of goals: 56-76. New York: The Guilford Press.

Elliot, A. J., Sheldon, K., \& Church, M. 1997. Avoidance personal goals and subjective well-being. . Personality and Social Psychology Bulletin, 23: 915-927.

Emmons, R. A. 1998. The personal striving approach to personality. In L. Pervin (Ed.), Goal concepts in personality and social psychology: 87-126. Hillsdale, NJ: Erlbaum.

Emmons, R. A., \& King, L. A. 1988. Conflict among personal strivings: Immediate and long-term implications for psychological and physical well-being, Vol. 54: 10401048: Elsevier.

Emsley, D. 2003. Multiple goals and managers' job-related tension and performance. Journal of Managerial Psychology, 18(4): 345-356.

Erez, A., Gopher, D., \& Arzi, N. 1990. Effect of goal difficulty, self-set goals, and monetary rewards on dual task performance. Organizational Behavior and Human Decision Processes, 47: 247-269.

Erez, M., Kleinbeck, U., \& Thierry, H. (Eds.). 2001. Work motivation in the context of a globalizing economy. Mahwah, New Jersey: Lawrence Erlbaum Associates

Eyrolle, H., \& Cellier, J. M. 2000. The effects of interruptions in work activity: Field and laboratory results. Applied Ergonomics, 31(5): 537-543.

Festinger, L. 1957. A theory of cognitive dissonance Stanford, CA: Jossey-Bass. 
Fiore, S. M. 2008. Making Time for Memory and Remembering Time in Motivation Theory. In R. Kanfer, G. Chen, \& R. D. Pritchard (Eds.), Work Motivation: Past, Present, and Future: 541-552. New York: Routledge.

Fitzsimons, G., \& Bargh, J. A. 2004. Automatic self-regulation. In R. F. Baumeister, \& K. D. Vohs (Eds.), Handbook of self-regulation research, theory, and applications: 151-170. New York: Guilford Press.

Fleeson, W., \& Cantor, N. 1995. Goal relevance and the affective experience of daily life: Ruling out situational explanations. Motivation and Emotion, 19: 25-57.

Ford, M. E. 1992. Motivating humans: Goals, emotions, and personal agency beliefs. Hillsdale, NJ: Erlbaum.

Ford, M. E., \& Nichols, C. W. 1987. A taxonomy of human goals and some applications. In M. E. Ford, \& D. H. Ford (Eds.), Humans as self-constructing living systems: A developmental perspective on behavior and personality. Hillsdale, NJ: Erlbaum.

Frese, M., \& Sabini, J. 1985. Goal directed behavior: The concept of action in psychology. Hillsdale, NJ: Erlbaum.

Frese, M., \& Zapf, D. 1994. Action as the core of work psychology: A German approach. In H. C. Triandis, M. D. Dunnette, \& L. M. Hough (Eds.), Handbook of industrial and organizational psychology, 2 ed., Vol. 4: 271-340. Palo Alto, CA: Consulting Psychologists Press.

Fried, Y., \& Slowik, L. H. 2004. Enriching goal-setting theory with time: An integrated approach. Academy of Management Review, 29(3): 404-422.

Frisch, S., Förstl, S., Legler, A., Schöpe, S., \& Goebel, H. 2012. The interleaving of actions in everyday life multitasking demands. Journal of Neuropsychology, 6(2): 257-269.

Fulford, D., Johnson, S. L., Llabre, M. M., \& Carver, C. S. 2010. Pushing and Coasting in Dynamic Goal Pursuit : Coasting Is Attenuated in Bipolar Disorder. Psychological Science, 21: 1021-1027.

George, J. M., \& Jones, G. R. 2000. The role of time in theory and theory building. Journal of Management, 26(4): 657-684.

Gevers, J. M. P., Claessens, B. J. C., Van Eerde, W., \& Rutte, C. G. 2009. Pacing styles, personality and performance. In R. A. Roe, M. J. Waller, \& S. Clegg (Eds.), Time in Organizational Research: 80-102. London / New York: Routledge.

Gevers, J. M. P., Claessens, B., Van Eerde, W., Rutte, C. C. G., \& Roe, R. A. 2006. Beyond conscientiousness: Testing the predictive validity of pacing styles. Paper presented at the Paper presented at the Symposium It's about time! Increasing the temporal focus in organizational research. Maastricht: Maastricht University / Meteor, June 8-9, 2006.

Gollwitzer, P. M. 1990. Action phases and mind-sets. In E. T. Higgins, \& R. M. Sorrentino (Eds.), Handbook of motivation and cognition, Vol. 2: 53-92. New York: Guilford Press.

Gollwitzer, P. M. 1993. Goal achievement: the role of intentions. European Review of Social Psychology, 4: 141-185. 
Gollwitzer, P. M. 1996. The volitional benefits of planning. In P. M. Gollwitzer, \& J. A. Bargh (Eds.), The psychology of action: Linking cognition and motivation to behavior: 287-312. New York: The Guilford Press.

Gollwitzer, P. M. 1999. Implementation intentions: Strong effects of simple plans. American Psychologist, 54: 493-503.

Gollwitzer, P. M., \& Brandstätter, V. 1997. Implementation intentions and effective goal pursuit. Journal of Personality and Social psychology, 73: 186-199.

Hacker, W. 1986. Arbeitspsychologie: Psychische Regulation von Arbeitstätigkeiten. Berlin: Deutscher Verlag der Wissenschaften.

Hacker, W. 1998. Allgemeine Arbeits- und Ingenieurspsychologie. Bern: Huber.

Hackman, R. 1969. Toward understanding the role of tasks in behavioral research. Acta Psychologica, 31: 97-128.

Hambrick, D. Z., Oswald, F. L., Darowski, E. S., Rench, T. A., \& Brou, R. 2010. Predictors of multitasking performance in a synthetic work paradigm. Applied Cognitive Psychology, 24(8): 1149-1167.

Harris, C., Daniels, K., \& Briner, R. B. 2003. A daily diary study of goals and affective well-being at work Journal of Occupational and Organizational Psychology 76: 401-410.

Hecht, T. D., \& Allen, N. J. 2005. Exploring links between polychronicity and well-being from the perspective of person-job fit: Does it matter if you prefer to do only one thing at a time. Organizational Behavior and Human Decision Processes, 98: 155178.

Heckhausen, H., \& Kuhl, J. 1985. From wishes to action: The dead ends and short cuts on the long way to action. In M. Frese, \& J. Sabini (Eds.), Goal directed behavior: The concept of action in psychology: 78-94. Hillsdale, NJ: Lawrence Erlbaum.

Heckhausen, J., \& Heckhausen, H. 2006. Motivation und Handeln. Heidelberg: Springer.

Hendriks, A. A. J., Hofstee, W. K. B., \& De Raad, B. 1999. The Five-Factor Personality Inventory (FFPI). Personality and Individual Differences, 27: 307-325.

Higgins, E. T. 1998. Promotion and prevention: Regulatory focus as a motivational principle. Advances in experimental social psychology, 30: 1-46.

Hill, A. B. 1975. Extraversion and variety-seeking in a monotonous task. British Journal of Psychology, 66(1): 9-13.

Hobfoll, S. E. 1989. Conservation of resources: A new attempt at conceptualizing stress. American Psychologist, 44(3): 513-524.

Hodgetts, H. M., \& Jones, D. M. 2006. Contextual cues aid recovery from interruption: The role of associative activation. Journal of Experimental Psychology: Learning, Memory, and Cognition, 32(5): 1120-1132.

Hodgetts, H. M., \& Jones, D. M. 2006. Interruption of the Tower of London task: Support for a goal-activation approach. Journal of Experimental Psychology, 135(1): 103115.

Hollenbeck, J. R. B., A.P. . 1987. The effects of individual differences and goal origin on 
goal-setting and performance. organizational Behavior and Human Decision Processes, 40: 392-414.

Hull, C. L. 1943. Principles of behavior. New York: Appleton-Century-Crofts.

Jansen, K. J., \& Kristof-Brown, A. L. 2005. Marching to the beat of a different drummer: Examining the impact of pacing congruence. Organizational Behavior and Human Decision Processes, 97: 93-105.

Jett, Q. R., \& George, J. M. 2003. Work interrupted: A closer look at the role of interruptions in organizational life. Academy of Management Review, 28(3): 494507.

Judd, T. 2013. Making sense of multitasking: Key behaviours. Computers \& Education, 63: 358-367.

Junco, R., \& Cotten, S. R. 2012. No A 4 U: The relationship between multitasking and academic performance. Computers \& Education, 59(2): 505-514.

Just, M. A., Carpenter, P. A., \& Miyake, A. 2003. Neuroindices of cognitive workload: neuroimaging, pupillometric and event-related potential studies of brain work. Theoretical Issues in Ergonomics Science, 4(1): 56-88.

Kahneman, D., \& Tversky, A. 1979. Intuitive predictions: Biases and corrective procedures. TIMS Studies in Management Science, 12: 313-327.

Kanfer, R. 2005. Self-Regulation Research in Work and I/O Psychology. Applied Psychology: An International Review, 54(2): 186-191.

Kanfer, R., Chen, G., \& Pritchard, R. D. 2008. The three C's of work motivation: Content, context, and change. In R. Kanfer, G. Chen, \& R. D. Pritchard (Eds.), Work Motivation: Past, Present, and Future: 1-16. New York: Routledge Taylor Francis Group.

Kantrowitz, T. M., Grelle, D. M., Beaty, J. C., \& Wolf, M. B. 2012. Time is money: Polychronicity as a predictor of performance across job levels. Human Performance, 25(2): 114-137.

Karniol, R., \& Ross, M. 1996. The motivation impact of temporal focus: Thinking about the future and the past. Annual Review Psychology, 47: 593-620.

Karoly, P. 1993. Mechanisms of self-regulation: A systems view. Annual Review Psychology, 44: 23-52.

Karpinski, A. C., Kirschner, P. A., Ozer, I., Mellott, J. A., \& Ochwo, P. 2013. An exploration of social networking site use, multitasking, and academic performance among United States and European university students. Computers in Human Behavior, 29(3): 1182-1192.

Kaufman-Scarborough, C., \& Lindquist, J. D. 1999. Time management and polychronicity: Comparison, contrasts, and insights for the workplace. Journal of Managerial Psychology, 14(3/4): 288-312.

Kernan, M. C., \& Lord, R. G. 1990. Effects of valence, expectations, and goal performance discrepancies in single and multiple goal environments. . Journal of Applied Psychology, 75(2): 194-203.

Kirchberg, D. M., \& Roe, R. A. 2009. Time Management: Performance Preferences and 
Multiple Goal Management Strategies. Paper presented at the 14th European Congress of Work \& Organizational Psychology, Santiago de Compostela, Spain.

Kirchberg, D. M., Roe, R. A., \& Van Eerde, W. 2008. Multiple goal management: A dynamic within-person approach to work motivation. Paper presented at the Academy of Management Conference, Anaheim, CA.

Klein, H. J., Austin, J. T., \& Cooper, J. T. 2008. Goal Choice and Decision Processes. In R. Kanfer, G. Chen, \& R. D. Pritchard (Eds.), Work Motivation: Past, Present, and Future: 101-150. New York: Routledge.

Klinger, E. 1975. Consequences of commitment to and disengagement from incentives. Psychological Review, 82: 1-25.

König, C. J., \& Waller, M. J. 2010. Time for reflection: A critical examination of polychronicity. Human Performance, 23(2): 173-196.

König, C. J., Bühner, M., \& Mürling, G. 2005. Working Memory, Fluid Intelligence, and Attention Are Predictors of Multitasking Performance, but Polychronicity and Extraversion Are not. Human Performance, 18(3): 243-266.

König, C. J., Oberacher, L., \& Kleinmann, M. 2010. Personal and situational determinants of multitasking at work. Journal of Personnel Psychology, 9(2): 99-103.

Koo, M., \& Fishbach, A. 2008. Dynamics of self-regulation: How (un)accomplished goal actions affect motivation. Journal of Personality and Social Psychology, 94(2): 183-195.

Kristof, A. L. 1996. Person-organization fit: An integrative review of its conceptualizations, measurement, and implications. Personnel Psychology, 49(1): $1-49$.

Kruglanski, A. W. 1996. Goals as knowledge structures. In M. Gollwitzer, \& J. A. Bargh (Eds.), The psychology of action: Linking cognition and motivation to behavior: 599-619. New York: Guilford Press.

Langfred, C. W., \& Moye, N. A. 2004. Effects of task autonomy on performance: An extended model considering motivational, informational, and structural mechanisms. Journal of Applied Psychology, 89(6): 934-945.

Latham, G. P. 2007. Work motivation: History, theory, research, and practice. London: Sage.

Latham, G. P., \& Locke, E. A. 1991. Self-regulation through goal setting. Organizational Behavior and Human Decision Processes, 50: 212-247.

Latham, G. P., \& Pinder, C. C. 2005. Work motivation theory and reserach at the dawn of the twenty-first century. Annual Review Psychology, 56: 485-516.

Latham, G. P., \& Seijts, G. H. 1999. The effects of proximal and distal goals on performance on a moderately complex task. Journal of Organizational Behavior, 20: 421-429.

Levine, L. E., Waite, B. M., \& Bowman, L. L. 2012. Mobile media use, multitasking and distractibility. International Journal of Cyber Behavior, Psychology and Learning, 2(3): 15-29.

Lewin, K. 1926. Untersuchungen zur Handlungs- und Affektpsychologie II.: Vorsatz, 
Wille und Bedürfnis. Psychologische Forschung, 7: 330-385.

Lewin, K. 1935. A dynamic theory of personality New York: McGraw-Hill.

Lewin, K., Dembo, T., Festinger, L., \& Sears, P. S. 1944. Level of aspiration. In J. M. V. Hunt (Ed.), Personality and the behavior disorders: Vol. 1: 333-378. New York: Ronald Press.

Li, J., Waller, M. J., \& Roe, R. A. 2008. Individual temporal characteristics: An exploration of construct stability over time. Paper presented at the Academy of Management Conference, Anaheim, CA.

Little, B. R. 1983. Personal projects: A rationale and method for investigation. Environment and Behavior, 15: 273-309.

Locke, E. A. 1968. Toward a theory of task motivation and incentives. Organizational Behavior and Human Performance, 3: 157-189.

Locke, E. A. 2000. Motivation, cognition, and action: An analysis of studies of task goals and knowledge. Applied Psychology: An International Review, 49(3): 408-429.

Locke, E. A., \& Latham, G. P. 1984. Goal setting: A motivational technique that works. Englewood Cliffs, NJ: Prentice Hall.

Locke, E. A., \& Latham, G. P. 1990. A theory of goal setting and task performance Englewood Cliffs, NJ: Prentice Hall.

Locke, E. A., \& Latham, G. P. 1990c. Work motivation and satisfaction: Light at the end of the tunnel. Psychological Science: Psychologi-PsyScience.

Locke, E. A., \& Latham, G. P. 1994. Goal setting theory, O'Neil, Harold F. Jr. (Ed); Drillings, Michael (Ed); et-al. (1994). Motivation: Theory and research. (pp. 1329). Hillsdale, NJ, USA: Lawrence Erlbaum Associates, Inc. viii, 332 pp.SEE BOOK: 13-29). NJ, USA: Lawrence Erlbaum Associates Inc. viii, 332 pp.SEE BOOK: Hillsdale.

Locke, E. A., \& Latham, G. P. 2004. What should we do about motivation theory? Six recommendations for the twenty-first century. Academy of Management Review, 29(3): 388-403.

Locke, E. A., Smith, K. G., Erez, M., Chah, D. O., \& Schaffer, A. 1994. The effects of intra-individual goal conflict on performance. Journal of Management, 20(1): 6791.

Logie, R. H., Trawley, S., \& Law, A. 2011. Multitasking: Multiple, domain-specific cognitive functions in a virtual environment. Memory \& Cognition, 39(8): 15611574 .

Lord, R. G., Diefendorff, J. M., Schmidt, A. M., \& Hall, R. J. 2010. Self-regulation at work. Annual Review Psychology, 61: 543-568.

Louro, M. J., Pieters, R., \& Zeelenberg, M. 2007. Dynamics of multiple-goal pursuit. Journal of Personality and Social Psychology, 93(2): 174-193.

Macan, T. H. 1994. Time management: Test of a process model. Journal of Applied Psychology, 79(3): 381-391.

Macan, T. H. 1996. Time-management training: Effects on time behaviors, attitudes and 
job performance. Journal of Psychology, 130: 229-236.

Madjar, N., \& Shalley, C. E. 2008. Multiple tasks' and multiple goals' effect on creativity: Forced incubation or just a distraction? Journal of Management, 34(4): 786-805.

Mark, G., Gonzalez, V. M., \& Harris, J. 2005. No task left behind?: examining the nature of fragmented work. Paper presented at the Conference on Human factors in computing systems Portland, Oregon.

Markus, H., \& Nurius, P. 1986. Possible selves. American Psychologist, 41(9): 954-969.

Maslow, A. H. 1954. Motivation and personality. New York: Harper \& Row.

Mayo, E. 1933. The human probelms of an industrial civilization. New York: Macmillan.

McClelland, D. C. 1971. Assessing human motivation. New York: General Learning Press.

McDaniel, M. A., \& Einstein, G. O. 2000. Strategic and automatic processes in prospective memory retrieval: A multiprocess framework. Applied Cognitive Psychology, 14(7): 127-144.

McMillan, L. H. W., O'Driscoll, M. P., \& Burke, R. J. 2003. Workaholism: A Review of theory, research, and future directions. In C. L. Cooper, \& I. T. Robertson (Eds.), International review of industrial and organizational psychology, Vol. 18: 167189. New York: Wiley.

Mecham, J. A. 1988. Interpersonal relations and prospective remembering. In M. M. Gruneberg, P. E. Morris, \& R. N. Sykes (Eds.), Practical Aspects of Memory: Current Research and Issues, Vol. 1: 354-359. Chichester: Wiley.

Meyer, D. E., \& Kieras, D. E. 1997. A computational theory of executive cognitive processes and multiple-task performance: Part 1. Basic mechanisms. Psychological Review, 104: 3-65.

Mitchell, T. R., \& James, L. R. 2001. Building better theory: Time and the specification of when things happen. Academy of Management Review, 26(4): 530-547.

Mitchell, T. R., Harman, W. S., Lee, T. W., \& Lee, D. Y. 2008. Self-regulation and multiple deadline goals. In R. Kanfer, G. Chen, \& R. D. Pritchard (Eds.), Work motivation: Past, present, and future. New York: Routledge.

Mohammed, S. 2008. Diversity on Temporal Individual Differences and Team Performance: The Moderating Role of Temporal Leadership, Colloquium. TU Eindhoven.

Mohammed, S., \& Nadkarni, S. 2011. Temporal diversity and team performance: The moderating role of team temporal leadership. Academy of Management Journal, 54(3): 489-508.

Molenaar, P. C. M., Huizenga, H. M., \& Nesselroade, J. R. 2003. The relationship between the structure of interindividual and intraindividual variability: A theoretical and empirical vindication of developmental systems theory. In U. M. Staudinger, \& U. Lindenberger (Eds.), Understanding human development: Dialogues with lifespan psychology: 339-360. Dordrecht: Kluwer Academic.

Monsell, S. 2003. Task switching. Trends in Cognitive Sciences, 7(3): 134-140. 
Morgan, B., D’Mello, S., Abbott, R., Radvansky, G., Haass, M., \& Tamplin, A. 2013. Individual differences in multitasking ability and adaptability. Human Factors, 55(4): 776-788.

Morgeson, F. P., \& Humphrey, S. E. 2006. The work design questionnaire (WDQ): Developing and validating a comprehensive measure for assessing job design and the nature of work. Journal of Applied Psychology, 91(6): 1321-1339.

Oettingen, G., Pak, H., \& Schnetter, K. 2001. Self-regulation of goal setting: Turning free fantasies about the future into binding goals. Journal of Personality and Social Psychology, 80(736-753).

Offer, S., \& Schneider, B. 2011. Revisiting the gender gap in time-use patterns: Multitasking and well-being among mothers and fathers in dual-earner families. American Sociological Review, 76(6): 809-833.

Palys, T. S., \& Little, B. R. 1983. Perceived life satisfaction and the organization of personal project systems. Journal of Personality and Social Psychology, 44(6): 1221-1230.

Pashler, H. 2000. Task switching and multitask performance. . In S. Monsell, \& J. Driver (Eds.), Attention and Performance XVIII: Control of mental processes. Cambridge, MA: MIT Press.

Pinder, C. C. 1998. Work motivation in organizational behavior: Prentice Hall Upper Saddle River, NJ.

Pinder, C. C. 2008. Work Motivation in Organizational Behavior (2 ed.). Hove: Psychology Press.

Podsakoff, P. M., MacKenzie, S. B., Lee, J.-Y., \& Podsakoff, N. P. 2003. Common Method Biases in Behavioral Research: A Critical Review of the Literature and Recommended Remedies. Journal of Applied Psychology, 88(5): 879.

Poposki, E. M., \& Oswald, F. L. 2010. The Multitasking Preference Inventory: Toward an Improved Measure of Individual Differences in Polychronicity. Human Performance, 23(3): 247-264.

Poppelreuter, W. 1928. Die Arbeitskurve in der Diagnostik von Arbeitstypen. Psychotechnisches Zeitschrift, 3: 35-51.

Pychyl, T. A., Lee, J. M., Thibodeau, R., \& Blunt, A. 2000. Five days of emotion: an experience sampling study of undergraduate student procrastination Journal of Social Behavior \& Personality, 15(5): 239-254.

Rasmussen, J. 1986. Information processing and human-machine interaction. Amsterdam: North-Holland.

Raudenbush, S. W., \& Bryk, A. S. 2002. Hierarchical linear models: Applications and data analysis methods: Sage Publications, Inc.

Revelle, W. 1989. Personality, motivation and cognitive performance. In R. Kanfer, P. L. Ackerman, \& R. Cudeck (Eds.), Abilities, motivation and methodology: Minnesota symposium on learning and individual differences: 297-341. Hillsdale, NJ: Erlbaum.

Riediger, M., \& Freund, A. M. 2004. Interference and facilitation among personal goals: 
Differential associations with subjective well-being and persistent goal pursuit. Personality and Social Psychology Bulletin, 30(12): 1511-1523.

Robinson, A. M., \& Smallman, C. 2006. The contemporary British workplace: A safer and healthier place? Work, Employment, and Society, 20(1): 87-107.

Roe, R. A. 1999. The calendar model: Towards a less parsimonious but more realistic model of work motivation European Congress of Work \& Organizational Psychology. Espoo-Helsinki, Finland.

Roe, R. A. 1999. Work performance: A multiple regulation perspective. In C. L. Cooper, \& I. T. Robertson (Eds.), International review of industrial and organizational psychology 1999, Vol. 14.: 231-335. New York, NY US: John Wiley \& Sons Ltd.

Roe, R. A. 2008. Time in Applied Psychology: The study of "What Happens" Rather Than "What Is". European Psychologist, 13(1): 37-52.

Roe, R. A. 2008. Time in applied psychology: The study of 'what happens' rather than 'what is.'. European Psychologist, 13(1): 37-52.

Roe, R. A. 2013. Test validity from a temporal perspective: Incorporating time in validation research. European Journal of Work and Organizational Psychology: 115.

Roe, R. A. 2014. Performance, motivation and time. In A. Shipp, \& Y. Fried (Eds.), Time and Work. Vol. 1: How time impacts individuals. London, UK: Routledge / Taylor \& Francis, p.63-110 .

Roe, R. A., \& Quist, S. J. 2004. Strengths and limitations of work calendars as a reserach tool: University Maastricht, Faculty of Economics \& Business Administration.

Roe, R. A., Gockel, C., \& Meyer, B. 2012. Time and change in teams: Where we are and where we are moving. European Journal of Work and Organizational Psychology, 21(5): 629-656.

Roe, R. A., Leonova, A. B., Zijlstra, F. R. H., \& Krediet, I. 1996. Interruptions in mental information work. Effects on work activity and psychological well-being (ISBN 90-750001-10-X). Tilburg: WORC - Tilburg University.

Roe, R. A., Zinovieva, I. L., Dienes, E., \& Ten Horn, L. A. 2000. A comparison of work motivation in Bulgaria, Hungary, and the Netherlands: Test of a model, Vol. 49: 658-687: John Wiley \& Sons.

Salthouse, T. A., Hambrick, D. Z., Lukas, K. E., \& Dell, T. C. 1996. Determinants of adult age differences on synthetic work performance. Journal of Experimental Psychology Applied, 2: 305-329.

Salvucci, D. D., \& Taatgen, N. A. 2008. Threaded cognition: An integrated theory of concurrent multitasking. Psychological Review 115(1): 101-130.

Salvucci, D. D., \& Taatgen, N. A. 2011. The multitasking mind. New York, NY US: Oxford University Press.

Sanderson, K. R., Bruk-Lee, V., Viswesvaran, C., Gutierrez, S., \& Kantrowitz, T. 2013. Multitasking: Do preference and ability interact to predict performance at work? Journal of Occupational \& Organizational Psychology, 86(4): 556-563.

Schaufeli, W. B., Taris, T. W., \& Van Rhenen, W. 2007. Workaholism, Burnout, and 
Work Engagement: Three of a Kind or Three Different Kinds of Employee Wellbeing? Applied Psychology: An International Review, 57(2): 173-203.

Schmidt, A. M., \& DeShon, R. P. 2007. What to do? The effects of discrepancies, incentives, and time on dynamic goal prioritization. Journal of Applied Psychology, 92(4): 928-941.

Schmidt, A. M., Dolis, C. M., \& Tolli, A. P. 2009. A matter of time: Individual differences, contextual dynamics, and goal progress effects on multiple-goal selfregulation. Journal of Applied Psychology, 94(3): 692-709.

Schmidt, A., \& Dolis, C. M. 2009. Something's got to give: The effects of dual-goal difficulty, goal progress, and expectancies on resource allocation. Journal of Applied Psychology, 94(3): 678-691.

Schneider, W., \& Schiffrin, R. M. 1977. Controlled and Automatic Human Information Processing: I. Detection, Search, and Attention. Psychological Review, 84(1): 1-66.

Shah, J. Y., \& Kruglanski, A. W. 2000. Aspects of goal networks. In M. Boekaerts, P. R. Pintrich, \& M. Zeidner (Eds.), Handbook of self-regulation: 85-110. San Diego: Academic Press

Shah, J. Y., \& Kruglanski, W. 2003. When opportunity knocks: Bottom-up priming of goals by means and its effect on self-regulation. Journal of Personality and Social Psychology, 84(6): 1109-1122.

Shah, J. Y., Friedman, R., \& Kruglanski, W. 2002. Forgetting all else: On the antecedents and consequences of goal shielding. Journal of Personality and Social psychology, 83(6): 1261-1280.

Simon, H. A. 1955. A behavioral model of rational choice. Quarterly Journal of Economics, 69: 99-118.

Slocombe, T. E., \& Bluedorn, A. C. 1999. Organizational behavior implications of the congruence between preferred polychronicity and experienced work-unit polychronicity. Journal of Organizational Behavior, 20(1): 75-99.

Spie $\beta$, E., \& Wittmann, A. 1999. Motivational phases associated with the foreign placement of managerial candidates: An application of the Rubicon model of action phases. International Journal of Human Resource Management, 10(5): 891-905.

Spink, A., Cole, C., \& Waller, M. 2008. Multitasking behavior. In B. Cronin (Ed.), Annual Review of Information Science and Technology, Vol. 42: 93: John Wiley \& Sons, Ltd.

Stajkovic, A. D., Locke, E. A., \& Blair, E. S. 2006. A first examination of the relationships between primed subconscious goals, assigned conscious goals, and task performance. Journal of Applied Psychology, 91(5): 1172-1180.

Steel, P., \& König, C. J. 2006. Integrating theories of motivation. Academy of Management Review, 31(4): 889-913.

Steers, R. M., Mowday, R. T., \& Shapiro, D. L. 2004. The future of work motivation theory. Academy of Management Review, 29(3): 379-387.

Stephens, K. K., Cho, J. K., \& Ballard, D. I. 2012. Simultaneity, sequentiality, and speed: Organizational messages about multiple- task completion. Human Communication 
Research, 38(1): 23-47.

Strickland, O. J., \& Galimba, M. 2001. Managing time: The effects of personal goal setting on resource allocation strategy and task performance. Journal of Psychology:

Interdisciplinary and Applied, 135(4): 357-367.

Strickland, O. J., \& Galimba, M. 2001. Managing time: The effects of personal goal-setting on resource allocation strategy and task performance. The Journal of Psychology, 135(4): 357-367.

Sykes, E. R. 2011. Interruptions in the workplace: A case study to reduce their effects. International Journal of Information Management, 31(4): 385-394.

Taylor, F. W. 1911. Scientific management. New York: Harper \& Row.

Thorndike, E. L. 1911. Animal intelligence. New York: Macmillan.

Tubbs, M. E., \& Ekeberg, S. E. 1991. The role of intentions in work motivation: Implications for goal-setting theory and research. Academy of Management Review, 16(1): 180-199.

Van der Horst, A. C., Klehe, U. C., \& van Leeuwen, L. 2012. Doing it all at once: Multitasking as a predictor of call center agents' performance and performace-based dismissal.. International Journal of Selection and Assessment, 20(4): 434-441.

Van Eerde, W. 2000. Procrastination: Self-regulation in initiating aversive goals. Applied Psychology: An International Review, 49(3): 327-389.

Van Eerde, W. 2003. Procrastination at work and time management training. The Journal of Psychology: Interdisciplinary and Applied 137(5): 421-434.

Vancouver, J. B., \& Day, D. V. 2005. Industrial and organization research on selfregulation: From constructs to applications. . Applied Psychology: An International Review, 54: 155-185.

Vancouver, J. B., \& Putka, D. J. 2000. Analyzing goal-striving processes and a test of the generalizability of perceptual control theory. Organizational Behavior and Human Decision Processes, 82(2): 334-362.

Vancouver, J. B., Weinhardt, J. M., \& Schmidt, A. M. 2010. A formal, computational theory of multiple-goal pursuit: Integrating goal-choice and goal-striving processes. Journal of Applied Psychology, 95(6): 985-1008.

Volpert, W. 1982. The model of the hierarchical-sequential organization of action. In W. Hacker, W. Volpert, \& M. Von Cranach (Eds.), Cognitive and motivational aspects of action: 35-51. Amsterdam: North-Holland Publishing Company.

Vroom, V. H. 1961. Work and motivation. New York: Wiley.

Wajcman, J., \& Rose, E. 2011. Constant connectivity: Rethinking interruptions at work. Organization Studies, 32(7): 941-961.

Wallenius, M. 2000. Personal project level of abstraction and project conflict: Relations to psychological well-being. European Journal of Personality, 14: 171-184.

Waller, M. J. 2007. Preferences, behaviors, and strategies in multiple-task performance. In F. Yammarino, \& D. F. (Eds.), Research in Multi-Level Issues, Vol. 6: 239-247: JAI/Elsevier. 
Waller, M. J., Conte, J. M., Gibson, C. B., \& Carpenter, M. A. 2001. The effect of individual perceptions of deadlines on team performance. The Academy of Management Review, 26(4): 586-600.

Weckauf, K. 2005. The Calendar Model in practice. What work calendars reveal about employees' planning behavior with respect to goal management. Maastricht University, Faculty of Economics and Business Administration.

Wickens, C. D., \& McCarley, J. S. 2008. Applied Attention Theory. Boca Raton: CRC Press Taylor \& Francis Group.

Wiese, B. S., \& Freund, A. 2005. Goal progress makes one happy, or does it? Longitudinal findings from the work domain. Journal of Occupational and Organizational Psychology, 78: 287-304.

Wood, R. 2005. New pointers for self-regulation research in I/O psychology. Applied Psychology: An International Review, 54: 192-198.

Wood, R., \& Bandura, A. (1989). Social cognitive theory of organizational management. Academy of Managment Review, 14 (3): 361-384.

Wrosch, C., Scheier, M. F., Miller, G. E., Schulz, R., \& Carver, C. S. 2003. Adaptive selfregulation of unattainable goals: Goal disengagement, goal reengagement, and subjective well-being. Personality and Social Psychology Bulletin, 29(12): 14941508.

Wu, C., Zhao, G., Lin, B., \& Lee, J. 2013. Navigating a car in an unfamiliar country using an internet map: Effects of street language formats, map orientation consistency, and gender on driver performance, workload and multitasking strategy. Behaviour \& Information Technology, 32(5): 425-437.

Zaheer, S., Albert, S., \& Zaheer, A. 1999. Time scales and organizational theory. Academy of Management Review, 24(4): 725-741.

Zhang, Y., Goonetilleke, R. S., Plocher, T., \& Liang, S.-F. M. 2005. Time-related behaviour in multitasking situations. International Journal of Human-Computer Studies, 62(4): 425-455.

Zijlstra, F. R. H., Roe, R. A., Leonova, A. B., \& Krediet, I. 1999. Temporal factors in mental work: Effects of interrupted activities. Journal of Occupational and Organizational Psychology, 72(2): 163-185. 
APPENDIX A
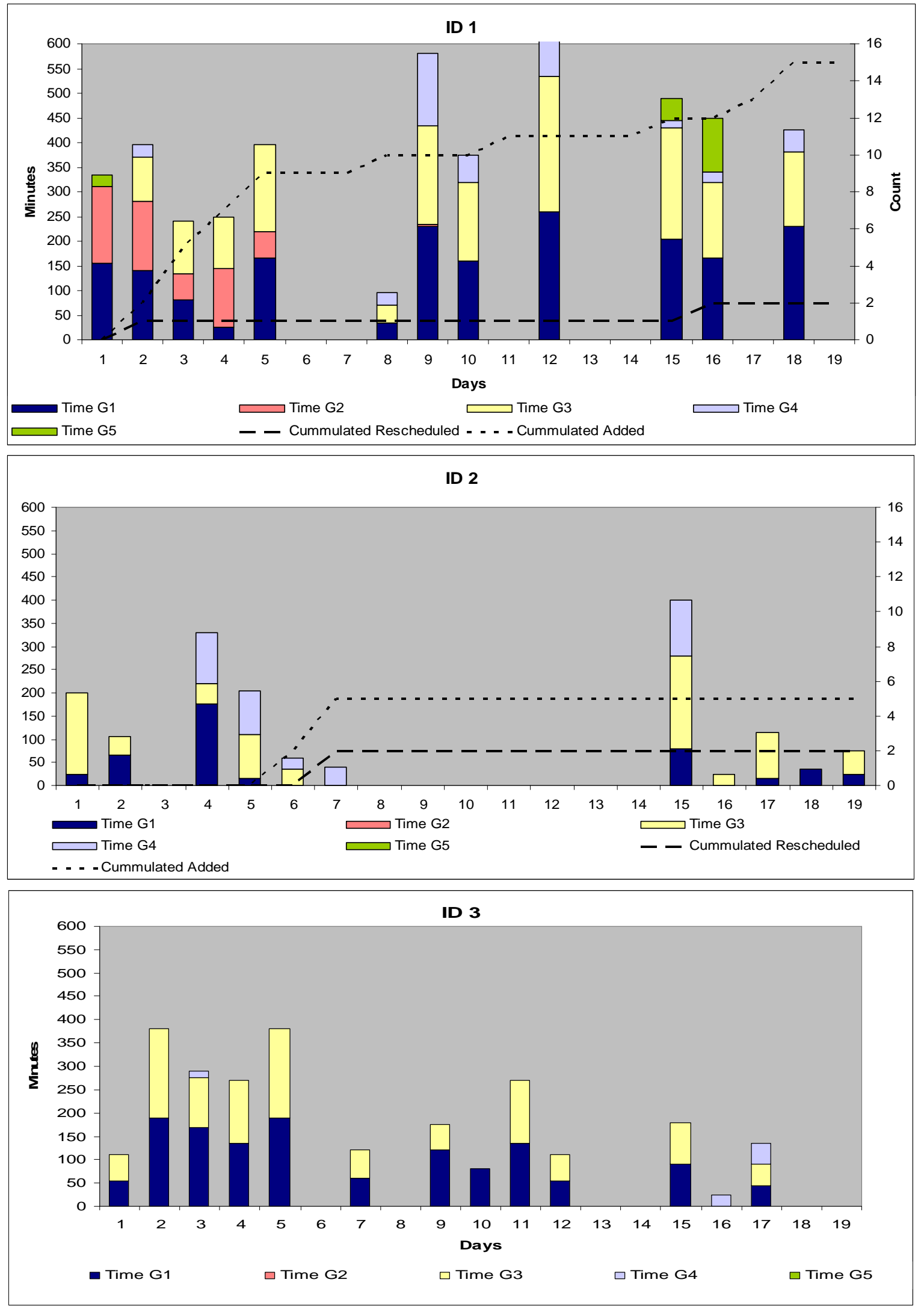

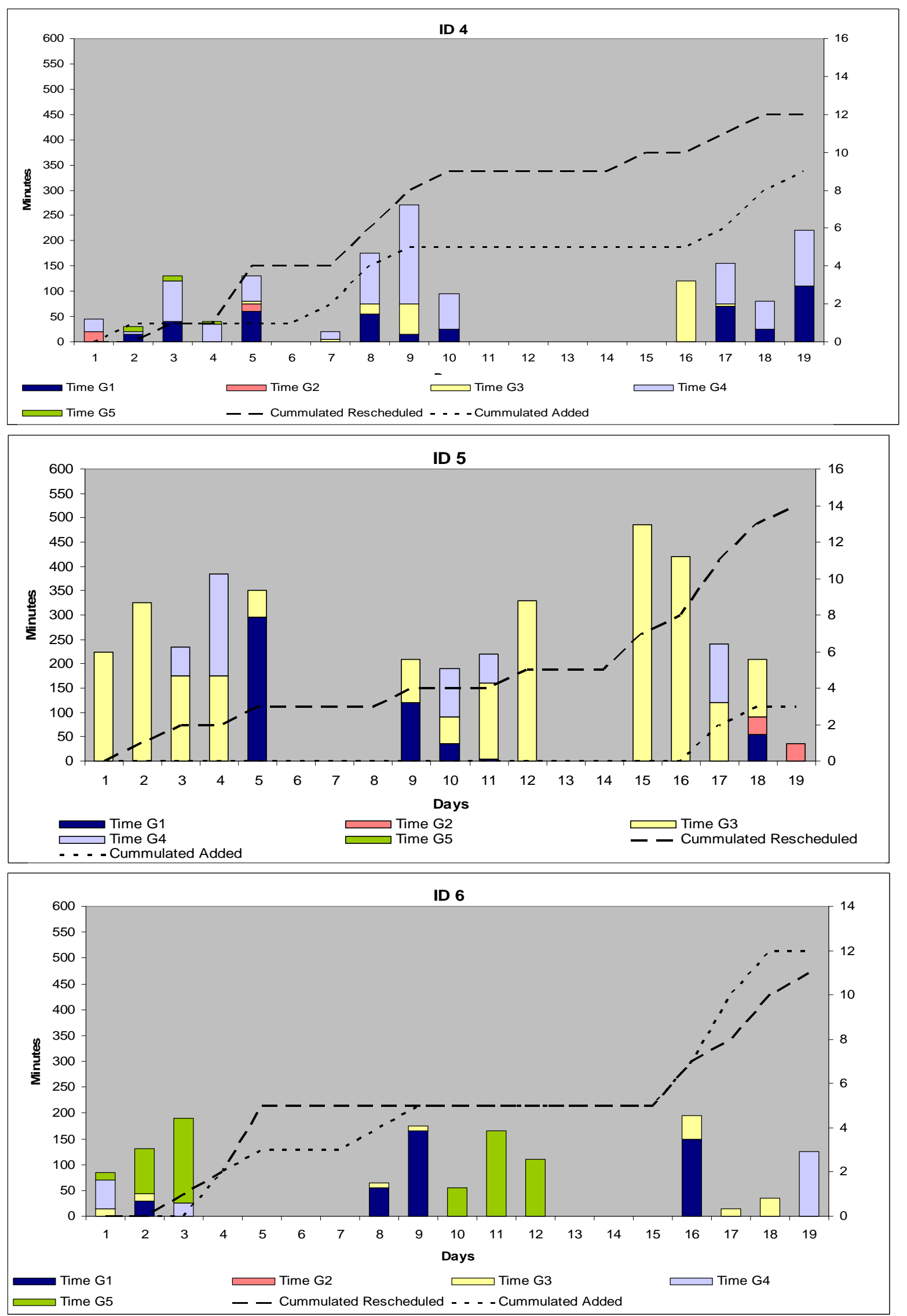

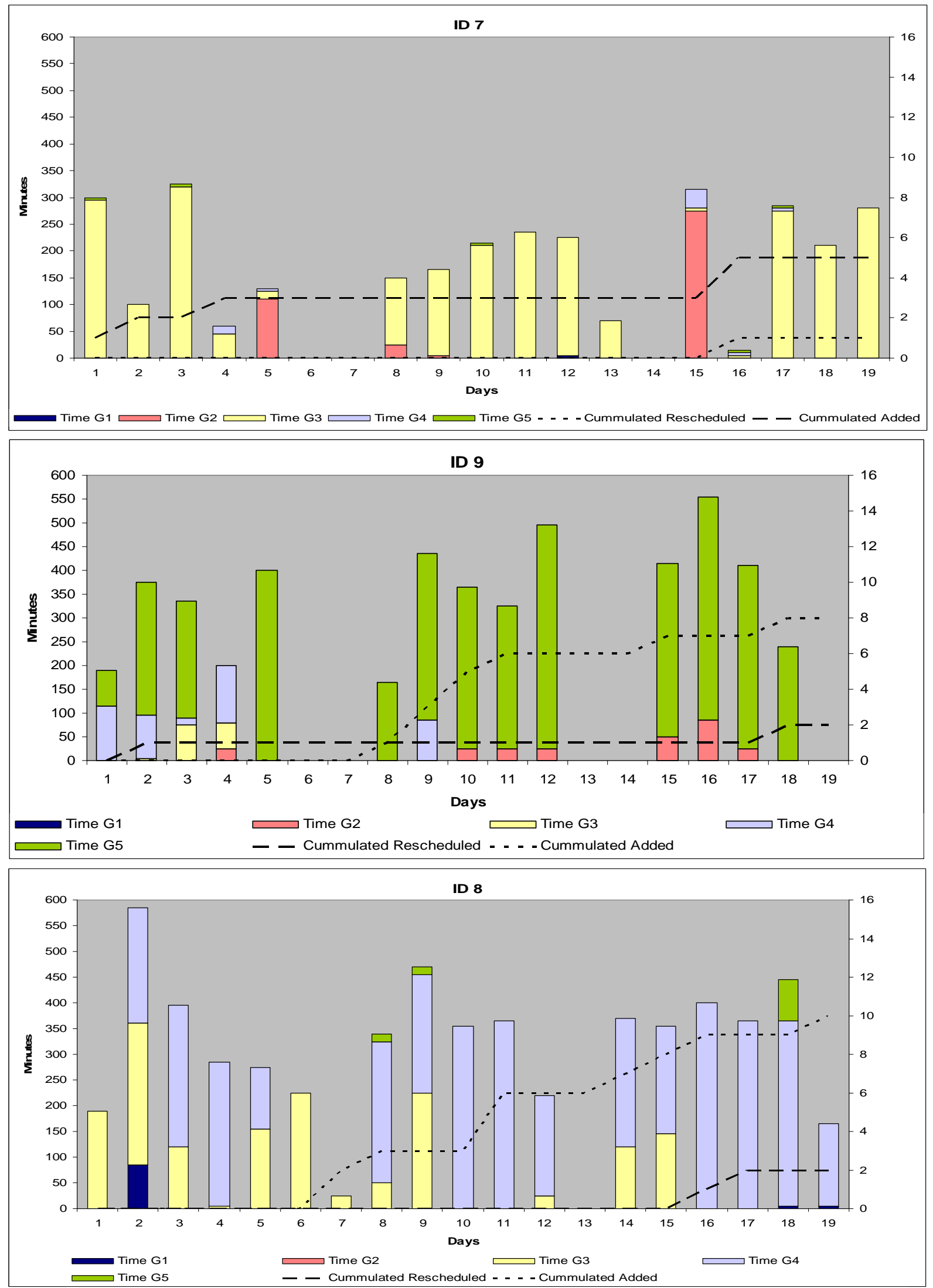

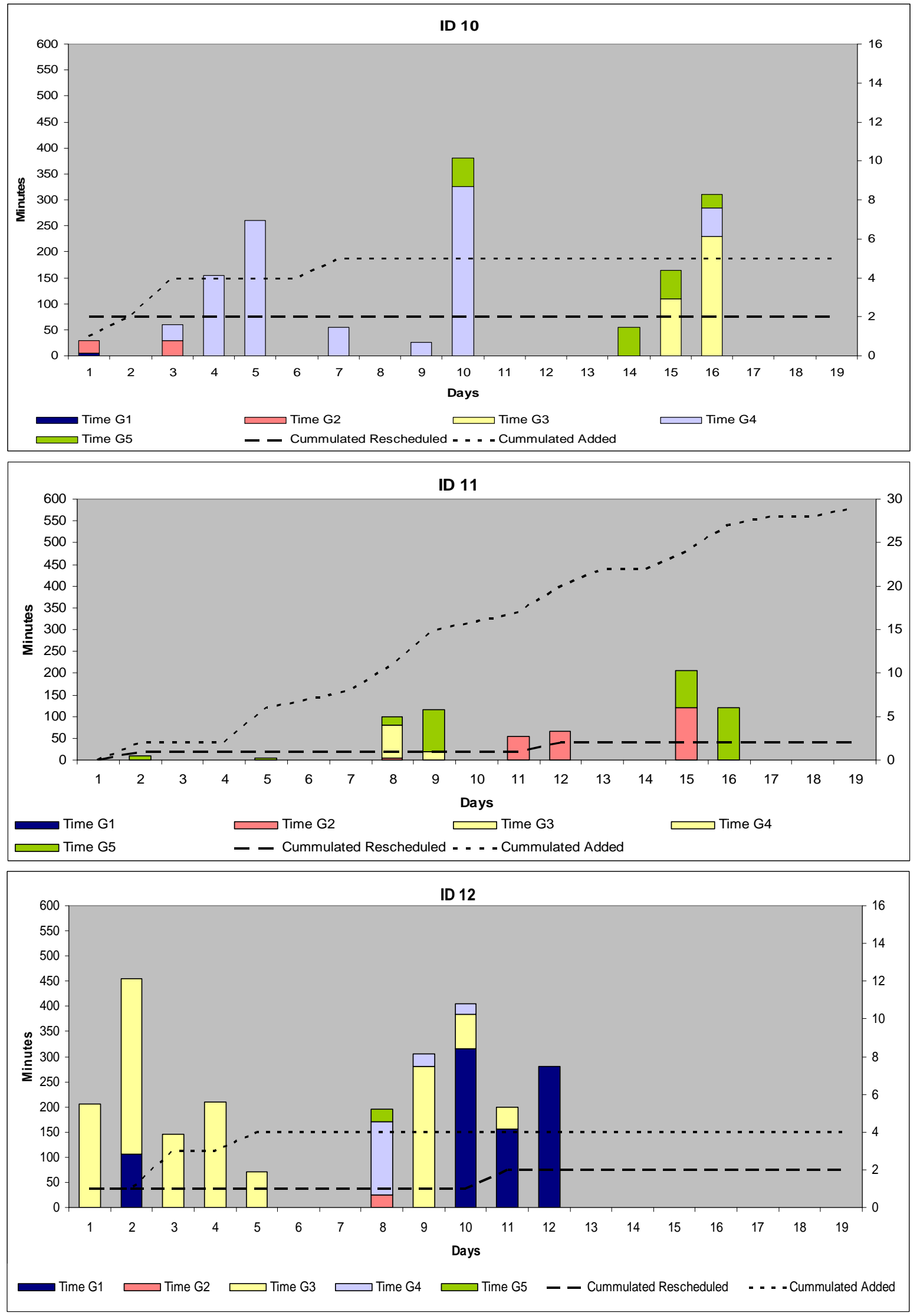

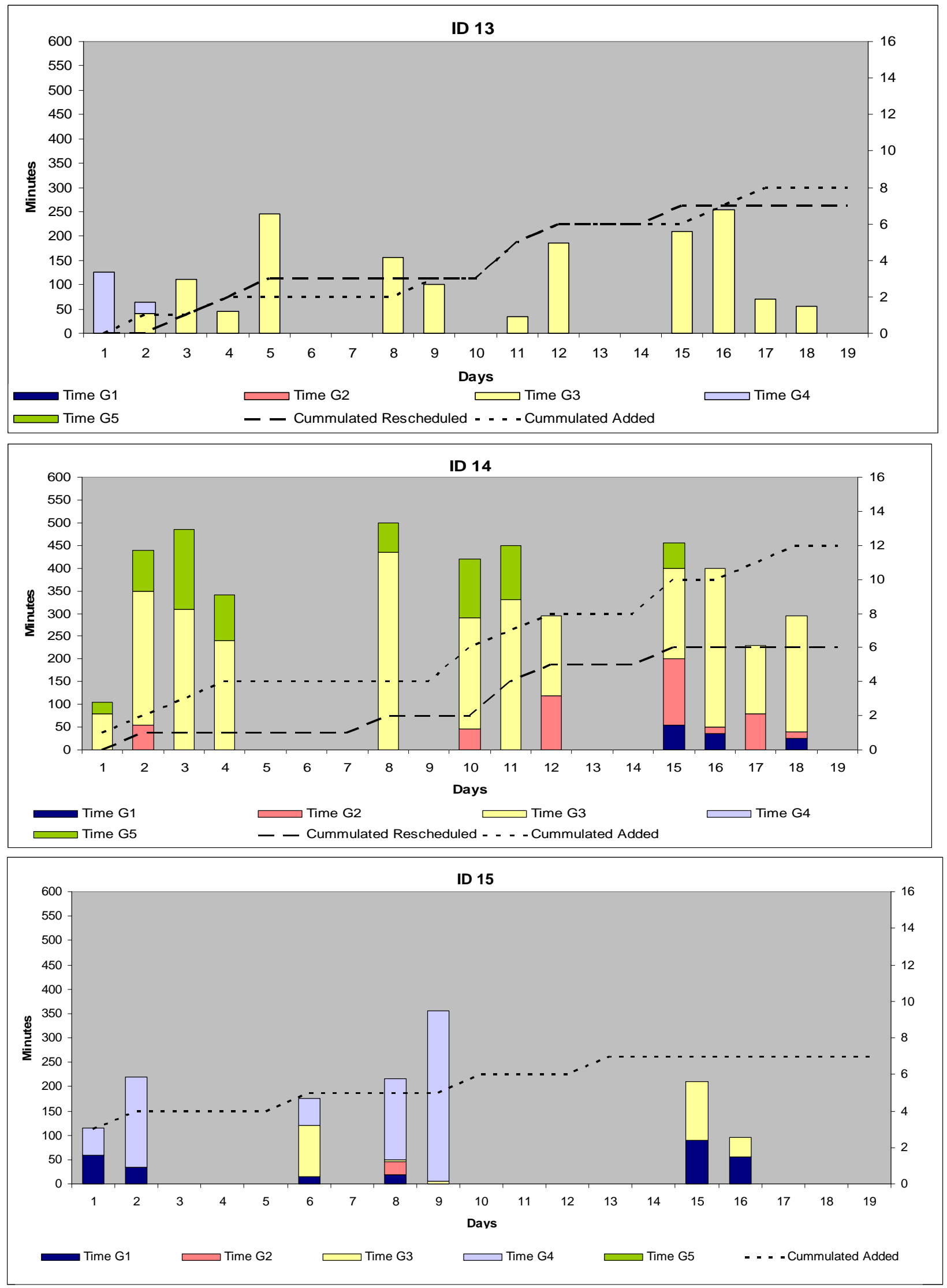

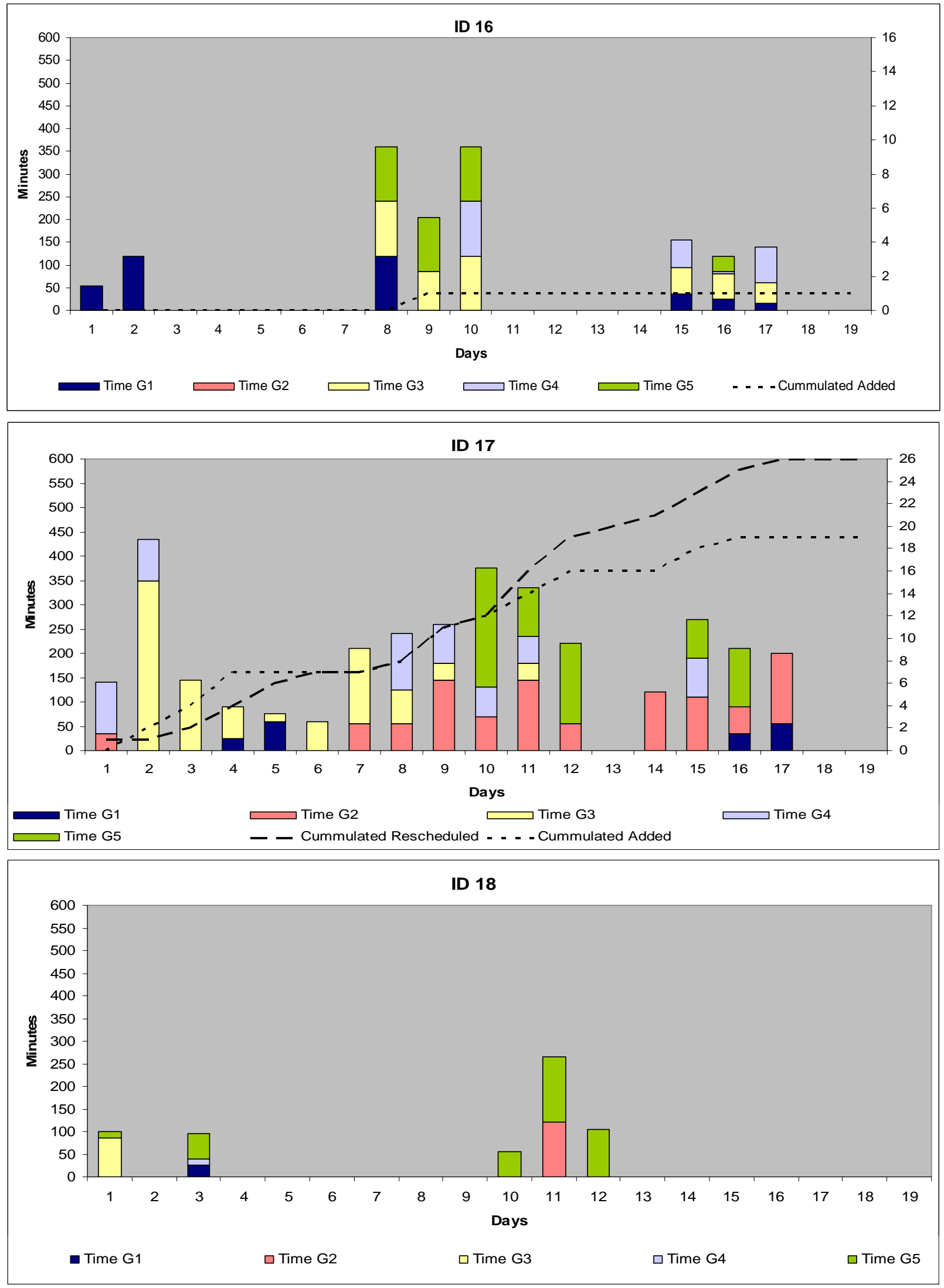

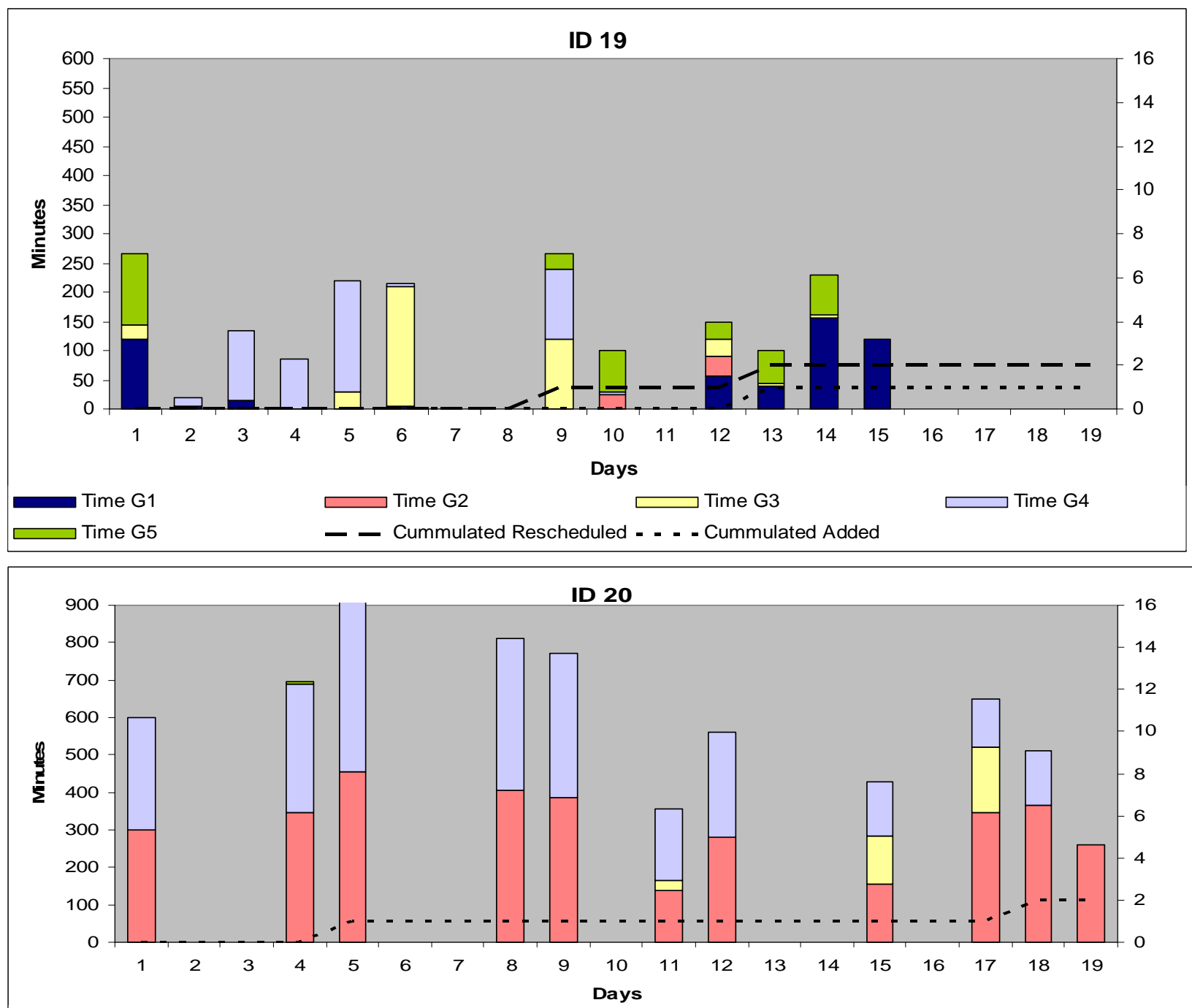

Time G1 $\square$ Time G2 $\square$ Time G3 $\square$ Time G4 $\square$ Time G5 - - - Cummulated Added

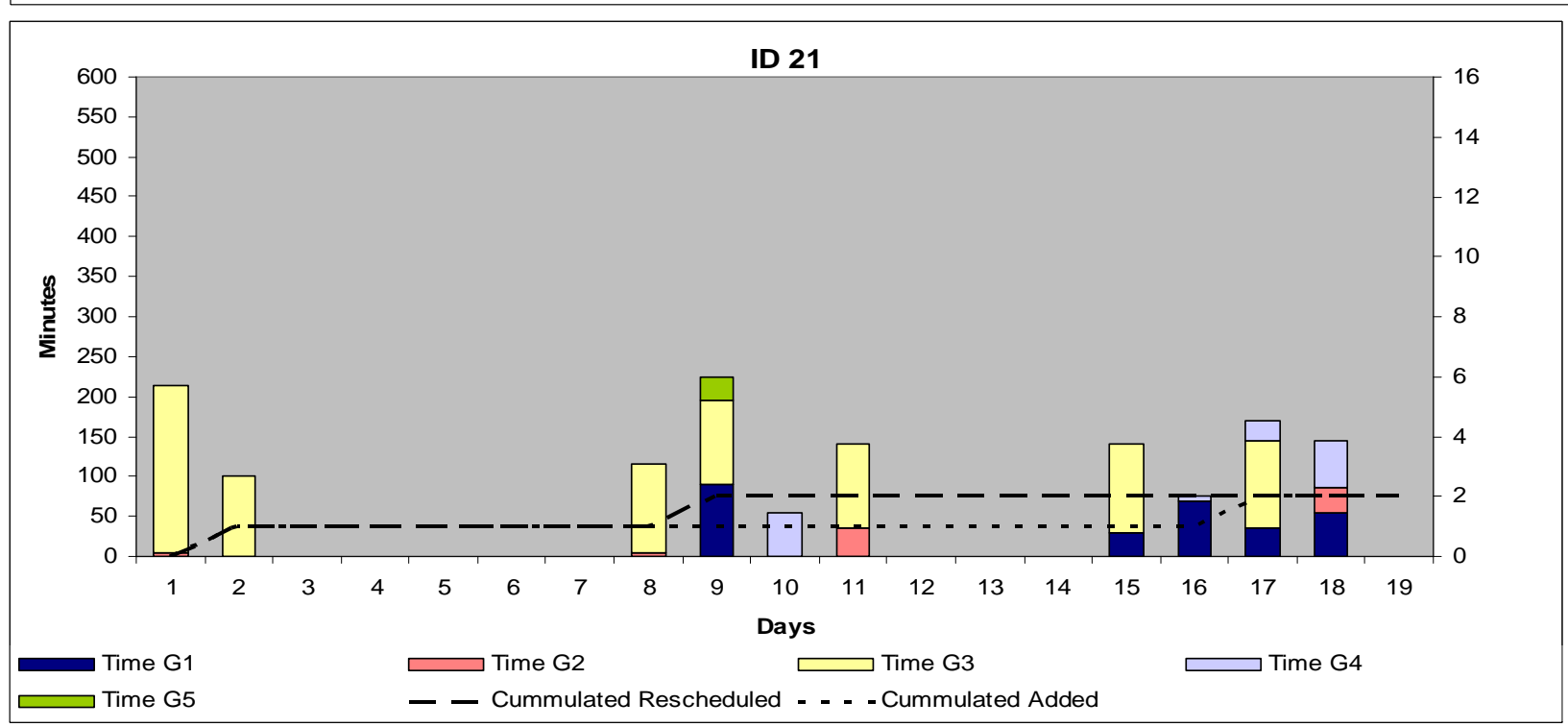



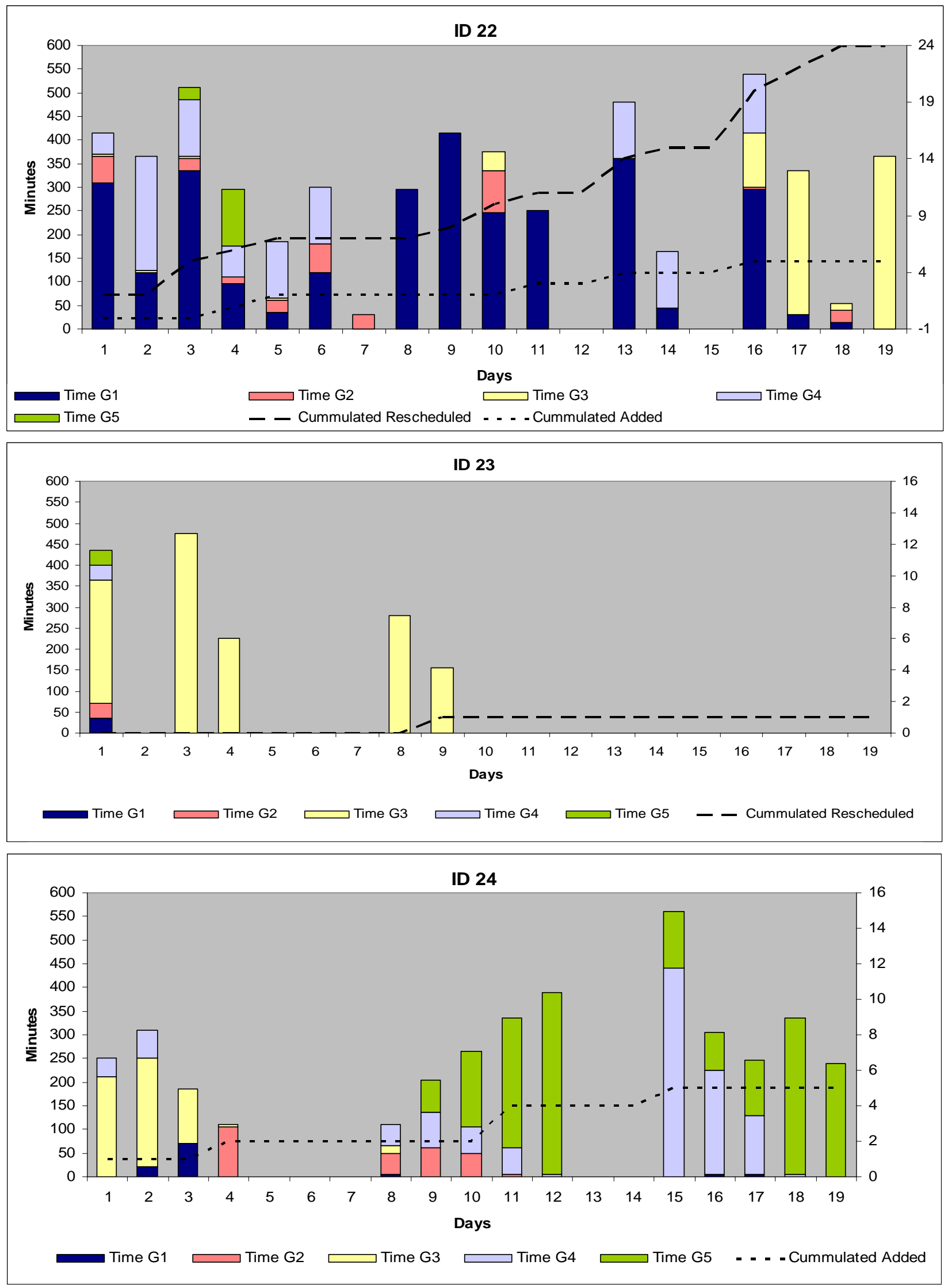

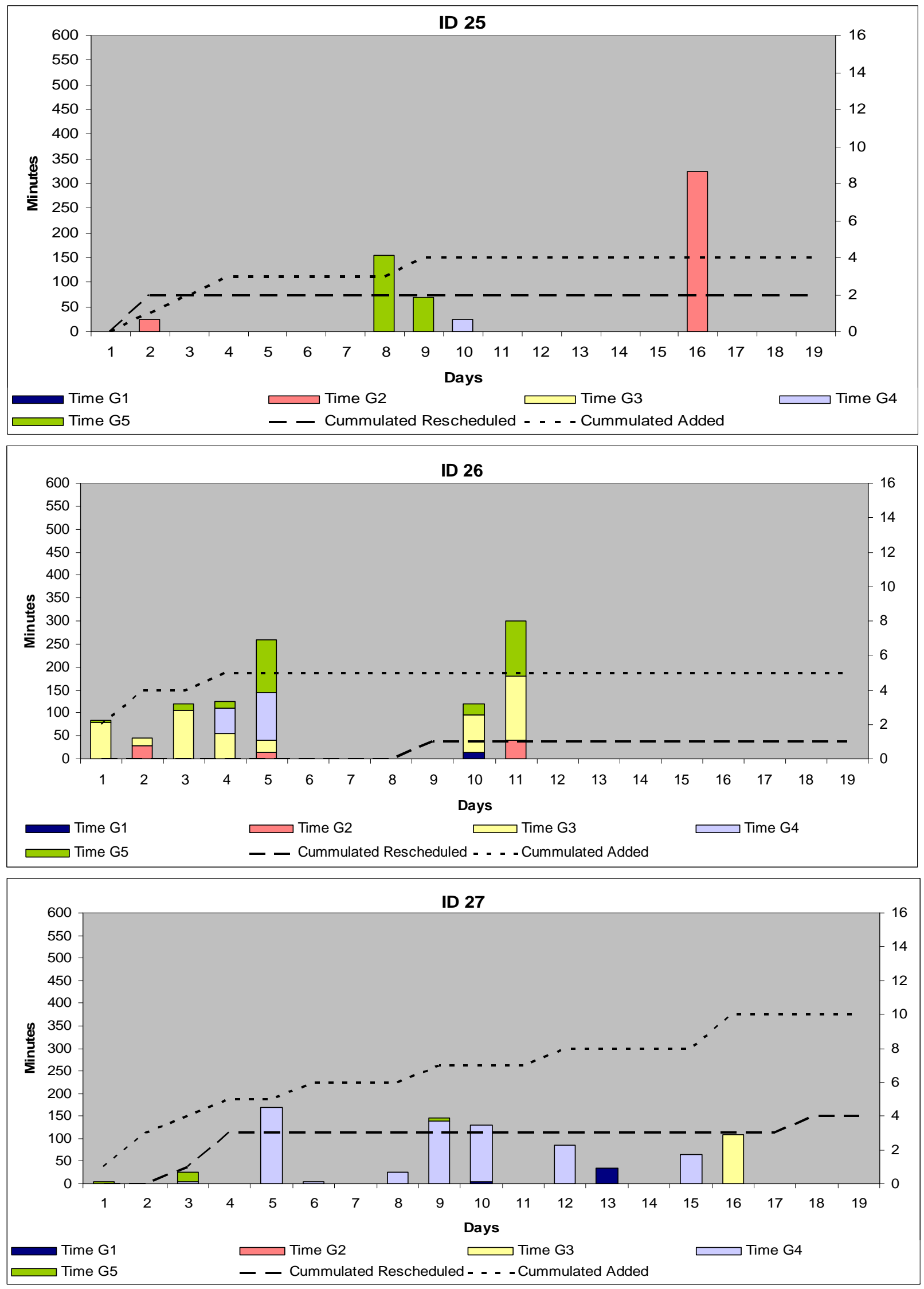

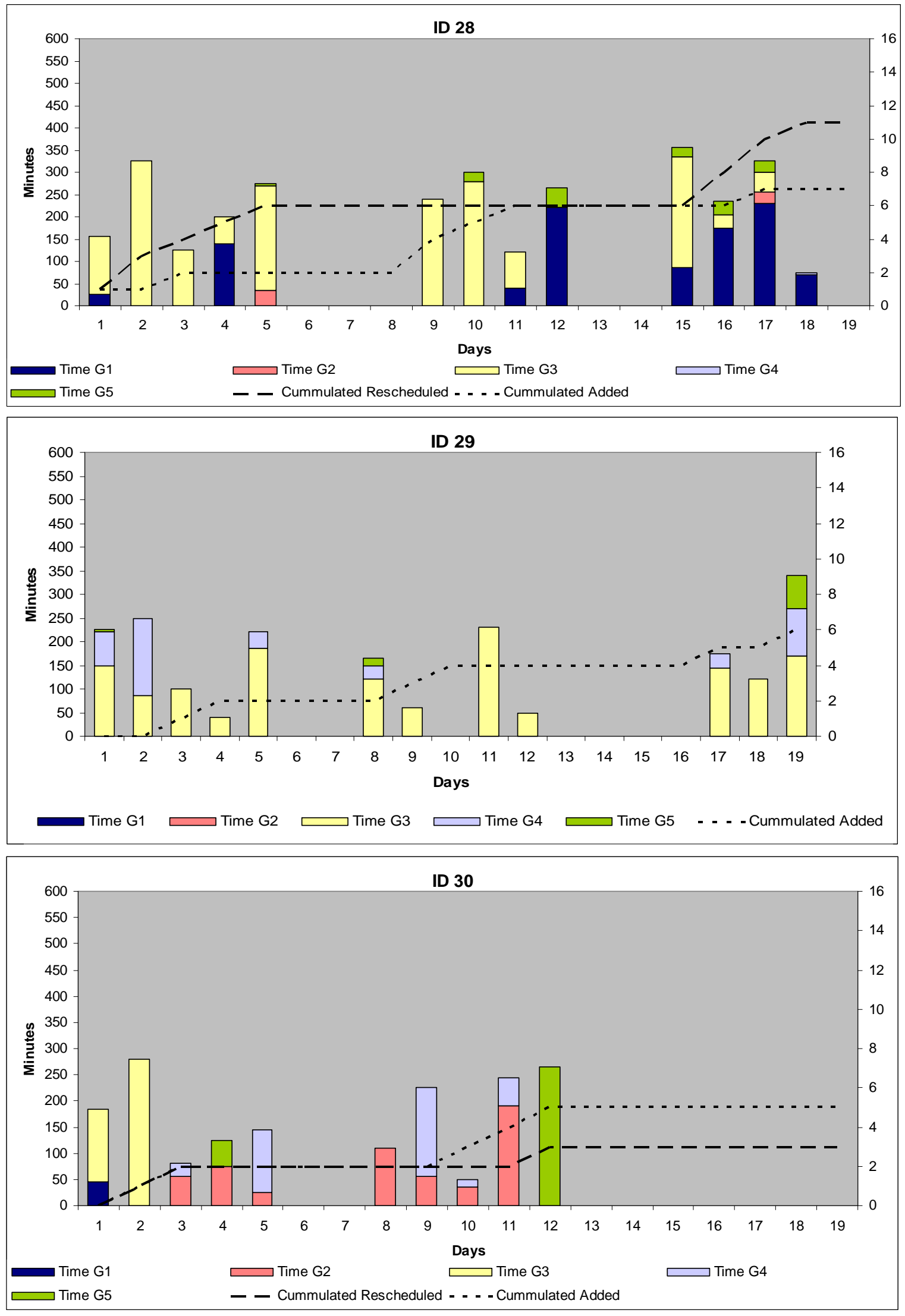

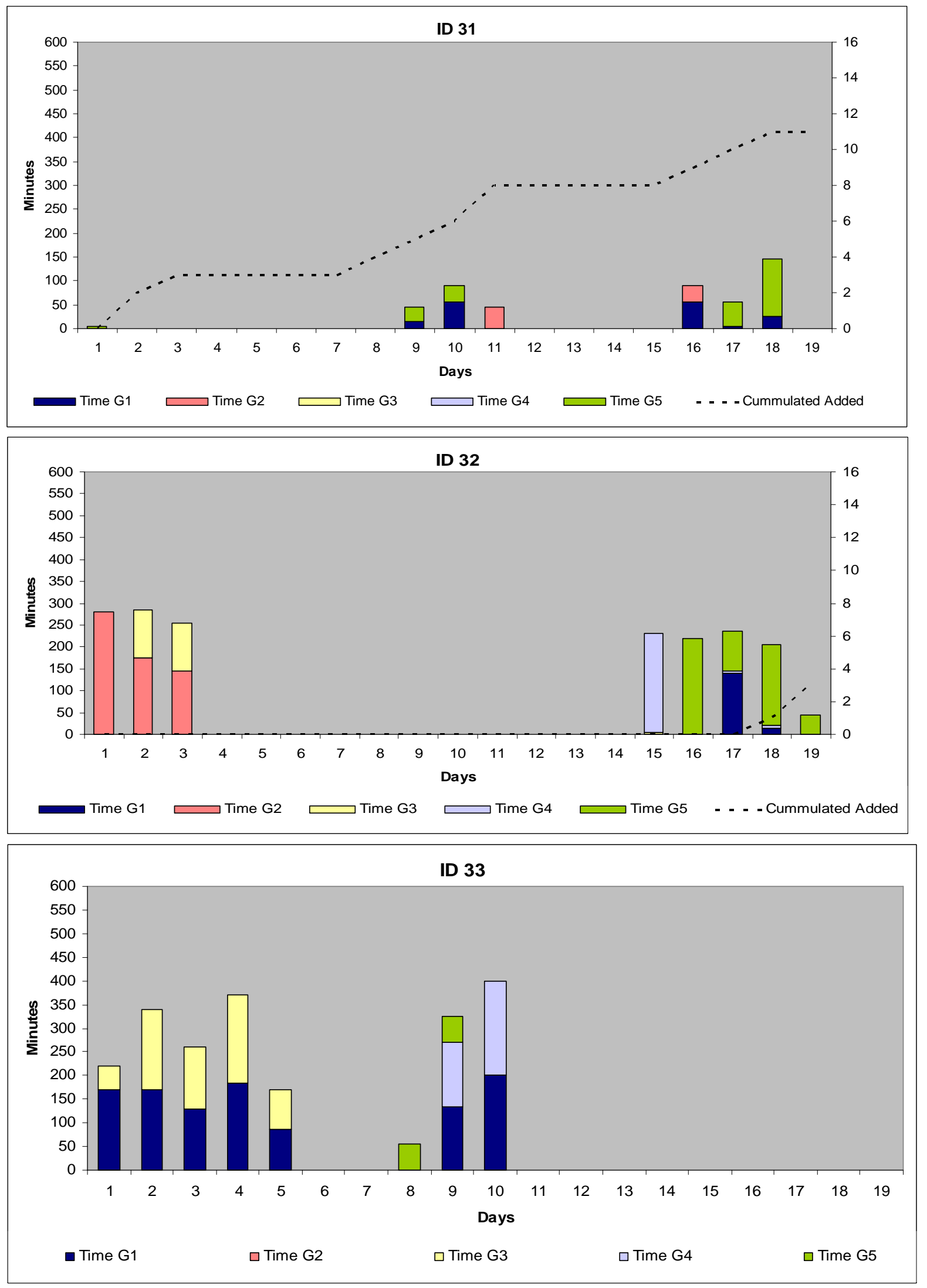

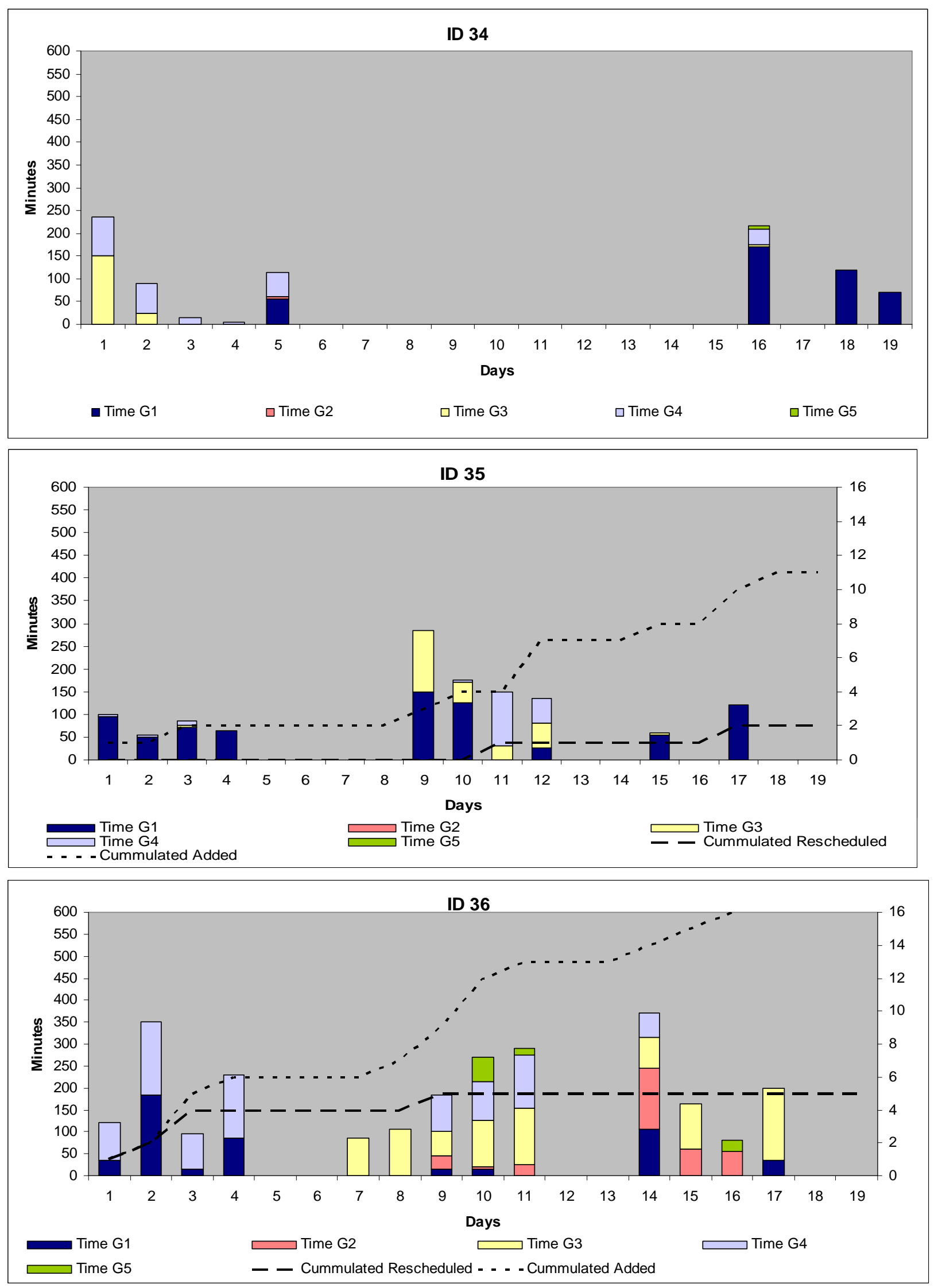

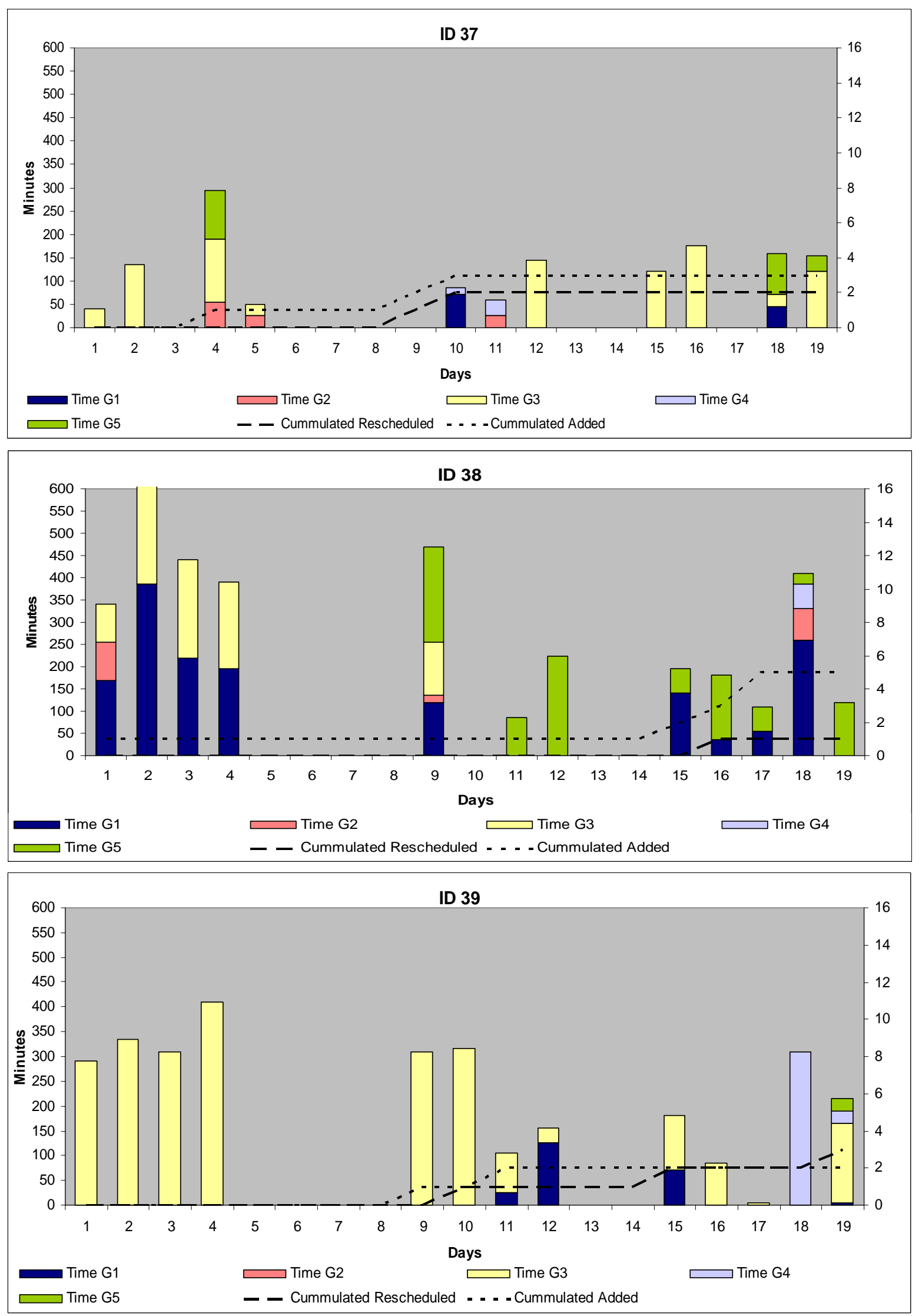

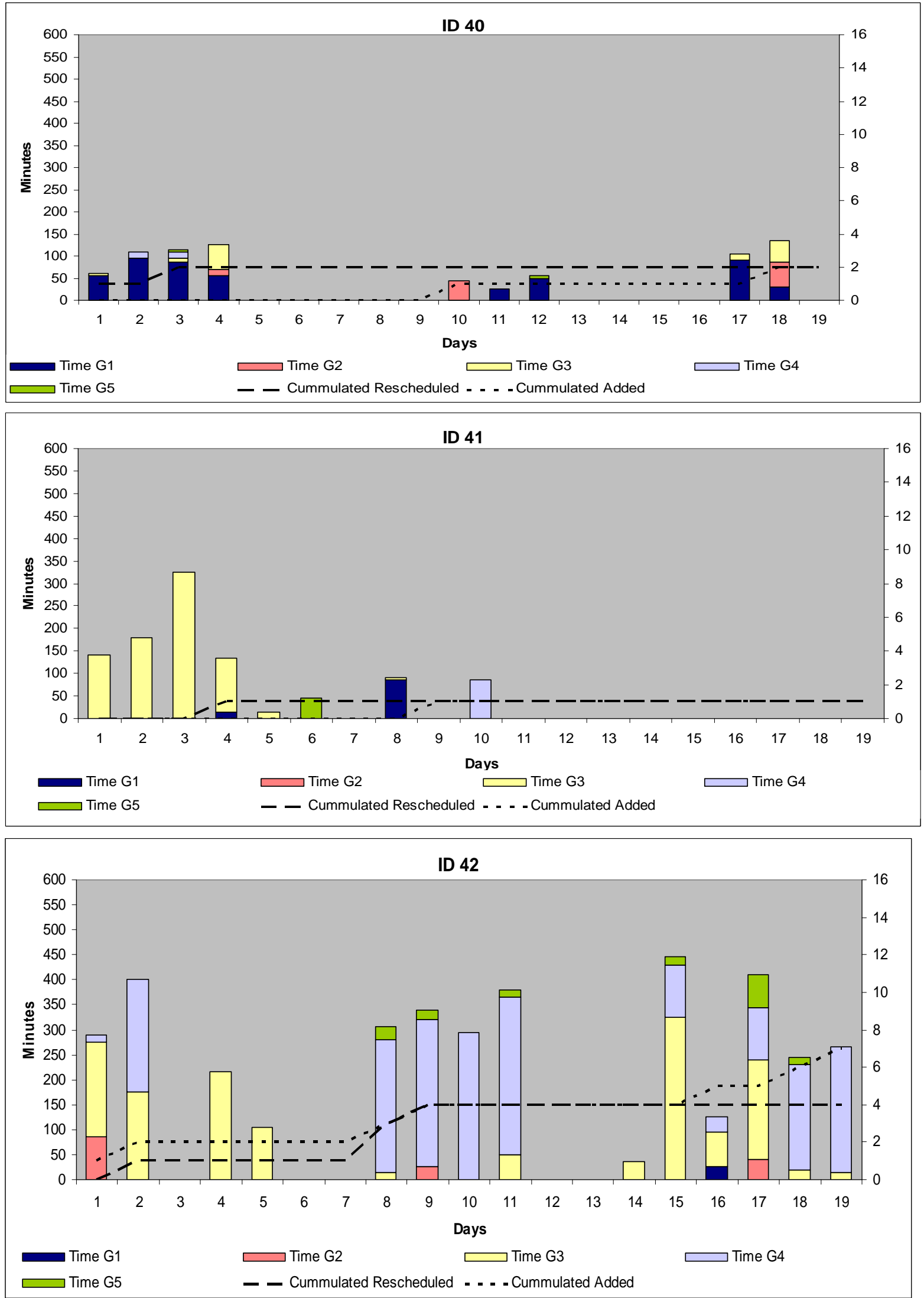

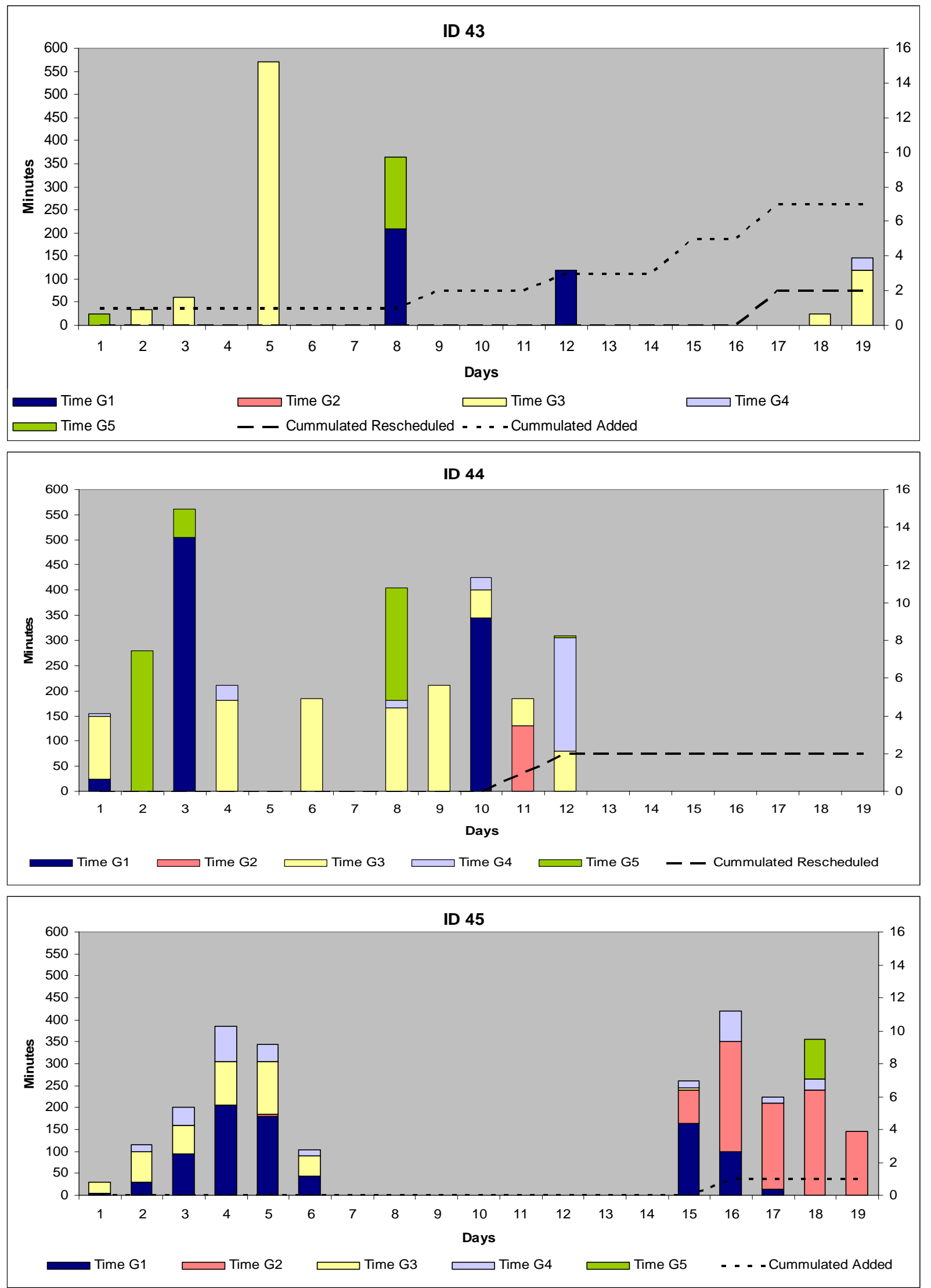


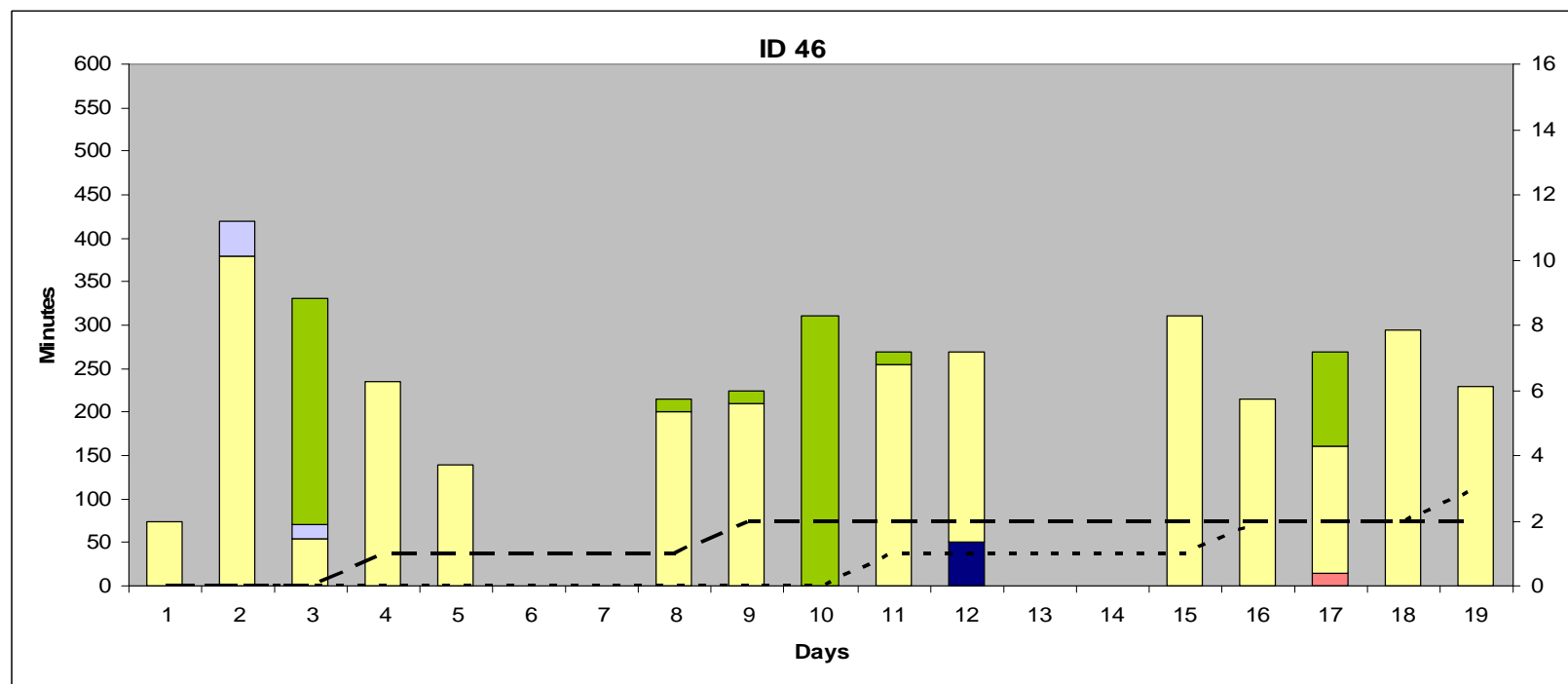

-Time G1 $\longleftarrow$ Time G2 $\longleftarrow$ Time G3 $\longleftarrow$ Time G4 $\longleftarrow$ Time G5 — — Cummulated Rescheduled - - - - Cummulated Added
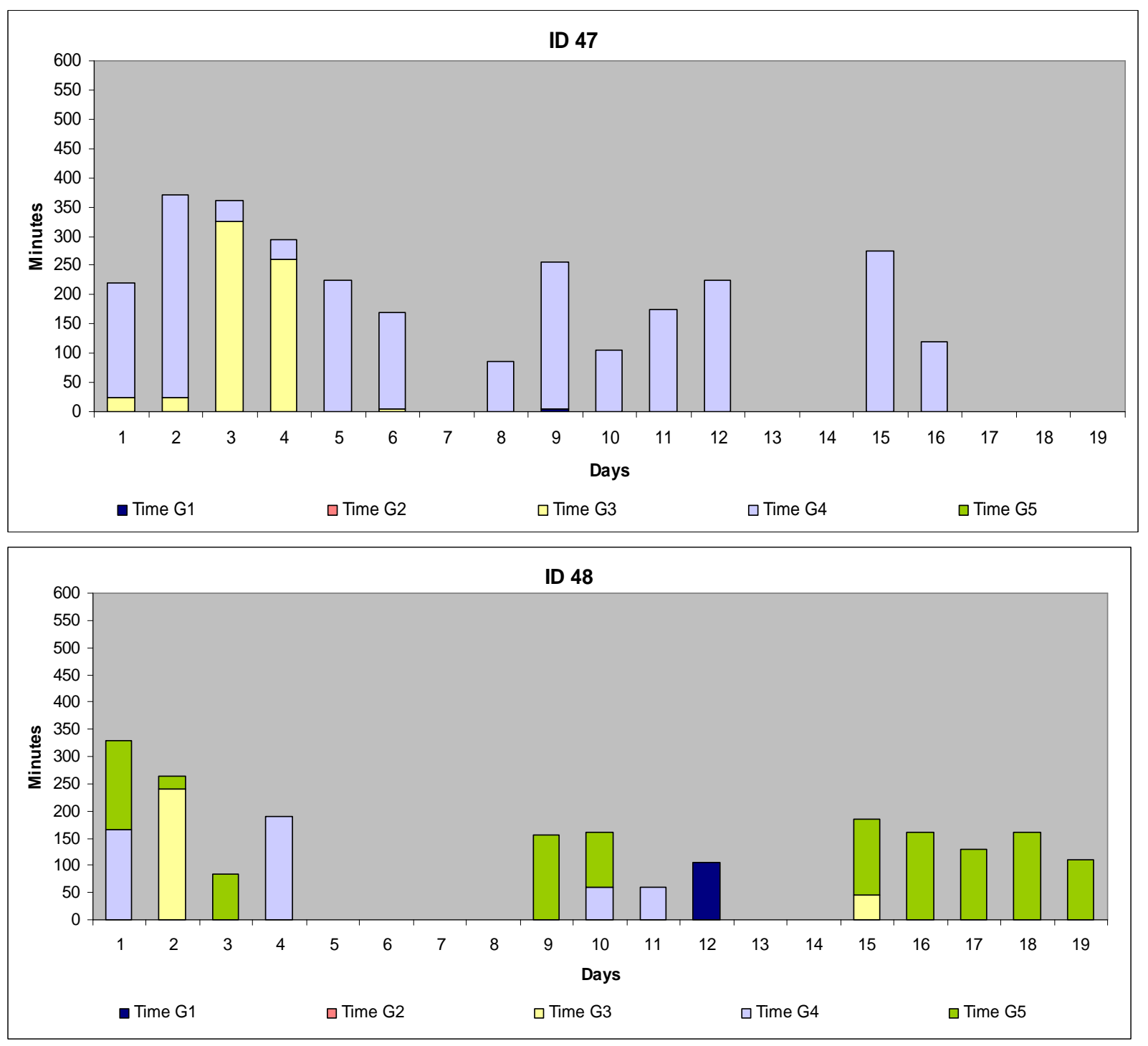


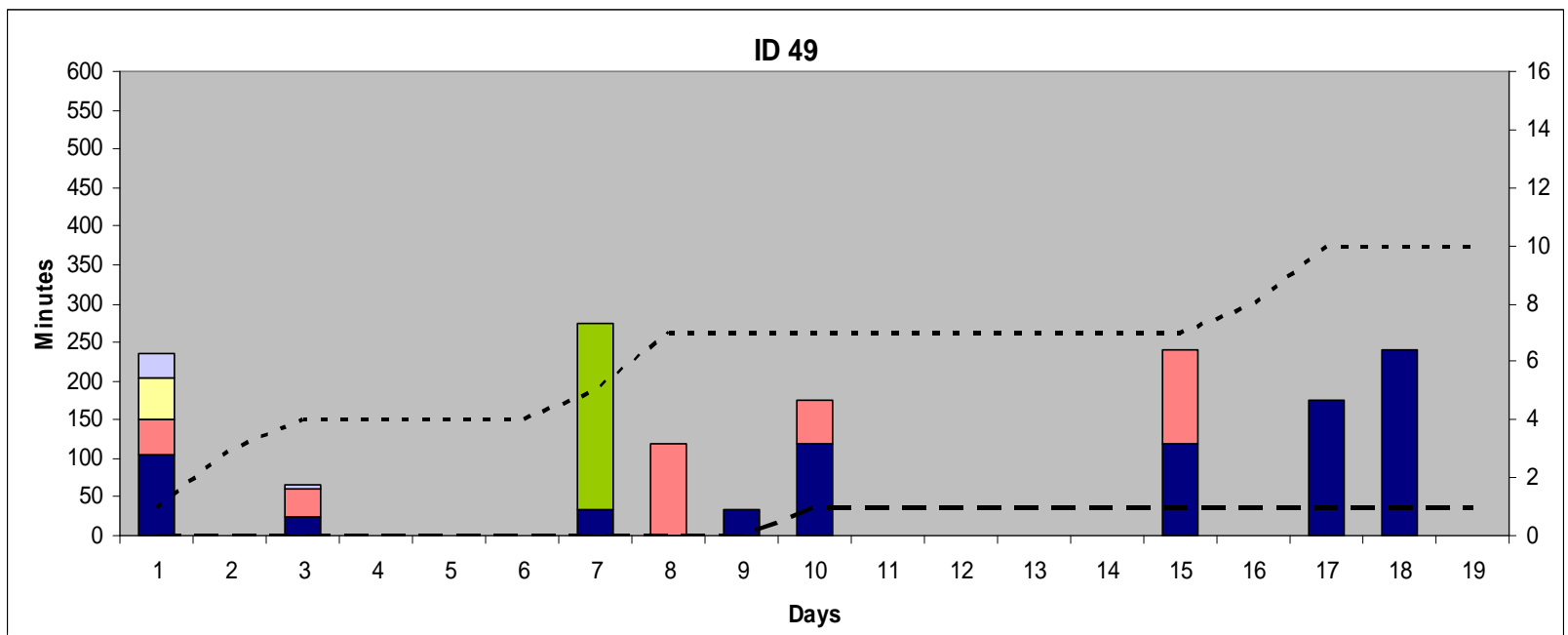

$\square$ Time G1 $\square$ Time G2 $\square$ Time G3 $\square$ Time G4 $\square$ Time G5 - - Cummulated Rescheduled - - - - Cummulated Added

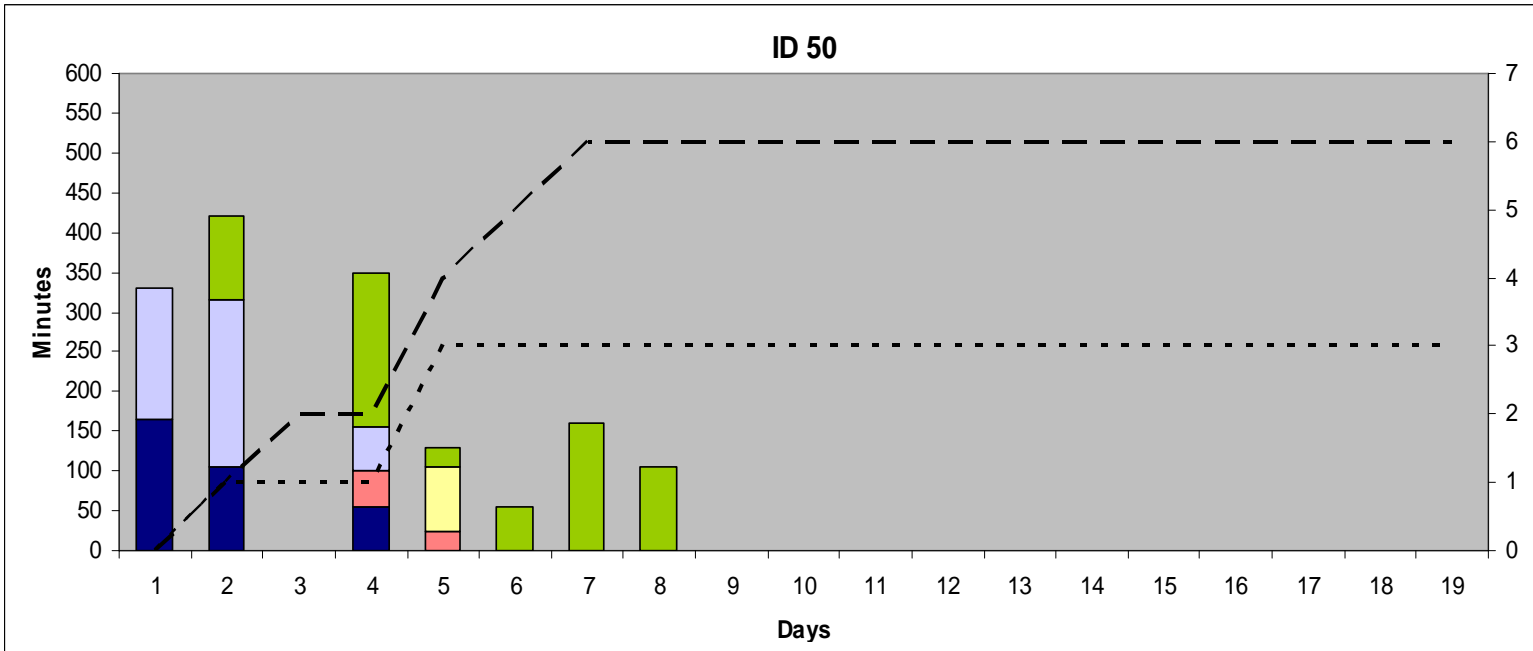



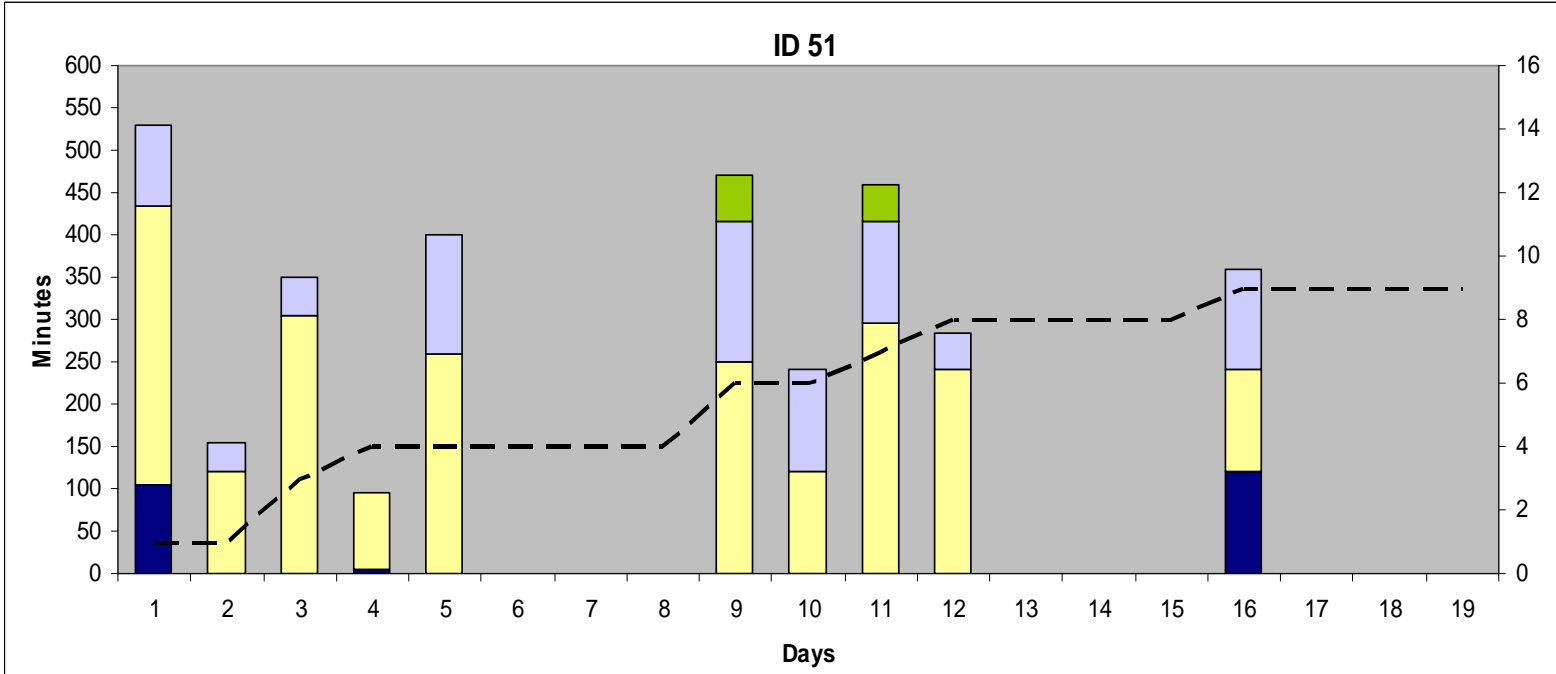

Time G1 $\sqsubset$ Time G2 $\sqsubset$ Time G3 $\sqsubset$ Time G4 


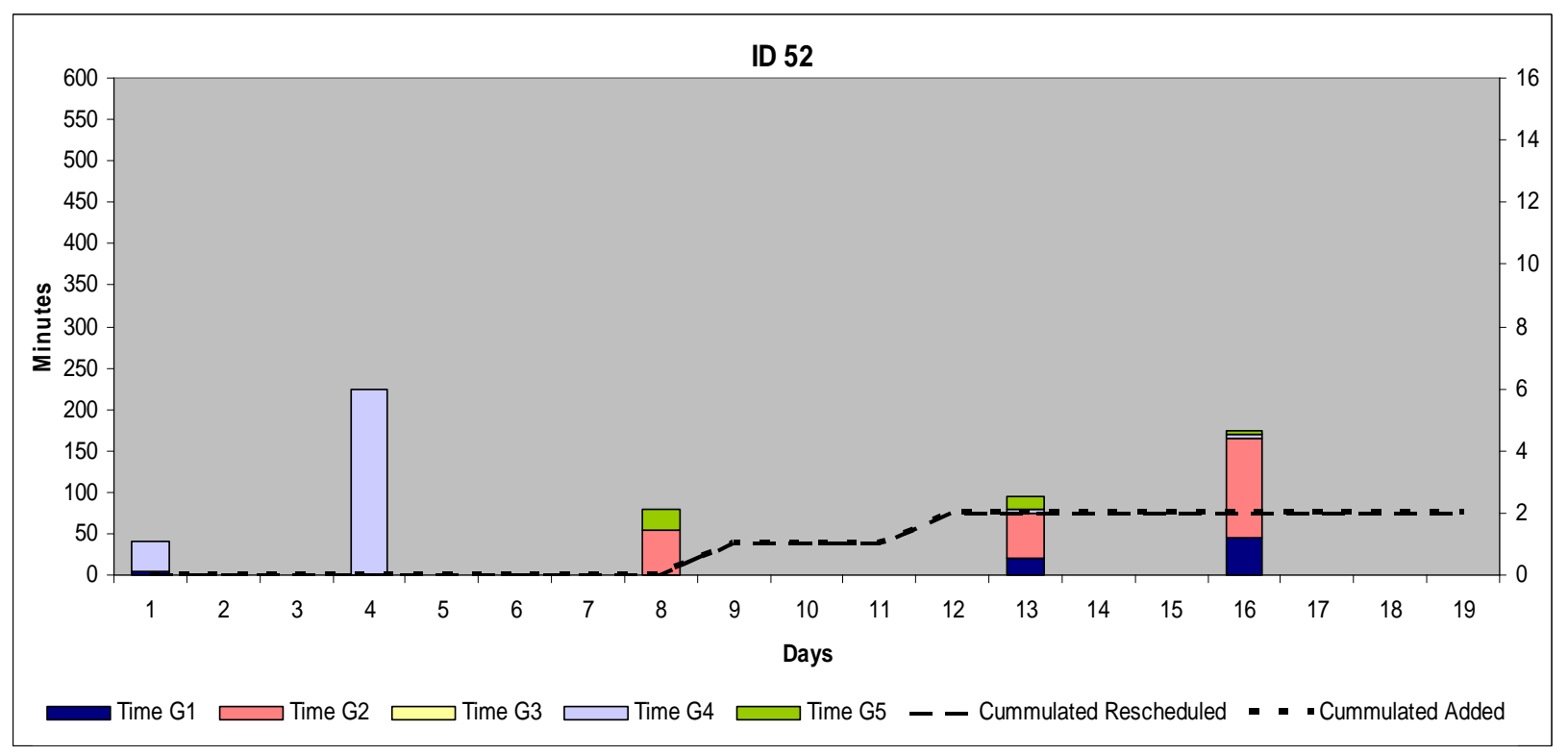




\begin{abstract}
ABOUT THE AUTHOR
Daniela Maria Kirchberg was born on August $29^{\text {th }}, 1981$ in Bocholt, Germany. She studied international business studies at Maastricht University at the School of Business and Economics and graduated in August 2006. During her studies she spent one semester abroad at the Università commercial Luigi Bocconi in Milan. In September 2006, she started her PhD research at the


Department of Organization and Strategy at Maastricht University. Between September and December 2004 she was a visiting PhD student at the Department of work psychology at the University of Konstanz, Germany.
\end{abstract}

In January 2011, she started working as an executive assistant to the board member of HR at AXA Konzern AG in Cologne, Germany. Since January 2014 she is the head of HR of AXA ART Versicherung AG headquartered in Germany. 